\title{
WRR
}

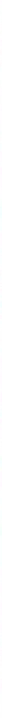

Peter van Lieshout, Robert Went \& Monique Kremer

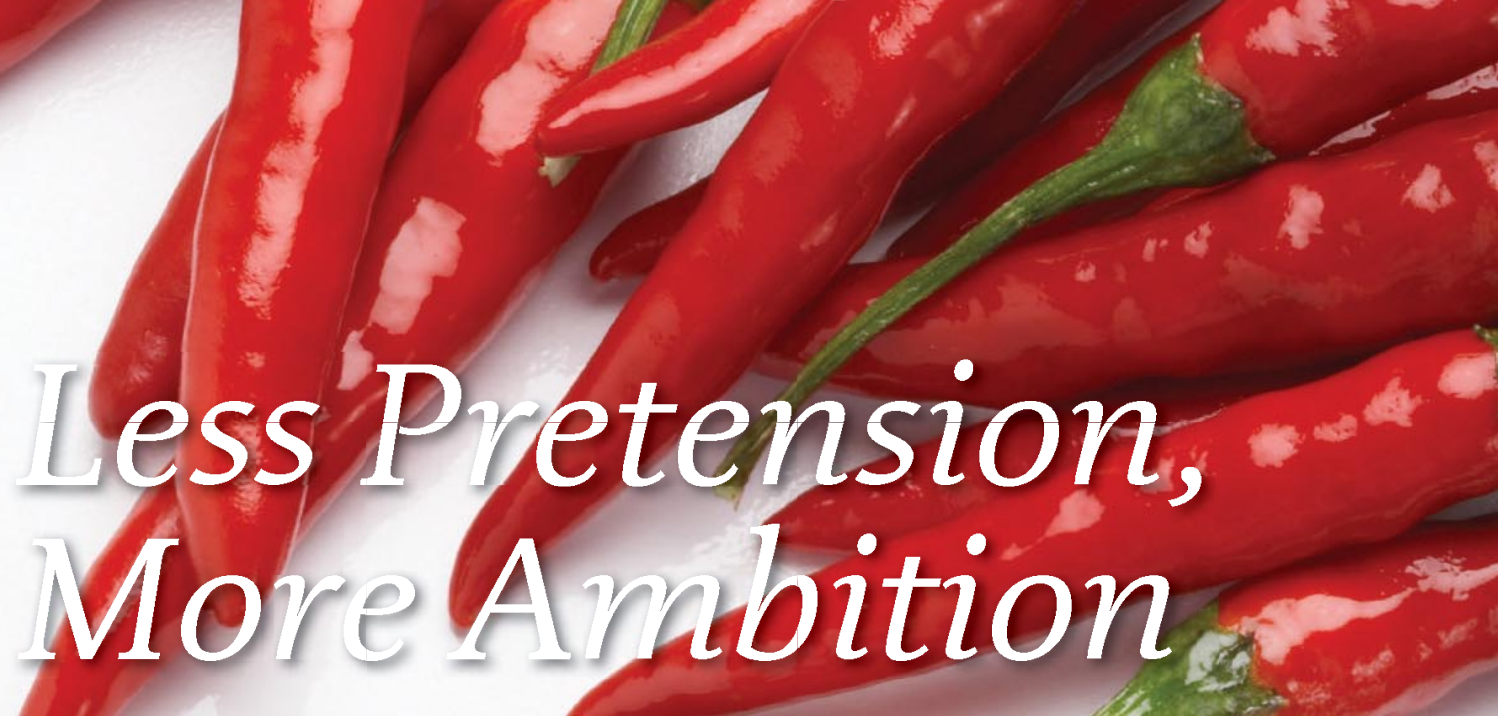

DEVELOPMENT POLIEY IN TIMES.OF GLOBALIZATION

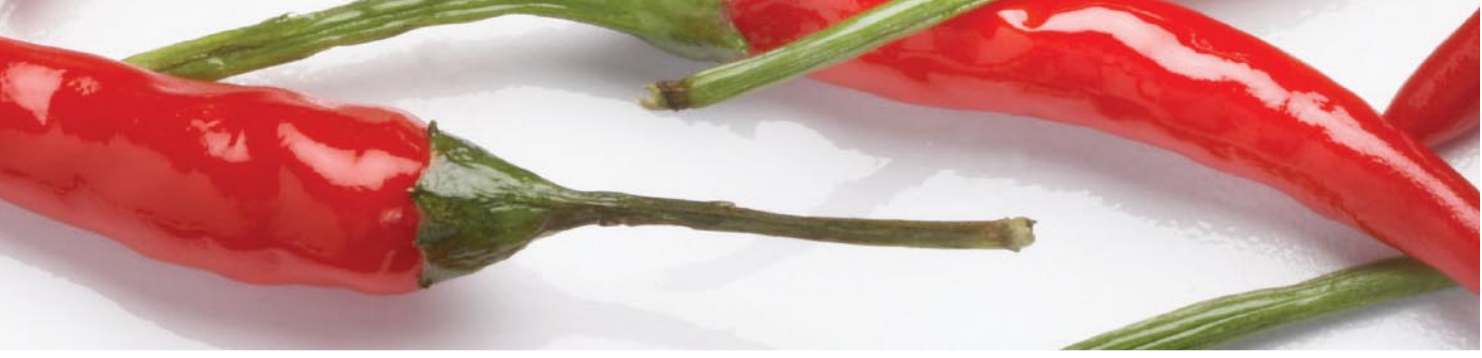


Less Pretension, More Ambition 
This book is based on a report that was published by The Netherlands Scientific Council for Government Policy (WRR). According to the Act of Establishment, it is the Council's task to supply, on behalf of government policy, scientifically sound information on developments which may affect society in the long term, and to draw timely attention to likely anomalies and obstacles, to define major policy problems and to indicate policy alternatives.

The Council draws up its own programme of work, after consultation with the Prime Minister, who also takes cognisance of the cabinet's view on the proposed programme.

The Council (2008-2012) has the following composition: prof. dr. J.A. Knottnerus (chairman) prof. dr. ir. M.B.A. van Asselt prof. dr. H.P.M. Knapen prof. dr. P.A.H. van Lieshout prof. dr. H.M. Prast prof. mr. J.E.M. Prins prof. dr. ir. G.H. de Vries prof. dr. P. Winsemius

Executive director: dr. W. Asbeek Brusse

Lange Vijverberg 4-5

P.O. Box 20004 2500 EA 's-Gravenhage Tel. +317035646 oo Fax +31703564685 E-mail: info@wrr.nl Internet: http://www.wrr.nl 


\section{Less Pretension, More Ambition}

DEVELOPMENT POLICY IN TIMES OF GLOBALIZATION

Peter van Lieshout, Robert Went $\&$ Monique Kremer 
Front cover illustration: (C) ALEAIMAGE

Cover design: Studio Daniëls, The Hague

Layout: Het Steen Typografie, Maarssen

Translation: Andy Brown and Howard Turner

ISBN 9789089642950

e-ISBN 9789048513888

NUR $\quad 754$

(C) WRR/Amsterdam University Press, The Hague/Amsterdam 2010

All rights reserved. Without limiting the rights under copyright reserved above, no part of this book may be reproduced, stored in or introduced into a retrieval system, or transmitted, in any form or by any means (electronic, mechanical, photocopying, recording or otherwise) without the written permission of both the copyright owner and the author of the book. 


\section{CONTENTS}

Preface

1 Development aid in a changing context

$2 \quad$ The development aid split $\quad 25$

2.1 Two basic motives for development aid 25

$\begin{array}{lll}2.2 & \text { The moral assignment } & 27\end{array}$

2.3 Self-interest 31

$2.4 \quad$ Interdependencies 34

2.5 How to combine big and small 42

$3 \quad$ Understanding development 49

3.1 Defining development 49

$3.2 \quad$ Other starting points 54

3.3 Effective governments and path-dependent trajectories 57

$\begin{array}{ll}3.3 .1 \quad \text { Rediscovering the state } & 58\end{array}$

$\begin{array}{lll}3 \cdot 3 \cdot 2 & \text { Antecedents and variety } & 61\end{array}$

3.3.3 What about Africa? 64

$\begin{array}{lll}3.4 & \text { Political institutions } & 67\end{array}$

$\begin{array}{lll}3.5 & \text { Social fabric } & 70\end{array}$

3.6 Own development paths 81

$4 \quad$ Measuring development $\quad 87$

$\begin{array}{ll}4.1 & \text { Is development taking place? }\end{array}$

4.2 What does aid contribute? 94

4.3 Should we then focus on the micro level? 101

$\begin{array}{ll}4.4 & \text { Does aid help? } \\ & 103\end{array}$

$5 \quad$ Designing development aid $\quad 105$

5.1 Narrowing down: development aid becomes poverty reduction 105

5.2 Fragmentation: more and more chaotic organization 112

5.3 Delusions of grandeur: the constant lure of social engineering $\quad 118$

5.3.1 Capital and import substitution as a remedy $\quad 119$

5.3.2 The Washington Consensus 122

5.3.3 Good governance and democracy as a remedy $\quad 128$

$\begin{array}{lll}5.4 & \text { Lack of intervention ethics } & 133\end{array}$

5.5 Compartmentalization: underestimating other instruments 141

$\begin{array}{ll}\text { 5.5.1 New themes } & 142\end{array}$

$\begin{array}{ll}\text { 5.5.2 Searching for coherence } & 147\end{array}$ 
6 The task ahead 153

6.1 Linking will become increasingly unavoidable 153

6.2 The task: to be more development-oriented, more specific and $\begin{array}{ll}\text { broader } & 158\end{array}$

6.3 The first consequence: being more development-oriented 160

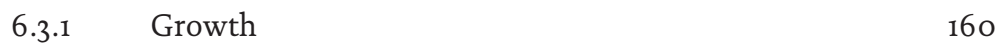

6.3.2 What about water supply, education and healthcare? $\quad 167$

6.3.3 And what about security and stability? 173

$\begin{array}{lll}6.4 & \text { The second consequence: being more specific } & 177\end{array}$

$\begin{array}{ll}\text { 6.4.1 Country and regional differentiation } & 177\end{array}$

$\begin{array}{ll}6.4 .2 & \text { Diagnostic approach } \\ 6.4 .3 & \text { Choice }\end{array}$

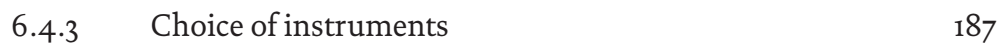

$\begin{array}{ll}6.5 & \text { The third consequence: being broader } \\ 6.69\end{array}$

$\begin{array}{lll}6.6 & \text { A dual strategy for development } & 192\end{array}$

$7 \quad$ Being more specific: professionalizing aid $\quad 195$

$\begin{array}{lll}7.1 & 195\end{array}$

$\begin{array}{lll}7.2 & \text { Supporting governments } & 197\end{array}$

7.3 Other actors: NGOs for development 201

$\begin{array}{lll}7.4 & \text { Other actors: businesses for development } 207\end{array}$

$\begin{array}{ll}7.5 & \text { Other actors: citizens for development } 214\end{array}$

$\begin{array}{lll}7.6 & \text { Programme aid } & 220\end{array}$

7.7 Doing good can and must be done better 230

8 A broader perspective: looking beyond aid 233

$\begin{array}{lll}8.1 & 233\end{array}$

8.2 Coherence for development 240

$\begin{array}{lll}8.3 & \text { International public goods } & 245\end{array}$

8.4 Global governance 251

8.5 Beyond 'international cooperation' 254

9 Conclusion $\quad 259$

$\begin{array}{ll}\text { 9.1 Development more central } & 261\end{array}$

$\begin{array}{lll}9.2 & \text { Professionally organized development } & 264\end{array}$

9.3 Beyond classical aid 270

$\begin{array}{lll}9.4 & \text { Less pretension, more ambition } & 272\end{array}$

$\begin{array}{ll}\text { References } & 275\end{array}$ 


\section{PREFACE}

This book is about the future of development aid. In recent years there has been increased public debate in the Netherlands, as in many other Western countries, about development cooperation - in terms of both the media attention devoted to the theme and the intensity of the positions taken. In a country which liked to see itself as one of the pioneers in the field, the self-evidence of development aid - about which there had long been broad political and social consensus - seemed to have come to a definite end. It was for this reason that the Dutch Scientific Council for Government Policy (WRR) undertook to examine this issue thoroughly.

The WRR is an advisory body to the Dutch government. Its task is to make proposals, based on broad analysis and scientific insights, on the strategic direction of Dutch policy. To this end, the WRR submits advisory reports to the government several times a year on issues which merit specific attention. At the start of 2010, an advisory report on development aid was published in Dutch under the title Less Pretension, More Ambition. Academics, practitioners, policymakers and politicians engaged in all manner of debate about the report's analysis and recommendations. The government started drawing up a detailed response on the consequences of the report for its policy, with the intention of debating it in parliament. In October 2010, the new Dutch government decided to use the report as the basis of a thorough modernization of the Netherlands' policy.

To make the Dutch report accessible to an international audience, it has not only been translated into English, but also adapted and amended. Details referring to the specific Dutch organization of development aid that are irrelevant for an international audience have been removed. Only those from which wider lessons may be drawn have been retained. Secondly this publication has benefited from the responses to the report (more than 1oo detailed responses were posted in the online debate organized by the website of The Broker alone; see www.thebroker online.eu). The changes made include coverage of new themes, more elaboration on specific lines of reasoning and more comprehensive analyses. The main argument has not been changed. The result is a book aimed at a wider international audience, even though the examples chosen and the emphasis laid will undoubtedly have a noticeable Dutch bias.

The report was compiled by a project group headed by WRR member Peter van Lieshout. The scientific team comprised Robert Went (project coordination) and Monique Kremer. The team engaged in a long process of consultation and analysis. We drew significantly on the insights and information provided by the abundant scientific literature from various disciplines. We also talked with external experts 
from various backgrounds. Some were affiliated to Dutch universities, knowledge institutes, aid organizations, ministries and embassies, and others to foreign knowledge institutes or ministries. In addition, intensive consultations were held with experts at relevant international organizations (EU, World Bank, IMF, OECD, WTO, ILO, UN organizations, etc.). In total, around 300 specialists were consulted over a two-year period. Some of these were also asked to elaborate their insights in the form of written texts. In May 2009 this resulted in the publication of the background study Doing Good or Doing Better. Development policies in a globalizing world (Kremer, Van Lieshout \& Went 20o9; also available online at www.wrr.nl). In addition, the WRR invited a number of specialists (Nancy Birdsall, Ha-Joon Chang, Paul Collier and Dani Rodrik) to conferences in the Netherlands where we examined a number of key themes of development policy in detail. The discussions held in other Western countries on the future of development aid were also very instructive. We learned a great deal from those debates, as well as from visits to researchers and policymakers in various countries (including Belgium, Denmark, Germany, Norway, Sweden and the United Kingdom).

A proper analysis of development aid cannot be made without including the views of the recipient countries. A number of specific country studies were therefore conducted, during which we talked extensively with policymakers, practitioners in the development aid field, members from the business community, and representatives from the academic world and the media. Country studies were carried out in Afghanistan, Bangladesh, Ethiopia, Indonesia, Nigeria, Uganda and Surinam. Extensive working visits were made to India and China, countries that in many ways have developed successfully and are now becoming increasingly important players on the development aid stage themselves. Singapore also provided valuable insights. All in all, ideas were exchanged with a further 250 people during these case studies in the global South.

We would like to take this opportunity to thank all the people who contributed to this book. First of all, we want to thank Vanessa Nigten for organizational help and research assistance during our whole project, and Chris van der Borgh, Marcia Valkenhoff and Martijn Vink for research assistance with part of the work.

A special word of thanks also for Ton Dietz, Paul Engel, Jos van Gennep, Peter Ho, Paul Hoebink, Rolph van der Hoeven and Jeroen de Lange for reading and commenting on a draft of this text. A big thank you to our colleagues on the council and the staff of the WRR for stimulating discussions of drafts and practical support in the preparation of our report and this book. Around 550 people in all parts of the world were prepared to exchange their views with the project group over a long period. We are grateful for their insights. They are, in alphabetical order of country and name: 
In Afghanistan: Qasim Akhgar, Ramazan Bashardost, Anja de Beer, Martine van Bijlert, Hans Blankenberg, Paul Fishstein, Esmathullah Haidary, Horia Mosadiq, Floortje Klijn, Jarullah Mansoori, Joanna Nathan, Hamish Nixon, Noorulhaq Olomi, Yunus Qanuni, Aziz Rafiee, Rachel Reid, Mariam J. Sherman, Alexandra Strand Holm, Yvonne Stassen, Mirwais Wardak, Khalil Wedad, Faizullah Zaki, Ehsan Zia.

In Bangladesh: Fazle Hasan Abed, Afsarul Ameen, Chris Austin, Rasheda Choudhury, Saber Hossain Chowdhury, Arthur Erken, Ellen Goldstein, Milko van Gool, Manzoor Hasan, Mirza Hassan, Alphons Hennekens, Urs Herren, Samsul Huda, Ifty Islam, Einar Jensen, Kushi Kabir, Sultana Kamal, Abdul Kasem Khan, Hasan Mahmud, Ainun Nishat, C. Karim, Stephan Preisner, Atiq Rahman, Mahbubur Rahman, Carel de Rooy, Hans Spruijt, Rehman Sobhan, Ad Spijkers, Pieter Terpstra, Doris Voorbraak, Muhammad Yunus, Iftekhar Zaman.

In Belgium: Danny Cassimon, André van Heemstra, Nathalie Holvoet, Liesbeth Inberg, Francine Mestrum, Nadia Molenaers, Francoise Moreau, Robrecht Renard.

In China: Halima Begum, Irene Bain, Rudolf Bekink, Ira Belkin, Lu Bin, Wang Canfa, Adrian Davis, David Dollar, John Fitzgerald, Mark George, Wang Guoqian, Arjan de Haan, Kathleen Hartford, Ying Hwang, Duncan Innes-Ker, Qiao Jianrong, Eve Wen-Jing Lee, Hans Moleman, Hou Rui, Hou Shaoze, Jiao Shoutian, Constance Thomas, Bettine Vriesekoop, Canfa Wang, Xu Weizhong, Li Wentao, Zhang Xiaoshan, Dayuan Xue, Dayuan Xue, Chen Yan, Wang Yi, Lu Yibin, Daojiong Zha.

In Denmark: Annette Aarestrup, Erik Brøgger Rasmussen, Lars EngbergPedersen, Lindsay Whitfield.

In Ethiopia: Assefa Admassie, Yelfigne Abegaz, Aniley Amentie, Araya Asfaw, Miguel Barreto, Jan Bloemen, Joep van den Broek, Douwe Buzeman, Paolo Curradi, Mohammed Diab, Paul Dorosh, Jasmina van Driel, Marc Driessen, Elobaid Ahmed Elobaid, Hr. Esaya, Kalayu Gebre-Selassie, Zinabu Gebremariam, John Graham, Jan van de Haar, Ton Haverkort, Dirk Hoekstra, Pim de Keizer, Toon van Kessel, Gijs Van 't Klooster, Henk Kuipers, Bas van der Lee, Maaike de Loor, Erik Lundsgaarde, Rem Neefjes, Grethe Petersen, Arie Plieger, Hans Poley, Janny Poley, Dessalegn Rahmato, Dino Sinigallia, Eva Smulders, Andrew Spezowka, Fikru Tarekegn, Daniel Truneh, Ronald Vijverberg, Dörthe Wacker, Nico van Wageningen, Geert Westenbrink, Sonali Wickrema, Franta Wijchers.

In Germany: Jörg Faust, Dirk Messner, Imme Scholz. 
In India: Michael Anderson, Niraja Gopal Jayal, K.P. Kannan, Coen Kompier, Giovanni van der Lugt, Alex Oosterwijk, A.S. Panneerselvan, Sanjaya Panth, Arjun Sengupta, Alakh Sharma, Aruna Sharma, Ravi Srivastava, Rajesh Tandon, Sukhadeo Thorat, Mitu Varma, Prem Vashishta.

In Indonesia: Joachim van Amsberg, Marrik Bellen, Ward Berenschot, Shubham Chaudhuri, Nikolaos van Dam, Daniel Dhakidae, Lukita Dinarsyah Tuwo, Malik Gismar, Hermin Indah Wahyuni, Fasli Jalal, Thee Kian Wie, Ignas Kleden, Alexander Kofman, Cornelis Lay, Margiyono, Felencia Oktaria Hutabarat, Arianto Patunru, Pratikno, Firliana Purwanti, Purwo Santosa, Wicaksono Sarosa, Mesdin Simarmata, Mahendra Siregar, Asep Suryahadi, Staffan Synnerstrom, Roger Tol, Farid Wajidi, William Wallace, Raharja Waluya Jati, Ria Widati, Arnold van der Zanden.

In the Netherlands: Agnes van Ardenne, Age Bakker, Maarten van den Berg, Thijs Berman, Ben Beuming, Frans Bieckmann, Kees Biekart, Arend Jan Boekestijn, Pieter Boele van Hensbroek, Joan Boer, Diederik de Boer, Ad Boeren, Bart van Bolhuis, Frans van den Boom, Jeroen Bordewijk, Sylvia Borren, Jone Bos, Ben Bot, Jan Karel Bout, Jan Breman, Maarten Brouwer, Mirjam de Bruijn, Leni Buisman, Erwin Bulte, Patrick Cammaert, Renko Campen, Lo Casteleijn, Gemma Crijns, Ferdinand van Dam, Koen Davidse, Jan Deelstra, Marc Dierikx, Ton Dietz, Han van Dijk, Meine Peter van Dijk, Geske Dijkstra, Jaap Dijkstra, Jan Donner, Martin Doornbos, Edo Driessen, Gerard Duijfjes, Sjef Ederveen, Marion Eeckhout, Hans Eenhoorn, Sander van den Eijnden, Stephen Ellis, Dirk Elsen, Jan van Elst, Louis Emmerij, Paul Engel, Ewald Engelen, Kathleen Ferrier, Alan Fowler, Louise Fresco, Jacques van der Gaag, Chris Geerling, Jos van Gennip, Chantal Gill'ard, Pieter de Gooijer, Peter Gortzak, Richard Griffiths, Albert de Groot, Robert de Groot, Jasper Grosskurth, René Grotenhuis, Jan Gruiters, Jan-Willem Gunning, Arjan de Haan, Allert van den Ham, Peter Heintze, Duco Hellema, Henny Helmich, Roger Henke, Godelieve van Heteren, Thea Hilhorst, Peter Ho, Paul Hoebink, Rolph van der Hoeven, Enno Hommes, Jan van Hout, Ewout Irrgang, Wiet Janssen, Peter Janus, Annemiek Jenniskens, Renée JonesBos, Eelke de Jong, Henk de Jong, Wilco de Jonge, Agnes Jongerius, Robert de Jongh, Gerd Junne, Paul Kalma, Frank van Kappen, Marion Kappeyne van de Coppello, Farah Karimi, Karel van Kesteren, Nanno Kleiterp, Piet Klop, Jan Klugkist, Bert Koenders, Marleen van der Kooij, Peter Konijn, Niek Koning, Martin Koper, Arie Kraaijeveld, Peter Van Krieken, Ed Kronenburg, David Kuijper, Arie Kuyvenhoven, Ellen van der Laan, Maarten Lak, Jeroen de Lange, Robert Lansink, Ton Lansink, Susan Legêne, Ronald de Leij, Wampie Libon, Jules van Lier, Marianne Linder, Ruud Lubbers, Geertje Lycklama à Nijeholt, Harro Maat, Frank Majoor, Thomas de Man, Wijnand Marchal, Peter Martens, Roel von Meijenfeldt, Leon Meijer, Ad Melkert, Loet Mennes, Iman Merison, Arthur Mol, Henk Molenaar, Klaas Molenaar, Jacques Monasch, Jan Nederveen Pieterse, Co 
Neeteson, Annemieke Nijhof, Jan Gerrit van Norel, Isabelle van Notten, Maaike Okano-Heijmans, Joke Oranje, Bram van Ojik, Frank van Oorschot, Joost Oorthuizen, Hans Opschoor, Teun van Os van den Abeelen, Bram van Overbeeke, René Paas, Arnoud Passenier, Bernike Pasveer, Pieter Pekelharing, Mariko Peters, Theo Peters, Marcella Petri, Jan Douwe van der Ploeg, Rick van der Ploeg, Thijs van Praag, Jan Pronk, Willem van de Put, Maartje van Putten, Winand Quaedvlieg, Rudy Rabbinge, Kees Rade, Niels Redeker, Paul Richards, Koos Richelle, Louk de la Rive Box, Nico Roozen, Ruerd Ruben, Arie de Ruijter, Guido Ruivenkamp, Theo Ruyter, Louise van Schaik, Onno Schellekens, Michiel Scheltema, Wouter Schilperoort, Tobias Schmitz, Nico Schrijver, Lau Schulpen, Anton Schuurman, Jan Geert Siccama, Wout Siddré, Anneke Slob, David Sogge, Sam Stevens, Eddy Szirmai, Jos Uleman, Dian van Unen, Myriam Vander Stichele, Ruud Treffers, Rob van Tulder, Kees Vendrik, Roel van der Veen, Emile van Velsen, André Veneman, Maxime Verhagen, John Verhoeven, Rob Visser, Joris Voorhoeve, Maarten Voors, Lodewijk de Waal, Geerte Wachter, Marieke de Wal, Jeroen Warner, Frauke de Weijer, Flip Wester, Josine Westerbeek-Huitink, Francis Weyzig, Bernard Wientjes, Wiert Wiertsema, Herman Wijffels, Sweder van Wijnbergen, Pieter van der Zaag, Fred Zaal, Kees Zevenbergen, Annelies Zoomers.

In Nigeria: Aderanti Adepoju, Yusuf Ageni, Stella Amadi, Kemi Asiwaju, Ojobo Atuluku, William Awinador-Kanyirige, Thessa Brongers, Gertjan van Bruchem, Innocent Chukwuma, Marjo Cromvoets, Chukwuemeka Eze, Paul Hamers, Peter Hawkins, Michiel Herkemij, Amina Ibrahim, Felix Morka, Ifeanyi Okechukwu, Constance Okeke, Oso Osobou, Hanneke Peeters, Peter Poulsen, Onno Rühl, Lamido Sanusi, Benjamin Soares, Jean de Dieu Somda, Ronald Sonnemans, Loenard Ugbajah, Ken Ukaoha, Arie van der Wiel.

In Norway: Poul Engberg-Pedersen, Hege Hertzberg, Leiv Lunde, Guri Sandborg, Olav Stokke.

In Singapore: Chua Beng Huat, Toby Carroll, Ann Florini, Vedi Hadiz, Shamsul Haque, Kishore Mahbubani, Tess del Rosario, Yap Mui Teng.

In Surinam: Renaud Adams, Rakesh Adhin, Mascha Baak, Jim Boussaid, Hans Breeveld, Ancile Brewster, Mireille Brunings-Stolz, Hennah Buyne, Chan Choennie, Steven Couthinho, Pitou van Dijck, Astrid Elburg, Derrick Ferrier, Sharda Ganga, Lilian Gonçalves - Ho Kang You, Ruben Gowricharn, Aart Jacobi, Dirk Kruijt, Hans Lim A Po, Marion Maks, Marcel Meyer, Gert Oostindie, Henry Ori, Kermechend Raghoebarsing, Winston Ramautarsing, Anil Ramdas, Rick van Ravenswaay, Marten Schalkwijk, Ramsewak Shankar, Stephen Simon, George Soerjoesing, Marianne Spier, Annette Tjon Sie Fat, Wilma Udenhout, David Yateman, Marc Willems. 
In Sweden: Mia Horn af Rantzien, Erik Jonsson, Bertil Odén, Eva Tobisson, Lennart Wohlgemuth.

In Switzerland: Michel Cichon, Heiner Flassbeck, Katja Hujo, Marion Jansen, Thandika Mkandawire, Habib Ouane.

In Uganda: Patrick Birungi, Dónal Cronin, Godfrey Dhatemwa, Justin Ecaat, Mayoka James, William Kalema, Chris Kassami, Arthur Larok, Gwyneth Lee, Onesmus Mugyenyi, Andrew Mwenda, Theophane Nikyema, Michiel Rentenaar, Jacques Schrier, Abebe Selassie, Emmanuel Tumusiime-Mutebile, Jeroen Verheul, Paul Wade, Julian Wood.

In the United Kingdom: Ha-Joon Chang, Paul Collier, Lawrence Haddad, Alan Hudson, James Kariuki, Mustaq Khan, Simon Maxwell, Mick Moore, David Mosse, Nick Perkins, Fiona Shera, Kevin Sparkhall, Dirk Willem te Velde, Robert Wade, Alan Winters.

In the United States: Dean Baker, Tariq Banuri, Marion Barthelemy, Nancy Birdsall, Pedro Conceição, Shantayanan Devarajan, Koldo Echebarría, Shahrokh Fardoust, Stephany Griffith-Jones, Merilee Grindle, Ricardo Haussmann, Monika Huppi, Gerald Hyman, Robert Kaplan, Shigeo Katsu, Caroline Kende-Robb, Ruben Lamdany, Branko Milanovic, Manuel Montes, Richard Morford, Todd Moss, José Antonio Ocampo, Isabel Ortiz, Stephen Quick, Zia Qureshi, Sanjay Reddy, Dani Rodrik, Charles Sabel, Hartwig Schafer, Nikhil Seth, Rob Vos, Mark Weisbrot, Franck Wiebe, Justin Yifu Lin, Hania Zlotnik. 
In recent years development aid has become the subject of much discussion in the Western world. In the media, a passionate debate has developed which has addressed fundamental questions, but in which examples are happily quoted out of context and stereotypes are rife. Books on development aid have appeared in rapid succession and interviews with their authors have graced the front pages of the weekend supplements of the leading dailies. A fascinating genre has emerged. For most of the authors, the topic was clearly very loaded, as was evident by their cutting tone, their sweeping statements, the pamphlet-like undertones, the apocalyptic cover notes, the easy use of statistics and the degree to which their arguments were shot through with references to their personal lives, as if this were some guarantee that what they were saying was the ultimate truth. It would all have made a perfect topic for a thesis by a student of literature. In The End of Poverty (2005), Jeffrey Sachs invoked his wife, in Bad Samaritans (2007) Ha-Joon Chang his children, in The Trouble with Africa (2006) James Calderesi his friend, in The Bottom Billion (2007) Paul Collier his son, in The White Man's Burden (2006) William Easterly described his disillusions as a former World Bank employee, while in Dead Aid (2009) Dambisa Moyo called her parents as witnesses for the prosecution. In this way, criticism of development cooperation has itself become a million-dollar business.

It is time to thoroughly reflect on the future of development aid. Besides the tone of the debate, there are a number of fundamental reasons for doing this. After all, there have been a number of significant changes. Developing countries are not what they were sixty years ago, when development aid took its first cautious steps. Meanwhile, the nature of aid itself has also changed - under the influence of changes not only in the South but at least as much in the West. Western countries no longer automatically have the hegemonic position in the world that they held sixty years ago. Furthermore, thinking among policymakers and academics has evolved on what development is and how it can or cannot be effectively promoted.

\section{Developing countries have changed ...}

Most people in the West think of Africa primarily as a continent struggling with an enormous scarcity of food. The single iconic image of Africa is of malnourished children, whether they are victims of war in Biafra (1968), drought in Ethiopia (1984), locust plagues in the Sahel (2004) or militias attacking the people of Darfur (2007). In the 196os Westerners got to know India as a country facing not only great hunger, but terrible diseases, especially cholera and tuberculosis. Slowly but surely, these images are changing. In the eyes of many people, Africa is no longer a continent where people have nothing to eat: the soil may be exhausted in many areas and most people still have difficulty in growing enough to meet their basic 
needs, but it is also a fertile continent. A relatively small country like Uganda could produce enough food for the whole of Africa on its own, if its agricultural land were to be cultivated with the same intensity as in Europe. Sudan could become the grain basket of Europe - as Egypt used to be for the Roman Empire. A major part of East Africa is a plateau that is exceptionally suited to agriculture and horticulture. It is the same story in large areas of West Africa. Nigeria, for example, has enough fertile ground to easily become a large food exporter, if it were not to focus so much on its oil revenues. India, the subcontinent with more poor people than the whole of Sub-Saharan Africa, is also changing. Western eyes are focused on the emerging IT sector and the Oscars for Slumdog Millionaire mark the merger of Hollywood and Bollywood. Fewer people are aware that the fourth largest industry in the country is the medical sector: patients fly in from neighbouring countries and countries further afield for good-quality and relatively cheap treatment - just as Western Europeans have laser treatment for their eyes in Turkey, and Americans go to Costa Rica for plastic surgery.

\section{... and are still changing}

Many things in Africa are changing fast. That is most apparent in highly visible changes like the use of mobile telephones. At the turn of the century, one in fifty people in Africa had a mobile telephone but, by 2009, 28 percent of all Africans were registered as mobile users (ITU 2009). This is the fastest rate of growth in the world. Africa is now preparing for an internet revolution. At the moment, fewer than five percent of Africans have internet access, but this percentage is also set to rise quickly and sharply. The changes are also apparent in the increasingly manifest pride of African leaders, who speak with more and more disdain about Western paternalism and turn to China as an example - though as yet few have refused Western aid when it has been offered. Africa also has its committed leaders: Mo Ibrahim, the man behind the extremely successful African mobile provider Celtel (now Zaï), set up a foundation that gives substantial amounts of money to leaders who voluntarily step down - which in any case stops them from hanging on to office because they have made no provisions for their retirement.

However, the changes are also affecting the population make-up. For example, there will soon be a large global middle class. In The Lexus and the Olive Tree (1999) Thomas Friedman made an interesting observation: there has never been a war between two countries that both have branches of McDonald's. The reasoning behind this was that McDonald's only operates in countries with a sizeable middle class, and these people “didn't like to fight wars any more - they preferred to wait in line for burgers". Whether or not this hypothesis still holds water today, the basic idea remains valid: a middle class ensures stability. That has radical consequences for developing countries. In 2000, an average of 82 percent of people in developing countries were poor - defined as an income below the average in Brazil - while 8 percent were middle class and to percent were classed as rich - defined as 
having an income higher than the average in Italy. By 2030, the number of poor - defined in the same way - will have fallen to 61 percent, the middle class will have grown to 16 percent and the number of rich to 22 percent, according to estimates by Bussolo and others (2008). That is a drastic shift, especially given the strict criteria.

Demographic changes will have an impact. By 2050, seven billion of the projected world population of more than nine billion will live in what we now call developing countries. India will have the largest population - partly because of the 'onechild' policy in China - with around 1.7 billion people. Around that time there will be two billion people living in Africa. Europe will have around 690 million, about 7 percent of the world population, compared to 25 percent in 1950. In 1960, twothirds of the global population lived in rural areas. In 2009 there were as many people living in cities as in the countryside, and by 2050, more than two-thirds will be urban dwellers. That, too, will have consequences: people living in cities in developing countries have much fewer children than those who live in the countryside, and also engage in different economic activities. Consequently, the falling trend in numbers of children will continue: whereas women in developing countries had an average of six children in 1960, this has now dropped to three.

Nevertheless, prediction remains a difficult task. In 1968, Nobel Prize winner Gunnar Myrdal published his Asian Drama: An inquiry into the poverty of nations. The book became famous and Myrdal was widely praised for his analysis of the effects of population growth in Asia in the coming decades. He showed that Asia is running headlong towards an inescapable drama. Like the eighteenth century British demographer Thomas Malthus, he predicted that world food production, which displays linear growth, would lag behind the growth of the world population, which increases exponentially. In the past fifty years, however, advances in agriculture have allowed food production to expand at a rate that has outstripped population growth - and that at a time when the global population grew more rapidly than ever before in history. Today, we not only produce twice as much food worldwide as in the 1960 s, but even more food per capita than fifty years ago (FAO 2008). Furthermore, in the period before 1990, it was often claimed that the political structure of countries like China, India and Vietnam was not open enough to offer much opportunity for progress, and that the economic policies of these countries too closely resembled those of a centrally planned economy ever to be successful. Developments since then have taught us to be less arrogant. Many have also claimed, after the event, to have foreseen the Fall of the Wall, not to mention the recent financial crisis.

\section{... and interdependencies increase}

In addition to all this, we are linked to each other more than ever before by problems that can no longer be solved within the borders of a single country and which 
are becoming increasingly intertwined. Climate change, $\mathrm{H}_{1} \mathrm{~N}_{1}$ influenza, financial stability, biodiversity, terrorism, migration, water scarcity, fish threatened with extinction - these are all global issues that call for cooperation beyond national borders. As a result of this sharp increase in cross-border interdependencies, national policy more frequently has an impact in other countries, questions and problems on policy agendas are more often coloured and influenced by developments and activities elsewhere in the world, and governments no longer have a monopoly on international relations in which businesses, non-governmental organizations (NGOs) and individual citizens also play a role. In this way, the policy agendas of rich and developing countries are becoming linked to each other on an increasing number of issues, generating a complex matrix of relationships and connections with new questions and problems for which there are no readymade answers (Bhargava 2006; Richard 2002).

Television, the internet and mobile telephone, and the increase in tourism - since 1950 the number of international arrivals has increased annually by 6.5 percent are making the world smaller and the immense differences in living standards and conditions between poor and rich countries more tangible. The increasing internationalization of trade, financial flows and the various, separated, stages of the production of goods and services is connecting employers, employees, consumers, investors and individual citizens in various countries with each other, whether they want it or not. The world currently has 82,000 transnational companies with 810, ooo foreign branches, which employ some 77 million people (more than twice the total labour force of Germany) and account for a third of the global export of goods and services. These companies are most dynamic in developing countries only twenty of the top fifty emerging transnational corporations were also on the list ten years ago (UNCTAD 1999, 2009c).

In the long term this will lead to the emergence of a completely new constellation of international relations. In the North and the South, races, religions, lifestyles, languages, and cultures will become increasingly interwoven. Passports, appearance, and territory will decreasingly run parallel. The focus will no longer be on multicultural links within societies, but on multidimensional links between them. The significance of the nation state will decline as all kinds of decisions are made elsewhere. Region-forming is rapidly increasing worldwide, with not only Europe forming a bloc, but North America and Southeast Asia as well, and in the Middle East plans for a single currency are already at quite an advanced stage. New transnational fora focus not only on issues like climate and food, but also on accounting standards and the protection of intellectual property rights. The G2O has rapidly become a household name. 


\section{Global relations have changed ...}

In the meantime it is becoming increasingly misguided to speak of a North-South relationship, and it is overly clear that it no longer reflects the gap between rich and poor. In Vietnam, 58 percent of the population still lived below the poverty line of a dollar a day in 1993. By 2006, this had fallen to 16 percent and, if the country continues to grow at the same rate as between 1995 and 2007, Vietnam will be considered a middle-income country by 2010 (World Bank 2008c). In two decades, it has developed from a food importer to the world's second largest exporter of rice. If China continues to grow at its current rate - which is by no means certain - it can be expected to have eradicated poverty to a significant degree by $202 \mathrm{O}$, and be able to take care of its remaining poor.

Many people are becoming concerned about China's expanding role in Africa every self-respecting daily or weekly has carried a report on this issue in recent years, usually with an alarming undertone that China is plundering the continent. That is, however, a one-sided viewpoint that takes no account of the fact, for example, that 25 percent of trade between Africa and China consists of Angolan oil, or that a single copper mine in Poland produces as much as the whole renowned Copper Belt in Zambia. Africa's share in the global production of nearly all minerals, excluding gold, is less than to percent. The emergence of China is undoubtedly having a considerable impact, but it is more likely to manifest itself in other ways. Increasing welfare in China, for example, will probably mean that its people will eat less grain and more animal protein products - and that will require much more farmland to produce. Three kilograms of grain are required to produce a kilogram of chicken meat, five for a kilo of pork and eight for a kilo of beef (Rabbinge 2009). While we could currently feed 112 percent of the global population with an almost vegetarian diet, the same would apply to only a little over half the world's population if we were all to obtain 25 percent of our daily intake of calories through animal protein (IAASTD 2009). In that respect it is fortunate that the Chinese traditionally prefer chicken and pork to beef. Like South Korea, China has started buying up large areas of fertile land in Africa to secure its own food production. South Korea recently bought more than a million hectares of land in Sudan, Mongolia, Indonesia and Argentina, the equivalent of the entire area of farmland in Belgium (Daniel \& Mittal 2009). China too has bought comparable amounts of land in Madagascar and other countries.

It is as yet unclear what effect the emergence of the new economies will have on the relations between them. There will certainly be more mutual trade. Cheap Chinese bicycles have already completely taken over from dependable Dutch models on the streets of Bamako and Kampala: their inferior quality is completely outweighed by the lower price. The only threats to the popularity of Chinese bikes are their slightly more expensive but also slightly better Indian counterparts. Anyone looking for adventure in Afghanistan will buy a Chinese motorcycle, 
rather than a Japanese one. The fact that the markets in the South often benefit more from each other's products than from expensive Western products, can in principle be beneficial to all of them. Furthermore, new political alliances are developing. The Brazilian president Lula already has an idea to set up a television channel aimed especially at Africa.

At the same time, there are clear inequalities. The position of Africa in particular on the world market may well come under pressure. Now that cheap production has reached such high levels in the countries of South and East Asia - and these countries have become very advanced in the logistics and commercial organization of the production process - Africa will have to seek other niches. However, it is unclear where these lie. Consequently, the newly emerging economies are, to a certain extent, more of a competitive threat to Africa than to the countries of the West. Vietnam has taken over a large share of the market in cashew nuts from Tanzania, not to mention the serious impact it has had on coffee production in Nicaragua due to it producing cheap coffee on a large scale. Furthermore, if Obama were to decide to reduce cotton subsidies to his farmers, it will not be Mali that benefits, despite cotton basically being the country's only export. Estimates show that 98 percent of these measures will benefit China. The BRIC countries (Brazil, Russia, India and China) have good reason for becoming defenders of free trade. This also explains why African countries are demanding to be allowed to impose trade protection measures.

It is clear that the economies of developing countries have to find their way in a system of global trade that is becoming increasingly international. Between 1950 and 2007 world trade grew at an average of 6.2 percent per year and global GDP by 3.8 percent. A growing proportion of goods and services produced are therefore being marketed in other countries. Developing countries are also taking part in this trend: the ratio of trade (imports plus exports) to GDP for low-income countries rose from 47 percent in 1990 to 70 percent in 2007. The share in world trade of all developing countries together increased from 18 percent in 1990 to 28 percent in 2007. At the same time, the world economy is much more regulated than when Japan and South Korea took such great steps forward. In the meantime, systems of intellectual property and trade provisions relating to security and health have become much more complex.

\section{There are successes ...}

Real income in developing countries has doubled in the past twenty-five years. Even in Africa there had been some progress in the decade leading up to the start of the financial crisis. Macroeconomic stability has increased enormously: the days when a tourist arriving in an African country first had to try and change money on the black market because the official exchange rate bore little relation to the real value of the currency are also over since, in by far the majority of African coun- 
tries, visitors can draw money from a cash machine on arrival at the airport. In addition, where average inflation in Sub-Saharan Africa was still 47 percent in 1994 , by 2007 it had fallen to 8 percent and the enormous national debts of many countries have been significantly reduced.

Tax revenues in Africa have doubled in absolute terms in the past six years, and in 2008 these were higher than official development aid for the first time, a sign that this part of the world is cautiously moving towards self-sufficiency. Foreign investments and remittances (the money that migrants send back to their families) already outstripped official aid in the early 1990s, although their distribution remains very unbalanced. Two-thirds of foreign investments go to twelve countries, with China the largest recipient (accounting for more than a quarter), while the thirty-three least developed countries in Africa receive less than 2 percent, and most of that goes to oil extraction and gold mining. It is the same with remittances: the least developed countries receive the least. While India, China and Mexico benefit considerably from migration - receiving some 25 billion dollars a year - the whole of Sub-Saharan Africa receives a total of only 1o billion dollars. Yet, here too, there are exceptions: in Uganda, for example, remittances account for almost 9 percent of GDP (World Bank 2008c).

Worldwide progress is also being made in other areas: smallpox was eradicated in 1977, river blindness is now very rare, 188 countries around the world are now polio-free and striking results have been achieved in the fight against measles and malaria - even the enormous wave of AIDS that ravaged Central, Southern and East Africa in the past two decades gradually seems to be coming under control. In the 1990s, the number of children dying from diarrhoea was halved - primarily through improved access to drinkable water and the availability of oral rehydration therapy. More than 85 percent of all children now attend primary school. There even seems to be progress in political terms. While in 1989 only four countries in Africa could be said to have some form of democracy, that now applies to around 20 of the total of 53 countries. In 1980, thirty-five African countries were still suffering under dictatorships and that figure has now fallen to fifteen. Most countries now hold some form of multiparty elections.

\section{... and problems}

No one can deny that progress has been made. However, it is limited - especially because much of the material growth is offset by the still rapid population increases. In 2008, a quarter of the world's population, which had in the meantime expanded to almost 6.8 billion people, had to live on less than 1.25 dollars a day - the poverty line applied by the World Bank since 2008 - and half on less than 2.5 dollars a day (World Bank 2008d). Tonight, a billion people will once again go to bed hungry. A third of the children in the world are undernourished. A billion people cannot write their names, especially girls and women. Two billion people 
- around half of whom live in India and Bangladesh, and the other half in SubSaharan Africa - have no access to electricity. The situation in South Asia differs from that in Sub-Saharan Africa: India may be experiencing rapid economic growth, but that is manifesting itself to a significant degree in widening regional differences - the state of Bihar is four times poorer than the state of Punjab and eleven times poorer than the Chandigarh region. Poverty reduction here is therefore increasingly also a problem of allocation. That situation has not yet been reached in Sub-Saharan Africa. In coming decades the region will remain insufficiently stable and experience insufficient growth to be able to meet the basic needs of its inhabitants without direct aid from the West. Although the countries of Sub-Saharan Africa now also have their own elites - every capital in Africa has its own covered shopping malls for the rich - a substantial middle class is still only present to a limited degree. Reallocation can be advocated here on political or moral grounds, but it offers no answer to large-scale poverty. Lastly, it is questionable whether the growth of many developing countries is sustainable. In numerous cases their economies are based on revenue from the sale of natural resources. That is in itself a vulnerable situation, as prices are so dependent on the world market. Although that may have worked to exporting countries' advantage in recent years, it certainly did not in the decades before. Furthermore, raw materials are finite - oil and gas reserves, the most important exports, will eventually run dry, often within two or three decades, and the question then is whether other sectors will emerge before that time that can take over as drivers of the economy.

\section{And there was development aid ...}

For six decades, Western donors have tried to use money to promote the development of countries that are lagging behind economically. Between 1960 and 2008, rich countries, united in the Development Assistance Committee (DAC) of the Organisation for Economic and Social Development (OECD), spent 2,941 billion dollars on development aid. In 2008, that official aid, which had now risen to 120 billion dollars annually, was supplemented by another 15 billion dollars from non-DAC members like China and South Korea. In recent years in particular, much more money has been made available for development aid: in 2001, total aid was only 60 billion euros, 44 percent of what it was in 2008. In Sub-Saharan Africa, for example, that is equal to 44 dollars per inhabitant per year, approximately 3.5 percent of GDP. Yet what contribution has that effort made? Many believe that it has produced insufficient observable results. There has been a series of spectacular development successes, like Taiwan and South Korea in the 196os, Indonesia in the 1970s, Bolivia and Ghana in the 1980s, Uganda and Vietnam in the 1990s, and Mozambique and Ethiopia in the past decade. To what extent, however, can these successes be attributed to the contributions of Western donors? 
The main line of argument is usually that, despite all the aid it has received, SubSaharan Africa has not yet really developed, while Southeast Asia has developed very successfully with no aid at all. The counter-argument is that the 17 billion dollars - 13 percent of the Us government's budget - that Western Europe received in the form of Marshall Aid between 1948 and 1952 was significant in getting these countries back on their feet as quickly as possible, and that the European Structure Funds helped countries like Greece, Portugal and Ireland catch up rapidly in the 1970 and 1980 s. The 1990 s produced yet more successes, with the 'accession' countries in Central and Eastern Europe experiencing a period of enormous growth - partly due to the fact that they had to comply with the acquis communautaire of the European Union, which compelled them to pursue a sound government policy, but also due to the aid they received. Comparisons, however, always fall short - they suggest a similar starting point or situation, and that is never more than partially true.

\section{... but aid itself has also changed}

Studies of the impact of development aid often imply that aid itself is a constant that can be used as an independent variable in a regression study with development as the dependent variable. The problem with that is that the nature of development aid itself has changed. Certainly up to the early 199os, a great deal of aid was strongly coloured by the Cold War, and the countries which received it and the form in which it was given were partly determined by the political persuasion of the countries' leaders. That proved to be not necessarily a good recipe for development. Until the middle of the 1970s, 80 percent of American aid went to a belt of countries surrounding the Soviet Union and China; from the end of the 1970s (after the Camp David agreement) the large majority went to Israel and Egypt, and in the 1980 s, to a lesser extent, to America's own 'backyard' in Central America. A number of European countries were fortunately exceptions to this rule. Anyone familiar with the daily practice of development aid can see that much has also changed in that respect. A few decades ago, Dutch companies very enthusiastically supplied complete, ready-to-go dairy farms to Tunisia, Egypt and Tanzania, but that enthusiasm waned when it became clear that the Frisian Holstein cattle could not survive in the heat. Aid is still sometimes provided in the form of projects, but new instruments like general and sectoral budget support have since been introduced.

\section{In the meantime the motivation has also changed ...}

The landscape of development aid has changed in other ways. People increasingly want to decide for themselves how they wish to be involved. In the United States this is related to people's growing interest in their own personal family history. In the US, you can have your DNA tested for 349 dollars: in this way some 35 , 00o Afro-Americans have traced their roots. Oprah Winfrey, for example, now knows that she descends from the Kpelle in Liberia. As a result, the slave forts along the 
Ghanaian coast have become places of pilgrimage for many Americans. In Western Europe this trend is manifesting itself in a different way. For young people, there is the 'Causes' application on Facebook, through which you bring your friends on the internet directly into contact with development projects. As backpackers, many of these youngsters have seen large parts of the world, including the poverty, and chains of shops aimed at this group offer not only backpackers' equipment but also placements in developing countries. Adults can choose for themselves which fair trade products from which countries they wish to buy at their local supermarket - the number of households doing just this is increasing every year and more than three and a half million people in the Netherlands now buy these products. If people want to support development projects, they can make a regular donation to the more well-known NGOs - which some 20 percent of the population does ever year - or they can give their money directly to a specific project, through a wide variety of new NGOs, which pledge that 100 percent of the money will go to the project and nothing will be kept back for overheads (Gijsbers \& Van der Lelij 2009). Furthermore anyone who has built up a little capital can start up a fund at various aid organizations, while some organizations, like Medics without Vacation or Architects without Borders, offer you the chance to go and help on the spot. Lastly, there is always the possibility of starting up a project yourself, and an estimated 6,ooo of these projects are already running from the Netherlands.

\section{And what is the place of Western countries?}

In short, after sixty years, the ways in which development cooperation is provided, the motives that underlie it, the instruments that are used, and the organizational form that has evolved are all still very much in flux. How are we to assess and respond to this? In the past year, many Western countries have published visionary policy memoranda on the future of development aid. Although the answers they come up with vary widely, there is one strikingly constant thread: they are all asking what place their own country has in the larger whole. The place of Western countries in the world order used to be clear, so that it was also clear how they should act as donors, but that certainty has now disappeared. These countries are now very visibly questioning their own positions.

\section{Citizens are hesitating}

The Western debate on development aid is shooting off in all directions. A few people suggest scrapping aid completely and allowing developing countries to go through a kind of 'cold turkey'. Others are looking for new, more personal forms of development aid. Yet, although the necessity of aid is being questioned in the public debate, support for it among people in the West is not declining. Public support when it comes to helping poor countries has remained high in OECD/DAC countries over the past two decades, whether the times have been good or bad in economic terms. Public donations and the number of NGOs providing emergency 
aid have increased, though opinion polls in France, Italy and elsewhere show that people have become a lot more cautious since the financial crisis (Zimmerman 2008). In the World Values Survey, the United States emerges as the great exception: only 55 percent of people in the Us support development aid, while in the remaining OECD countries this is around go percent. The figures must be seen, however, in the light of American culture, in which people prefer - much more than in Europe - to provide aid through private, charity-based channels (Paxton \& Knack 2008: 18-19).

In European countries, too, providing aid through non-governmental organizations is gaining in importance. In 2007, for example, 45 percent of Dutch households gave to international aid causes. A Motivaction survey in June 2009 showed that 72 percent of Dutch people had participated in some way in an activity relating to international cooperation in the previous twelve months. The most popular form of participation is to give money in the form of one-off donations to a charity in the field of development cooperation ( $38 \%$ of Dutch people), followed by donating goods and taking part in lotteries that support charities (both 34\%). In exceptional circumstances the participation rate can rise substantially: after the tsunami in Asia at the end of 2004, for example, 67 percent of Dutch people donated money. Involvement can also take the form of actual help on the spot. The NCDO Barometer of June 2009 shows that one percent of Dutch people had done some form of voluntary work relevant to development aid in the previous twelve months (Gijsbers and Van der Lelij 2009).

\section{Difficult position}

The lack of clarity is expressed in the widely varying image of Western policy on development aid: one day we see pictures of a minister patting the heads of children in Colombia or Yemen, and the next we see the same minister at the G2O drawing attention to the capital needs of developing countries. One day he is reminding the private sector about corporate social responsibility and the next he is negotiating on the further development of tradable emission rights. One day he criticizes the way in which the price of fertilizer is being kept artificially high, the next he is defending women's rights. The international arena is large, very large, with players like the United Nations, the European Union and the World Bank, all with their own agendas. The challenge is how to operate effectively within it.

\section{Structure}

All this is a good reason to take a close look at the future of development aid. This book starts, in the following three chapters, by asking how development can best be understood. That offers a framework within which to assess efforts to promote development through aid, which is the subject of chapter five. This analysis leads to conclusions about the way in which aid should develop in the future - chapter six offers an outline of the direction that path should take. The following two 
chapters examine this general direction in more detail. Chapter seven focuses on how Western governments could give shape to targeted efforts in the field of development aid. Chapter eight shows that it is increasingly important to give general policies a clear development perspective. Finally, chapter nine brings the whole together and offers conclusions in a broader perspective.

\section{Terminology}

To conclude, a short word about terminology. The world of development aid is fond of insisting on politically correct terms, though what is considered politically correct changes with each decade. In this book we try to distance ourselves from that debate. We refer here to development aid, because the term development cooperation implies an equality that not only does not exist but also conceals the reality of the situation. An aid relationship is always asymmetrical, and even more so if the recipient country firmly believes that it is unable to survive without the aid - as is often the case. Although this book does sometimes refer to developing countries, in doing so we are also clouding the issue, as the distinction between developing and developed countries is becoming more and more difficult to maintain - you can divide the world in many different ways and according to a variety of criteria, but it is increasingly rare for that division to be in terms of North and South. Where possible we are more specific, but sometimes we choose a collective term. 


\section{THE DEVELOPMENT AID SPLIT}

Development aid aims to contribute to a better world. There are all kinds of motives for creating a better world and each has its own emphases and leads to a specific design of development aid. The roots of these different motives can all be found in the current practice of development aid, therefore making it the result of a blend of motives. The more divergent the motives, the more difficult it is to realize a productive whole when designing development aid. The fact that the motives - which each have their own value - are so different has brought increasing pressure to bear on the design of development aid in recent decades. This pressure is becoming more and more of a problem. With a view to showing that this is the case, we start this chapter with an analysis of the motives.

\subsection{TWO BASIC MOTIVES FOR DEVELOPMENT AID}

The history of Dutch development aid illustrates the way the Western world has regarded aid over the years. When, on 3 October 1949, the Dutch government first decided to make funds available for development aid - while still receiving aid itself via the Marshall Plan (!) - its policy was shaped primarily by the process of decolonization. The Memorandum concerning the Dutch contribution to the programme of the United Nations for technical aid to economically under-developed countries (Ministry of Foreign Affairs 1950) must be read against the background of the Netherlands handing over power in Indonesia three months later, on 27 December 1949. The memorandum summarized the clear benefits of development aid for the Netherlands, such as an enhanced reputation, new export possibilities and, most importantly, finding something useful to do for all the superfluous experts in the field. "Now that Indonesia is going to lose its significance as an outlet for Dutch intellect, we will have to look for a field of activity in other areas like Africa, Latin America and Asia" (p.7). All in all, the Netherlands decided to make 1.5 million guilders available, all with a view to transferring knowledge.

The processing of the post-colonial trauma initially had a strong influence on government policy in Western countries. In France, the Ministry for the Colonies was divided into two ministerial departments: one for "related states" and one for French overseas territories. In the United Kingdom too, an aid system was constructed which was grafted strongly on old relationships and institutions (Stokke 2009). The colonial focus endured for quite some time, most notably in France. From the 196os onwards, De Gaulle developed a policy for bilateral development with former French colonies. Supported by financial, technical, cultural and military aid, France thus gained an influential position in Francophone Africa. Even after De Gaulle's resignation in 1969, successive French presidents 
carried on providing aid primarily to Francophone countries in Africa. France also became militarily involved in such countries on a number of occasions.

In most countries the colonial focus gradually faded into the background. When, in 1956, the second memorandum on development aid was issued in the Netherlands (Ministry of Foreign Affairs 1956), the most important motive was already being referred to as 'human dignity', with this mainly being developed by outlining how an international economy can eventually benefit everyone ("we need natural resources"). Knowledge transfer shifted to the background and investments of foreign private and public capital became the new priority. In 1962, Minister Luns again presented a memorandum on development aid (Ministry of Foreign Affairs 1962) which referred to less-developed countries (this description replaced the term 'least-developed countries' and was soon followed by the terms 'under-developed countries' and 'developing countries', after which they were also referred to as recipient countries and partner countries). The main focus of the memorandum was on a stable world order. "The discontinuation of excessive differences in wealth is important from the political perspective as well. The social tensions which result from poverty and hunger lead to political tensions, extremism and chaos. Even if they are initially determined at national level, such circumstances tend to generate international tension and risk of war. Peace in the world is enhanced by increasing prosperity and particularly by helping underdeveloped countries to catch up" (p. 1). It was for this reason that the Netherlands decided to invest structurally in knowledge accumulation. "Lastly, in view of the need for accelerated social development in the underdeveloped countries the government proposes making a one-off contribution available, as a specific Dutch initiative, for an institute for social development planning" (p. 14).

These views illustrate a fundamental motive for development aid, namely selfinterest. Self-interest comes in various forms. It can be very practical (for example the provision of new employment for people returning from the colonies and increasing export opportunities) or more enlightened (the creation of a stable world elsewhere will also be good for us in the long term). To date, self-interest has played an important role in policy on development aid (see also Dierikx 2002-2008).

There is also a second category of motives for aid, namely moral motives. These have their roots in a period when development policy did not yet officially exist. The Christian church in particular had been sending missionaries to far-off places since the beginning of colonial times. Travelling in the wake of soldiers, government officials, settlers and traders, they had carved out a niche for themselves in many parts of the world by the end of the nineteenth century. They converted people but also contributed to their general development - initially by teaching but also, in the twentieth century, by providing medical services. To a 
certain extent missionaries took a different standpoint to other Westerners in that they wanted to preserve indigenous customs and learn the local languages. In this way they had a definite influence on cultural anthropology. The practice of sending out missionaries came to an end sometime in the mid-196os. The motive behind this practice was partially transformed into support by the Christian parties for an increase in the budget for development aid by Western governments, while at the same time three papal encyclicals and similar developments in the protestant church linked these religious persuasions to international social engagement.

Although there was less of a focus on missionary work in the 1960 , this did not mean that the moral motive disappeared. However, the most important manifestation of this motive changed and became part of a more general and secularized idea of 'decency' which had been around for somewhat longer. In the 1960 os and 1970s, the third world movement started to gain momentum in the form of groups in many Western countries debating poverty and oppression, unfair trade, war and tyranny, capitalism and imperialism. There were calls to refuse tax reductions and introduce a 1 percent global tax. The war in Vietnam, the fall of President Salvador Allende in Chile, and the freedom movements in South Africa and Latin America resulted in all kinds of debates, movements and activities. In the public discourse, development policy became more and more a question of civilization and of not abandoning people beset with problems to their fate. This civilization ideal was broadly supported by people in the West. It also offered excellent possibilities for a political compromise. After all, the classical liberal endeavour of elevating the underclass could be linked to the Christian Democratic idea of love for one's fellow man and the socialist idea of solidarity. Although the principles differed, in everyday practice they were easy to unite. Political conflicts surrounding development aid were therefore few and far between from the 1960 os until the end of the first decade of this century.

The two basic motives for development aid are still present in 2010, although they have evolved. There are now different variants of both, and their relationship has become more complex. The two motives are now interpreted more individually. While it was possible, for a long time, to combine the interpretations to form a workable political and organizational compromise, there are many indications that this gradually became more and more problematic. Before examining this relationship more closely, we will first analyze the way in which these two motives have developed.

\subsection{THE MORAL ASSIGNMENT}

The endeavour to help your fellow man elsewhere is a leitmotiv for a great deal of development aid. As already mentioned, this is often founded on ideological posi- 
tions, whether religious ('love thy neighbour') or secular (solidarity, decency). Bit by bit, attempts have been made to bolster the foundations for those motives. After all, motives have to do with issues to which we attach value for material or idealistic reasons. Many theorists wish to replace those motives with principles and try to develop a reasoning which justifies development aid in generally acceptable terms. There are three possible variants.

\section{Individual potential}

A first group starts out from the anthropological idea that people have to be able to realize their 'individual potential'. This liberal branch of political philosophy became well-known largely through the work of Amartya Sen and his notion of capabilities. Strikingly, in his work, Sen (1999) himself always remained quite vague about the question of which capabilities actually exist. He provides no exhaustive list, despite referring to matters such as working, rest, being a member of a community, being able to read and being respected.

Sen - and authors like Nussbaum (2006), who developed a justification strategy to suit this approach - make a strict distinction between capabilities in the sense of capacities, and the specific functioning of those capacities - that is the outcome of what people do with capacities, given the circumstances in which they live. The extent to which people can express their capacities is the extent to which they experience freedom - and the creation of a greater degree of freedom is the goal of development (Robeyns 2005).

Sen does outline how that freedom is conditioned. He identifies five sorts of instrumental freedoms: political freedom, economic possibilities, social opportunities, guarantees of transparency and openness, and protective certainties. By doing so he tries to strike a happy medium between theorists who talk about welfare only in terms of feelings (welfare as happiness), and others who only focus on material circumstances (for example, income) and the equal distribution of resources, without asking what these mean in the lives of individual people, who are of course all different.

Sen's way of reasoning is a feature of much of the work of the United Nations Development Programme (UNDP), such as the Human Development Index and the accompanying Human Development Report, developed by the Pakistani Mahbub ul Haq, a fellow student and friend of Sen. The index is a function of life expectancy, level of education and standard of life in a specific country. These days the report includes all kinds of other themes, such as cultural freedom and participation. The UNDP had hoped that this concept would counterbalance what it regarded as the excessive economic focus of the World Bank. 


\section{Right to development}

A second line of approach is to start not from the extent to which individual capacities can become a reality, but from a predetermined set of individual rights. That approach also has a long tradition, and has become a resonant feature of debates on development aid more and more frequently during the past fifteen years. Increasingly, the question is being asked of how rights should be interpreted at global level. Why, up to now, have notions of justice applied in individual countries and not elsewhere? In other words, as formulated in the editorial to a theme-based edition of The Economist (2004), "Why justice at home and charity abroad?" 'Cosmopolitan' ethicists have developed the concept of global justice further (see Pekelharing 2009). In particular, Pogge $(2005,2008)$ acquired a reputation for his argument that everyone actively bears responsibility for the continued existence or eradication of poverty. He even goes so far as to say that he believes the famous first Millennium Development Goal (MDG), (halving poverty by 2015) to be a crime against humanity because it implies that it is 'permissible' for half of humanity to still be living in poverty in 2015 .

The institutional counterpart of a universal concept of justice consists of the intricate UN system of human rights. This comprises a summary of universal rights and with that a moral, legal and political obligation to realize these rights on a global scale. This resulted in the introduction of an impressive collection of rights, as in the Universal Declaration of Human Rights (1948), the Declaration on the Right to Development (1986), the Vienna Declaration on Human Rights (1993) - in which political rights are formally put on a par with economic and social rights - and the Rome Declaration on World Food Security (1996). In recent years the UN has tried to clarify, via the work of various task forces, why reasoning in terms of human rights provides a suitable foundation for development thinking.

However, thinking in terms of rights is not everyone's idea of the ideal way of substantiating development aid. The tension in that relationship can be largely traced back to the fact that human rights can be interpreted in a variety of ways. They are often hastily interpreted as political rights (freedom of association, the right not to be tortured) while the world of development aid, if indeed it reasons in terms of rights, attaches more importance to economic and social rights. Many countries in the South reproach Western countries for claiming that they acknowledge the indivisibility of civil and political rights on the one hand and economic, social and cultural rights on the other, but in practice show little interest in enforcing the latter category of human rights at a worldwide level (Alston 2005). There does seem to have been some improvement now that a large number of countries have included social and economic rights in their constitutions. In South Africa citizens can now take legal action to claim their right to work. The standards of the ILO with regard to decent work have also 
acquired a more than symbolic meaning over the course of time. However, it will be some time before social and economic human rights become legally enforceable rights.

A rights-based approach is complicated in other ways (Gready 2008; Grugel \& Piper 2009; ICHRP 2008; O’Neill 2004). For example, it is difficult to relate rights to a distribution perspective. After all, everyone can be entitled to good health but everyday practice is primarily one of setting priorities and sharing resources, not ideal subject matter for a rights discourse. Neither is it always clear who the relevant actors are. Who, for example, is responsible for food security? On the other hand, rights have the advantage that they constitute a clear point of departure from the idea that development is no more than a favour and that they, in any event, try to designate and specify responsibilities, even if the interpretation is contentious.

\section{A better world}

The third group starts by tackling the question of whether development is, in any case, the right term to represent our aim of creating a better world (for example Rist 2007). In their eyes, it has strong links with a Western image of limitless progress - an image which itself is an expression of the enlightenment project that has dominated Western societies for two centuries. It is closely related to the notions of 'more' and 'universal values'. Making a distinction between 'developed' and 'underdeveloped' countries makes it very easy to advance the idea of the superiority of Western society. In fact, this is the twentieth century successor to the nineteenth century division between the civilized and the wild. The alternative has not been elaborated in any detail but points towards a conceptualization of the notion of a 'better' world.

As a result, the authors in this group conform to the wider, Aristotelian criticism of the Western enlightenment project, by pursuing a 'much more substantial', that is substantive definition of the good life. This approach emphasizes the fact that growth often goes hand-in-hand with unbridled consumption, and all the consequences for the environment that this entails. On the other hand, sustainability is promoted as being crucial for a broader 'good life approach'. Those who adhere to this approach also value the very diverse and specific ways in which different groups of people around the world view the 'good life'.

These attempts to give development a more fundamental foundation are interesting but have had limited political significance up to now. Reasoning in terms of capabilities is not unusual - and even standard practice in UNDP circles - but it would appear, for the time being, to function more as a vocabulary by which to substantiate activities which are already being undertaken, than an independent line of thought as a guideline for action. Rights-based reasoning is based heavily 
on the international legal order. However, in daily practice its meaning is not strong enough to affect the scope or nature of development aid. The same is evident in the context of UN practice in which hardly any serious and influential debates take place on the content of the individual countries' development policy. UN organizations with an explicit development assignment have ended up politically in increasingly marginal positions in recent decades, such as UNCTAD, or are continuing to remain marginal, such as the Development Corporation Forum. The latter was launched only in July 2007 as the platform for structuring consultation on the implementation of development policy, but has still not progressed much beyond being a discussion group. The original task of the UNDP, which still has the strongest position, was to coordinate the development work of others.

However, its focus continues to lie for the time being on executing its own development activities. Its position does not allow it to coordinate the development policy of all donors, let alone guide or influence it.

\subsection{SELF-INTEREST}

The moral motive is contrasted by the self-interest motive. That motive has also evolved over the course of time. Once again there are three variants.

\section{Self-interest as money and influence}

A Western country can provide development aid because it generates money and influence. That is the most direct form of self-interest - and in the perception of many the crudest. In this context money refers almost always to the explicit interests of the business community. This motive has been around for quite some time and remains a small element of Western government policy. A set of instruments is available to the business community, including a scheme for export credits, but generally speaking the point of departure that applies in most Western countries is that a country's own companies should not be able to count on preferential treatment when it comes to spending the development budget. The United States and Japan are the best-known exceptions to this, but elsewhere, companies can compete for contracts on the basis of open competition.

In recent years, the theme of financial interest has also been approached from a different viewpoint. The question is why should we help countries to try to develop at all? Are we not then playing into the hands of the competition? The classic answer is that growth elsewhere is in fact favourable for Western economies in that it facilitates specialization and exchanges which are of benefit to everyone. A few years ago, in anticipation of such a debate, the Netherlands Bureau for Economic Policy Analysis (СРB) published studies on the emergence of China (2006) and India (2007) which calculated that the development of China had led to a 0.5 percent increase in employment in the Netherlands, and that of India to an increase of 0.25 percent. In a recent study (Creusen \& Lejour 2009), the 
CPB even calculated that, since 1970, the increased openness of the Dutch economy has resulted, thanks to international agreements on freer trade, in higher growth and now generates between around 1200 and 1600 euros per resident per year.

There is also a geopolitical version of Western countries' self-interest, oriented not around money, but influence. Western countries occasionally use development aid as an instrument by which to project an image of themselves and to buy 'a place at the table' in international fora. A number of small countries in particular engage in this behaviour. Large countries are always able to make an impact in the international arena by adopting positions on the 'key' issues of peace and security. In that context, small countries carry less weight and development aid is one of the ways in which they can make their voice heard. That is why it generally applies that the smaller the country, the bigger the percentage of aid they provide.

\section{Self-interest as stability}

As a variant of the self-interest motive, money and influence sometimes play a role but neither are a significant motive for the direction and structure of Western development aid. In so far as the self-interest motive is relevant, it more frequently takes a second guise. The self-interest is then primarily aimed at stability. The core of the argument is that being good to others eventually means that they will cause us fewer problems. The benefit is then no longer a specific gain in the here and now, but in the stability which aid helps to bring about in the long term. This is then a form of enlightened self-interest.

A variant which features this idea is the notion that development aid can halt migration flows. Some politicians advocate development aid because, in time, it would mean that people in Africa would no longer feel any urge to come to Europe. The idea can also be formulated without linking it to migration: investing in the South makes the situation there more stable. In those terms, enlightened self-interest has played an important role from the beginning of modern development aid, and can already be seen in Tinbergen's work. It is also reflected, in particular, in the pursuit of what passed, for many years, as 'security'. After Truman's famous speech in 1949, in which he introduced the world to American development policy and Marshall Aid, 8 o percent of the massive flow of aid went to the belt of developing countries around the Soviet Union and China, in the first instance mainly to Taiwan and South Korea, later to Persia, Pakistan and South Vietnam. In Western Europe Marshall Aid was also intended to help prevent the development of a breeding ground for Communism. That political undertone was a characteristic of American aid for many years. The fact that Egypt and Israel were the most important recipients of American aid from 1979 onwards had less to do with poverty in those countries than with the political situation in the Middle East (Hoebink 2010). 
The United States and, during the Cold War, the Soviet Union were not the only countries to be motivated by geopolitical considerations. For example, West Germany was long unwilling to give aid to a country that recognized the existence of East Germany. Australian bilateral development aid started in Indonesia and was motivated by the fear that cattle diseases could blow over to the Australian continent from Nusa Tenggara, the most remote of Indonesia's islands. Combating cattle diseases consequently became one of the first projects to be carried out there. France, in particular, maintains links with its former colonies, with economic and geopolitical interests being mixed in with notions of development aid. Not so long ago, French soldiers came to the aid of the Chadian dictator Idriss Deby. Although this took place with international approval, no pressure was put on Deby to take serious steps towards democratizing the country. France is also still considering whether it wants to investigate the possessions of the president of Congo-Brazzaville, Sassou Ngueso, who is said to have eighteen houses and 112 bank accounts, or those of Omar Bongo of Gabon, who was in power from 1967 to 2009 and who has thirty-nine houses and seventy bank accounts.

Enlightened self-interest can serve as a motive for the West to help the South. Although that may sound crass to those who act on the basis of a moral motive, self-interest was once an important motive for creating a welfare system in the West itself. Take, for example, the development of the Netherlands. The first form of government care for the needy came about at municipal level in response to the large group of vagrants who moved from one town to another in times of economic hardship in search of work. There was a fear of them bringing infectious diseases or rising up in rebellion. When, after 1840, a number of consecutive potato harvests failed, the percentage of needy people rose from 10 to 15 percent of the population and the political unrest in the countries around the Netherlands increased substantially, a decision was made to make care for the poor an explicit municipal task by including it in the Municipalities Act of 1851 . However, this safety net turned out to be insufficient in the face of increasing industrialization. Fifty years later a start was made on building up a social security system in the Netherlands which was largely based on the model which Bismarck had developed in Germany several decades earlier. Bismarck was a member of the German landed nobility and a self-proclaimed opponent of the emerging workers' movement. At the same time he wanted to give the recently formed country of Germany a clear power base and mould it into a unified whole. As a result the authoritarian Bismarck, of all people, became the first in Europe to develop a social security system - without incidentally ever consulting formally with workers' organizations on the matter. He introduced accident insurance in 1871 , health insurance in 1883, and pension and disability insurance in 1889. These schemes would serve as a model for what would happen in Western Europe in subsequent decades. Social security arrangements in other countries were also mainly set up by authoritarian regimes. Therefore, our 'own' Western welfare system is largely based on the 
middle class' and elite's fears of chaos, rebellion, crime and infectious diseases (De Swaan 1988). A similar argument can also be applied to development aid.

\section{Self-interest as part of the general interest}

If enlightened self-interest is seen as a way of creating stability, it can quite easily become synonymous with the general interest. Development aid then becomes a contribution to global survival. The starting point of this variant is the fact that countries have become dependent on each other in a number of essential areas. This variant is rapidly attracting a greater emphasis thanks, mainly, to the significant increase in attention to climate issues and the realization that these cannot be solved without the involvement of the countries in the South. There has also been a rapid increase in the awareness of interdependence. Globalization, presented in the 1990 s primarily as the intertwining of economies, similarly had far-reaching consequences in other fields. When goods move around in a globalizing world, people, knowledge, polluted air, financial flows, and cultures also move, and this leads to mutual dependencies in these areas too. These developments require careful analysis. We will therefore examine them separately and in more detail in the following section.

\subsection{INTERDEPENDENCIES}

\section{Demographic changes}

Interdependence first of all increases under the influence of demographic changes, with huge consequences. Between 1950 and 2009, the world population increased more than two and a half times, from 2.5 to 6.8 billion. These figures are also important when pondering the scale of the 'development task' (ironically enough this task has become even greater thanks to development efforts: combating infectious diseases and improvements in healthcare contributed substantially to this population explosion in the 1950 os and 1960 s). The world's population will continue to grow at a considerable rate until 2050. The rise during the coming four decades will be equal to the total world population in 1950. That growth is going to take place almost exclusively in developing countries. In 2050, more than 7 billion of the 9.2 billion people in the world will live in countries which we currently refer to as developing countries. The most significant growth will be in India, where almost one-fifth of the increase is going to take place. Until 2025 , the number of inhabitants of India is set to increase by 240 million to 1.45 billion, reaching 1.7 billion in 2050. Over the same period, the population of China is set to grow by 100 million, reaching a total of 1.45 billion. This is partly thanks to the single child policy which has caused China's population to age much more quickly than that of India. During the same period, the population of Sub-Saharan Africa will increase by around 350 million. On the other hand, the population in 'Western' Europe, Japan, the United States, Canada, Australia and New Zeeland will only grow by 4 percent in the period up until 2050. The population in the West 
will actually drop by 7 percent in the same period to 1.15 billion if the predicted net immigration of 2.4 million people per year does not occur (United Nations Population Division 2009). While 24 percent of the world population lived in the West in 1980, this will have dropped to just 16 percent in 2025, taking account of the assumed net immigration. Many Western countries, including Russia, Ukraine, and a number of Eastern European countries, will undergo population decreases in the same period, sometimes by even more than 10 percent (National Intelligence Council 2008).

\section{Figure 2.1 World population in $\mathbf{2 0 5 0}$}

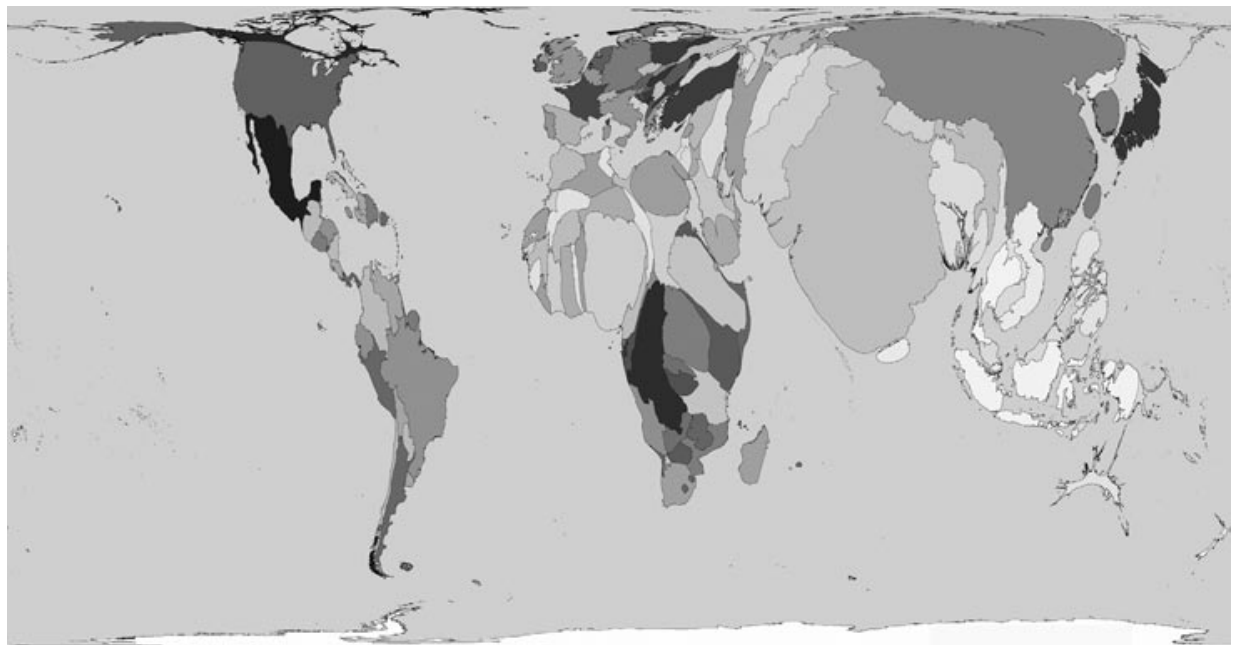

Source: Worldmapper.org 2009

The consequences of the growth in population are considerable. In developing countries the primary task is to cope with urbanization (Van Dijk 2006). Based on the current trend, 57 percent of the world population will live in urban areas in 2025 , as opposed to 50 percent now. In around 2025 , the world will have eight new mega cities to add to the nineteen that currently exist. All but one of these new cities will be in Asia and Sub-Saharan Africa. However, the greatest urban growth will take place in smaller cities, often along motorways and the coast. A relatively large population increase will also take place in areas close to the coast at locations which are very sensitive to climate change. In the meantime, population ageing will mean Western countries are confronted by a different challenge, namely to maintain the size of the working population. If the EU wants to keep its working population at the current absolute level, it will have to absorb the entire population growth of North Africa and the Middle East in 2040. The alternative is to increase productivity in the entire EU to the level of the most productive European country, Denmark, and simultaneously raise the pensionable age to 75 (WRR 2006b). 


\section{Climate, the environment and biodiversity}

The growth in world population has clearly left its marks. It is estimated that the human race has already chopped down between 30 and 50 percent of all the world's forests, while three-quarters of all commercial species of fish are seriously overfished, and the speed with which species are dying out has been a thousand times higher during the past 100 years than in the periods before then (MEA 2005, DEFRA 2005). Between 1970 and 1999, 50 percent of all marshes worldwide have been drained and it is estimated that, as a result, 20 percent of all freshwater species have disappeared, as well as half the water buffer capacity which used to be available worldwide to prevent floods along major rivers. During the past 100 years, 75 percent of all genetic diversity in agricultural varieties has disappeared and one-third of coral worldwide has perished or has been very seriously affected. The effect of such developments initially manifests itself in areas and communities which are primarily dependent on their local ecosystems. Quite often those areas are in developing countries, but the problems they face also affect the developed world.

On top of these forms of source depletion there is the problem of climate change. In 1972, the Club of Rome published the report The Limits to Growth. In contrast to the frequently expressed view, the authors did not predict that the world would collapse at the end of the twentieth century. Instead, their findings remain of interest to this day. Anyone who now analyzes the data relating to the period 1970 to 2000 and compares it with the various scenarios can only conclude that they fit into the business-as-usual scenario referred to in the report, which the Club calls the standard run scenario. This scenario puts forward the possibility of an eventual collapse of the global system in the mid-twenty-first century. More recent reports, like that of the Intergovernmental Panel on Climate Change (IPCC) and the Stern Review on the Economics of Climate Change (Stern 2007), contain details on how such a global collapse of the environment, economy and social order might happen. According to these reports, both developed countries and countries in the South will have to develop low-carbon economies in the coming decades and start adopting a climate-adaptive approach. After all, the climate is already changing drastically (see also Netherlands Environmental Assessment Agency 2009b).

In addition, there is the problem that has developed over time of rich countries being responsible, based on the principle of 'the polluter pays', but poor countries mainly facing the risk of actually having to pay the price. According to calculations by the United Nations Framework Convention on Climate Change (UNFCCC) the costs for the adaptation of poor countries to climate change vary from 30 to 90 billion dollars per year with an average of 75 billion dollars. Developed countries that try to evade this moral responsibility end up facing a considerable problem because the future of the entire human race also depends on us stopping global warming. This requires a joint and yet differentiated effort and cooperation by all 
countries since mitigating climate change is a global public good in which everyone in the world benefits from every contribution, no matter where it is made, to the reduction of $\mathrm{CO} 2$ emissions while, conversely, every extra emission of $\mathrm{CO} 2$ will have a detrimental effect on every world citizen. This not only means that the efforts in rich countries to limit $\mathrm{CO} 2$ emissions can be more than negated by an increase in emissions in growing developing countries, but also that it is costeffective to separate, to a certain extent, the party that pays for mitigation from the question of where those adaptations take place. Mitigation in the agriculture and forestry sectors of developing countries in particular is a lot cheaper than in rich countries, and poorer countries ought to be able to leapfrog directly to environmental-friendly production methods, transport systems, energy generation and urban development without having to pass through more contaminating phases first.

In short, if the poor countries do not participate, it can cost us a great deal of money, and we may even end up with wet feet into the bargain. If the five countries with the largest emissions (which represent two-thirds of global emissions) are made responsible for reducing emissions to the desired global level, the related costs will be three times higher than when all countries participate. That participation requires these countries not to be approached as potential recipients (and payers) of advanced technologies which are largely the intellectual property of Western companies, but instead to acquire the necessary techniques and knowledge. According to Birdsall \& Subramanian (2009) revolutionary technological improvements in developing countries are needed since "improvements in technology at rates consistent with those we observed historically, even for the most carbon-efficient economies among major emitters, provide little hope of meeting the broadly agreed global target for emissions reductions of 50 percent relative to 1990". The European Parliament has adopted a resolution to the effect that intellectual property rights may not constitute a barrier to development and technology transfers, and the British economist Nicholas Stern has suggested that the relevant technologies for climate policy have to become available without patents. What is more, being able to use that knowledge requires more than machines, equipment and large-scale projects for the transfer of hardware for clean technologies. Other very important elements are the transfer of underlying (implicit) knowledge and skills and the building of the capacity to be able to use technology and adapt it to the different specific cultural and technological requirements between and within countries.

It is also important to emphasize that climate changes will affect people in the developing world more immediately than in the West. While, in the short term, some more moderate climates may well even benefit from climate change (for example, Russia and Canada), populations closer to the equator will primarily experience negative effects. While agricultural production may well increase in 
some areas, developing countries may experience a decline of between 10 and 25 percent in their production by 2080 if policy stays the same and temperatures continue to rise. That decline may even be greater in some countries, for example of between 30 and 40 percent in India, 52 percent in Senegal, and 56 percent in Sudan (Dervis 2008). However, the accuracy of many of these figures is very uncertain. What does it mean, for example, if in the near future East Africa were no longer to have two rainy seasons, but just one? It does not take much to imagine that the effects would be considerable, but it is difficult to assess what the general impact would be (Netherlands Environmental Assessment Agency 2009a; Ockwell 2009; Ockwell et al. 2008; OECD 2009, Srinivas 2009; UN 2009c; UNCTAD 2009d; World Bank 2009b; WRR 2006d).

\section{Food}

Climate change will also affect food production, while food production itself will come under pressure due to changing eating habits. The effect of a growing global middle class, with meat and dairy-rich eating habits, is already tangible. Meat and dairy products generate high-quality proteins, but their production is much less efficient in terms of energy consumption, and therefore land use (for cattle fodder). A diet based on grain requires nine times less land than a diet based on beef for a comparable quantity of calories. This can be translated into higher food prices and regional food shortages. The United Nations Food and Agriculture Organization (FAO) estimates that, in 2009 alone, and primarily as a consequence of the relatively high food prices, the number of chronically hungry people in the world rose by 75 million to 1.02 billion (FAO 2009a). The sudden increase in food prices in 2007 and 2008 and the resulting unrest in many cities in the South has put food quantity back on the agenda, and with good reason. After all, the Australian Commonwealth Scientific and Industrial Research Organization calculated that, in the coming fifty years, the ever-growing world population is expected to require as much food as the total quantity the human race has produced to date (Clark 2009). Achieving this is going to require quite some effort.

In contrast to food quality, food quantity has never been 'guaranteed'. While diseases like AIDS, SARS, and bird flu have led to the setting of international safety priorities, and the UN Security Council has concentrated its attention on terrorism, there has never been a similar focus on food quantity. Although the World Trade Organization (WTO) has a long tradition of international safety agreements in the field of food quality and everyone can almost assume that the food in international supermarket chains is safe, there are still no binding international regulations governing food quantity (Warner \& Burger forthcoming). Countries are working on food security via regional partnerships (for example the EU agricultural policy, which was set up from this perspective). The question is to what extent this is a good idea and what form regulation could take. 
The recent significant rise in food prices (more than 80 percent in the three years prior to the spring of 2009), and the resulting unrest, show that food security in many countries has a very loaded political priority. It is also clear that the global food market is becoming increasingly dependent on a range of factors which are no longer just technical in nature, but also political. Because demand for grain has exceeded supply in the past seven years, grain stocks in 2007 were at their lowest for thirty years. This was a consequence of a conscious policy since 200o. The collapse of global market prices a decade ago, together with improved trade logistics and overwhelming reserves on the world market resulted in many governments (including China) regarding large grain stocks as inconvenient and expensive. Bad weather caused the grain stock to decline even further in 2005 and 2006 . However, there were other factors that played a role. When the dollar started declining steadily in 2002, and the price of oil rose as a result, transport prices for food doubled and fertilizer prices tripled (Evans 2009; FAO 2008). The emergence of the biofuels industry also played a part. Industry is a significant user of agricultural products such as sugar, maize, cassava, oil seed, and palm oil. In 2007, 4.7 percent of the world grain production was already being used for biofuels. Lastly, world food prices were also influenced by the policy measures by food-exporting countries to restrict exports in response to imminent internal social unrest (FAO 2008).

All this sent huge shockwaves through the global food market. It also resulted in individual countries like South Korea, China and Saudi Arabia securing their food production in recent years by purchasing land in Africa. They have started clearing forests and people from the land, which is - at least for the time being - very fertile, to cultivate food on a large scale. Stricter food export regulations are being introduced, because countries only maintain limited grain stocks (Europe, for example, only has enough grain for two months). If the harvests in China fail on a grand scale and that country decides to stop exporting more grain and purchase all its food on the world market, this would result in such excessive price rises that many a country would have to hold on to its own food in order to avoid national unrest. All this is compounded by the imminent shortages of energy, water and fertilizer. Based on current agricultural production, reserves of phosphate, the basic constituent of fertilizer, will only last another 125 years. However, if we take the increasing demand for food into account, it is estimated that it will already be gone in sixty years (US Geological Survey 2009).

In order to feed the future world population sustainably, stably and efficiently, it is in everyone's interest for the right food to be cultivated in the right way and at the right location. Only then can there be any guarantee that, based on current worldwide agricultural acreage, we can produce sufficient food in a nutrient, water and energy-efficient way for a population of 9.2 billion people and, at the same time, preserve biodiversity and the environment (Evans 2009; FAO 2008; Fresco 2009; Rabbinge \& Bindraban 2005). 
A telling example is the cultivation of crops which use a relatively large quantity of water per unit of yield in areas where water is scarce. The production of one kilo of wheat requires a thousand litres of water and, from the perspective of water efficiency, it is strange that countries where water is scarce, like Tunisia and Kazakhstan, or dry areas of China, produce such cheap water-inefficient bulk crops for export to countries where water is plentiful, such as Canada or the Netherlands (The same applies, for example, to cotton, which, although not a food crop, still requires large quantities of water). From the perspective of resources it would be better for Tunisia to focus on the cultivation of high-quality drought-resistant cash crops like olives or oil seed, and import its grain from water-rich areas in North America. In terms of water required to produce one unit of grain or cotton, Kazakhstan, a country where water is scarce, exports five cubic kilometres of 'virtual' water packed in its export crops every year, and imports hardly any. Paradoxically, the water-rich Netherlands imports almost three cubic kilometres of virtual water annually. Of course, these kinds of comparisons can also be made for efficient nutrient use, agricultural acreage, energy or pesticide use, and illustrate the importance of coordination and strategic agricultural specialization for a sustainable global food supply (Allan 1999, 2001; Hoekstra \& Hung 2002; World Water Council 2004).

\section{Water}

Huge water-related problems can be expected to occur. In many African semi-arid and arid areas such problems are primarily caused by irregular rainfall, high levels of potential evaporation and the fact that, due to inhospitable physical conditions and the lack of an organized technological and institutional infrastructure, water cannot be properly stored. Annual rainfall in Burkina Faso is actually almost the same as that in the Netherlands. However, in Burkina Faso it falls during a short and usually irregular period, and potential annual evaporation is usually more than twice as high (1500-2000 mm) as the rainfall itself (FAO 2007; KNMI 2009). By way of comparison, the long-term average evaporation in the Netherlands is $540 \mathrm{~mm}$. Furthermore, much of the water flows out of the country during and immediately after the rainy season via seasonal rivers (wadis) due to the lack of water storage infrastructure such as dams and small-scale water tanks.

Africa is not facing a water shortage, but other places are. Central Asia, North China, and the northern part of South Asia can experience considerable problems due to glaciers receding and disappearing. For example, many of the large river systems in Asia will, in the short term, discharge a lot more water than normal, but will then decrease in size once the glaciers have completely melted. These river systems provide water and food for more than two billion people. 


\section{Financial crisis}

The recent financial crisis is an entirely different example of increasing interdependence. It is still too soon to say with any certainty what effect the current crisis will have on developing countries, but what we know so far does not give much cause for optimism. The forecasts indicate a significant drop in private flows of capital to developing countries. In 2009, foreign direct investments (FDI) already fell by 30 percent, that is 1 percent of these countries' GDP. At the beginning of 2009, the UN counted thirty low-income countries with reserves under the critical limit (enough to finance three months of imports). What has now become a quite thick pile of studies point out the unpleasant truth that this crisis is the responsibility of developed countries, but that it is also having a very detrimental effect in developing countries that were unable to do anything to prevent it. In the first instance it was thought that the consequences for these countries would not be too bad but, after the demise of Lehman Brothers in September 2008, the external environment for emerging markets quickly deteriorated. The crisis is putting pressure on structural changes and national development processes via a number of transmission mechanisms, including a stark decrease in private capital flows and higher costs of external financing, lower external sales and falling prices for products and raw materials as a consequence of the greatest decline in world trade since the 1930s, and an expected reduction in remittances by between 7 and 10 percent in 2009 (ECLAC 2008; Economist 2009; Ghosh \& Chandrasekhar 2009; Griffith-Jones \& Ocampo 2009; IDB 2009; Ocampo 2009; Sánchez \& Vos 2009; UN 2009a; UNCTAD 2009a, 2009b; World Bank 2009a).

The effect is different per country but, generally speaking, the crisis signals the end of a number of years of stellar performance in Asia (Loser 2009), of a Panglossian period for Latin America which lasted from 2003 to 2008 (IDB 2009), and five years during which the group of forty-nine least developed countries experienced strong growth performance (UNCTAD 2008b). As a result, a need for financial aid arose in many countries in the short term in order to limit their balance-ofpayments problems and create fiscal space to stimulate the economy and absorb the social consequences of the crisis. International financial institutions, at both global and regional levels, responded by extending their resources in order to support countries in difficulties. There is a potential downside to this because the focus is mostly on loans rather than on donations, meaning that a lot of poor countries are facing a new debt crisis. "It took the international community twentythree years from the beginning of the modern sovereign debt crisis in 1982 until an alleged 'full' cancellation was agreed upon at least for a small group of the poorest countries", Kaiser warns in a paper for the Friedrich Ebert Stiftung. "This failure of a global governance cost millions of people in the indebted world their health, their opportunities to live a decent live and even life itself" (Kaiser et al. 2009; see also Dijkstra 2008). 


\section{Global, but how?}

This short outline of the way in which the world has become more and more interdependent shows that development aid can no longer be seen separately from such broad issues. However, what the role of development aid can and should be in the context of global issues is by no means a foregone conclusion. It is clear, however, that these issues significantly increase the importance of development aid and change its nature. The classical idea was that development aid is essentially one-way traffic and focuses on helping developing countries to realize their goals. By contrast, the idea behind the new model is that important goals cannot be realized only at national level, and that they should be addressed at international level as well. Development aid then becomes an instrument for managing global interdependence. If India is given financial help to build new power stations using recent technology which reduces emissions of greenhouse gas, two birds can be killed with one stone: India is helped to meet its energy requirement and, at the same time, the burden on the worldwide climate is mitigated. At the same time this throws up all manner of new questions. For example, who will then determine the priorities as regards spending the aid, and how are global themes related to local and national development, which still has a long way to go in many countries?

\subsection{HOW TO COMBINE BIG AND SMALL}

Development aid can be provided on the basis of moral motives, but also on the basis of self-interest. The existence of different motives does not, in itself, have to be a problem. It may even be an advantage, facilitating the creation of a broad political and social support basis for development aid. That has been the case in recent decades. However, the existence of a number of different motives can also cause problems. After all, each motive leads to specific views on the way in which development aid should be designed. Those views do not have to be contradictory, but they often accentuate different things. Those accentuations can lead to the ever-increasing divergence of the prevailing ideas about how development aid should be shaped. This has also been evident in recent decades. People have started to see development aid on the one hand as a way of alleviating immediate need by means of concrete activities and, on the other hand, as an overall strategy for tackling global issues.

The idea that 'doing good' mainly entails concrete activities is reflected in the image of development aid in the media. 'Goed TV' - a digital channel which is included in the supplementary packages of most Dutch cable providers and which uses slogans like 'Passion for a better world 24 hours a day' - is currently bombarding viewers with a constant succession of projects, including pictures of the inevitable gathering of the residents of an entire African village to thank the generous givers from the West. Posters suggest that donating a few euros will 
protect a child from malaria (As former Dutch Prime Minister Balkenende claims on the www.malarianomore.nl website: "You too can help! For $€ 3.50$ you can provide a mosquito net and save someone's life."). For a number of years, Dutch NGOs have been forced to acquire a quarter of their income from fundraising and, as a result, they have started using impressive graphics to show that their aid directly helps the poorest.

The situation is similar at international level. In the 1960 a media culture emerged which led to citizens being shown more factual images. In 1968, Biafra was the first really major drama to receive broad television coverage and the pictures had a huge effect on people in the West. Artists also started focusing on the provision of aid to developing countries. George Harrison and Ravi Shankar were the first of many when they organized a Concert for Bangladesh in 1971, which raised 240, ooo dollars for the United Nations Children's Fund (Unicef). Originally the undertone was primarily humanitarian and aimed, in particular, at food aid. This continued until the Do they know it's Christmas? initiative for the victims of the famine in Ethiopia in 1984. By then the two concerts that Bob Geldof organized attracted more than one billion viewers and raised 140,000, ooo dollars. After that, the attention switched more towards politicians. U2 singer Bono was nominated for the Nobel Peace Prize after lobbying politicians to write off the debts of developing countries in the run-up to the jubilee year 200o. The 24 million signatures for debt relief made it into the Guinness Book of Records. Many will remember the ten 'Live 8' concerts which preceded the G8 summit in Gleneagles, where a doubling of aid to developing countries was on the agenda. Eventually, almost every right-minded celebrity could be seen doing their thing for Africa: 'glamour aid' was born. As a consequence, during the past sixty years, practical aid in the field of food, healthcare and education has increasingly become the standard, not only in the Netherlands, but in almost all other Western countries (Mosse 2005; Bolton 2007). How did that process take place?

\section{Development aid made small}

The first ever memorandum on development aid referred to in the beginning of this chapter - which was actually a short clarification to the 1950 budget - was called the Memorandum concerning the Dutch contribution to the programme of the United Nations for technical aid to economically underdeveloped countries. The theme of the entire memorandum is aid in the context of the UN. That would remain so for another ten years. Rich countries jointly undertook to help poor countries develop, primarily via the UN, with a clear emphasis on technical assistance and support for the building of infrastructure. Until 1963 all government aid was issued via international organizations and consortia. In other words, the focus was not on the immediate improvement of living conditions, and there were not yet any NGOs that provided aid locally. This changed subsequently in two waves. 
At the beginning of the 1960 s, the focus switched for the first time to the bilateralization of the aid, on the basis of the self-interest motive. The United States was an important driver of bilateralization because it offered the country more possibilities for supporting friendly powers. It led John F. Kennedy to set up USAID in 1960. For other Western countries economic, rather than political, motives became a key driver. From 1960 onwards interest groups from the business community in particular started exerting substantial pressure on governments to provide more bilateral aid because otherwise the Western business community would miss out on export orders. In the Netherlands, for example, employers got their way in almost everything. Bilateral aid started in 1965 and was gradually increased until it exceeded multilateral aid in 1968. Project aid started to be provided on a large scale. Parallel to this bilateralization, a shift occurred from technical assistance to financial aid. Technical assistance focused primarily on agriculture. The former Ministry of Agriculture and Fisheries was therefore the lead ministry for development aid. In the mid-196os, the aid focus shifted towards financial support for governments, largely in the form of shopping lists which were drawn up with countries receiving aid under the leadership of the Ministry of Economic Affairs. This aid had to be spent within the Dutch business community. From then on, the Ministry of Economic Affairs was the lead ministry for development aid for a decade.

In addition to the self-interest motive, there was now plenty of space for the moral assignment motive. The second shift in the 1960 s was therefore the emergence of NGOs, partly as a result of missionary work. These organizations also wanted to receive money from the government, and they got their way as well. In December 1964, the Dutch government proposed, for the first time, that resources be made available to non-commercial private organizations. The amount made available for this soon rose, provisionally in the form of project grants. The policy-related framework also gradually started to take shape. The 'NGO-ization' of aid continued steadily, and NGOs started to play a more and more fundamental role in development aid practice and in the execution of policy. That process would continue in phases until, in 2009, more than 20 percent of the total Dutch development aid budget was being made available via the non-governmental channel. A comparable development could also be observed in other countries, albeit to a lesser extent.

At a slightly slower rate, NGOs started to become active in recipient countries as well. In the first forty years of development aid via government, the actors in the recipient countries were primarily governments and related, organized institutions. However, since the 1990s, large numbers of NGOs have appeared on the scene. This is partly due to increased democratization in African countries and the development of civil society, although it is also partly an artefact of aid policy. More and more embassies and multilateral organizations are starting to involve NGOs in the execution of their policies. Western NGOs are implementing fewer 
and fewer projects themselves and are leaving the task to local organizations. To a large extent Western NGOs therefore function as switching stations with local NGOs, which are also referred to informally as 'partner organizations'.

A key characteristic of this NGO-ization of aid is that a lot of NGOs have become increasingly dependent on the government, certainly since the 199os. There have been various responses to this development. In the United Kingdom, for example, Oxfam does not want to receive more than 10 percent of its budget for development aid from the government, to avoid becoming dependent. In the Netherlands, more than three-quarters of the budget of the Dutch Oxfam Novib organization is dependent on government grants. This has led to a lively ten-year debate on whether such a 'suffocating embrace' is actually desirable (see for example Grotenhuis 2008). Any comparison of the progression of development NGOs since the 196 os with that of environment NGOs shows that Dutch development NGOs have largely become state-dependent. Although most civil society organizations are critical of the policy of multilateral organizations like the EU, the IMF and the World Bank, and are perfectly capable of organizing all kinds of campaigns and political networks, they tend to be a lot less critical of Western development policy. Their most important critical contribution is to emphasize the fact that more money should go to development aid. The same applies, albeit to a lesser extent, to many NGOs in other Western countries.

The bilateral policy that took shape in the 196os initially symbolized the selfinterest motive more than anything else. Gradually this shifted, partly due to pressure from Western NGOs, but also under the influence of a broader change in the political climate. This in turn caused bilateral aid gradually to become more oriented around the moral assignment motive. In the Netherlands a first important step was taken when the decision was made in 1973 for bilateral aid to no longer be managed by the Ministry of Economic Affairs, but by the Ministry of Foreign Affairs. Initially that had little effect on the tying of aid, partly because, in the 1970s, the development budget had grown so significantly that it was already difficult to spend the money adequately. In subsequent decades tied aid gradually disappeared and eventually all that was left was a limited set of tied aid instruments in the form of export credits.

Multilateral aid became relatively less important, albeit not in an absolute sense. At the end of the 196os it made up only a quarter of the budget, a percentage that did not change substantially after that. Significant changes started to take shape gradually from the 1970s onwards. The World Bank developed into an important player. The same applied to the IMF, which was originally set up to help achieve financial stability in the world as a whole but which, more and more, only played a role with regard to developing countries. The World Bank and the IMF often acted together and acquired more and more influence - some would say too much after 
the large-scale macroeconomic reforms of the 1980s. By contrast, the UN gradually started losing influence. As a political decision-making body it has become relatively impotent, as the guardian of international security it is largely coloured by the sharp differences between the power blocs, and the implementing organizations such as the FAO and Unesco are often paper tigers characterized by an excess of power politics and a lack of cohesion. This shift in the balance of power has continued to the present day. While the World Bank gave twice as many resources to developing countries as all UN organizations together in 1990, this had risen to six times as many in 2007.

\section{Personalized aid}

Development aid has therefore become more diffuse. Now, a wide range of parties play an active role, including NGOs, embassies and multilateral organizations, and a number of different motives can be identified in a variety of forms. For most citizens, however, the image of development aid is becoming increasingly personalized. The prevailing image of development aid is one of concrete projects with concrete results. The media, parliament, and the representatives of the NGOs who want to persuade everyone to become a member are all helping to evoke the same image. This image also ties in with the desires of modern citizens. More and more Westerners want their development aid efforts to produce immediate results for which they themselves can partly bear responsibility. For example, the $1 \% \mathrm{Club}$ maintains a kind of digital marketplace. Private individuals, associations, schools, foundations, and companies can create a kind of Facebook profile on the website and choose their preferred project from a number of small-scale concrete projects which organizations and private individuals themselves can offer on the same site. The project leaders provide an accurate description of the costs, including accompanying photos and an action plan. For the time being the spotlight has primarily been on monetary donations. However, work is also being done on creating a 'knowledge marketplace function', where questions arising from the projects and the offers of the $1 \%$ members are matched. Citizens also want to help by donating time. A clear trend towards more voluntary work is visible in the development aid sector. Young people can participate in work placements while people with work can spend their holidays working in a developing country. This has brought development aid back to the level of concrete projects which are linked as much as possible to people's own personal lives. That fits in with a world in which it is easy for people to travel to far-off destinations and in which internet and mobile telephones are making direct communication with these locations easier than ever before.

However, personalized aid is not the only development aid reality. Another part is aimed much more at long-running, structural activities. From the end of the $1990 \mathrm{os}$ onwards there has been a broad focus on the transition from project aid to a sectorwide approach (in other words wide-ranging aid to governments for a certain sector, such as agriculture or education) or general budget support (whereby the 
recipient country itself determines its priorities). Western countries are now considering the idea of being active in no more than two sectors per country and in drastically reducing the number of countries in which they are active. This has only happened to a limited degree. Following on from this, current practice in a number of developing countries is for a group of donors to give money in the form of joint budget support. This generates a substantial amount that can be used for structural activities, usually on the basis of a performance assessment framework which lays down which goals have to be achieved. At the same time almost all Western countries shy away from rigorous choices. Under the influence of the media and parliament they want to show that they do useful work wherever there is suffering.

Sectoral support is invisible to most citizens and the same applies to the addressing of global issues. All kinds of fora are focusing attention on themes such as migration, trade, food and climate in relation to development issues, but only very rarely do they manage to convey any of this to the wider public. Riddell (2007), the former head of Christian Aid in the United Kingdom, talks in this context of 'the big lie' of development aid: image and reality are diverging all the time and he predicts that this will lead to a legitimacy crisis. However, it is too simple to say that image and reality are constantly diverging. Rather, two realities are emerging. While a lot of aid is provided in the form of concrete projects, at the same time much is being invested in global themes. It would therefore seem to be more accurate to talk of a growing split.

\section{Conclusion}

There are a number of different motives for development aid. The two most important basic motives have resulted in practices which are continually diverging. Development aid practice partially focuses on direct projects with immediate results. Aid provided in this way has gradually become small but visible. There is, however, another side to aid. In a lot of Western European donor countries the self-interest motive scarcely occurs any more in its rough, purely financial form, and has transformed into forms of enlightened self-interest and attention for global themes referring to a general interest. This has had the effect of making development aid a lot bigger, even unmanageably big, since it is not clear where the borders are - literally or figuratively. As a result, ideas about what development aid ought to offer have started to seriously diverge.

Development aid has therefore ended up split in two. According to Freud, people sometimes feel like worms and sometimes like gods, and life consists of constant oscillation between those two poles. The same can be said of development aid: from making a modest contribution to the welfare of a few to writing the coalition agreement for the new world government, and everything in between - all this is reflected in aid's ambitions. The question is how to make this manageable. 



\section{UNDERSTANDING DEVELOPMENT}

Development aid - and this is sometimes forgotten - is about development. No matter what the motives for development aid might be, it is always important to have a clear picture of how 'development' should be interpreted. The answer to that question can provide a framework for assessing how 'development' might be stimulated and how this relates to the current organization and control model. This chapter addresses the question of what development is, and how the Western community has, in that respect, become sadder and wiser.

\subsection{DEFINING DEVELOPMENT}

What people mean by development often remains implicit. Nevertheless, there appears to be a common thread in public debates and academic literature. Development is almost always defined as a deliberate acceleration of modernization, interpreted as the synchronized fourfold transition of economy, government, political system, and society. Modernization is envisaged as what has been achieved in the West since the nineteenth century: the creation of a well-developed and productive economic system embedded in international trade relations, a government apparatus that is able to provide or help provide essential services in the fields of education, healthcare, housing, and security, a political system that ensures collective decision-making processes resulting in citizens feeling connected to the outcome and each other, and a society which is sufficiently open and offers space for various individual and collective ambitions.

Certainly not everyone will entirely agree with this description. Over the past twenty years, there has been growing resistance to an interpretation that implies that the Western model is the best, and the above formulation comes close to doing just that. However, closer examination reveals that there are not many radical alternatives, as shown by those who have studied the many attempts of countries and people from the South to produce their 'own' formulations. A wellknown variant of this non-Western perspective is the Beijing Consensus (Ramo 2004), but the list of 'perspectives from the South' is much longer (Matthews 2004). Anyone who strips these formulations back to the bare bones will see that they can largely be interpreted within the above framework. This is borne out by study of the Beijing Consensus. More than in the Western economic model, this formulation calls for constant experimentation and innovation, for Western gross national product to be replaced as the most important criterion by criteria such as sustainability and the fair distribution of income and, in a political sense, for more space for countries' national autonomy. All these formulations fit neatly into the notion of development as accelerated modernization described above. 
Moreover, it is important to read the above formulation of development as an outline of guiding ideas rather than an exact institutional framework. A productive economy does not necessarily mean large-scale industrial production, a responsive government does not necessarily imply a system of representative democracy, and an open society does not necessarily mean that freedom of speech is of overriding importance or that group interests are ignored. The exact way in which the different dimensions are elaborated in detail is based on history and deliberation, and is certainly not the only option. Neither does the above description explain exactly how development comes about. It is highly questionable whether development processes in the South exactly follow the paths taken by the West in the nineteenth century. Moreover, there were differences, of course, within the West itself - in that respect it is perhaps wiser to follow Eisenstadt (2002) and speak of "multiple modernities".

Development, as accelerated modernization, is what Japan achieved after the Meiji Restoration of 1868 when it emerged from its self-imposed isolation and developed from an isolated land in the backwater into a world power. It is also what South Korea achieved from 1962 onwards when it evolved from a poor, weak, powerless post-conflict state into what it is today - a country richer than New Zealand or the Czech Republic. It is also what Brazil is aspiring to and the dream of many people and countries in Africa and South Asia.

Over time, various attempts have been made to identify development processes more effectively. There is an intrinsic value in doing this: it is interesting to find out how countries have developed, no matter whether that country is the Netherlands or Mauritius. However, the process also has instrumental value. After all, it is logical to try and draw lessons from the experience of other countries. That is, of course, a complicated process. Comparisons always fall short. No country is entirely comparable with another and we should certainly not assume that what was possible one or two centuries ago is feasible in this day and age. Care therefore needs to be taken. At the same time it would be a shame not to try to learn from history - no matter how difficult that may be, and no matter how open to criticism those lessons might be.

If one thing characterizes the past sixty years of targeted development aid, it is the repeated confrontation with the fact that there are no simple frameworks which indicate the hierarchy between the economic, political, administrative and social dimensions when it comes to achieving development. It has always been very tempting to try and find the One Great Answer. In every period, a different concept is presented as the overriding principle, only to result after time in the acknowledgement that other dimensions are also important. 
This does not mean that it is impossible to draw lessons from specific situations. For example, it is reasonable to assume that the rapid post-war economic growth in Western Europe was based largely on the existence of legitimate political structures, effective governments and a relatively harmonious social fabric, which enabled economic dynamism to be restored quickly to its old level. Moreover, no energy had to be invested in developing nation states, as a sense of nationhood was already highly advanced. At the same time, this observation also carries the warning that it is by no means self-evident that transposing a Marshall Plan to another situation will have a comparable effect, because the conditions will be completely different.

On the basis of all the available analyses it is not possible to draw up a credible 'grand theory of development' which could serve as a formula for success for all developing countries. However, existing studies can provide an insight into interesting mechanisms which may also play a role. We shall therefore try to identify a common thread in the multitude of interesting studies which attempt to gain more grip on development processes. After all, the only thing worse than poor insight into development processes is no insight at all. A well-known adage says that scientists have tried too hard to understand the world and not hard enough to change it. In the field of development aid, however, the opposite may be true.

\section{What drives development?}

The question of why the West has become so rich, and what developing countries can learn from that experience intrigues many authors and invites interesting perspectives. In The Wealth and Poverty of Nations. Why some are so rich and some are so poor (1998), historian David Landes seeks an explanation not only in knowledge, technology and the quality of political ideologies, but also in the beneficial effects of the warm Gulf Stream that ensures that countries like the Netherlands and Great Britain enjoy a more pleasant - and therefore more industrious - climate than other countries at similar latitudes. In his famous book Guns, Germs and Steel (1998), Jared Diamond sees the key in the natural conditions in which people lived: nomadic peoples eventually settled between the Euphrates and the Tigris because the region offered high-protein grain, easily irrigated land, a mild climate and animals that were easy to domesticate. The Mesopotamians could do things with horses that the Indians could not do with bison. Others seek the explanation more in the social context within which economic activity can take shape - they see the industrial revolution as the product of an open climate within which people could travel, look and learn, experiment and sell their products. In Understanding the Process of Economic Change (2005), North refers to this as "adaptive efficiency".

A few commentators look completely beyond the economic sphere. In L'enfance du Monde (1987; published in English under the telling title The Causes of 
Progress), French anthropologist Emmanuel Todd (1987) begins by observing that there is a precise correlation between the economic growth of Western countries and their level of education 150 years previously. He then seeks an explanation for the differences in educational level in the various types of family in these countries. Ultimately he comes up with a simple sequence: authoritarian family types produce a higher level of learning because they provide more structure and that, in turn, reduces the chances of mortality, which itself leads to a fall in the birth rate, ultimately resulting in a higher standard of living. Clark (2007) adopts a similar line of argument in A Farewell to Alms. A brief economic history of the world, in which he seeks to explain the success of the West in a process of natural selection in which families with a strict work ethic gradually make their way to the top.

All of these accounts are compelling, especially in their capacity to identify, in the midst of a complex process of events, a single determining element that can explain the rest. Yet this charm is also their inherent weakness - the world is too complex to be contained by such simple blueprints. Attempts have therefore also been made to bring together the various aspects that may play a role. They primarily analyze development as a process of differentiating the different spheres in modern societies, and of the interaction between those spheres. Theories that differentiate these spheres take a variety of forms, but their basic patterns are remarkably similar. Many build on the ideas that Polanyi (1944) puts forwards in The Great Transformation. He uses this term to refer to the period in the United Kingdom between the end of the eighteenth and the end of the nineteenth century, when the meaning of the term 'market' changed from a temporary, local place where people bought and sold goods to the key concept on the basis of which relations between land, labour and money were organized at national level. For the first time, Polanyi claims, the principle of market organization became an end in itself, instead of being subordinated to broader social objectives. After Polanyi, many authors have produced similar descriptions of the way in which separate domains gradually evolved within societies, with their own rules and institutions. These domains include the economic and political spheres and the apparatus of government, with it being possible to include others like the religious and cultural spheres.

In the process of seeking development paths, the question is then how these spheres relate to each other. One well-known formulation is that of Nobel Prize winner Douglas North (2009) in Violence and Social Orders. A conceptual frameworkfor interpreting recorded human history, which he co-authored with Wallis \& Weinglas. His starting point is what he calls the "natural state", that is a situation in which a political elite controls the economy and uses the revenues to buy the support of the relevant groups; take, for example, medieval rulers who tied the nobility to them with a tenth of the yield of their farmers, or the way that Western countries used to govern their colonies. Sharing out revenues inevitably leads to 
problems - North shows clearly how what history books call civil wars are usually armed conflicts in which one elite believes that it has the right to resources that the other has acquired. Gradually, partly as a result of upscaling, ensuring the support of various groups becomes not only a matter of making gifts at opportune moments, but also of imposing rules. These are initially drawn up to the advantage of privileged groups. Rules can, however, be fought over. Because more and more people share power, the rules become increasingly universal - resulting in what North and others call an "open access" society. The social order is then governed by a broad spectrum of institutions, and there is competition between different ideas and initiatives.

Such blueprints, of course, also have their limitations. The many detailed descriptions, however, do offer a good portrayal of how the process has taken shape over time. Interestingly, the process has become so advanced in the West that we are hardly aware of it anymore - despite that fact that we have all learned that universal suffrage dates back less than a hundred years. Yet it is important to be aware that, for example, the existence of an independent government is also only a recent achievement. Independent government assumes the emergence of the 'civil servant', an official who serves the public interest and who can be expected to defend that interest. A number of special constructions were initially contrived to achieve that: civil servants had no collective labour agreements and were not permitted to strike, because their position was considered different to that of 'ordinary' employees. They were protected against dismissal, so that they could serve the public interest and not be the subject of political wrangling. Civil servants have only gradually become ordinary employees again in the past few decades, with all the consequences that brings with it. The process of differentiation - constructing markets, political and administrative systems and keeping them separate from each other - takes up a lot of time and energy.

It may no longer be completely clear to Westerners how their societies have been formed, but stripping everything back to its bare bones clarifies a lot. Barrington Moore's Social Origins of Dictatorship and Democracy (1966) remains a classic work in this respect. It shows how pressure from groups within agriculture and, later, trade which were aiming to make a profit gradually transformed the old bureaucracies in a way that led to industrialization, but also how that process can take different forms, in which institutions can develop in the direction of democracy or, conversely, of (left or right-wing) fascism. Thinking in terms of such broad development blueprints not only helps us to understand the past, it is also very valuable to our understanding of developing countries and the processes taking place within them. In these countries, after all, societies, governments, democracies and economies often have to seek a more productive relationship with each other. Development policy aims to influence that process, and the conceptual framework described above can help to achieve that. One of North's conclusions is 
that much traditional development aid is focused in the wrong areas. In his view, it is impossible to expect elites in developing countries to interact with others in important matters like the economy and power on the basis of impersonal relations. The recent (and problematic) nature of state-building means that identification with the state is still limited. That identification and the process of entering into impersonal relationships cannot be enforced, and takes a long time to evolve.

Thinking in terms of the interaction between different spheres is essential to understanding what constitutes good development policy. Take, for example, Botswana, one of the classical development success stories. Botswana, a small landlocked country, has experienced the highest economic growth in the world in the past thirty-five years. In 1950, it was the fourth poorest country in the world, but by 2001 its real income had increased fourteen-fold. What is the explanation for this success? At first glance the answer is simple: diamonds. From 1967 onwards, income from diamonds helped the country to grow. However, at least as important is that the country's government has used the revenues well and pursued a macroeconomic policy that, in terms of the quality of governance and the absence of corruption, can be favourably compared with that of a country like Belgium. To find out why the institutions that pursued this policy functioned so well, we have to go back to the nineteenth century. Colonization in remote Botswana was so marginal that it had little noticeable impact on the existing institutions. These institutions were structured in such a way as to keep the Tswana leaders and the political elites under tight control. That provided a sound basis for further development after independence, aided by the fact that the country's leaders also had a material interest in the efficient functioning of, for example, the system of ownership rights, as they had substantial interests in the large agricultural enterprises that had been set up. The transition passed off relatively smoothly: the Tswana leader became the country's president after independence, and has since been succeeded by his son. That led to the further development of institutions, and then to growth. The homogeneity of Botswana today - which, despite some Westerners considering it too much of a one-party state, is essentially a binding political system - is more the result of the process of state-building than a precondition for it. Anyone wishing to emulate the miracle of Botswana elsewhere will first have to determine to what extent these mechanisms are also present (Vaughan 2003).

\subsection{OTHER STARTING POINTS}

In this way, a framework for discussing development eventually emerges, based on the complex interaction of the economic sphere, the government, the political system and society. What does this framework teach us about the possibilities of accelerating development in the desired direction? For example, to what extent should developing countries more or less follow the same path embarked on by 
Western countries? The starting point in the West (including Japan) was economic development through liberalization and a fairer distribution of means of production like land and capital, which stimulated the emergence of a middle class of entrepreneurs. That was followed by the modernization of law (including property law), the administrative sector and the administration of justice, and ultimately democratic reform. The role of the state, as it were, grew along with the economy and the increasing complexity of society. We see this pattern not only in European history since the Middle Ages, but also since the eighteenth century in the Us and Australia, and since the end of the Second World War in significant parts of Southeast Asia. It shows that the development of all these countries is the result of a gradual process of internal modernization and the emancipation of population groups, in which economically strong groups like merchants, guilds, bankers and industrialists play a central role (Dellevoet 2005).

The comparison of this situation with that of today's developing countries does, however, have its limitations. Unlike in Europe, state-building in Africa was not the consequence of coalitions of middle classes securing their possessions. In developing countries it often had its origins in colonization. Forming political systems remains problematic, and there are hardly any cases of political party systems with deep roots in society. Government structures were predominantly copied from those in the West, and rarely fitted the situation and phase in which the country found itself. As a result they are only partially effective in achieving their objectives. Social elites are often not grounded in agriculture, as was the case in Europe. The process of development in countries in the South will therefore have to take off from a different starting point. As far as further development of the economy, government, political system and society goes, developing countries will, to a large extent, have to follow their own individual paths. The question is what paths are most suitable in each case.

\section{Agriculture}

The development process, as it occurred in the West, can therefore not simply be copied, but that does not mean that it is without significance. It contains a genuine lesson that can, to a certain extent, be generalized. All the evidence suggests that, in the process of modernization that took place in the West in the eighteenth and nineteenth centuries, agriculture played just as crucial a role as it is now playing for a large number of developing countries. The transition to productive economies proceeded in almost all cases through the further development of agriculture, which allowed farmers to gradually move away from subsistence farming to at least partial production for the market. These production surpluses paved the way for urban development which, after all, depends on farmers producing more food than they need for themselves. Urban development, in turn, is an important precondition for industrialization. Agricultural policy was also the key to the success of the Southeast Asian tigers. In 1945, Vietnam suffered a disas- 
trous famine, while people were still going hungry in Indonesia in the 196os. Vietnam solved the problem by subsidizing both the production and consumption of rice. That provided the best conceivable safety net. Indonesia's food policy was based on fertilizer subsidies, which laid the foundations for later economic successes. Developments in agriculture were also often supported by land reforms - it is no coincidence that Japan, South Korea, Taiwan and China all introduced land-reform programmes in the decades before they experienced spectacular growth. The importance of these programmes cannot be overestimated. It is precisely on this point that these countries differ from Latin American countries like Brazil and Argentina which, partly for this reason, have experienced much lower rates of development. These countries have been independent for around two centuries, yet they have seen hardly any growth in that long period. The only countries that have escaped this pattern of rural development are the Gulf States and small city-states like Singapore and Hong Kong, whose wealth has been accumulated without major developments in their own agriculture. They, however, form a separate category which is difficult to imitate.

The development of agriculture has benefited considerably from technological advances. As a response to the threat of famine in Asia, the introduction of new crops, fertilizer, irrigation methods and pesticides in the 1960s, 1970s and 1980s led to substantial increases in rice production. This second green revolution secured the food supply for large parts of Asia and laid the foundations for the continent's later economic success (The first green revolution took place in Europe and, through mechanization, the use of artificial fertilizer and new crop varieties, secured the food supply for a rapidly growing population, establishing a solid base for the Industrial Revolution). Despite the introduction of 'green revolution crops' in Africa, a similar revolution has to date not taken place on the continent, and agricultural production has only partially kept pace with population growth. In Asia, where agriculture displays an advanced degree of uniformity, all the physical and institutional conditions for the success of the new crops were present. In Africa, however, these crops were not suited to the much more diverse situation. Harvests largely failed due to the absence of institutions providing fertilizer, of large-scale organized irrigation and of a well-structured system of agricultural extension. Where there was progress because governments stimulated agriculture - for example, in the 1980 in Kenya, Tanzania, Malawi and Zambia - this ground to a halt because, under the influence of the World Bank and the IMF, providing subsidies was considered to distort the workings of the market. Large parts of SubSaharan Africa are therefore still dominated by self-sufficient farmers with only limited access to markets, who still farm in very much the same way as their fathers and forefathers did for centuries. For these farmers, the supply of food is directly dependent on their vulnerable production systems. With soil frequently depleted, rains that increasingly fail to materialize, disease and very limited access to capital, knowledge and technology, failed harvests are the order of the day. 
Although the cities of Africa now have a guaranteed food supply through the world market, 200 million African farmers still lack food security (IAC 2004; Rabbinge \& Bindraban 2005; Rabbinge \& Van Diepen 2000; World Bank 2008a).

In the past, some developing countries have tried with little success to give priority to their own capital-intensive heavy industry, expecting that that would enable them to industrialize more rapidly, as happened in the former Soviet Union before the Second World War. Today, too, we still sometimes see low-income countries trying to promote development by ignoring the agricultural sector and focusing all their efforts on the accelerated development of a modern, relatively capital-intensive industrial sector. Such efforts seem doomed to failure because competition with highly-advanced companies and countries is very unequal. They can also be counterproductive, increasing the inequalities between city and countryside. After all, if agriculture is too heavily taxed to provide the necessary revenue for the investments, prices become distorted and the rural population in the underdeveloped, peripheral agricultural sector is ignored (World Bank 2008a).

\subsection{EFFECTIVE GOVERNMENTS AND PATH-DEPENDENT TRAJECTORIES}

The importance of agriculture is a genuine lesson that can be learned from history. A second hard lesson is that the building of effective states precedes the process of industrialization. While, in the nineteenth century, the process of industrialization in the West ran parallel with the process of state-building, certainly since the twentieth century all countries that have successfully industrialized have had an effective state. The organization of the state, including the process of political decision-making, still has a determinant impact on the context within which private economic decisions can be made. Those decisions, in turn, have been of overriding importance to the process of industrialization.

This lesson has by no means been properly taken on board. Within developing countries, the government and the market have - at least from a Western perspective - a true love-hate relationship. Lindauer \& Pritchett (2002) show that, every twenty years or so, a whole new set of ideas about the role of government emerges. In the 1950 and 1960 , development was primarily associated with infrastructure and capacity building - and that required the state. After that, in the 1980s, the trend moved towards macroeconomic stability, and especially very small government that did not stand in the way of the private sector. The problem was often formulated in terms of a simple dichotomy, also very much in evidence in debates on the organization of Western welfare states, of the state versus the market. The idea was that less state would mean more market, and therefore more development. In the past decade, there was once again a consensus that a well-functioning state is a precondition for effective development aid. 


\subsubsection{REDISCOVERING THE STATE}

In recent years, full attention has once again been given to the fact that the state is a precondition for a thriving economy, but it is ultimately a lesson that can be learned from the history of the Western welfare state. In the Netherlands, for example, the industrialization that occurred in the nineteenth century - relatively late in comparison with surrounding countries - was only possible because it was facilitated and guided by an active government. The government facilitated the physical infrastructure that made transport possible: by water (on canals specially dug for the purpose), by road and by rail. That transport infrastructure would neither have been possible without a system of land expropriation and regulations, nor without state-run companies or private companies that could, if necessary, rely on the state to bear the financial risk.

A system of public utilities also developed. The government established the infrastructure for supplying energy by setting up electrical power plants as public companies. It did the same for communications, establishing and operating postal and telephone systems. The government also played a crucial role in the creation of 'soft' infrastructure, introducing standards for all kinds of sizes and dimensions, and a system of patents (though the Netherlands was something of an exception in that, for a long time, it was not willing to recognize patents something that, in any case, meant that Philips did not need to observe Thomas Alfa Edison's rights regarding the light bulb). Lastly, the government put in place a system of property rights that could be enforced by an effective legal system.

The importance of effective government was demonstrated in similar fashion by the Asian tigers, whose growth was based on a strong government. In most cases, they were authoritarian, sometimes even military regimes. Once many East Asian countries gained independence in the years following the Second World War (starting with South Korea in 1945, and ending with Malaysia and Singapore in 1957 and 1963), their governments devoted themselves immediately to developing their infrastructure. At first all the Asian tigers pursued a policy of import substitution, protecting their own industries through tariffs and developing their own economic sectors. From the mid-196os, they changed course. Partly as a response to the declining volume of American aid, they concentrated on labour-intensive production for the external market. That occurred in waves. The first generation included South Korea, Taiwan, Singapore and Hong Kong, which, from the mid1960 s, started producing goods that were no longer cost-effective in Japan. They climbed the ladder rapidly (South Korea was the best example: it was initially renowned for its production of steel, then of big ships, then cars, then household electrical appliances, and now advanced satellite equipment). In the second wave, Malaysia, Thailand and Indonesia took over the bottom of the market. These countries have now also closed their sweat shops en masse and are themselves climbing the ladder. In the third wave, China - followed a little later by Vietnam - took over 
the bottom of the market. It is to be expected that, in the not too distant future, this position will be taken over by India (which is currently achieving part of its growth at the top end of the market but which realizes that this is not a sustainable growth model because it is not sufficiently labour-intensive: only o.25 percent of the Indian workforce is employed in the IT sector). Bangladesh has already found an excellent position for itself, acquiring a leading role in the production of readymade garments, paying wages that are a third of those in India and a fifth of those in eastern China.

The economic development made partly possible by the strong guidance of the state, gradually makes itself felt politically and socially. The Asian countries initially spent very little on redistribution (Haggard \& Kaufman 2008). In fact, in certain periods of their development, the Asian tigers had a de facto degressive tax regime, under which the elites in particular benefited from growth. Most of them were quick to emphasize the importance of full enrolment in primary education, followed by rapid expansion of secondary education, and a high percentage of pupils finishing it. In the 1980s, when the growth of the middle class began to take on serious proportions, a period of democratization and redistribution of income was initiated. The democratic revolution in East Asia started in the Philippines in 1986, when President Marcos was ousted. South Korea, Thailand and Taiwan all followed, taking their own paths. Malaysia and Singapore are making the least progress, though their political systems now also display clear competitive elements. Politicians have opportunities galore to present themselves as progressively minded: the relative absence of social services means that they can promise a great deal, especially in a period of sustained economic growth. Even the severe financial crisis of 1997 had little real impact on this process - in contrast to the crisis in Latin America in the 1980s, the effects of which could still be felt more than ten years later.

In this way, the contours of a broad social safety net gradually emerged. To some extent, that project ran parallel to the privatization of state-owned enterprises that in many countries had been an important state vehicle for economic growth. These companies provided their employees with social services. When they were privatized, they were no longer able to offer that degree of protection, and it had to be supplied by a safety net provided for the population as a whole and based on universal entitlements. It is striking that this development was not a response to emerging labour movements or left-wing parties (or fear of them), which played at most a limited role. The process was largely driven by conservative regimes, and the political parties were (and continue to be) to a large extent non-ideological, at least in terms of the classical Western left-right dichotomy. Here too - as had been the case a hundred years earlier in Europe - conservative and centralist politicians often used social policy for political purposes. 
Growth, that much is clear, occurred in Asia because governments were in a position to pursue a targeted growth policy. Following Chalmers Johnson (1982) and Peter Evans (1995), these countries are referred to as 'developmental states'. It is not important what ideology or common policy is pursued, as long as the state apparatus operates on the basis of central planning, combining interventionism with a strong focus on economic growth. These states often have a leader who is very committed to development objectives, and who is able to incorporate personal enrichment and short-term political gains into that broader goal (Fritz \& Rocha Menocal 2007; Leftwich 2008; Mkandawire 2001). The developmental state is based on a coalition of leaders, elites and interest groups, and is grounded in the common idea that long-term growth is in everyone's interest.

These developmental states focused their attention on imperfections in the functioning of the capital market that prevented them from raising the level of industrialization, on problems in the labour market that insufficiently facilitated the increase in the general level of skills and education of the working population, and on problems relating to land rights, which acted as a brake on urbanization and growth (see also Khan 2005). They practised a strategy in which governments actively developed economic activity, varying from the subsidies that South Korea gave to its state-run companies to the use of public funds to acquire and develop technologies in Taiwan and Malaysia. The latter model is still current as shown, for example, by the way in which Singapore recently succeeded in building up a leading biotechnical industry over a period of only a few years.

It is important not to translate the success of developmental states simply into a plea for a policy of economic liberalization. In that respect the distinction that Khan (2007) makes between "market-enhancing strategies" and "growth-enhancing strategies" is relevant. The first entails mainly the liberalization of markets, a strategy that has become popular in Africa. Countries like Uganda, Kenya, Tanzania and Ethiopia have the idea that admitting foreign investors (in the same way that China did in the 1990 os and, on the African continent, Tunisia a decade ago) is the answer to their growth ambitions. They offer new investors a broad package of facilities - a sort of one-stop-shop for new businesses. The underlying idea is that growth will then come automatically. In the case of targeted growth strategies, investments focus more on technological innovation (capacity), creating a welltrained and hard-working class of workers and managers, achieving social stability and developing a sector-wide approach. In other words, industry policy in its classical form. The instruments to achieve this coincide partly with those of a liberalization programme, but are also somewhat different. This is where an important difference lies between the strategies of China and India. Both have been engaged in opening up their markets since the early 1980s, but the Chinese have been more successful at allocating their resources to specific growth sectors and at making it attractive for foreign investors to bring in advanced technologies. These are typical 
elements of a growth-enhancing strategy. Compare, too, most of the countries in Latin America and, within Asia, the Philippines: they went further along the path of market liberalization, including opening up their capital accounts, rather than adopting a specific growth strategy, with limited growth as a result.

\subsubsection{ANTECEDENTS AND VARIETY}

The Asian tigers appeal to the imagination. Their success has been described many times, and the importance of the state in achieving it is increasingly recognized (Chang 2007; Wade 1990). The question is to what extent this development model holds the key for all developing countries. Theories on this have developed further along various lines (Migdal 2001). It has become clear that, in newly independent countries, development is to an advanced degree determined by the way colonization took shape. In particular, the colonialism of the first half of the twentieth century set the tone for the institutions that, in their turn, created the economies that emerged in the second half of the century (Bruhn \& Gallego 2008). The development of developing countries is in that respect as much path-dependent as that of the Western welfare states. Let us briefly take a closer look at this important lesson.

The standard example of a developmental state is South Korea. In an analytical sense it is better to follow Kohli (2004) and speak of a cohesive-capitalist state. The South Korean state had its origins in the way in which the Japanese colonized the country for thirty-five years. In its own development, Japan had relied heavily on the state playing a strong role. The Japanese approach in South Korea was robust, radical and 'architectural': a relatively corrupt agrarian bureaucracy was transformed into an authoritarian and far-reaching political organization; the government developed intensive and growth-oriented alliances with the dominant elites, and acquired effective state control over civil society ( Vu 2007).

At the other end of the spectrum is a country like Nigeria, a state without an effective public arena, and with a government structure in which behaviour is largely determined by personal ties and personal gain. Politicians and civil servants are expected to function as representatives of their 'clients'. The distinction between formal and informal is then of little significance. The government is only to a limited extent focused on development. This, too, has its origins in colonial history. The British ruled their colonies on a low budget, never having too many people present in the colonies themselves. With the exception of 'settler' colonies like South Africa and Rhodesia, which attracted large groups of colonists after the discovery of gold and diamonds, there were never more than a few hundred Britons in the African countries. They could only achieve that by playing a complicated and opportunist power game with existing local elites. An additional complication in Nigeria is that the country was created from three areas that were originally ruled separately, and which had little in common in terms of ethnicity, 
culture and religion. British rule in Nigeria reinforced a patrimonial and personal government that never produced a serious central government capable, for example, of collecting taxes. This meant that a balanced process of state-building never really had a chance, and the leading elites have never been able to rectify that situation, particularly after sufficient oil reserves were discovered to push the necessity of reform even further into the background.

Other states, too, bear the traces of their colonial past. The Belgians left the Democratic Republic of Congo behind without any functioning political or government institutions and, to this day, there is still no working postal system. Guinea-Bissau also inherited nothing, and still has as good as nothing. Somalia enjoyed the attentions of four foreign powers. As one of the few African countries that did have an ethnically homogenous population, it was divided into Somalia (ruled by the Italians), Somaliland (the British), Djibouti (the French), Ogaden (formally part of East Ethiopia), and parts of North Kenya. This essentially laid the foundations of a future failed state (Gruffydd Jones 2008). India inherited a relatively comprehensive network of functioning institutions, enabling it, after the civil war of 1947, to develop relatively peacefully, initially with very limited growth, and since 1990 with substantial growth. To a certain degree, the same applies to the Dutch East Indies. The former French colonies inherited a more elitist education system than the British colonies, and that also had an impact on their growth potential (Bolt \& Bezemer 2009). Nonetheless, development is determined by other factors than a country's colonial past. Côte d'Ivoire started from a relatively strong position, but the government still collapsed, while Mali - which embarked on independence almost from scratch - is taking cautious steps forward.

The states also bear the marks of their post-colonial past. Military structures often formed a basis on which other institutions were able - or, in some cases, unable to grow. The emphatic presence of the military in the development of a country did not always have negative effects: sometimes it also led to efficient state systems that could be deployed in the common interest. Perhaps the most striking example is that of Vietnam, which, within a decade, succeeded in reducing the number of people with malaria to below the level of France. To achieve that, the country not only had to distribute malaria nets in every single village and hamlet, it also had to ensure that they were used, and to identify and treat the sick.

Recently emerging from a war, the Vietnamese government proved more efficient in achieving that feat than the French were at informing their citizens who were going to the tropics on holiday.

\section{Differentiation}

The developmental state is a specific variant within a broader range of processes of state-building in developing countries. There is a tendency to call all Southeast Asian states developmental states, but that is using the term very loosely. The 
classical developmental states (South Korea, Taiwan, Singapore and Hong Kong) are at one end of a spectrum: they are typified by a very low degree of personal patronage by politicians and civil servants. That clearly helped in achieving growth, but was not a precondition for it. Other Southeast Asian countries that also focused strongly on development had many more neo-patrimonial elements. These states - examples of which were the Philippines under Marcos and Indonesia under Suharto - were sometimes referred to as 'booty capitalist' or 'crony capitalist' states. These concepts are less applicable to China and Vietnam, which in that respect come closer to classical developmental states: they do have forms of nepotism and personal patronage, but the informal selection process of the elites also contains meritocratic elements. Neopatrimonial elements, in turn, can be found in Japanese society, though here personal ties have more impact on career opportunities and reciprocal involvement than on personal enrichment.

Countries in Africa and Asia - and elsewhere - all have some neopatrimonial elements, to a greater or lesser extent. The extent to which a development perspective can take shape in a neopatrimonial structure varies. Some countries - those which became the classical developmental states - succeeded either in mitigating neopatrimonial mechanisms or, in some cases, rendering them productive for development (Khan 2005). Most countries, however, display a different relationship between the two elements. They have a clear state structure, but the capacity to operate effectively is limited for a wide variety of reasons. These 'hybrid' states have both authoritarian and democratic characteristics. India is a classic example, but Brazil also fits into this category, even though its history shows that, given time, a country can change its style: in certain periods, Brazil shifted in the direction of a 'cohesive-capitalist' state. This category is an amalgamation of states that, from a Western perspective, are often seen as 'incomplete' states, but which differ from each other considerably.

The lesson here is that effective states are of great importance, but it must be added that they are not easy to achieve, and certainly not along uniform lines. Furthermore, it is rather depressing to add that the history of countries in the West in the eighteenth and nineteenth century, and of the countries in the East and the South in the twentieth century, shows that development is generally speaking not a pleasurable process. Karl Polanyi (1944:36), who identifies the origins of the process in the expropriation and allocation of land, formulates it as follows: "The economic logic involves a tragic necessity by which the poor man clings to his hovel doomed by the rich man's desire for a public improvement which profits him privately." As for Europe, Barrington Moore (1966: 506) concludes: "There is no evidence that the mass of population anywhere has wanted an industrial society, and plenty of evidence that they did not. (...) At the bottom all forms of industrialization have been (...) the work of a ruthless minority." There is now plenty of evidence that people in developing countries definitely do want indus- 
trialization, but that it is indeed generally created by a ruthless minority. What does this mean for developing countries that have not yet made the leap towards industrialization?

\subsubsection{WHAT ABOUT AFRICA?}

In Africa, growth is not yet usually achieved through strong governments. Stable political systems are not self-evident. Many states in Africa are artificial constructs. Of course, states in the West are artificially constructed too, but they are usually much older and had more time to form. Even then it was by no means a smooth process. Take the Netherlands for example. First Holland and six other provinces formed the alliance of the United Provinces, then came the Southern Netherlands, and that later evolved into the Netherlands as we know it today. In our case, the process was to a large extent aided by the existence of an external enemy, Spain. Where nation-building started later and then advanced more rapidly, the friction was greater. Germany has been a nation for a little less than one and a half centuries. Before that it consisted of smaller principalities, and the process of nation-building was characterized by heavy clashes, contributing significantly to the outbreak of two World Wars. In Europe, nation-building was typically accompanied by warfare. In the words of Tilly et al. (1985): "States make war and war makes states."

With all comparisons that are made between the ways in which Africa and Asia have developed in the past half a century, it is important to realize that the colonization process in Asia dates back much longer than in Africa. That has had farreaching consequences. In the nineteenth century, India had a well-educated civil service and even an embryonic political elite. When they departed after independence, the British left behind 26,0oo kilometres of railways - in that respect the Dutch lagged behind, leaving only 5, ooo kilometres of track in Indonesia. Introduction of the renowned cultural system in Indonesia started already in the middle of the nineteenth century. In these Asian countries - and the same applied to, for example, Malaysia - new institutions had ample time to evolve. At that time, the colonization of Africa had not yet begun. It actually started in 1871 when France invaded Tunisia and the following year, when the United Kingdom set its sights on ruling Egypt. Before then, Europeans had only had a presence along the coast, in trading posts and forts. For a long time that was all they needed to make money, as slaves were supplied by local traders. From 180o, trade shifted towards agrarian products that had to be produced inland. It was not until 1850 , however, that it became necessary to bypass local merchants and increase control of production. That need coincided with a process of Western nation-building expressed in overseas expansionism. When diamonds were discovered in Southern Africa around 1870 , followed by gold a decade later, the 'scramble for Africa' really got under way (Reid 2009). 
Before 1870, there were hardly any European possessions in Africa; after 1914, there were only two independent countries - Liberia, founded in 1847, and Ethiopia, the only country that had successfully resisted Western domination, repelling the Italian armies in 1896. At the conference of Berlin in 1884, Western powers, under the leadership of Bismarck, divided the continent up with a map and a ruler on the table. Countries that had never had colonies were even allowed to take part in the process. Belgium - or more accurately, Koning Leopold as a private individual - was given the Congo, which was around eighty times larger than Belgium itself, while inconsequential Portugal received enormous countries like Mozambique and Angola, partly because it was under the protection of the British (Pakenham 1991; Wesseling 2003). Western countries may have divided Africa on paper, but they still had to conquer it, map it, provide it with a physical and institutional infrastructure and, at least in a formal sense, build nations. In the decades that followed, explorers like Stanley and Livingstone, missionaries and the first civil servants moved into the African interior. It became a rush from the coast into the hinterland, and led to the demarcation of often bizarre territorial units that ignored the existing relationships within Africa - an extremely heterogeneous continent with 2,ooo languages and more genetic diversity than the rest of the world put together. That took some time, as a result of which most African countries emerged around 1900. Uganda was created in 1908, Nigeria in 1914 and Morocco finally in 1934. Many countries were created by merging regions that previously had little to do with each other or had even fought each other in the past. In the strip to the south of the Sahel, a series of countries were created that were Islamic in the north and Christian in the south. These included Côte d'Ivoire, Ghana, Nigeria and Sudan. They also had little in common in a broader cultural sense, which was a persistent source of tension in the century that followed.

The role of the state remained limited until the 1920s, with healthcare and education initially the concern of missionaries. Gradually, as with agriculture, the government started to become more involved in these sectors, but that was only for a short period. In Europe, economic recession led to a world war, and when it was over, Western countries had lost their dominant position. The period of institution-building along Western lines was therefore very short, often no longer than a few decades, and resulted in a system that was far from fully developed. At the same time, there was no way back, if for no other reason than that the transport infrastructure and the resulting incorporation of Africa into the global economy could no longer be reversed.

In nearly all cases, the process of state-building in Africa was imposed from above and from the outside. The differences in strategy are interesting. The British were firm advocates of 'indirect rule', which meant that the colonies were governed through local power holders, such as kings or tribal leaders. The British governance and control system was therefore considerably decentralized and allowed 
space for local, voluntary participation. The French, true to their Jacobin tradition, preferred a more centralized system and introduced 'modern' governance and control structures. In the name of their great republican principles, they wanted to assimilate les indigènes as citizens of a single French empire. Other countries sent large numbers of colonists to settle in the colonies - take, for example, the many Portuguese who settled in Latin America, Angola, Mozambique and Cape Verde, or the Spanish in Latin America (Develtere 2009).

No matter what form the state and institution-building had taken under the colonial regimes, when the countries of Sub-Saharan Africa were decolonized (they followed the Asian countries about a decade later: Sudan became independent in 1956, and Ghana in 1957), their governments inherited systems that were neither tried and tested nor particularly popular, were inappropriate to the stage of development in which the countries found themselves, and were not based on natural borders and ties. They were expected to automatically transform themselves into democratic states. "They might as well have left Ugandans the instruments of the London Philharmonic Orchestra and told them to play Beethoven's Ninth Symphony”, concludes Dowden (2009: 41), director of the Royal African Institute in London. In the first ten years after independence, everything went well in Africa. The system that the colonial powers had left behind made private investment possible and provided good education and healthcare. That led to high growth rates, averaging more than 5 percent per year, higher than ever before. The relatively favourable weather conditions in this period also contributed to the success.

Gradually, however, the whole construction collapsed. Informal relationships got the upper hand, corruption spread, rival elites engaged in a no-holds-barred battle for power, and to make matters worse, armed forces started to manifest themselves as independent interest groups (Van der Veen 2004). In addition, the weather conditions now took a turn for the worse, with many years of severe drought. When the first Ghanaian leader Nkrumah was forced from office in 1966, it heralded the collapse of a series of regimes - and the institutions behind them soon followed. From the 1970s, there was hardly an efficient system of healthcare or education to be found in Africa, and initially reasonably good African universities went into decline. The political system also started to show cracks on all sides. This was the period of absolute rulers who, under the influence of the Cold War, received sufficient political, financial and military support to survive, with all the consequences that brought with it: from Mobutu, who transferred 5 billion dollars from the Democratic Republic of Congo ('Zaire') to his Swiss bank accounts and adorned his capital city with replicas of royal palaces in Peking, to the ruler of Côte d'Ivoire, Felix Houphouët-Boigny, who had a replica of St. Peter's Basilica in the Vatican built in his birthplace Yamoussoukro. This is still the largest church in the world, where the observant visitor can see a black face in the leaded glass window, 
that of the president himself. One-party states soon became one-man states, and after the One Great Man came the One Great Military Man: there were at least forty military coups in the first two decades after independence, and in only three cases did the population rebel against them successfully.

Only a few leaders - like Senghor in Senegal from 1960 to 1984 and Nyerere in Tanzania from 1964 to 1985 - succeeded in forging something approaching a national identity in these ethnically diverse countries. Nyerere copied the colonial example of a single language by introducing Kiswahili throughout the whole country, similar to the way in which Sukarno had earlier united Indonesia by creating a new language, Bahasa Indonesia, on the basis of a relatively unimportant trade language, instead of adopting Javan, the language of the elites. In the 199os, with the Cold War over, political support for the great dictators in Africa came to an end and internal conflicts flared up. That led to a series of armed confrontations. Ten years later, partly through Western interventions, peace seems to have returned, at least in terms of the absence of open hostilities. In the meantime, with the necessary fits and starts, a process of democratization was under way, with forty-five of the forty-eight countries in Sub-Saharan Africa having held multiparty elections since 1989. The degree of democracy remained limited, however. Generally speaking, although many regimes had been formally democratically elected, the quality of the process left a great deal to be desired. Of the forty multiparty elections that were held between 1989 and 1997, only fifteen were reasonably fair, and only twelve led to regime change. Ten years on, most of the leaders who came to power during the elections were busily changing their countries' constitutions so that they could be re-elected for the third, fourth or fifth time (Brown \& Kaiser 2007).

\subsection{POLITICAL INSTITUTIONS}

It is clear that strong government is of great importance to development. Such governments are, however, lacking in large parts of Africa. The nation state is by no means a given, nearly all political systems display considerable neopatrimonial characteristics, and governments are weak in implementation capacity. The simple answer seems to be to make sure governments are strong. However, as we learned the hard way in the 1990s, it is not that simple. Institutions and governments can only thrive in a climate that fulfils one substantial precondition: stability.

\section{Stability}

After the end of the Cold War, armed conflicts broke out in rapid succession within countries, and these soon claimed more victims than conflict between countries. That is historically a new phenomenon. Before 1990, internal conflicts were limited in number and did not last long (less than three years). Since 1990, they have increased in number and last, on average, three times as long. In the 
decade after 1990, some 5.5 million people died in thirty-five civil wars. How can countries develop themselves in such situations? Civil war is especially a problem in Africa. The problem is that the process of nation-building and absorption into the global economy is now too advanced to hark back to the way in which nations were originally formed on the continent. At the same time, many states lack sufficient internal support and stability. Consequently, every attempt to promote development also has to address the question of how to achieve stable political systems.

The importance of stability is without doubt the most significant insight in relation to development in the past two decades. Initially this entailed a strong focus on ending armed conflicts, but gradually the concept has acquired a broader meaning. Stability is a characteristic of societies, and armed conflict is an extreme consequence of instability. Too little stability also has other effects. Long before conflicting parties resort to arms, a lack of stability can lead to social disruption and destroy a positive outlook on the future and these elements, in turn, can have an impact on economic activity. Just as Western economists like to emphasize the importance of a good investment climate for economic growth- meaning the relative absence of strikes and other forms of unrest and the presence of a well-trained, motivated workforce - development too benefits from stability. Etzioni (2007) had good reason to call his book, in which he outlines a general perspective for international policy, Security First.

For Western countries the question became one of how to deal with the importance of stability. Especially after the genocide in Rwanda in 1994 and the wars in the Balkans in the early 1990s, there was a strong feeling that the traditional concept of development was in dire need of revision. It quickly became clear that the period following a conflict calls for special attention if all development aid is not to be futile, as countries tend to lapse quickly into armed conflict. Of all intrastate conflicts, 20 percent flare up again within four years. The traditional aid repertoire proved inadequate to meet these new challenges. Peacebuilding, however, soon received a great deal of attention. In the 1990s, the UN conducted four times as many peace missions as in the four preceding decades, spending an average of 7 billion dollars per mission. Security Sector Reform became a concept, especially after 2002 when the number of violent conflicts started to fall again. It is not enough to establish peace, it is also necessary to build a stable security sector, enabling a transition from a military regime to one in which the police and the legal authorities can guarantee public safety and the armed forces are once again subordinated to the political and administrative system.

\section{Democrazy}

The question is how to achieve social and political stability. In Western circles there is a tendency to answer that question primarily in terms of good governance 
and the rule of law. More particularly, many place their faith in the value of Western-style democracy. That is, however, purely in historical terms, a doubtful argument: democratic Senegal experienced no growth under the non-corrupt Leopold Senghor, while Indonesia did under Suharto, the autocrat that headed the Transparency International list of the most corrupt leaders of all time. Furthermore, it soon became clear that introducing Western-style democracy could even be counterproductive. In a country that is just starting to recover from internal conflict, elections and a system of political parties are often more likely to open wounds that are only just starting to heal than generate a peaceful system of conflict settlement. Democracy, in both a narrow and a broader sense, can in many cases lead to less rather than more stability in a period immediately following political violence (Jarstad \& Sisk 2008; Mann 2005; Paris 2004).

Paul Collier (2009) calls the exaggerated expectations of democracy 'democrazy'. On the basis of a regression analysis, he goes a step further and comes to the conclusion that, although in middle and high-income countries democracy decreases the chances of political violence, in low-income countries the reverse is true. In his view, democracy - when seen as a system of elections, political parties and a parliament - has made life in low-income countries more dangerous. That is because, in these societies, democracy can be manipulated so that it no longer guarantees the accountability of governments or the transparency of policy processes. He concludes that democracies become safer as income rises, while autocracies become more dangerous. That does not make autocracies the obvious solution - as well as being more successful, they can also be more disastrous than democracies. However, if mechanisms of selection on the basis of quality and meritocracy are present, often through a layer of leaders that are unknown to the outside world, an autocracy can work well in economic terms - as is evidenced by countries like South Korea, China and Vietnam. Without such internal correction mechanisms, the effects can be disastrous - as we have seen in the Democratic Republic of Congo, Ethiopia and Uganda.

Democracy is just as little a guarantee for stability as it is for economic growth. The recent history of Singapore, South Korea, Vietnam and China (after the reforms) shows that countries can develop perfectly well without Western-style democracy. This is not to say that authoritarian regimes are by nature better for economic growth: not every leader is a Lee (Singapore) or a Park (South Korea). Furthermore, there are democracies that experience growth, like India and Botswana, the African growth miracle. Whether democracy leads to sustainable economic growth is therefore still the subject of academic debate (see Berendsen 2008 and others). For the time being, no direct causal relationship has been identified (Carothers 2002). 
What we can say with some degree of certainty is that a number of specific characteristics of states are important for economic development, especially the presence of an effective, responsive and transparent state apparatus, but this does not necessarily have to be based on a Western-style democratic political system with political parties and elections (Chang 2007; Fukuyama 2004; Khan 2005; Zakaria 2003). State capacity is much more important than the rule of law or democracy, certainly in low-income countries. South Korea and China had no strong rule of law, property rights had little significance, and the administration of justice was negligible, and none of these elements were legitimized democratically. Yet these countries had the capacity to be effective. That means above all, the capacity to deliver. That is not the same as the rule of law or democratic legitimacy. It is not even the same as the absence of corruption. A number of countries with high growth, including South Korea, China and Indonesia, actually had high levels of corruption. The growth of corruption and economic growth progressed hand in hand. This was known as the East Asian Paradox (Weiss 2008). This does not mean that there is a causal relationship: in other countries, especially smaller ones, the relationship between corruption and growth proved to be negative. Countries like Singapore and Malaysia are also increasingly legitimizing themselves in terms of responsive government: they are well aware of what their people expect, but acquire that awareness through other means than classical Western institutions. In Singapore, for example, civil servants have to speak directly to members of the public for half a day every week.

It has also become clear that democratization often comes after economic growth. Lipset (1959) claimed that "the more well-to-do a nation, the greater the chances that it will sustain democracy", and that statement still holds water. A large comparative study covering the period from 1950 to 1990 showed, for example, that democracy has a better chance of survival in middle-income countries, as in Latin America, than in poorer countries, where the average life expectancy of a democracy is only eight years. Per capita income proved by far the most important predictor, more significant than ethnic groups, religion, or a country's colonial and political past (Przeworski et al. 200o).

\subsection{SOCIAL FABRIC}

If a Western democratic model is not the only solution, how are we to understand the stability of countries and their institutions? Clearly, a country's social fabric is of crucial importance. This has been the subject of a number of studies, several of which take the behaviour of local elites as their starting point. According to one analysis, during the process of state-building, specific elites were able to take possession of the state apparatus in such a way that there was no adequate system of checks and balances to prevent them from becoming rent seekers looking only to advance their own interests. The best known advocate of this perspective is 
Robert Bates in Markets and States in Tropical Africa (1981) and many subsequent works (Bates 2001, 2008). In a variant of the rational-choice theory, he describes the strategies elites adopt to secure their interests and how that eventually leads in many developing countries to weak states and ineffective development paths. This perspective certainly has some explanatory value, as rent seeking is clearly a reality in many countries. At the same time, however, it has its limitations. Firstly, there is much evidence to show that the leaders of many successful countries also engaged in rent seeking. Mustaq Khan (2005) goes even further, claiming that a significant part of the success of the Asian tigers was due to the fact that local elites had an interest in the further development of the country as a whole. Furthermore, these elites often benefited more than their countries, as shown by long periods of degressive tax systems. It was a side-effect of their quest for personal gain that their countries also benefited.

The most important problem with this analysis of elites is the assumption that group-forming is by definition bad and that groups will always seek to pursue their own self-interest. That is a too limited interpretation of social bonding and social segmentation. Other analyses therefore give high priority to the importance of social relations for development. There are two reasons for this: on the one hand there is clearly a painful deficit in terms of social relations in developing countries. This is clear from the prevalence of ethnic conflict and corrupt practices. On the other hand it is becoming increasingly clear that people survive because of their networks. To clarify the problems and potential of human relationships, the concept of 'social capital' has been devised.

The honour of coming up with the concept of social capital has been attributed to numerous commentators (Bourdieu 1985; Coleman 1990; Portes 1998; Putnam 1993) and there are as many definitions. In short, in this context, it means that it not what you know but who. The basic idea is that family, friends and acquaintances have an important social value. Possessing a lot of social capital has great advantages. At the level of the individual, it means better education, better income and better health, for companies it means better performance, and at community level, more collective action (Narayan 1999; Portes 1998; Woolcock 1998). Easterly et al. (2006) even come to the conclusion, on the basis of a meta-analysis, that social cohesion at community level leads to better institutions, and that better institutions lead to more growth.

What is the relationship between social capital and the formation of institutions? In Making Democracy Work, Putnam (1993) compares different regions in Italy. He comes to the conclusion that the degree of good governance depends on the quantity of social organizations. It is not so important what these organizations do they may be football clubs or groups of people coming together to play cards - but they do ensure that a country functions better politically. That is partly because 
social organizations have a number of important characteristics - such as shared norms, mutual trust and a network of contacts - that make it easier to achieve common objectives.

Bonding has disadvantages as well as advantages (Portes \& Landolt 2000). Some communities can become so closed that they become isolated and act against the wider collective interest. This is the case, for example, with Al Qaida or drug cartels. Too much bonding can also impose excessive claims on group members, which can present an obstacle to upward social mobility. In East Africa, for example, it is not unusual for people who have moved upwards on the social ladder to have themselves declared dead, to avoid a sudden flurry of interest from hitherto unknown family members. Another option is to move to a metropolis. Closed systems also often lead to social norms being adjusted downwards. This occurs, for instance, in fragile states where political and social organizations are often also criminal. Social networks are therefore not the key to happiness. Three thousand registered agricultural cooperatives and 30,00o informal groups were unable to prevent the genocide in Rwanda. In Kenya, there are more than 200,000 agricultural community groups active, but that is no guarantee for economic prosperity (Woolcock \& Narayan 200o).

What the research into social capital does show clearly is the importance of crosscutting ties for development. Where there are few such relationships, there can be negative consequences. People can find themselves confined in networks of poverty and violent inter-ethnic conflicts can occur. Putnam (2000) makes the distinction between bonding and bridging, the former occurring within networks and the latter referring to the ties between different groups.

In reality, of course, social relations are much more complex than can be expressed by terms like bonding and bridging. Every society has its own dynamics and survival mechanisms. It is, however, clear that social structures have a real impact on development paths, and that they interact with political and economic systems. Four important dimensions require special attention in that respect: the role of the middle classes in developing countries, the significance of ethnicity and gender, and religion.

\section{The middle classes}

The development of a country is closely related to the development of its middle classes (Birdsall 2007b, 2010; Davis 2004; Easterly 2001b; Huber 2009). A middle class, in the city and in the countryside, is not only an effect of economic development, but also a cause. The middle classes have other interests, values and economic habits than the elite or the poorest groups. Their long-term objective is capital accumulation, as they want to secure their children's future. The middle classes therefore have a tendency to temper some of the excesses in the way in 
which their countries are organized (Banerjee \& Duflo 2008; Easterly 2001b). That makes a wide-ranging middle class an important factor in stability and institutionbuilding. To safeguard their investments, the middle classes force governments to draw up clear rules and enforce laws. They also have an interest in good collective services like roads, healthcare and public education (Birdsall 2007b). This is how European welfare states came into being. It was not until a broad-based middle class developed and wished to benefit from collective arrangements that public services really got off the ground.

The middle classes can play a significant role in the development of a country. Davis (2004) shows that clearly in her appropriately titled comparative study Discipline and Development. The success of developmental states like Taiwan and South Korea is partly due to the evolution of a rural middle class. Farmers were members of associations that made agreements between themselves, thereby limiting the power of big business. They also encouraged their governments to promote economic development. This enabled South Korea, Taiwan and Hong Kong to take the first cautious steps towards a welfare state (Haggard \& Kaufman 2008). In Mexico and Argentina, which failed to achieve economic prosperity, a middle class did not develop. That was hampered by regional conflicts and ethnic differences. These countries have therefore not yet developed into welfare states: social protection is only available to those in the formal economy. The middle classes not only have a role to play in the economy and establishing welfare services, but also in democracy. Rural and urban middle classes can be the main guardians of democratic development, as they have a considerable interest in being part of the decision-making process. The history of democratization in Latin America illustrates that clearly (Huber 2009; Rueschemeyer et al. 1992), though the argument does not apply (yet?) to Singapore and Indonesia.

It is clear that the middle classes can play an important constructive role. Yet the extent to which, and the circumstances under which, they do that is an interesting but insufficiently explored question. Many are eager to apply more generally the classic Weberian notion that the Protestant ethic of the Europeans who migrated to America in the eighteenth century - with the emphasis on hard work and sacrifice - provided fertile ground for the development of raw capitalism. In that argument the importance of the middle class lies in a long-term perspective and selfdiscipline. It is, however, debatable whether the emerging middle classes in developing countries always have such a perspective. People from the middle classes invest in healthcare and educating their children, but some also develop their own consumption-based culture, including fine houses, expensive weddings and holidays in far-off places (Embong 2001; Hsiao 2006). The middle classes are also often the groups that pay their taxes and benefit from a government that genuinely delivers. However, that too, is by no means self-evident: the middle classes in developing countries sometimes tend to turn their backs on the govern- 
ment. In India they are more interested in the market than the government, preferring to buy cheaper healthcare than arranging it collectively (Fernandes 2006). Perhaps the most important lesson to be drawn from the history of Western welfare states is that it is crucial to maintain a link between the interests of the middle classes and the government. If that does not happen, the middle classes become a social group that puts its own interests first, rather than helping to build the nation.

Furthermore, economic growth does not automatically produce a thriving middle class. India is poorer than China but by 2020 , although it will still be poorer, its already sizeable middle class will be larger than that of its neighbour, because in India the distribution of income is more equal. Huge discrepancies may also occur. Its growing middle classes are located largely in a number of economic metropolises, like Hyderabad, Bangalore, Mumbai and Delhi, but the rural middle classes remain limited in size. Furthermore, the new middle classes prove very vulnerable in times of economic crisis. In 2001, the middle classes in Argentina suffered severely, as did those in Korea, Taiwan and Malaysia during the Asian crisis of 1997 - not only because they lost their jobs, but also because their lifestyle was based on borrowed money. The middle classes are crucial for development, but the extent to which economic growth leads to their formation, and the degree to which they contribute to the creation of collective arrangements and democratic institutions, vary enormously.

\section{Ethnicity}

It is also important to determine the importance of ethnicity, especially in Africa. In much of the literature, ethnic fragmentation is seen as the main factor explaining lack of development. It is often assumed that ethnically diverse countries are more fragmented, are more likely to suffer from armed conflict, are less suited to democratic government, and achieve less economic growth. There is a lot of evidence to suggest, however, that diversity is not always problematic (Collier 2007; Easterly 2006). The link between social problems in Africa and ethnicity is not as self-evident as it seems. Ethnicity did not become the most important component of social identity until the twentieth century.

A striking example is the genocide in Rwanda in 1994. The standard interpretation is that it was a fierce ethnic conflict and that the institutions in Rwanda were not strong enough to bridge the deep-rooted divisions in the social structure. However, looking back into the history of Rwanda reveals that the social structure itself was a consequence of earlier political interventions (Meredith 2005). In the nineteenth century, the distinction between the Hutus and the Tutsis was completely different. Although the Hutus preferred agriculture and the Tutsis cattle-breeding, they spoke the same language, intermarried and adopted each other's customs. There was a good political balance, with Tutsi leaders who made 
decisions about the cattle and Hutus who did the same for agriculture, separate groups in the armed forces, and a king who kept the whole country under control. During German occupation, however, ethnic differences acquired a new social significance. With insufficient German troops in the country, Tutsis were elevated to the position of the leading elite and given responsibility for defending German interests. The Belgians, who 'took over' the country from the Germans after the First World War, went a step further. They introduced a system of identity cards stating the holder's ethnic origins. Because there were no records of this, they adopted a simple formula: every one with more than ten cows was a Tutsi, everyone with fewer a Hutu. A government apparatus was set up consisting only of Tutsis, and when the Belgians transferred responsibility to the Catholic Church in the 1930s, the local bishop ordered his missionaries only to teach Tutsis. In this way, the Tutsis gradually acquired all the leading positions and, by the end of the 1930s, the resulting ethnic division had become the main principle of social organization in the country. This led, at the end of the 1950 , to the first unrest, causing the Belgians to panic and change sides, supporting the Hutus. That had little effect and, after independence in 1962, institutions were further developed along the existing lines of ethnic division. We all know the consequences of that. Intervening in Rwanda without understanding this history produces constructions that will not last.

The fact that ethnicity has acquired such clear political significance in Africa is therefore, in the first instance, due to the colonial powers. After decolonization, the politicization of ethnicity continued even more intensively. This time it was driven by African politicians, who discovered that ethnicity was a powerful mobilizer in the struggle for power and the neopatrimonial system strengthened its importance even more. Political and economic factors were therefore to blame for the ethnicization of Africa (Chabal \& Daloz 2006; Chabal 2009).

It is possible, however, no matter how difficult it may be, to manage ethnic diversity. The history of the Southeast Asian countries is proof of that. After independence, many of them inherited a complex ethnic structure: in Singapore, for example, as a consequence of British power politics, people from India were in a minority but held many leading positions, those with a Malaysian background were afraid and without a clear perspective, while the Chinese played an important role in trade. In all of these countries, the new rulers were forced to find quick answers to these problems. At times that was a very rough and ready solution, such as the split between India and Pakistan, at others a less-than-subtle policy of preferential treatment, as in Malaysia. Singapore, for example, adopted a more cautious approach, introducing quotas for housing and jobs. In all cases, an ethnic transition took place without too much lasting tension so that, over time, social relations became more manageable. 
Ethnic diversity can be managed in different ways: through political systems, like an electoral or party-based system, or through other institutions, like the civil service. The ethnic composition of a country is, of course, an important factor (Bangura 2006). In a country with one dominant ethnic group it is important, for example, that minority groups have more power than their numbers would entitle them to. That is the case, for example, in Botswana, where the dominant Tswana group does not demand all the leading positions for itself. The Kalanga, which only make up 11 percent of the population, hold about a quarter of the public positions in the country and 18 percent of seats in parliament. If there are two ethnic groups almost equal in size, managing ethnicity can often be more difficult, as became painfully clear in Rwanda. Two groups often confront each other directly, leading to a policy of 'winner takes all'. However, even in these cases pacification is possible, especially if there is a system of proportional representation in parliament, government and the civil service. That is the case in Nigeria, where three dominant groups have to share power. In the civil service, historically dominated by the better educated Yoruba, more and more jobs have been going to the HausaFulani and Igbo in recent years. Under the Constitution, the three groups also take turns in providing the president. Countries with many ethnic groups, like Tanzania, often seem in a better position, especially if there is also a dominant national ideology. Ethnic differences then become less important; this is another way of managing diversity.

In short, in many developing countries, ethnic dividing lines are strengthened by economic and political factors. Managing this diversity, instead of ignoring it, is often a crucial factor in a country's development.

\section{Gender}

Gender acquires meaning in societies to a similar degree and in a similar way to ethnicity: the differentiation into sexes acquires all manner of shapes and forms, and there is considerable variation in the extent to which this differentiation is relevant at a cultural, social and/or economic level. Cultural anthropology offers a multitude of studies that record this diversity. Some even show that 'woman' was not a self-evident category in some societies. "The fundamental category of 'woman' - which is foundational in western gender discourses - simply did not exist in Yorubaland prior to its sustained contact with the West. There was no such pre-existing group characterized by shared interests, desires, or social positions. The cultural logic of Western social categories is based on an ideology of biological determinism: the conception that biology provides the rationale for the organization of the social World. (...) The body was (and still is) very corporeal in Yoruba culture (...) but the body was not the basis of social roles, inclusions or exclusions; it was not the foundation of social thought or identity." This is how Oyèrónké Oyĕwùmí (1997) describes the way in which gender gradually became a category in the Yoruba society in Southwest Nigeria. 
Women take on a multiplicity of positions, and the same can be said of other social categories like the elderly or children. In reasonably functioning rural areas in Africa you can find old men gathered under a tree in the afternoons, while the younger generation tend the cattle. Elsewhere, young people have moved to the towns and cities and have reasonable standards of living there, while their parents are left behind with few future prospects. In some villages women have most of the economic power because they not only produce goods but also trade them, while elsewhere the men control the market.

Male-female relations vary greatly between and within countries. The Gender Gap Index, developed along the lines of the Human Development Index, reveals a wide range of differences. Strikingly, Southern countries like South Africa and the Philippines score considerably better than a number of Western countries like the United Kingdom or the United States. There are also major differences within continents. An African country like Mozambique not only has much less genderinequality than neighbouring Tanzania, but also less than an Asian country like Vietnam (World Economic Forum 2009).

It is therefore difficult to make generalizations, although the temptation is great. For example, many people are still preoccupied by the exact nature of the link between sexual inequality and economic growth. In a frequently quoted article, Klasen (2002, see also Klasen \& Lamanna 2009) states that economic growth increases when more girls attend school, as it improves the quality of employees, increases competition and keeps wages low. According to Klasen, this partly explains why development in Sub-Saharan Africa and Southern Asia lags behind. This argument, however, can be called into doubt. First and foremost, the fact that fewer girls attend school is not an isolated problem. Furthermore, the causal link between economic growth and gender equality may also work in the other direction: if family incomes increase, so will the probability of girls attending school in villages in Bangladesh where women are able to work in the garment industry, significantly more girls attend school than in villages in which that work is not available (see also UNCTAD 2004).

Similarly, there is a great deal of debate on the importance of women for agricultural development in Africa. In contrast to Latin America or China, small farmers in Africa are often women. Their production is often lower because they tend to cultivate for their own households and do not, like men, make the move to largescale production which eventually yields more. There may be a variety of reasons for this, including social norms dictating that men cultivate cash crops and women subsistence crops, unequal property rights, lower levels of education and poorer advice. According to the FAO (2009b) agricultural productivity in SubSaharan Africa could increase by 20 percent if women were to have equal access to land, seeds and fertilizers (World Bank 2008a; Momsen 2010). At the same time, 
Jackson (2007) demonstrates that a broader conception of the risk women are ready to take, makes their behaviour perfectly understandable.

Ironically enough, economic growth can sometimes even benefit from gender inequality (Seguino 2000a, 200ob). If women's wages are low, there is a greater chance that much money will be invested in labour-intensive, export-oriented industries. Korea and Taiwan owe much to the fact that gender standards and stereotyping convinced women to take on poorly paid work. According to Seguino, "Low female wages have spurred investments and exports by lowering unit labour costs, providing the foreign exchange to purchase capital and intermediate goods which raise productivity and growth rates". Once semi-industrialized economies use technology to try to upgrade their economies, however, gender inequality no longer offers any benefits because it is then properly qualified staff that is needed. It depends on the type of economy as to whether empowerment of women leads to greater efficiency and higher productivity (Momsen 2010). In many instances, it is not a clear case of good and bad. Ong's 1987 study provided a good illustration of how the introduction of factory work to a Malaysian village changes relationships. If young women are given opportunities to work, the power of the men declines and the women start making more demands on the men. At the same time, the price they have to pay is long hours performing monotonous tasks. Moreover, the men are afraid that women's new independence will lead to licentious behaviour, which gives them cause to impose new forms of control. In the end, the parties involved have mixed opinions about the new situation.

Even microcredits, which are for many the ideal instrument to help women progress (many NGOs only give these credits to women), have a complex effect. In Sri Lanka, microcredits have little effect on poverty but they do enable women to improve their position in the household and the community. In Cameroon, the effects differ according to the programme. In India and Bangladesh, existing gender relations mainly determine whether microfinance provided to women leads to social transformation (Mayoux 2001, Hunt \& Kaynathan 2001). In Africa, there are many examples where women who receive microcredits, in addition to being burdened with household chores and caring for children, are made solely responsible for earning income for their household units. This increases the pressure on them even more while men end up having to do less, certainly if the women also become responsible for financing their retirement in the form of micropensions.

Designing interventions is also difficult. In his ethnographic study entitled Cultivating Development, detailing the intended and unintended effects of a large DFID development project, Mosse (2005) showed how all the gender objectives eventually had no effect on the parties involved. The women did not want more indepen- 
dence or power than men, but wanted men to take on more roles and responsibilities. The problem was not the men's dominance but their weakness.

Women are often seen as the drivers of change (Batliwala and Dhanraj 2007). There is a tendency, as Cornwall et al. (2007) also record, to make even more hyperbolic claims about untapped female potential: for example, women are said to be better at resolving conflicts, saving the environment and enforcing good governance. Policy always has different impacts on different social categories and in that respect it is always a good idea to ask what interventions mean for specific categories. At the same time it is extremely difficult to provide a good answer to such a question.

\section{Religion}

Religion has also become an important factor in a similar way. In many parts of the world, religion is a stronger factor than ever in the public domain. There seems to be little evidence of what Max Weber called 'the disenchantment of the world'. The number of people who consider themselves religious has increased worldwide. In Asia, it is currently 50 percent of the population, in Europe 60 percent, and in Africa as many as 91 percent (Jenkins 2007). Furthermore, new religious groups are emerging: the Pentecostal church, for example, has acquired 400 million members since the Second World War, more than the population of the United States. The centres of gravity of many groups are also shifting. The Pentecostal church now has strong support among the new middle class in Brazil, the poorest groups in Sub-Saharan Africa, and the mountain folk of India, while a fifth of all Muslims now live in Africa.

For a lot of people, religion is an essential component of their identity and, in many countries, it has brought political, linguistic and structural unity. Religion can do what a nation state is much less able to do, despite the successes of the national football team (Chabal 2009; Ellis 2007; Kennedy 2004; Soares \& Otayek 2007). There is, however, a downside: the articulation of religion, especially politically, plays an increasingly important role in conflicts (UNDP 2004). If ethnicity is a spark that can ignite the flames of conflict, that also applies more and more to religion. In Nigeria, for example, many conflicts about power (and oil) have been fought between the three main ethnic groups, the Ibo, Hausa (Fulani) and the Yoruba, with the war in Biafra being a case in point. The country is now in the grip of violence between Muslims and Christians, who both account for about half of the population. Conflict also often occurs within religions, as in Malaysia or Turkey, where moderate and radical Muslims are fighting about the future of their countries (see also WRR 2006c). The kind of one-dimensional dilemmas described by Huntington (1996) in the Clash of Civilizations, do not exist. There is more often a series of layered and sometimes politicized articulations of religious dividing lines within religious groups, countries and regions. 
For a long time, religion was also seen as a cultural obstacle to development. Following Weber, it was assumed that societies outside Northern Europe could also only develop if they were driven by Protestant ethics, with the emphasis on an 'inner-worldly ascetism' of self-discipline, hard work and savings. Other religions were considered to delay or even counteract economic growth. In the 1980s, for example, facetious references were made to the 'Hindu rate of growth'. However, since the economic success of India, and of the Gulf States (Islam), Korea and China (Confucianism) and Brazil (Catholicism), that assumption has been belied by the facts, denying any causal relationship between religion and development. Nor is it true that Confucian values were the driving force behind the Asian growth wonders, as Prime Minister Lee of Singapore likes to claim. That was only one of many factors that contributed to their success (Berger 2008).

Religion is therefore not an explanatory factor for development, but must be taken into account in understanding it. Certainly in Africa, politics cannot be understood without taking account of the way in which religion, spirituality and magic penetrate to the very core of state and society (Ellis \& Ter Haar 2004). There is no separation of religion and state. That applies not only to the lowest layer of the population, who often see their president as the servant of God, but also to the elite. President Chiluba declared Zambia a Christian nation after he himself had converted to Christianity. Earlier, in the same country, president Kaunda and his entire cabinet were under the spell of a Hindu guru, recommended to the president by Indira Gandhi when he found himself in a 'spiritual stalemate'. In Mozambique, president Chissano introduced transcendental meditation in his cabinet and the civil service. Members of the armed forces were ordered to spend 20 minutes a day meditating, which the president claimed had a proven peaceful effect. Furthermore, while political elites act on the basis of religious inspiration, religious authorities also adopt political stances. It is not unusual for religious leaders to hold important positions in government. The archbishop of Rwanda before the genocide is still criticized for not doing more to stop it. In Senegal, the Mouride, a Sufi brotherhood, play a central political role.

As in many Asian countries, like Korea and the Philippines, democratization in Africa has led to the emergence and growth of a wide variety of religious groups, both Christian and Islamic, many of which are politically active. In countries like Benin, Cameroon, Ghana, Kenya and Ethiopia, that has generated a spectrum of new religious institutions that preach new interpretations of the traditional faith. It has also led to the growth of religious women's and youth organizations spreading the word and providing a new platform for the articulation of interests and ambitions that have not previously been articulated. In this way, religious organizations offer new opportunities for different population groups to take part in the political debate (Soares \& Otayek 2007). On the other hand, religious movements 
can also isolate people, especially if religion is the only identity they are permitted. The fact that Malian children now learn to read the Koran in Arabic, a language that is strange to them, does not help bring development closer. All in all, religion is an important force to be reckoned with, and one that can be destructive as well as constructive.

\subsection{OWN DEVELOPMENT PATHS}

Development is a matter of guided modernization. It is quite possible to record the factors that play a role in that process in a general schema. It helps, and certainly in the case of Africa, to reason in terms of an economic sphere, a political system, a government apparatus and a social structure, although these four layers can only be differentiated to a limited extent and continually affect each other. It also helps to learn from Western history, and not to be blind to the importance of agriculture and a middle class. It helps to be aware that economies cannot simply jump-start themselves, but often need a certain amount of support and protection from a government in the early stages. It helps to know that the most important question about governments is not whether they are legitimized by multi-party elections, but whether they are effective. It also helps to understand that stability and security are preconditions for development and that social ties should not only be interpreted as forms of patronage.

However, there are no simple recipes. Africa, for example, will never be able to follow the path taken by Europe. Western development was able to occur in a situation in which the West not only had centuries in which to complete the process, but was also lord and master of the rest of the world, which it was free to exploit in any way it wished. Such freedom of time and action is no longer possible. Moreover, with global trade integrated to such an advanced degree, economies are much more restricted in the extent to which they can be cultivated in the relatively protected comfort of their home markets, as Western economies were able to do. Nor will Africa ever be able to emulate the path followed in Asia. After independence, Africa inherited a completely different fundamental pattern of institutions from its colonial masters than Asia. In addition, the opportunities to pursue an independent policy have changed radically. Finally, the importance of expectations and ideals should not be underestimated.

\section{Legacy}

The political legacy of the very short period of colonization in Africa was a system of institutions that were not grounded in local relationships and were insufficiently developed to survive despite this shortcoming. The economic legacy was one of double dependence: the states on the continent were constructed around a handful of key raw materials, and focused on exporting these products rather than on internal consumption or the development of an internal market. As a conse- 
quence, prices were determined elsewhere, on the world market. In addition, the continent experienced enormous population growth from the 1950 os onwards, which increased the pressure on the entire system. The result was extreme economic fragility, as was evidenced by the dramatic fall in copper prices between the mid-1970s and the mid-198os, which as good as destroyed the economies of copper-producing countries like Zaire and Zambia. In that sense, Africa has never had its own economy. Much of its income has not been earned, in the literal sense that it has come from raw materials or, later, from donor contributions. The continent has never developed its own productive capacity, with the exception of a limited number of products, like cotton, coffee and cocoa. Commodity extraction and donations are still the essential sources of income in Sub-Saharan Africa.

In addition to this political and economic legacy, Africa has been unable to take advantage of the global growth in agricultural productivity. Since the green revolution in Asia in the 1960s, which introduced better crops, fertilizer, pesticides and irrigation, the yield of rice per hectare - under ideal conditions - has increased tenfold (World Bank 2008a). In Europe, too, agricultural reform programmes have led to great leaps forward in food production. In the 1980 os and 1990s, these advances led to enormous food surpluses on the world market. In the West, the problem of food supply disappeared into the background, to be replaced - after the dioxin chicken and mad cow scares - by concerns about food quality. Africa has been unable, however, to benefit from the rapidly developing global food market, and has largely remained dependent on its local markets for its food supply. Food production per capita has even fallen, partly as a consequence of rapid urbanization.

\section{Integration under new conditions}

As the world has become much more interdependent in recent decades, the scope for countries to develop in relative isolation has become progressively smaller. Developing in the way that Japan or South Korea did is impossible today, if for no other reason than the enormous increase in intellectual property rights. Furthermore, the phytosanitary and quality requirements the West imposes on imports are by no means comparable with those of fifty years ago. A typical developing country has to spend 150 million dollars just to fulfil the WTO's customs, phytosanitary, health and intellectual property requirements. This is more than the development budget of many countries for a whole year, and can be a serious obstacle to the integration of poor countries into the international trade system (Elliot 2009).

Wanting to trade more is one thing, but being able to decide for yourself what you export - and therefore produce - is a completely different matter. In recent decades, trade has become progressively regionalized, and regional trade blocs have gained in importance. How much trade takes place within the local region 
varies widely from continent to continent: in Europe 74 percent of trade transactions occur within the region, in North America that is 51 percent, and in Latin America 24 percent. African countries have the lowest intra-regional exports, amounting to 10 percent of their foreign trade (WTO 2008a, 2008b).

That presents Africa with the challenge of achieving regional economic integration if it does not want to remain heavily dependent on other trade blocs. African exports to the rest of the world consist predominantly of oil and other raw materials, and only for a small part of industrial products. Within Africa, the share in trade in industrial products is twice as large. If African countries therefore want to diversify to be able to make products with more added value and thereby to move higher up the production chain, they need to strengthen and broaden their mutual trade ties. There are many obstacles to achieving that in Africa, from the lack of good physical communications and a mass of bureaucratic red tape to wide differences in import regulations. Nor is it easy for African countries to escape from the 'natural' role they have acquired within the global economic order, primarily as suppliers of raw materials. According to some estimates, more than half of world trade takes place within multinational corporations, and a small number of these companies dominate the value chains of products like cocoa, coffee, tea, grain, fruit and vegetables. For example, the world's six largest chocolate producers control about half of global sales (Green 2008). That makes it very difficult for African developing countries wishing to not only supply the raw materials, but also make the products and sell them on Western markets.

The Asian tigers found a niche for themselves in the global economy largely by stimulating their own industries in specific areas and by protecting them where and whenever necessary. Compared to the period between 1950 and 1980, however, the margins for developmental industrial policy have become much smaller, not only through the increase in foreign direct investment and greater concentration of global production chains, but also as a result of changes in international trade and investment rules. Countries wishing to export to Western markets have to comply with these rules, which is often expensive and laborious. Furthermore, many instruments that rich countries used successfully to achieve their own development - such as tariffs, quotas, export subsidies, and 'borrowing' foreign technologies - have now been completely banned or rendered subject to strict regulation by the WTO. In this way, rich countries are kicking away the ladder which they themselves used to climb upwards (Chang 2002, 2009a). In addition, the rules on intellectual property rights have been tightened. The TradeRelated Intellectual Property Rights (TRIPS) agreement makes it much more expensive for developing countries to take advantage of new technologies. Since 97 percent of patents and the lion's share of copyrights and trademarks are in the hands of rich countries, the costs of acquiring knowledge soon escalate for developing countries if they have to pay more, and more often, for the privilege. The 
World Bank estimates the increase in licence payments for these countries as a consequence of the TRIPS agreement at 45 billion dollars a year, equivalent to a third of annual ODA. On top of this, many countries have to spend a lot of money on inspectors, scientists, engineers and lawyers specialized in patents to set up and operate a system of intellectual property rights (HAI \& Oxfam International 2009, 't Hoen 2009). In his book Why Globalization Works, Martin Wolf, a The Financial Times columnist, concludes that, although patents and other forms of protection of intellectual property may for these reasons offer advantages to some of the larger and more advanced developing countries like China, Brazil and India, "it is a rent-extraction device for the rest of them, with potentially devastating consequences for their ability to educate their people (because of copyright), adapt design for their own use (ditto) and deal with severe challenges of public health" (2004: 217). Former WTO adviser Philippe Legrain (2010: 20) therefore believes that global patent regulations cannot be justified, saying that "[j]ust as one size doesn't fit all in terms of labour and environmental standards, countries at different stages of development should not have identical intellectual property standards imposed on them".

The range of instruments for industrial policy available to developing countries has, in short, become considerably more limited in the past decade, especially compared to the post-war period when other countries did achieve development. However, this does not mean we have reached a brick wall as the WTO's rules are not all equally strict and sometimes allow exceptions for the least developed countries, large multinationals are not equally dominant in all sectors, and not all goods are equally mobile. Furthermore, the technology that developing countries need to strengthen their comparative advantages is not necessarily the most advanced and is often too old to still be protected by patents. Even if the rules do not change, there is still sufficient room for manoeuvre for countries that are "clever and determined enough" (Chang 20ogb). But it is by no means simple.

\section{Physical differences}

Trade conditions are not the only difference between the Asia of the 1960 os and the Africa of the twenty-first century. Physical differences also play a role. The soil in Africa is much older, and is exhausted in many areas. Furthermore, Africa is many times more thinly populated than Asia, and even more so if we take account of the fact that people in Asia largely live along the coast and in river deltas. In Asia, it was worthwhile building an infrastructure in the form of roads and waterways for irrigation (though the latter were often only profitable when also used to generate energy). In Africa, such infrastructure is (still) unprofitable.

The conditions under which land can be distributed also differ enormously. In Asia, bloody conflicts like those in China in the 1960s and in Vietnam in the 1970s brought land under control of the government, which was then able to allocate it 
to small farmers, either as owners or long-term tenants. In Malaysia, land is owned by the government, while in the Philippines it is in private hands. That is one major reason why the Philippines had a much lower growth rate than its neighbours. In Africa, the situation is different, with some exceptions. In Namibia, for example, partly thanks to German support, the government has substantial funds to buy land and redistribute it.

Land reforms do not occur in isolation, but are very much affected by the balance of political power within which development has to take shape. In most Southeast Asian countries, political elites were primarily afraid of resistance from the countryside. Many countries - including not only Indonesia and Malaysia, but also South Korea and Bangladesh and later China and Vietnam - therefore invested heavily in rural development to ensure rapid improvements in the living conditions of large groups of people. In Africa, political elites focus mainly on keeping on the right side of the urban population. In Asia, they tried to support agriculture with high food prices, while in Africa city-dwellers are courted with low food prices.

\section{New expectations}

For developing countries, the legacy is different, the circumstances under which they have to seek integration into the world market are different, and the physical and political context is different. Moreover, their expectations are different. The role played by changing expectations is difficult to pin down, but is nevertheless important. Through satellite television, people living in even the most remote areas of the South can see the attractions of modern life. That means that today's developing countries are starting from a completely different situation than that of Europe 200 years ago. Back then, a farmer might hope that one of his children would go to the nearest village and become a carpenter. That son, in turn, could hope that one of his children might train in the city to become a teacher. Some generations later, a talented son might even become a doctor and, a few more generations down the line, perhaps a talented daughter could do the same. Europe took two centuries to complete that process of rising expectations. In every African city today you can see impatient young people whose parents still worked on the land, but who consider themselves too good for that kind of work. In their designer training shoes and sunglasses, they hope for quick success, Westernstyle. In developing countries, agriculture generally holds little promise for the future, and anyone who has experienced at close range the state of repair of even the most luxurious hotel in Africa knows that learning a craft there is an equally bleak prospect. It is as though these countries want to pass through all the stages of development at the same time.

Migration and the modern media have ensured that developing countries have contact with the rest of the world. That not only produces different dreams, but 
also an intensive exchange of values, ideas and knowledge (Saxenian 2006). As a result, the middle classes increasingly lead 'transnational lives'. Where they used to compare themselves to their neighbours, they now emulate lifestyles elsewhere. They send their children abroad to the best schools - a trend that is referred to in Korea as a new social disease. English is becoming the lingua franca in more and more homes (Hsiao 2006). Religion, too, is creating transnational ties. Africa is coming into contact with the rest of the world through a wide variety of religious movements: with the United States and Latin America through the Pentecostal church, with the Middle East through Islam, and with Asia through the many Buddhist and Hindu movements.

Developing countries are therefore modernizing, but in their own ways. Development proceeds through unexpected combinations of order and chaos, based on sediments of precolonial and colonial relations mixed with modern technologies, institutions and ambitions, with all this taking shape in an increasingly interdependent world. Existing theory is finding it more and more difficult to clarify this hybrid form of development. It is clear that the state has a number of functions to fulfil. It has to provide a certain legal framework, a basic administrative structure in which obligations and rights can be embedded, and a physical, social and financial infrastructure. The form this all takes can, however, vary widely and must be grafted onto the existing social and institutional roots. Within that framework, developing countries will have to find their own development paths in a world that, at present, is not overly willing to adapt to their needs and ambitions. 


\section{MEASURING DEVELOPMENT}

Development is a complex business. While this might be a challenge to commentators and scientists, it is above all a problem for politicians and civil servants, who have the difficult job of explaining such a complicated concept to the man or woman in the street. It is equally difficult to formulate policy and evaluate whether that policy leads to positive results. The latter causes researchers all kinds of headaches. After all, it is their task to throw extra light on the question of where and when aid is useful. The question of how such a question can be answered is key to this chapter.

\subsection{IS DEVELOPMENT TAKING PLACE?}

Describing development is one thing, explaining it in measurable quantities is another. Nevertheless, this is what modern policy systems are expected to do. As a consequence, policy is being made 'result-oriented' in dozens of ways. What, on the whole, are the results? Demonstrating the achievement of development is easy if specific welfare indicators are taken as the criteria, but much trickier if other indicators are used. Welfare indicators, particularly in the field of healthcare, education, nutrition and political and social rights (including the position of women and children) present a predominantly positive picture. However, indicators which are socioeconomic in nature project a more diffuse picture. Although there are successes in this respect, these are very unequally distributed. There are major differences in both the degree to which poverty decreases and the level of economic growth, between both regions and population groups within countries.

The fact that specific indicators reveal substantial changes is one thing. The question of what causes these changes is another. The logical follow-up question is to what extent development aid was the decisive factor in bringing about those changes? Let us first examine the development indicators themselves. Anyone who wants to present successful types of development had better focus on healthcare, education and agriculture. In these areas the rate of change in developing countries has been substantially higher during the past half century than was ever the case in Western Europe (Maddison 2001). For example, life expectancy in developing countries appears to have increased by ten years between 1970 and 2005, and even by twenty years since 1950. That still leaves them twenty years behind Western countries, but they are making quicker progress.

The reduction in child mortality is also impressive. It has halved in developing countries over a period of thirty-five years. 
Figure 4.1 Life expectancy at birth in years

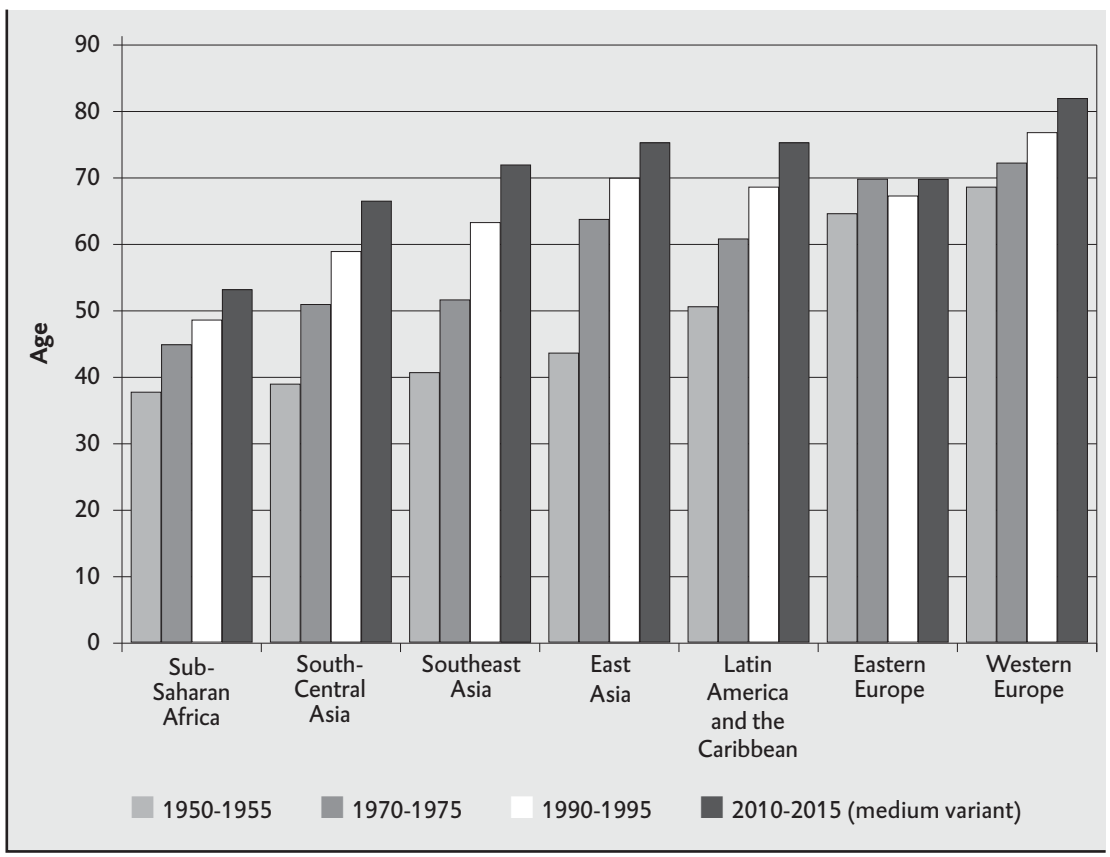

Source: Own calculations based on UN data

\section{Figure 4.2 Under-five child mortality per thousand births}

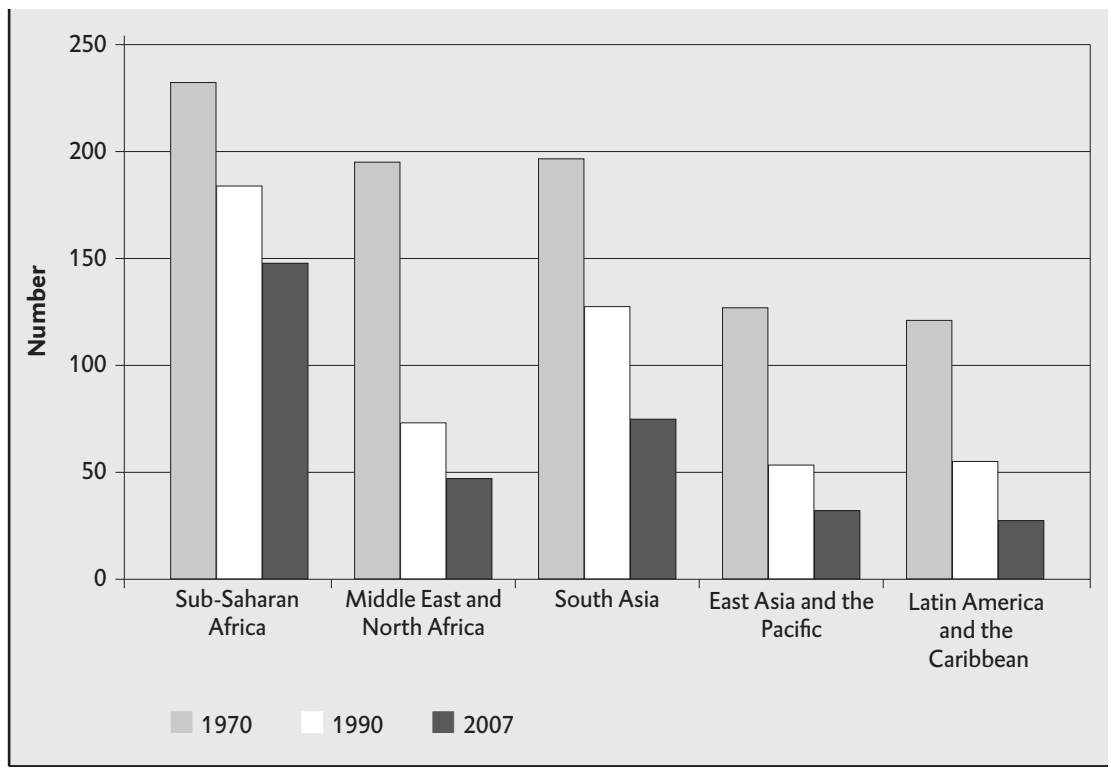

Source: Own calculations based on UN data 
Figure 4.3 Percentage of children 6-11 years old participating in education

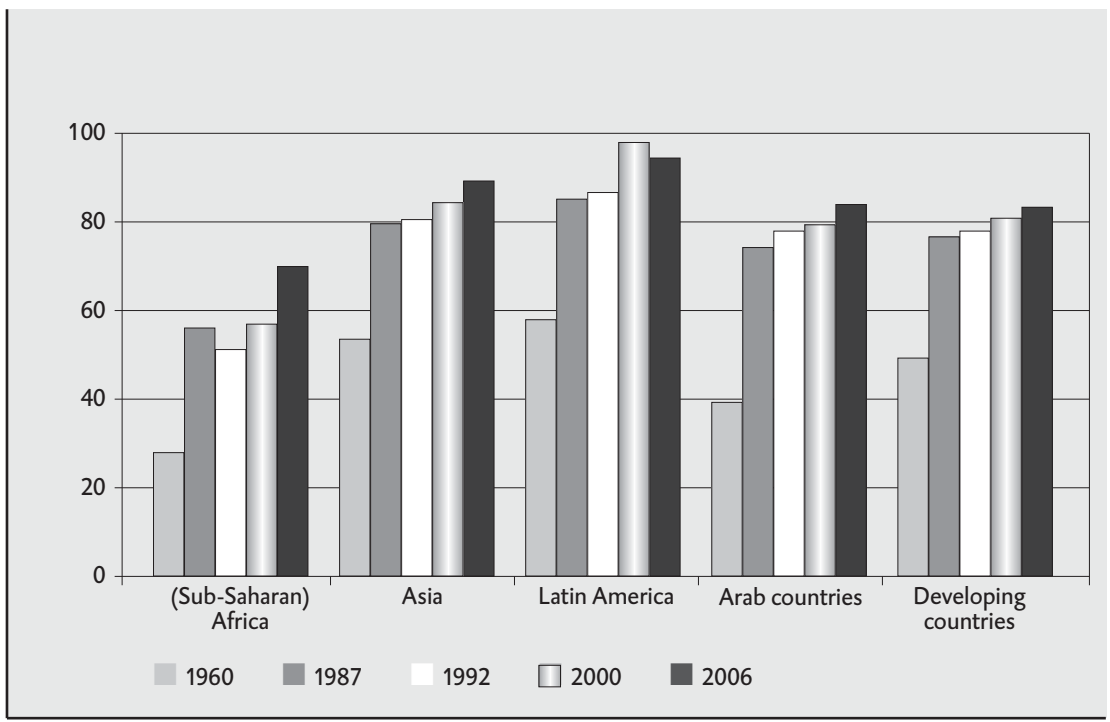

Source: Own calculations based on data from Szirmai and UNESCO 2009

The picture is similarly positive in the field of education. School attendance has increased everywhere. In Sub-Saharan Africa, the percentage rose from 29 to 70 percent between 1970 and 2006.

A degree of progress has also been observed in the field of food production and agriculture. The quantities of food per person have consistently grown, despite the enormous growth in population. In particular, production of the three most important food crops - rice, maize and wheat - has improved substantially. This had more to do with the green revolution than the increase in the quantity of available land. The majority of production and consumption takes place locally, with only 3 percent of rice being exported via the world market. While in the 1960 s there was still a dominant neo-Malthusian stream of publications predicting that population growth would place huge pressure on food supplies which, in turn, would lead to considerable political and social tension, it is now clear with hindsight that world food production to date has far exceeded population growth. However, one problem is that these observations apply primarily to Asia and not Sub-Saharan Africa. One consequence of this is that the interpretation of hunger has also changed. In the 196os, hunger was perceived primarily as a worldwide shortage of food, and with that availability. The increase in global food production means hunger is becoming more and more an issue of distribution and regional-specific food security. 


\section{Poverty}

People's health and level of education have been found to have risen enormously during the past sixty years. This applies to both rich and developing countries, and even more so to the latter than the former. However, the picture is less clear cut if we examine other indicators. Indicators such as growth in GDP or decrease in poverty mainly present a differentiated picture, both between and within countries. Figure 4.4 below shows this clearly on the basis of the development of GDP per head of population.

\section{Figure 4.4 GDP per capita}

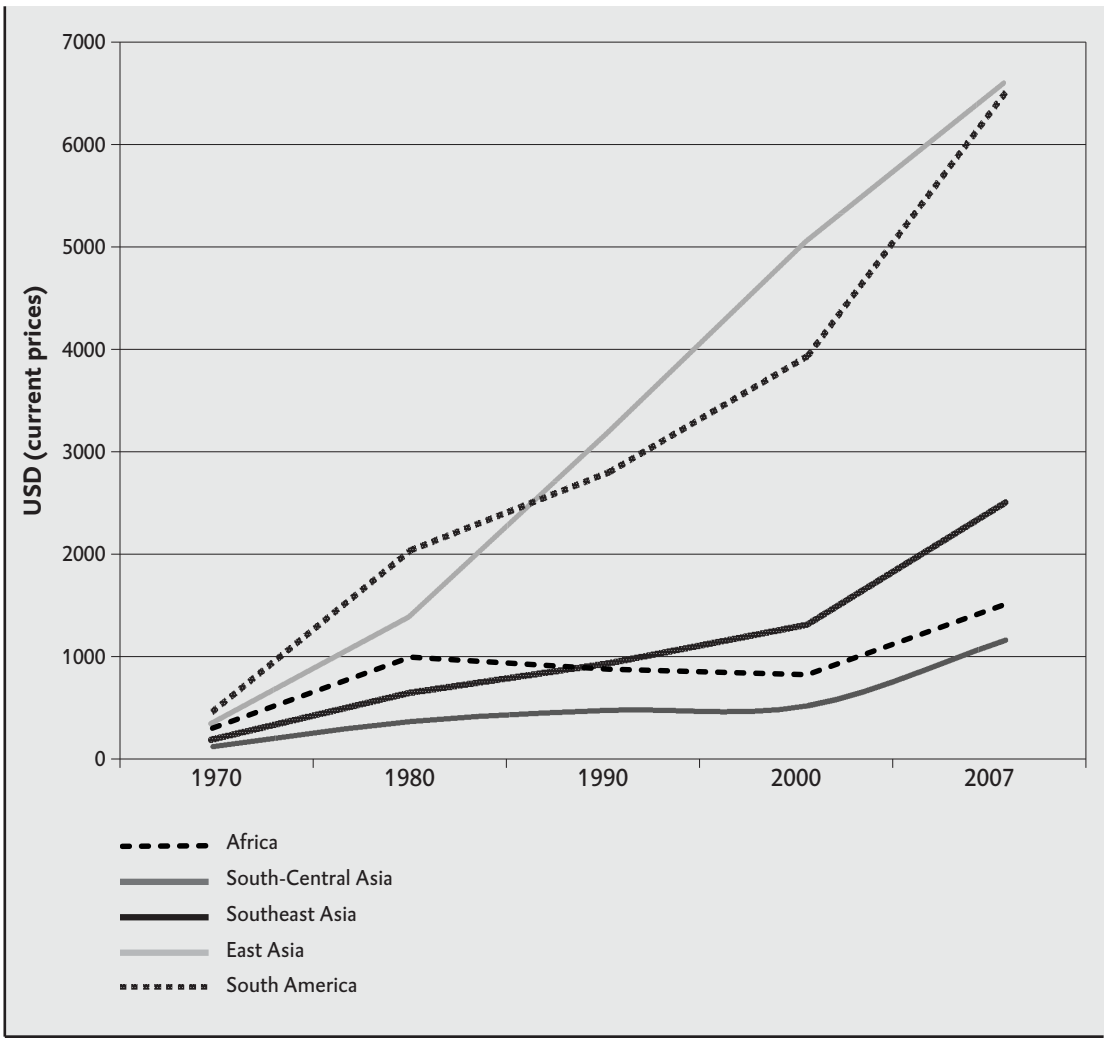

Source: Own calculations based on UN data

The picture becomes more complicated if we examine the development of poverty, as shown in Figure 4.5 . 
Figure 4.5 Percentage of people living below the poverty line ( $\$ 1.25$ per day)

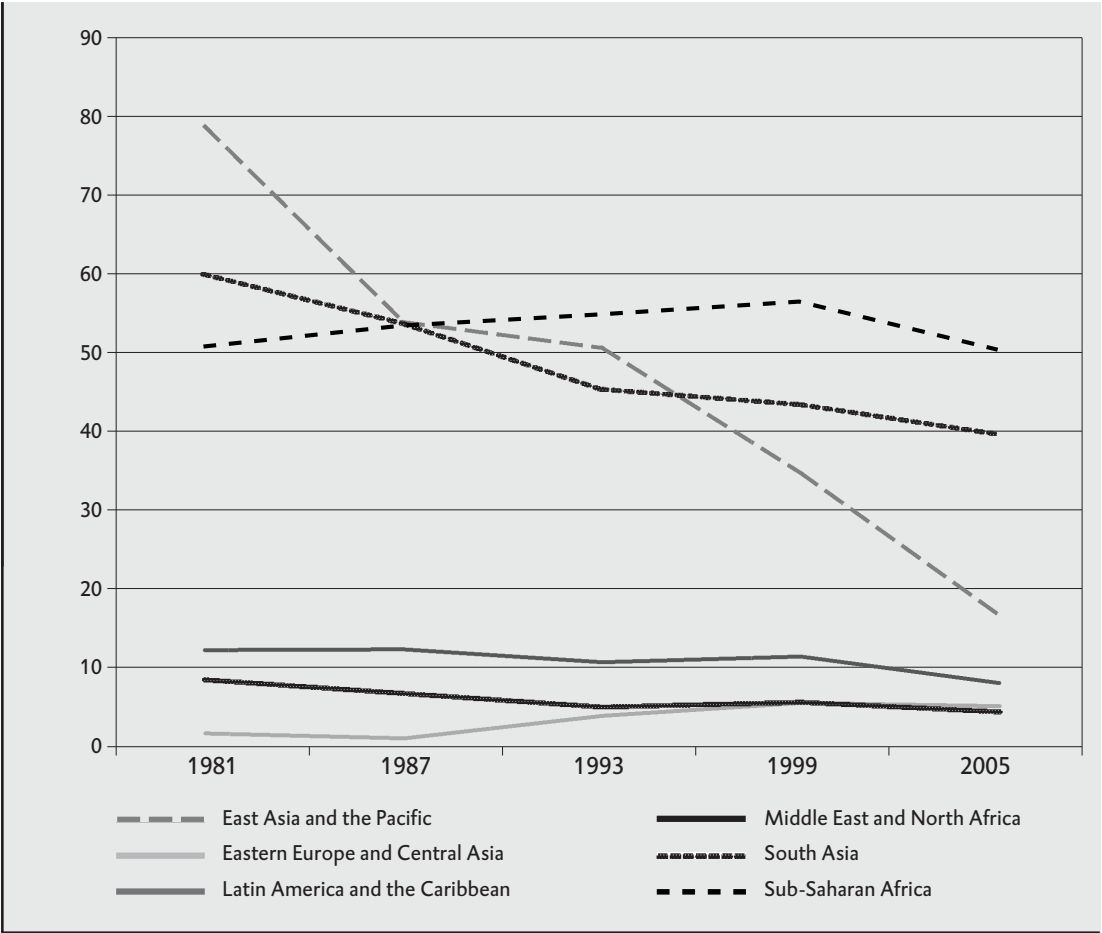

Source: Own calculations based on World Bank data

In the period between 1981 and 2005 , the percentage of the world population that had to live off less than 1.25 dollars a day halved, dropping from 52 to 25 percent. In absolute figures it dropped from 1.9 billion to 1.4 billion. These figures are gratifying. (Incidentally, the figures can also cause some confusion because the World Bank raised the official poverty line from 1.00 to 1.08 dollars per day in 2000 and from 1.08 to 1.25 dollars per day in 2008. This meant that three series of figures are in circulation.) As shown by the graph, that drop occurred primarily in East Asia. In that part of the world the Millennium Development Goal to halve the 1990 ‘\$ 1.08 per day' poverty level was reached shortly after 2002. Within East Asia, China is responsible for the lion's share of the reduction. Since it liberalized its economy in 1978, it accounts for more than three-quarters of all people who have escaped poverty (Gittings 2006). Today, 6oo million fewer Chinese people live in poverty than twenty-five years ago. Conversely, poverty in Sub-Saharan Africa has scarcely decreased. It remains at the 1981 level of 50 percent, though there is some good news in that the percentage increased until the mid-199os and then steadily decreased. Unfortunately, percentages do not show that the absolute number of people under the poverty line in Sub-Saharan Africa has almost 
doubled in those twenty-five years. When expressed in terms of the number of people who live on less than 1.25 dollars per day, the number increases from 214 to 390 million. As a result, poverty has gradually become 'Africanized', with the share of the world's poor in Africa rising from 11 percent in 1981 to 28 percent in 2005. That percentage is going to rise further (Chen and Ravillion 2008), despite the fact that most poor people still live in South Asia, in particular in India.

The contrasts in income have become sharper. According to Amsden (2007), over a period spanning less than three decades, the gap between the richest and the poorest countries has doubled, and differentiation within countries has also increased significantly. However, calculations of global income differences vary hugely, due mainly to differences in measuring methods and datasets (Milanovic 2002a, 2002b, 2005; Sala-i-Martin 2002a, 2002b; Wade 2004, 2008). World Bank researcher Milanovic (2003, 2005) carried out a comparison of economic growth and income development in the period 1960-1978 and in the two subsequent decades and concluded that, in comparison with the preceding period, the recent globalization had had a considerably less positive effect on growth and on the convergence of incomes between poor and rich countries. Moreover, the Indian economist Nayyar (2006) compared the growth of developing countries from 1940 to 1970 with that of the period from 1970 to 2000 and came to a similar conclusion that, on average, countries made a lot more progress in the first period than in the second. Growth was not more but less in the second period, and income differences between and within countries diverged during the last three decades of the twentieth century. In India, inequality increased mainly after the economic liberalization of the 1990s, in both the cities and the countryside, and between the cities and the countryside (Pal \& Gosh 2007; Sen \&Hiumanshu 2004).

On the basis of more recent figures - in particular on relative prices in China Milanovic (2007) calculated that worldwide income inequality is still a lot bigger than he had reported up to then. Even those who had until recently voiced opposition to the idea that, in these times of increased globalization, income differences between and within countries have increased, are now observing more and more frequently that this is indeed the case - in spite of theoretical expectations (IMF 2007; Krugman 2007, 2008). In the World Economic and Social Survey 2006 (UN 2006), the United Nations calculated that income differences between regions around the world increased during the period from 1960 to 2000 and that these differences largely explain income inequality at international level. In recent decades, income differences within regions have also increased.

What is more, differences in wealth within and between countries are considerably bigger than those in income. This was shown by a recent study by the World Institute for Development Economics Research (WIDER) at the university of the 
UN, which calculated the global distribution of wealth for the first time. Depending on the criterion used to determine the value of wealth, the study estimated that the wealthiest 10 percent of the adult world population owned 71 percent (based on purchasing power parity [PPP]) or as much as 85 percent of total global wealth (Davies et al. 2007).

\section{Significance}

The available data does not clearly show the extent to which development takes place. It is also becoming less and less clear what the data actually tells us. Take, for example, the concept of poverty. In 1993, the World Bank defined poverty as an income of less than one dollar per day per person. This sounds like a clear definition and, in any event, it has the advantage of allowing comparison of all countries throughout the world. First and foremost it should be noted that the completeness of the data is in stark contrast to the dogmatic way in which many people use these figures, which they have usually plucked from the websites of the World Bank or the UN. The data only relates to seventy-nine countries: in 2003, 62 percent of the people in Sub-Saharan Africa lived in countries in which no poverty surveys had been conducted during the past five years. Over sixty-five countries were unable to provide reliable data on the number of people under the poverty line, while in at least 100 countries a reliable measurement of shifts in time is impossible (Pogge \& Reddy 2005; Riddell 2009).

Another question is what one dollar per day exactly means, certainly in the case of people who have almost nothing. In so far as people participate in a market economy, they can buy very different things in different countries with one dollar. An additional factor is that a lot of the people involved do not even participate in a market economy and try to live off a small plot of land, possibly supplemented with a limited exchange of goods. Money then has very little meaning. The quality of life in a rural or fishing community which is self-sufficient but which has no money can be greater than in a slum where people have to live without sanitation and make a living selling small quantities of cigarettes (Broad \& Cavanagh 2006). Consequently, there is only a weak correlation between monetary and non-monetary indicators of poverty (Baulch \& Masset 2003). As far as the poorest are concerned, it might be more useful to express the development of their living conditions in terms of the nutritional value of the food they eat every day, but this data is not available on a large scale (Misturelli \& Heffernan 2008). It would also be more useful not to see poverty as static, but to chart its duration (chronicity). After all, living in poverty is terrible, but not being able to get out of it is much worse (Hulme \& Shepherd 2003). It would be even better to include factors like physical safety or the chance of a job (Alkire 2007), and to link poverty to the sustainability of natural resources and the environment people live in (Opschoor 2007). These are all dimensions for which there is insufficient data or methodological pointers. 
Similarly, GDP is a limited criterion. It gives a partial picture of collective production, but that production may well increase while the quality of life of a substantial part of the population deteriorates. Many comparative country studies have shown that there is indeed a correlation between GDP and parameters like health and level of education. In a study of eighty-one welfare indicators, Easterly (1999) established that only twelve were negatively correlated (such as pollution, suicides and some types of crime). However, taking a historical rather than a crosssectional approach produces a different picture, showing that there is only a weak correlation between welfare and national growth. Global changes are more important at political, economic and technical levels (improvements in antibiotics or water pumps have influenced the lives of a lot of people more than economic growth).

It is, of course, possible to devise more complex criteria which would be more satisfying from a substantive point of view. There is a good reason why the OECD is carrying out a major project with the splendid title of Measuring the progress of societies, and why the French President Sarkozy set up the Commission on the Measurement of Economic Performance and Social Progress in 2008, under the chairmanship of Nobel Prize Winner Joseph Stiglitz, with the explicit task of exploring the options for a better indicator than GDP (see also Manning 2009). It is clear, however, that - at least for the time being - it is not going to be possible to find an indicator which is usable and acceptable to everyone. In its report, the commission advocates dashboards of indicators which would allow various people and institutes to combine indicators as they see fit to monitor development of matters they regard as a priority (Stiglitz et al. 2009).

\subsection{WHAT DOES AID CONTRIBUTE?}

It is tempting to interpret improvements, particularly those of measured social indicators, as an indication of the usefulness of development aid. The question is to what extent this is justified. A great deal of research has been devoted to this issue. At first sight the research design also appears to be straightforward: compare countries with varying levels of development aid and assess the outcome. That approach has resulted in a series of comparative country studies. There is a serious problem, however, in that countries cannot simply be compared. The following is a case in point. It is popular to compare Ghana and South Korea. It features in many a study of development aid, because in 1960 both countries had a comparable GDP per capita, while in 2008 it differed by a factor of eighteen. In that period, Ghana received a great deal of aid while South Korea did not. This is often cited as proof of the deficient or event absent effect of aid (see for example Harrison \& Huntington in their well-known Culture Matters (2000)). Quite apart from the fact that South Korea received a lot of American aid in the 1950s, further analysis raises the question as to what extent this comparison has any meaning. Although 
South Korea did not have a high level of GDP in 1960, it did already have a robust business community, a well developed government apparatus, intensive trade links with Japan and the United States, a much better school system and much higher levels of literacy. How is this to be compared with a country like Ghana (see also Sen 2006)?

Is it then impossible to design research in such a way as to separate the effects of aid from other variables? Policymakers, researchers, evaluators and aid workers have been struggling with this question, in particular since Paul Mosley devised the now famous micro-macro paradox on aid in 1987: although aid may often be successful at project level, this is not reflected in the economy as a whole. Consequently, there does not appear to be any correlation between aid and growth figures. This paradox had a major effect on research into the effectiveness of aid, and the same applies to the rather unsatisfying statement by the World Bank, in 1998, that foreign aid has been "very effective, totally ineffective, and everything in between at various times and places". A variety of questions are being asked and various methodologies applied in order to find more unequivocal conclusions about the effectiveness of aid (Goderis \& Verbon 2007; De Haan 2009).

Comparative country studies which use complex econometric techniques to try and measure the effect of development aid on growth are very popular, but are plagued by all kinds of methodological and data-related problems (Riddell 2007; White 1992). For example, cause and effect are difficult to separate (does a country grow faster when it receives extra aid, or does it receive more aid because it grows faster?), sensitivity to the choice of control variables is considerable, and the reality is too complicated and too differentiated to capture in linear comparisons. Following a meta-evaluation of sixty-eight papers, in which 543 comparable estimates were made of the effect of aid on growth, Doucouliagos and Paldam (2008) draw the 'depressing' conclusion that, after forty years of research, it cannot be demonstrated that the effect of aid on growth - in statistical terms - is significantly greater than zero. The self-confessed aid sceptic William Easterly (2008a) refers to research that uses growth regressions to find variables that are important for growth. The authors identified up to 145 factors, but these did not include development aid.

Other researchers believe that these outcomes are actually not surprising at all because, if you include all aid in regression comparisons, you tend to miss the details. Differentiation is needed to acquire an insight into the effect of aid on growth. This has been done in a number of studies, such as research examining whether the effect of aid depends on the quality of policies (good governance) in the recipient country, research differentiating between 'real aid' and 'geopolitical aid', research measuring and comparing the effect of aid in the long term and the short term, research assessing whether aid was tied or untied, and research differ- 
entiating between bilateral and multilateral aid. However, none of these studies produced any clear answers. A paper that reports a positive outcome is usually followed sometime later by criticism questioning the solidity of the supposed conclusion, the data and/or the method used. 'Publication bias' is another factor that plays a role, given that articles which make strong claims tend to get published sooner in scientific journals (and scientists have to publish, i.e. have a greater tendency to submit such texts), and given that the popular media also prefer bold claims in favour or against something rather than nuanced accounts (Arndt, Jones \& Tarp 2009; Burnside \& Dollar 2000, 2004; Clemens et al. 2004; Easterly 2008a; Easterly et al. 2003; Faye \& Niehaus 2010; Goderis \& Verbon 2007; Minoiu \& Reddy 2007, 2009; Miquel-Florensa 2007; Riddell 2007; Roodman 2007a, 2007b, 2008). Let us now examine three of these obstacles in more detail.

\section{What is aid?}

An important factor to take into account is that it is too easily assumed in simple research designs which try to measure the effect of aid, that aid is a homogenous category. This is certainly not the case (Radelet et al. 2004). Over the course of time, although money has been made available for aid, the purposes that money has been used for have changed. Headey (2008) therefore applied all kinds of econometric instruments to establish which aid was effective and when. His conclusion was that bilateral aid had no effect at the time of the Cold War, but did thereafter. Multilateral aid had a certain effect during the entire period. This observation supports other evidence that, during the Cold War, bilateral aid was often a euphemism for supporting dictators. The fact that a lot of money failed to benefit the country and instead filled individual's pockets is documented in detail by the various historians of African development (Meredith 2005; Moss 2007). The calculations by Minoiu \& Reddy (2007) led them to a comparable conclusion, although they do make a distinction between developmental aid and geopolitical aid. In their analysis, the long-term effect of the first type of aid features in the data, while the second type does not.

Although these might be interesting results - certainly for people who believe in the usefulness of development aid - their validity has been questioned in some quarters. Kenny (2009) gives this discussion an interesting twist by asking whether you can assume that the types of aid referred to were used for homogenous goals. This question touches on a key point because, as we have seen in chapter 2, a lot of aid is not used to increase growth or facilitate structural changes, but rather to directly improve the living conditions of poor people in developing countries. The effectiveness of an instrument has to be assessed on the basis of the intended goal. Therefore, development aid to relieve an emergency should be evaluated and monitored differently to aid which is intended to increase growth. Unfortunately, there is no data which can be used to ascertain properly which aid is used for which goal. This increases the risk of aid being measured afterwards on 
the basis of growth objectives for which, in a number of cases, it was never intended. For example, many attempts have been made, certainly in the 1990s, to achieve stabilization with a great deal of budget and sectoral support being granted partly to keep governments in place and economically stable so that these could then be expected to deal with ethnic and other conflicts (Chabal \& Daloz 1999). When measured against that objective, that aid may have been quite effective, precisely because nothing changed. However, if the aid was intended for something else, it would have been ineffective. The problem is that no data is available to assess aid on its own merits because goals are rarely recorded.

\section{How does aid interfere with other developments?}

A subsequent problem is that development aid is just one of the many forms of foreign intervention in a country. This makes it difficult to properly identify the direct effects of aid. The amount of money spent on aid is also no more than a small part of the total flow of funds to developing countries, and that share is becoming smaller and smaller. This is shown by graph 4.6 , which compares foreign direct investments (FDI), money transfers by migrants to their families in their native countries (remittances) and official aid.

\section{Figure 4.6 Remittances, ODA and FDI}

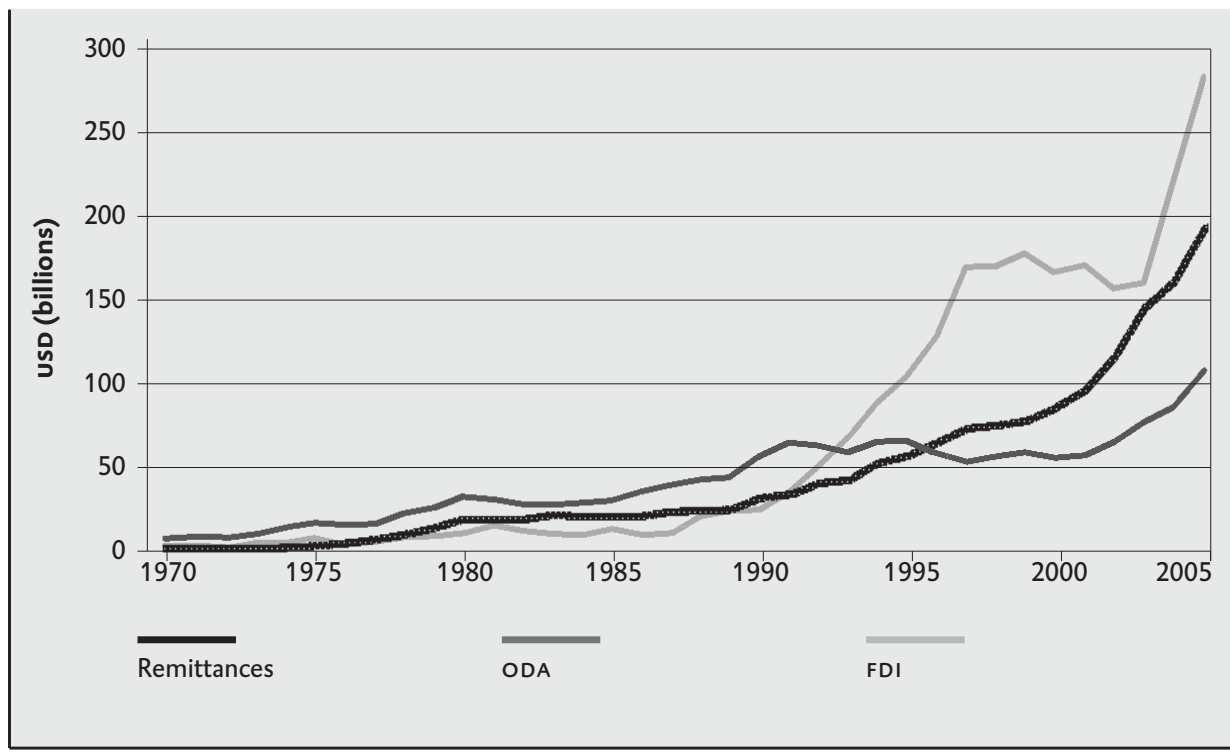

Source: Commission on Growth and Development 2008 
Just how difficult it is to isolate the effects of aid is demonstrated by the highprofile evaluation of the Netherlands' Africa policy published by the Policy and Operations Evaluation Department (ІОВ) in February 2008. It is a magnum opus, which summarized a lot of previous work and tried to answer the question of whether Dutch development aid had actually contributed to the development of Africa during the past twenty-five years. That implied that it is possible to assess Dutch development aid financed by taxpayers' money separately from other Dutch contributions, such as investments by the private sector or civil society organizations, and that Dutch interventions can be separated from the contributions by, for example, the British or Swedish. All this is to some extent possible at the level of concrete projects, as also shown for example in the bulky results report on Dutch efforts to achieve the Millennium Development Goals (Ministry of Foreign Affairs 2009c). However, it is a lot more difficult to answer the question of what sustainable contribution this makes to broader development.

Flows of money to developing countries come from various sources, but these countries have to deal with many more external developments. Chapter 3 has already discussed how strongly the economy of Africa depends on raw materials whose price is determined elsewhere. The effects of this can be considerable. Between 1970 and 2000, the price of raw materials in relation to end products dropped, except in the case of oil. Between 1980 and 2000, the price of cotton fell by 47 percent, coffee by 64 percent, cocoa by 71 percent and sugar by 77 percent. On top of this there were all kinds of internal developments, such as the periods of drought in the Sahel, or the lengthy periods of bitter conflict after 1990. At the beginning of the 1990s, 26 African countries were involved in a war or were confronted by violence against the state. You do not need to have had years of social-scientific training to realize that such external and internal factors had a much greater impact on developing countries than aid could ever dream of having.

\section{Causal blueprints and the time dimension}

A third problem is that there is no simple causal blueprint which facilitates a clear understanding of what precise effect interventions have. Development, interpreted as accelerated modernization, is an extremely complicated phenomenon. It relates to the complex interaction between the economic infrastructure, the quality of government, the functioning of the political system and the way in which social ties take shape. Sometimes it is possible, and then usually with hindsight, to identify this complexity, but that does not produce any attractive causal models. In an interesting project, the Japan Bank for International Cooperation (Ishikawa 2005) compared Japan's development policy in Asia with that of the British in Africa. It concluded that there are two ways of bringing about development. One way is to reform institutions, which, in the long run, will have an effect on growth. The other way is via economic growth, which will in the long term lead, 
as a by-product, to the setting up of adequate institutions. The Japanese concluded that the first way is inefficient and time-consuming, if indeed it works at all. Their experience told them that the second way was the preferable option. However, conclusions like these are generally no more than hunches. "Explaining economic development is not for the simple-minded", is how Szirmai (2008) starts his detailed study of explanatory models for development. "The first observation that one can make, is a negative one: every single monocausal explanation ever advanced for development falls down in the face of the empirical evidence" (see also Adelman 2001).

Causal blueprints have their shortcomings. Many interventions work indirectly and over a long period of time and the best one can hope for is to have a vague idea about their impact. The effect of money for schools depends on all manner of things, such as the presence of adequate teaching material and properly trained teachers who are prepared to go and live and work in remote regions (which is generally not the case). This too depends on there being a government or nongovernmental parties who are able to organize it. It also depends on how long children are able and willing to stay at school and that, in turn, is determined by the perceptions of their parents, and equally by the harvest yields, which determine whether children can be relieved of their tasks at home. That, in turn, is determined by the quality of the seeds and the quality of the land, which depends on, for example, research into crop breeding. The green revolution caused agriculture productivity to more than double in the 1970s, particularly in Southeast Asia and this resulted, for example, in India quickly changing from a food importer into a food exporter. That revolution was largely facilitated by research by the International Rice Research Institute, which was partly financed by the Rockefeller Foundation (Cullather 2004). If you want to you can go even further back and say that Obama's education was partly thanks to Dutch Catholic missionary work which contributed to the working of the kampong school that young Barack attended during the chaotic mid-196os in Jakarta. The school itself had been set up two years earlier by the Dutch Capuchin father Jansen (Van Gennip 2008). Does this mean that the collections taken in Dutch churches during the 1950 s led to Obama being awarded the Nobel Prize?

Apart from the lack of a sound causal blueprint, the time dimension is another exceptional problem. It takes decades rather than years before the effect of, for example, healthcare, education, water supply or land reform on development becomes clear. One solution open to researchers is therefore to assess a longer period, ideally as long as possible. However, this only exacerbates the abovementioned problem of the effect of aid being difficult to isolate from other influences. 


\section{An example: the resource curse}

The question of what the goal of aid is, interference with other developments, the lack of causal blueprints and the time dimension make it difficult to determine the effect of development aid. This is an unsatisfactory state of affairs. It is therefore tempting to keep on searching for correlations. In a widely discussed analysis, Collier (2007) claims that the greatest problem facing development policy is that fifty-eight unnamed countries are lagging behind the rest, and are often unstable or on the verge of disintegration. According to Collier, all these countries are stuck in one or more of the following four development pitfalls: internal conflicts, bad governance, landlocked and surrounded by bad neighbours, and the curse of having resources. Collier does not disclose what exactly the causal mechanisms are which turn resources into a curse, but the counter-intuitive idea that natural resources are a curse rather than a blessing for countries because they result in lower growth and increase the chance of conflicts, has been raised periodically since Adam Smith (Lederman and Maloney 2008). There are also clear examples. Nigeria, an oil-rich country, has received more than 250 billion dollars from oil in the last three decades, but Lagos became a dirty and dangerous city, while per capita income dropped by 15 percent between 1975 and 2000, and the number of people under the one dollar threshold quadrupled during the same period from nineteen million to eighty-four million. The question is whether resources are always a problem. Upon closer inspection this general theory is also problematic.

Brunnschweiler and Bulte (2008) criticize the methodology usually used to prove the curse of natural resources and claim, on the basis of their own calculations using data from the World Bank, that dependence on resources is a symptom rather than a cause of underdevelopment. According to Lederman and Maloney (2008), anyone who studies countries with natural resources such as Australia, Finland, Canada and Sweden in the West, Indonesia in Southeast Asia, and Namibia, Botswana and Zambia in Africa, has to conclude that the proof of a resource curse is, to put it mildly, weak. Van der Ploeg \& Poelhekke (2009) conclude that resources in themselves are not the problem but the volatility of prices, that countries with a sound financial system can do something about this, and that it is even possible to change the resource curse into a blessing, given that evidence exists of a direct positive effect of natural resources on growth if volatility is controlled. This discussion goes further, therefore, since experiences with natural resources are very heterogeneous and their effect on development depends very much on how the countries involved deal with their resources and the income they generate. Here too, the attractive simplicity of the explanation prevents a clear view of complex mechanisms.

It is always difficult, if not impossible, to evaluate complex interventions in social processes. Of course this is no reason for not trying to evaluate to the best of our abilities. However, in the context of discussions of what we know about the effects 
of development aid, it is important not to lose sight of the fact that it is just as impossible to measure the effect of policy in Western countries in the field of spatial planning or employment, since that too is complex. Even if the question is specified in more detail - for example, the effect of education policy or reintegration policy - the answer does not become any clearer. Every year, special issues of scientific journals are published in which experts adopt diametrically opposed positions as regards the effect of these kinds of activities. There is nothing wrong with that and we will have to make do with what we have. However, it is a good reason not to blow our own trumpet too much, certainly if we take into account that development aid and the regions it relates to are many times more complex.

\subsection{SHOULD WE THEN FOCUS ON THE MICRO LEVEL?}

As the hopes of the 196os that "thinking big would translate into clear guidance on how to move immediately into rapid growth and development" have been repeatedly disappointed, perhaps we should only "think small” in the future (Cohen \& Easterly 2009). An alternative for the attempts to measure the effects of aid at macro level is to examine the impact of concrete projects at micro level. Especially controlled randomized experiments have turned out to be very promising in recent years. Whether the intended output has been realized during a projectwhether new roads have been laid - can usually be assessed afterwards. However, whether the project has had the expected social impact in the short, medium and long terms - whether incomes in the region have been sustainably increased - is one of the most difficult questions to answer in the context of an evaluation because you have to make a counter-factual comparison, in other words what would have happened without the project? An interesting way of doing this is to allow some of the potential beneficiaries to become eligible for a project and others not, and then compare the outcomes. In a randomized experiment like this, some of the people receive the medicine to be tested and others receive a placebo, or the residents of certain neighbourhoods become eligible for microcredit while the residents of others do not.

However, there are objections to this approach. The ethical objection is that you purposefully deny aid (medicines, education, credit) to an eligible group. Although this may be justifiable if the available resources are, in any event, too limited to allow everyone to be eligible, or if the potential yield of the research project is enormous, it is at the very least dubious if the interested parties are selected primarily on the basis of donor interest. In addition, a lot of goals and projects are not suitable for randomized experiments, and that certainly applies to programmes. Martin Ravallion, head of the research department at the World Bank, refers to the example of specifying the best location for infrastructural projects like roads, bridges and railway lines. This is a core activity in the development strategy of any poor country, but it is difficult to imagine how you could 
do that with a randomized experiment (De Haan 2009; Ravallion 2009a). Another major question is the extent to which you can generalize the outcomes of this type of research given that a properly designed project which works in one country or area does not also have to work in another. This considerably reduces the policy relevance of this method. Supporters who recognize this advocate repeating experiments at other locations, but the incentives for doing that are small and the literature on randomized experiments does not provide an answer to the impossible but relevant question of how many repetitions are necessary (Easterly 2009). An additional practical problem is that scientists do not make a name for themselves by repeating something that has already been done and not, in any event, in the relevant journals. Another problem is that there are indications that donors permit randomized experiments primarily in relation to projects which they expect to be a success. There are examples of projects being stopped before the outcome of the randomized experiment appeared, without it being clear whether this was due to the evaluation. Governments are also less willing than NGOs to have new projects evaluated by means of randomized experiments. According to Ravallion this should not really come as any surprise since policymakers also want answers to questions which this methodology cannot provide, for example whether an intervention works as expected, which type of people benefit and which not, what happens if the project is intensified, and how the project can be designed differently to have a greater effect (Banerjee 2007; Banerjee \& He 2008; Deaton 2009; Easterly 2008a; Gunning 2006; Pritchett 2008; Ravallion 2009a; Rodrik 2008b).

Some randomnistas exaggerate the potential of this 'revolutionary' new approach, but many sceptics also regard randomized experiments certainly as a valuable addition to the instruments researchers have available to evaluate projects. To quote Easterly once again: “The RE methodology has had a positive demonstration effect showing the scientific method can be applied with marginal interventions, in an aid world that too often ignores any existing evidence (or any need to find such evidence)".

A practical alternative for situations in which a randomized experiment is impossible or not responsible is the 'quasi experiment' (or 'non-randomized experiment') whereby comparisons with comparative groups or situations are made after the project has been carried out. This is often done with advanced statistical techniques, although these are not always suitable. For such second best evaluations of projects, qualitative and descriptive assessments are sometimes also used. These qualitative and descriptive methods are also used when monitoring and evaluating programmes involving factors which are entirely different to those that apply to a project evaluation. It is, for example, very difficult, if not impossible, to measure the contribution a donor programme has made to social change, and there is probably not much point in comparing countries because the circumstances are too 
different. How to monitor the provision of aid, or to assess the cooperation between donors and governments in the context of budget support, is a complicated puzzle. In a bottom-up approach it is still possible to measure the effect of general budget support or sectoral support by means of a representative sample survey of intended beneficiaries. However, it is difficult to measure the extent to which governments feel they are the owners of agreed policy, or how you ascertain the extent to which there is actual participation in the formulation of a Poverty Reduction Strategy Paper (Gunning 2006; De Haan 2009). And last but not least, the question has to be answered what the people for whom aid is intended think about it. In order to find that out, experiments have been carried out more recently with another bottom-up approach in which local residents are monitored over a longer period of time. The question the people were asked is how they value a number of development initiatives in their region and the social changes which have ensued (Dietz et al. 2009; Dietz \& Van Zanen 2009).

\subsection{DOES AID HELP?}

If measured using a number of dimensions, the world has become a better place. In particular, the scores on welfare indicators (education, nutrition and health) have improved over the past sixty years in a way which is historically unprecedented. Progress has also been made on realizing growth and counteracting poverty, but that does not apply across the board, and it has been accompanied by greater inequality. The question is what contribution development aid has made to these changes. For the time being, that question cannot be answered unequivocally. Publications will continue to appear which attempt, using macro research, to prove that specific types of aid have a positive effect, in certain circumstances, on growth or development. Results of randomized experiments also continue to appear, showing that some concrete projects work and others not. However, none of these methods is the be all and end all, and it is sensible not to overestimate their possible policy implications. It is possible to show that projects work at micro level, although certainly not all of them and not at all times, and a plausible case can be made that, at meso level, progress has been made in a number of different areas, particularly in the fields of healthcare, education and nutrition. However, it cannot be unequivocally stated that this also means that people and countries are now more able to develop independently - nor can the opposite be claimed.

Some people even regard studies asking whether aid helps as not that relevant. In a flurry of policy cynicism, David Roodman of the Center for Global Development, and an expert in this field, stated that he believes that the macro research into the effectiveness of aid has received a disproportional amount of attention because policy rarely takes any account of research in any event. A perfect case in point is the famous study in which Burnside and Dollar demonstrate that aid leads to more 
growth in countries with good governance. That conclusion is still affecting donors today, as shown by, for example, the Millennium Challenge Corporation set up by President Bush, which selects countries wishing to be considered for aid using scores based on sixteen indicators for good governance. The popularity of the Burnside and Dollar study appears, however, to be based primarily on what policymakers want to hear. The fact that this study has been roundly slated and is treated with distrust by a large number of academics has not resulted in any corresponding policy change. Roodman has also asked how credible it is for a study whose outcome is that aid may or may not result in more economic growth to affect how much aid is given. Tradition and national characteristics are much more influential than any study when it comes to the question of why Sweden and the Netherlands give more aid than the United States and Japan. Moreover, the global increase in aid during the past ten years has undoubtedly had more to do with the wars in Iraq and Afghanistan and with international mobilization campaigns like Jubilee 2000 (aimed at reducing the debts of developing countries) and Live Aid (31 March 2005) than with the outcomes of macro studies into the meaning of aid (Burnside and Dollar 200o; Djankov et al. 2006; Easterly 2008a; Kenny 2009; Riddell 2007; Roodman 2007a, 2007b, 2008).

If we resist the temptation to side with the policy cynics and adopt the view that research certainly can have an influence on political decisions - albeit often with a certain amount of delay - the conclusion may be very straightforward: that it is perfectly possible to show that progress has been achieved, primarily in the field of welfare indicators. It is similarly possible to evaluate concrete approaches and sometimes to compare them, and to provide an insight into results at project and programme level using different types of impact studies (White 2007). However, it would be going too far, on the basis of historical data, to actually link the provision of development aid in general to major shifts. That observation allows us to draw a range of different conclusions, but discontinuing aid is not one of them. The only option left open to people who consider this an unsatisfactory response is to be clearer in the future about objectives and resources, and to continue investing in research and innovative methodologies to acquire better insight into what aid is capable of. It is perfectly possible to evaluate whether specific programmes have led to poverty reduction in a specific country. 


\section{DESIGNING DEVELOPMENT AID}

Development aid can be inspired by a number of different motives simultaneously. The existence of different and parallel motives does not, in itself, have to be a problem since social activities are usually driven by a variety of motives. The task facing the political system is to weigh up all these motives and combine them into a manageable structure for implementation. This is, however, tricky if the different motives give cause to engage in practices which continually diverge. In addition, as chapters 3 and 4 showed, helping with development is a tremendously complex job. It is therefore no surprise that the institutional system is running into all kinds of problems. In this chapter we discuss five persistent problems in more detail: the goals (the priority of poverty reduction), the organization (the proliferation of aid), the approach (the belief in social engineering and one size fits all), the view of aid (the absence of an intervention ethic) and the scope (the inability to involve other policy fields).

\subsection{NARROWING DOWN: DEVELOPMENT AID BECOMES POVERTY REDUCTION}

The image of development aid that is projected in the media is dominated by the idea that it primarily focuses on helping people in difficult circumstances to lead lives which are, in some way, dignified. The standard image of development aid is one of water pumps, latrines, schools and doctors. As shown in chapter two, this has not always been the case. This image emerged in the 1970s, continued in the 1980 and 1990 , and is now a global phenomenon.

Development aid was not always oriented around direct poverty reduction. When it started to take shape as government intervention in the 1950s, its primary focus was on the accelerated preparation of countries for a situation in which they would be able to cope on their own. The economic growth required for development was clearly the reference point. Providing loans - in particular for infrastructure - and technical support coupled to capacity building were the most important instruments. At the time, confidence in the role of governments was high and developing countries initially experienced substantial growth. The emphasis shifted in subsequent years, due to factors in both donor and recipient countries. An important factor in the recipient countries was that, during the period of lower growth and attempts to reduce inflation (with high interest rates) which followed the oil crisis in the 1970s, regimes in Africa increasingly ran into problems, which meant that classical development instruments (financing and capacity building) were no longer effective. Governments proved unable to deal sensibly with the available possibilities for entering into loans, and capacity building was unable to take root in failing institutions. 
The 198 os were dominated by the structural adjustment programmes of multilateral organizations like the IMF and the World Bank, with their one-sided emphasis on macroeconomic stability and the "Get prices right' mantra" (Mkandawire 2010a). This was partly a response to state failure in developing countries and partly an expression of the Western spirit of the times (it was the era when Reagan, endorsed by Thatcher, claimed that "government is the problem"). Conditions were imposed on loans and governments forced to downsize. In a lot of countries this led to considerable internal problems and a failure to achieve the desired results. Academics, NGOs and developing countries criticized this approach and, when the negative consequences of this policy for sectors like education and healthcare became clearer, various UN organizations also started sounding the alarm. In 1987, Unicef published the critical study Adjustment with a Human Face, and in that same year the Brundtland Commission placed the environmental dimension of development on the agenda in the report entitled Our Common Future. In the 1990s, UN organizations played a major role in getting the social dimension of development put on the agenda. UNDP has published the Human Development Report every year since 1990 and, during the UN Social Summit in Copenhagen in 1995, education and healthcare were characterized as being of strategic importance for development and poverty reduction. The 20-2O initiative was also drawn up at this summit, according to which developing countries had to channel 20 percent of their public expenditure into social programmes while donors, in turn, were expected to reserve 20 percent of their official development aid for social programmes (Cornia et al. 1987; Stokke 20o9; World Commission on Environment and Development 1987).

The pressure from developing countries and in donor countries to focus more attention on poverty and on the social consequences of structural adjustment programmes increasingly made its mark in large international organizations. In 1996, the OECD/DAC published a report listing international development goals, and the related progress was outlined by the UN, OECD, World Bank and the IMF in 2000 in the joint report entitled A Better World for All. Critical NGOs rechristened the report Bretton Woods for All and urged the UN to withdraw its support for it. Finally, the World Bank published an innovative report on poverty to which Joseph Stiglitz and Ravi Kanbur made a major contribution, and whose main focus was on the fact that poverty is the result of economic, political and social processes which influence each other and can be mutually reinforcing. Reducing poverty is therefore not just about access to income, food, housing, education and healthcare, but also about increasing security and reducing risks, and about having a say and mechanisms for increasing resilience to negative shocks (IMF et al. 2000; OECD/DAC 1996; World Bank 2001; Yusuf 2009).

In practice, all these modifications to the dominant adjustment policy of multilateral organizations like the IMF and the World Bank of the 1980s have led more and 
more to the idea that development aid essentially has to take the form of direct poverty reduction and that poverty reduction primarily means caring for the poor. This led to the emergence, certainly from the 1990s onwards, of a development practice which focused primarily on improving direct living conditions. Infrastructural projects, strengthening productive sectors, and the necessary reinforcement of national systems of production and innovation (see e.g. Cimoli et al. 2009) became less and less of a priority for multilateral organizations, bilateral donors and NGOs. That trend is also clearly shown in the figures which the DAC publishes on aid flows. As the graph below shows, aid in the 'social infrastructure and services' category - in which the DAC includes 'population policy and reproductive rights', 'water supply and sanitation' and 'government and civil society' in addition to education and healthcare - has increased significantly since the end of the 1990s, while ODA contributions to economic infrastructure and services and to productive sectors have stagnated or even decreased. As regards economic infrastructure and services, there have been some recent changes, but expenditure for productive sectors is still well below the level of the mid-1980s.

\section{Figure 5.1} Total ODA of all donors per sector

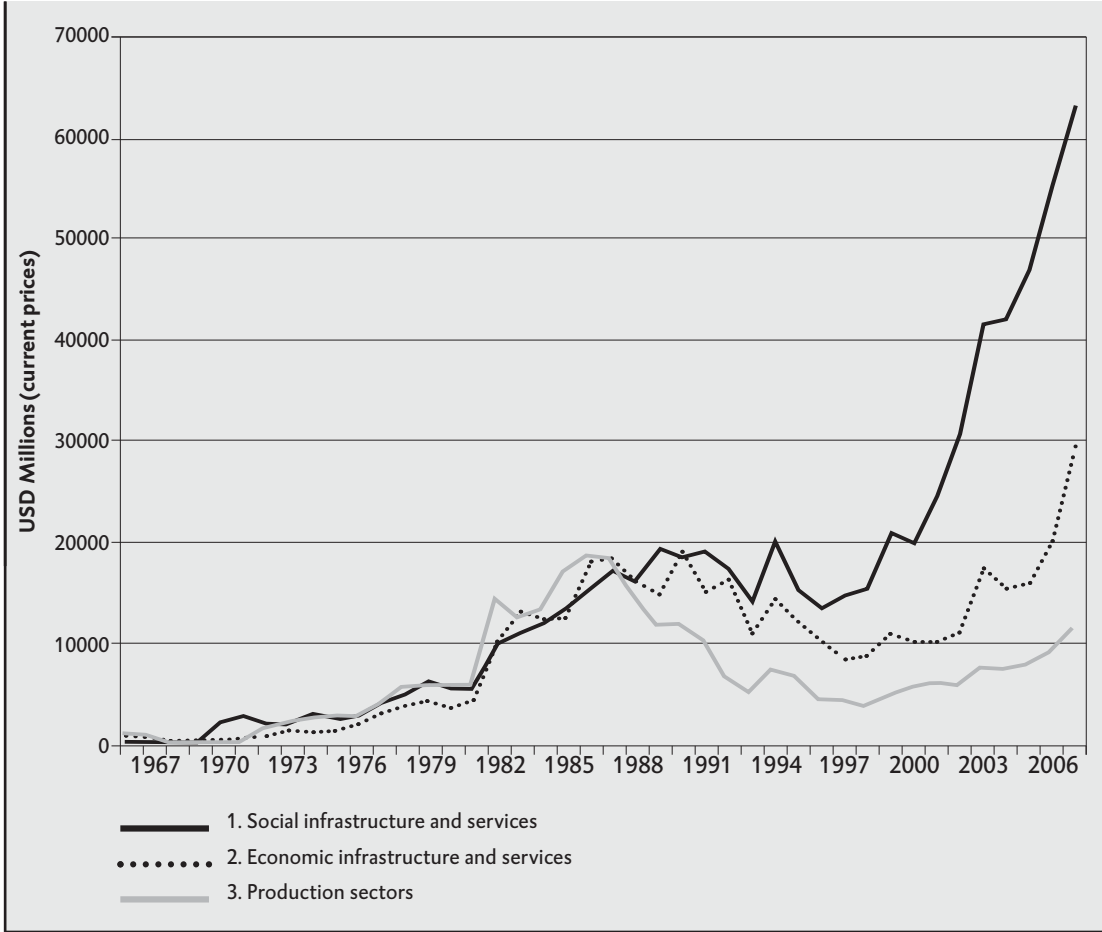

Source: Own calculations on the basis of OECD/DAC data 


\section{Target group policy}

Investing in social sectors is not the same as poverty reduction, but does represent a shift in emphasis, as a result of which the physical and economic structure receive little attention. The step towards poverty reduction is then a small one, and one that many donors, both governments and NGOs, have taken. The term 'poverty reduction' has since become a widely used, and apparently self-evident, term. To many it has become the goal of development aid. Given that people are familiar with the metaphor of the fish and the fishing rod, they usually add that the 'real' intention is for people to be able to fish themselves. Plenty of examples can be given of activities which indeed resemble the distribution of fishing rods, although there was not always a river nearby. However, a lot more activities have come to resemble the distribution of fish. One complicating factor is that reducing development aid to poverty reduction is often accompanied by poverty reduction in turn being reduced to the provision of direct services to the poorest.

From this perspective, development aid has come close to target group policy, and that makes it impossible to imagine situations in which poverty can be tackled more effectively by investing in an emerging middle class which can function as a motor for economic growth and employment. What is more, the poor benefit from the rule of law, property rights, taxes for the financing of public goods such as education, social provisions and healthcare and more accountable government as defended by the middle class. The real trade-off when making choices, according to Birdsall (2010), "may well be between the rich and the rest, and between short-term stability or high aggregate growth that preserves the status quo benefiting a small minority at the top of the income distribution versus the political risks and lower short-run growth of financial, tax, social insurance, country market and other policies that are conducive to building a middle class and, as it turns out, pro-poor as well." An excessively narrow direct focus on the poorest will, for example, often lead to the strengthening of primary education in rural areas, but insufficient attention for secondary and higher education, and with that the formation of the middle classes. Thandika Mkandawire who, for eleven years, was head of UNRISD, the UN research institute in the field of social development, and is currently the first professor of African Development at the London School of Economics, neatly summarizes sixty years of development: "With respect to Africa at least, 'development' is being watered down to poverty reduction, and the narrow concern of social policy is social protection without the transformative attributes that have been so central to successful development. And so, although poverty is now discussed in the context of governance, economic growth, stabilization and security, there appears to be no coherent and consistent framework that can tie these together in a developmental way" (2008: 111).

In The Bottom Billion, Paul Collier (2007) adopts the position that the term 'structural poverty reduction' is an invention by the PR department of the World Bank 
to bridge the traditional discrepancy between 'aid' which was often 'left' in nature, and 'growth' which, back then, appeared to be primarily associated with 'right'. Whether this is a correct historical representation is doubtful. The term was in any event already being used in policy documents in the Netherlands at the end of the 1970s. However, inherent in the term is a real tension, which has only increased in the meantime. On the one hand there is aid, which is increasingly expected to be concrete, demonstrably effective and directly benefit the poor. On the other hand there is a growing realization that development is a complicated process which, even if it were easy to influence from the outside, cannot in any event be reduced to direct poverty reduction and whose effect on the poor is not always immediately evident because of the role usually played by context-dependent "tensions and tradeoffs between strictly pro-poor and more inclusive and sustainable 'middle class' growth policies” (Birdsall 2010).

In this context, interesting parallels can be drawn with debates conducted in the West on social care. At the end of the nineteenth century the question was whether care for the poor ought to be replaced by mass education. At the beginning of the twentieth century the question was whether prevention in the form of clean water and health education would not be better than curative care, and at the end of the twentieth century the question was whether the primary function of the social security system ought not to shift from providing compensation for lost income in the event of redundancy to providing guidance in finding other paid work. In the context of development aid the same question can be asked, namely whether it ought not to focus on reinforcing people's self-reliance instead of alleviating poverty.

\section{MDGs: solution or problem?}

An important manifestation of the popularity of poverty reduction is the Millennium Development Goals (MDGs). The eight MDGs (including halving poverty, stopping the spread of HIV/AIDS, and primary education for everyone in 2015) were formulated after the UN millennium summit of September 2000, the largest gathering of world leaders ever to take place. The goals were the culmination of a number of world summits relating to special themes during the previous decade and a continuation of the document referred to above published by the OECD in 1996 (OECD/DAC 1996; Stokke 2009). From that moment on, Western donors adopted these goals as the point of departure for policy. They were given a significant boost when donors decided to invest substantially in the goals of Monterrey in 2002. Three years later the G8 met in Gleneagles and Prime Minister Blair had all the government leaders present show their commitment to the MDGs by signing - in full view of the cameras - a pledge to double their development aid budgets by 2010 at the latest. The MDGs enjoy broad support in the world of development aid and have become reasonably well-known outside that realm as well. They also offer a focus for efforts in the field of development aid and enable 
results to be measured. However, the MDGs are largely static goals which are strongly oriented around alleviating emergencies. They say nothing of the resources, the strategy and underlying mechanisms required to achieve the goals, nor about the capacities of societies to develop, and from a macroeconomic perspective they are rather vacuous. In that sense they are not very developmentrelated. Economic growth is not included as a final or intermediary goal in the MDGs, and important issues like transformation of the productive sectors are not even referred to. Although MDG8 does refer to the need for a fair trade system, this can only make a very limited contribution to the creation of productive national economic sectors.

The MDGs are inspiring but also problematic in that they detract attention away from structural changes and the strengthening and transformation of agriculture and other productive sectors. They have other drawbacks as well. The targets are not only arbitrary, they are also global goals which are directly applied to each individual country. According to Vandemoortele (2009), one of the architects of the MDGs at the UNDP, this was not the intention. The MDGs have to be achieved collectively and not necessarily individually but they have been wrongly interpreted as one-size-fits-all goals. The majority of the goals have been formulated in relative terms, meaning that they are de facto primarily unfair for many countries in Africa and other countries with low incomes. With the best will in the world, a number of MDGs cannot be achieved there, even if, for example, countries experience an annual increase in the number of children who attend primary education several times higher than it ever was in the West. The failure of many of these countries and 'Africa pessimism' are already built into the system. The question is therefore, according to Vandemoortele, "whether Africa is missing the targets or whether the world is missing the point". This problem has everything to do with the fact that donors imposed their mark heavily on how the goals were formulated. As yet, no clear answer has been provided to the question of how that links up the broad related idea of 'ownership' in the field of development. In order to achieve a true partnership of equals, any follow-up to the MDGs after 2015 will have to be more development-oriented and less donor-driven (Easterly 2007; Severino \& Ray 2009).

Lastly, doubts can be expressed about the large publicity and mobilizing value of the MDGs. The term 'MDG' is generating its own rhetoric on the basis of which suggestions are being made which are not adequate in all cases. Take, for example, the notion of the poverty trap, a term which was linked strongly to a lack of money - despite it being debatable whether the problems in parts of Africa do not have more to do with a shortage of human, social and institutional capital than with money (Birdsall 2007b). The superlative degree of this is the notion of the War on Poverty. Mistry sums it up perfectly by saying, "Wars on poverty are about as winnable as wars on terrorism and wars on crime" (2005:676). In the first 
instance such terms appear to be suitable for motivating people, but they detract from the real demand for underlying mechanisms, ignore the need to engage those directly involved in formulating goals, and suggest that simple solutions are possible for complex problems.

\section{What about emergency aid?}

If there is one area which, in the first instance, has escaped the criticism of poverty reduction's limited scope, it is emergency aid in the event of disasters. There appears to be no debate about the usefulness of this form of aid - which was worth around 15 billion dollars in 2006, of which two-thirds came from governments. The 'evidently good' character of emergency aid is also the image presented to the outside world. The prototypical example of recent years is the tsunami, which devastated parts of Asia in December 2004. A major appeal for help was made to the populations of Western countries, resulting in a great deal of aid being provided, even too much in many instances. If you were being benevolent you could regard this as a minor flaw from which we can learn. However, closer inspection leads to the more general conclusion that an excessive focus on projects aimed at saving lives visibly and acutely is also a dangerous form of reduction.

The problem starts with the question of what a disaster actually is. You cannot define disasters in terms of the event itself, but you can define them in terms of consequences. A natural event becomes a disaster if a country or group of people was insufficiently prepared for it. Whether houses are destroyed by earthquakes or tidal waves depends partly on the location and the way in which they have been constructed. While events can sometimes be understood as an external calamity (earthquakes just happen from time to time), the extent to which people are prepared is largely dependent on their skills and living conditions. The scope of a disaster is connected to the institutional strength of the country in which it takes place. Fewer people die in places where there are rules about how structurally sound a house should be and where the emergency services have a high level of expertise. That lesson also applies to countries in the South: in the 1980s, food production in Zimbabwe declined by as much as it did in Ethiopia, but one of these two countries had a good safety net and the other did not, and that is why Zimbabwe did not need any aid and Ethiopia did. The same lesson applies to Hurricane Katrina in New Orleans where the city was not properly prepared for such a storm, while Dutch dykes would have been able to resist the storm tide without any problem whatsoever. In that sense, therefore, disasters are social occurrences and not just physical ones. In addition, many such events are not natural phenomena, but social phenomena. While this is very clear in the case of armed conflicts, it is no less the case as regards hunger - given the fact that more than enough food is, and can be, produced in the world, hunger is a financial, technical, political and logistical problem, rather than a natural phenomenon. This is 
reflected by the fact that, in fifteen of the twenty-seven countries in which the World Food Programme (WFP) provided food aid in 2007, the cause of food shortages was civil war.

The fact that many disasters are essentially manmade - you could even say that disasters have become 'naturalized' - attracts scant media attention. This is understandable from the logic of the media. However, the consequences for aid are problematic since it means that emergency aid is structured as a short-term intervention, while scarcely any is devoted to questions such as how and where reconstruction has to take place in the future. In conflicts this kind of problem has an even greater impact. Any form of aid is an intervention in an existing power system, and can have a disruptive effect on it. If a choice has to be made for one of the conflicting parties, the situation becomes practically impossible. Based on official ideology, emergency aid should be provided without showing any favouritism, but this is usually an illusion. An ideal case in point is the aid many Western NGOs gave to the Hutus ousted to Congo when the Tutsis took over military power in Rwanda, after initially being the victims of mass slaughter. The refugee camps accommodated not only a lot of the old génocidaires but also provided a location where Hutu militias could regroup. This was something Western NGOs clearly did not know how to deal with, all the more because their headquarters in the West had been exposed to scenes of humanitarian suffering on a massive scale (Polman 2010).

In a word, emergency aid appears to be the most evident way to provide direct alleviation in emergencies and, at first sight, its value cannot be called into question. However, a closer examination reveals that narrow-mindedness can play a role in this case as well, if this aid is perceived purely as a form of direct poverty reduction. The success of emergency aid is very closely linked to the answer to the question of how countries structurally develop.

\subsection{FRAGMENTATION: MORE AND MORE CHAOTIC ORGANIZATION}

In practice the goals of development aid have significantly narrowed over time into visible poverty reduction. This is reflected in the organization pattern of development aid. Practice shows a proliferation of development organizations. Every year more countries and donors become involved in the field of official development aid. Around thirty years ago, the majority of aid to developing countries still comprised direct support by governments and multilateral organizations, with less than 1o percent coming from Western NGOs and the private sector. At the moment, the share of NGOs and large private foundations is estimated to make up one-third of aid flows (IDA 2007; Riddell 2009). At global level the scope of the aid provided by this proliferation of small initiatives is already at least 25 billion dollars (Edwards 2009a), although some estimate that this amount is in 
excess of 40 billion dollars (Kharas 2007). A total of more than 18 , ooo crossborder NGOs are involved and, in the United States alone, the amount provided via private channels has quadrupled during the past decade. Large new funds, such as the Bill and Melinda Gates Foundation, specialize in a limited number of sectors in which they cover the entire chain, from research and development to the delivery of services. In 2005, these 'vertical funds' represented 7 percent of multilateral aid (Brainard and Chollet 2008).

The largest NGO in the world, World Vision, has a budget (1.6 billion dollars) that is bigger than that of donor countries like Ireland and Finland. In addition, it is no longer only Western NGOs that are involved. Since the beginning of the $1980 \mathrm{os}$ there has also been a proliferation of Islamic NGOs. Some have links with radical Muslim brotherhoods and others are usually affiliated to governments or mosques. Many a mosque, school or hospital is financed in this way in Mali, an Islamic country, but the same applies to the north of Ghana or Nigeria - countries which have a predominantly more prosperous south, which tends to be more Christian, and a poorer Islamic north. Another example is the Aga Khan organization, an Islamic institution which carries out large-scale commercial activities (it owns the Serena chain of hotels) and which donates 150 million dollars a year to projects in Africa and Asia.

\section{New donors}

Besides the proliferation of NGOs, and the interest in development from the business community, the fact that the world has changed substantially in a political sense also has consequences for aid architecture. For example the new member states of the EU have become donors and have promised to allocate 0.375 percent of their GDP to aid in 2015. However, the changes go beyond this. While the world in the 1980 os was dominated by two power blocs and in the 1990 os by just one dominant power, it has since become multipolar. The emergence of countries with increasingly strong economies, like China, India and Brazil, wealthy countries in the Middle East and population-rich countries like Indonesia, Vietnam and Pakistan, means power relations have radically changed from what they used to be ten or twenty years ago. The changes are also set to continue for some time to come. By 2050, the economies of the E7 (the seven largest emerging economies) are expected to be twice as big as those of the G7 (the seven largest economies at this time).

An important new element in international relations is that China, India, Brazil and other countries in the South have started giving aid. Even Thailand recently started giving development aid to Bangladesh. China is already a larger donor than Australia, and has indicated that it is going to increase its aid to 10 billion dollars in the coming three years. China calls this aid 'foreign assistance' and says that it is intended to compensate 'economic imbalances'. In practice this means that aid from China is always part of a broader economic agreement and is arranged by the 
Ministry of Trade. China therefore has an emphatic presence in Africa, but it basically comes down to trade with a limited number of countries. This does not detract from the fact that Chinese activities in Africa are of real importance for the actual or potential roles of Western donors. For example, the China Development Bank, an important vehicle with which the Chinese government finances infrastructural and other development activities, regularly announces the availability of new funds “to support African countries' agriculture, manufacturing, energy sector, transportation, telecommunications, urban infrastructure, resource exploration and the development of Chinese enterprises in Africa" and expresses the ambition of having a larger portfolio than the World Bank in a few years time.

The significance of the activities of the new donors is much greater than can be deduced from the scope of their financial efforts alone. China attracts a lot of attention because it provides aid according to its own logic and does not take refuge in global standards regarding, for example, governance or transparency. A positive consequence of this for developing countries is that they have greater choice and can be more selective. However, it also applies pressure on the traditional donor community to reconsider current agreements on the provision of aid (Kaplinsky 2009; Kobayashi 2008; Kurlantzick 2007; UNCTAD 2008c).

\section{The effect}

From the perspective of recipient countries, the situation this all has created is chaotic. This is reflected in the figures. In 2007, there were 14, ooo donor missions active in fifty-four countries. Vietnam, for example, sometimes even received three missions per day. The continuing proliferation of aid activities also speaks volumes. In 2005, three times as many 'aid transactions' - defined as the allocation of funds for a specific activity (project or programme) in a recipient country - were registered worldwide as a decade before: 60,000 rather than 20,000. In 1960, a recipient country would be dealing with 'only' twelve donors. By 2005, this had risen to an average of thirty-three. While, in 1990, not one aid-receiving country had to collaborate with more than forty individual donors, these days this is true of at least thirty. More donors does not, by definition, mean more aid since the 'chunks' of aid are in fact getting smaller. In the same period the average scope of the transactions actually decreased by one-third, with 85 percent of projects involving less than 1 million dollars (Kharas 2007). The consequences of this for recipient countries are shown in figure 5.1.

Aid fragmentation is expensive. Donors incur a lot of indirect costs while identifying problems, negotiating, recording agreements, implementing, monitoring, evaluating and coordinating activities. A report for the European Commission estimates the indirect costs of aid activities organized by the EU at between 1.9 and 3 billion euros. If those projects were replaced by coordinated budget support, those costs would have been just 0.9 billion euros (European Commission 20ogd). 


\section{Figure 5.2 Aid architecture for recipient countries}

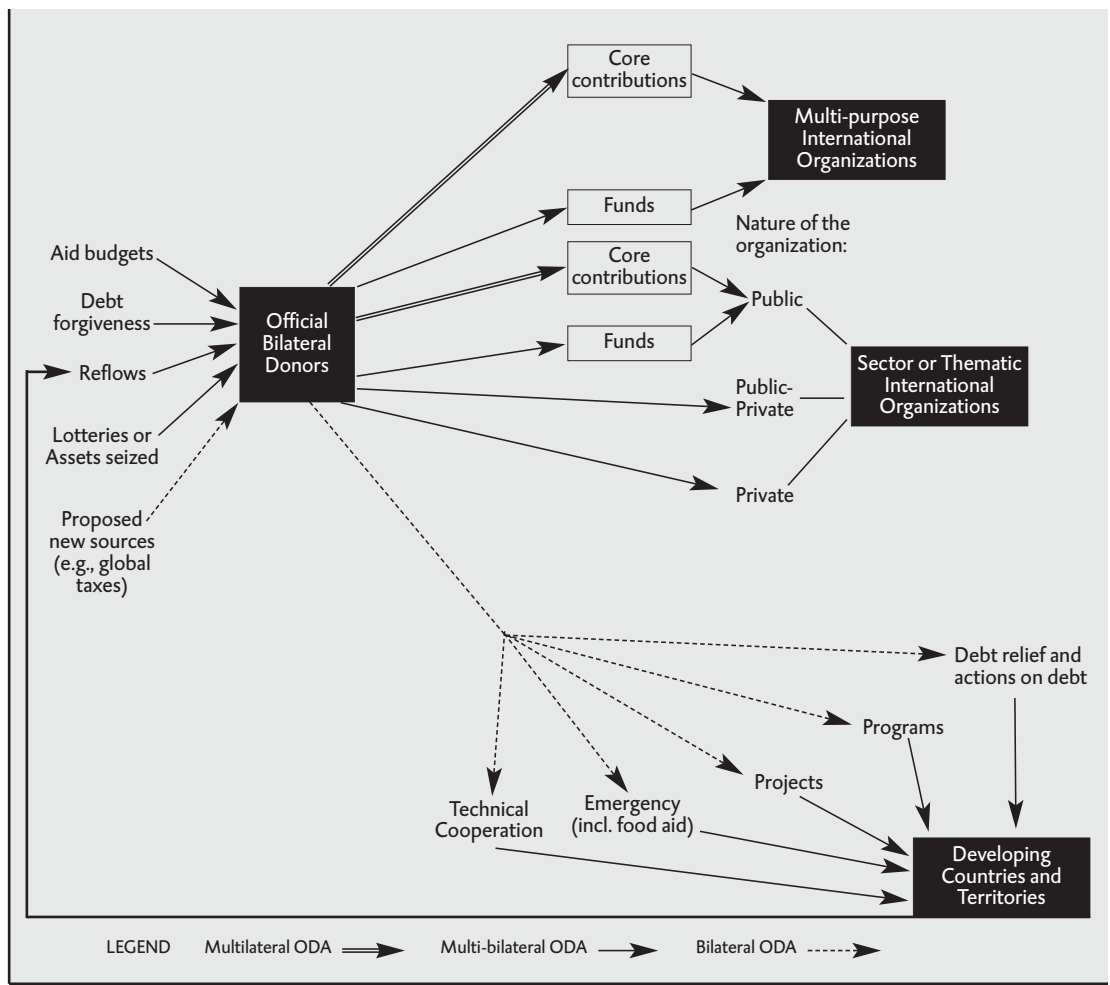

Source: IDA 2007

The indirect effects are even more expensive: fragmented aid is a burden on the already weak institutional capacity of developing countries (Acharya et al. 2003; Birdsall 2008; European Commission 2009d; Knack \& Rahman 2008). The number of missions alone lays a huge claim on the time and capacity of government systems and Southern NGOs. It is therefore understandable that Tanzania has a missions freeze during the months that the budget is drawn up. A poignant aspect is that the fragmentation of aid is most acute, and therefore most damaging, for recipient countries with the smallest institutional capacity (Kharas 2007). Apart from the burden, fragmented aid makes it increasingly difficult for governments to develop consistent, long-term policy, since NGOs, vertical funds, bilateral donors and international organizations all have varying wishes and desires. Moreover, each project financed by donors has a different goal, with different monitoring and evaluation rules. All this fragmentation also has a humiliating effect, because it means that developing countries have to say 'thank you' far too often. 
The fragmented aid architecture is a good example of the discrepancy between micro and macro rationality. Although all the parties involved really want to do things differently, and although there is no lack of speeches and conferences during which people advocate more coherence and cooperation, the net result of all the well-intended individual decisions is an aid maze, rather than well-organized and efficient aid architecture. This leads to a suboptimal use of aid funds. Every donor applies its own criteria and priorities to the allocation of aid, but there is no mechanism or 'invisible hand' ensuring that all those individual decisions add up to optimal social effects. For example, UNCTAD observed that there is no significant correlation between the income per capita of a country and the quantity of aid it receives per resident, although you would expect countries that need that aid most to receive more. Like birds of a feather donors tend to stick together (see also OECD/DAC 2009a).

\section{A solution?}

Western countries have tried to counteract aid fragmentation, but without a lot of success to date. In March 2005, in the Paris Declaration, 108 countries, twentyfour development organizations and twelve civil society organizations promised that they would immediately start coordinating aid, that they would arrange a division of labour and that lead donors would be appointed per country. It was also agreed that as much aid as possible would be given in the form of general or sectoral budget support. The non-binding code of conduct of the EU also states that donors are allowed to be active in no more than three sectors. These intentions were reconfirmed in the Accra Agenda for Action (2008), and within the European Union in the Triple $C$ evaluations (EUHES 2007).

The evaluations of the Paris Declaration show that progress has certainly been made, but that it is being made very slowly (OECD/DAC 2008a). In a very limited number of countries - Uganda is usually referred to as a success - a joint strategy exists whereby funds are 'pooled'. However, in the majority of developing countries cooperation like this rarely gets off the ground. A lot of donors are restricted in their freedom to make joint agreements. Sometimes this is down to their capital city - Paris is infamous for this - or to the strict rules of their own organization, as in the case of the World Bank or the UN. A significant number of donors, such as NGOs, vertical funds and countries like China, play no part at all in attempts to coordinate. Bilateral donors do choose a limited number of sectors in which to invest more often, but it is still common for more than ten EU donors to be active in a specific sector in a developing country (European Commission 2009).

A second way of combating fragmentation is to exchange project support for programme support, preferably in the form of general or sectoral budget support. At the level of a developing country, that ambition is only visible to a very limited extent. In the fifty-five developing countries investigated, only 22 percent of the 
Country Programmable Aid is sectoral and general budget support (OECD/DAC 2008a). If countries fulfil the conditions of good governance, they are in principle eligible for general budget support. In 2008, this represented however only 3.8 percent of the entire ODA budget and around 14 percent of the bilateral budget. Sectoral budget support is more common, with for example around 30 percent of Dutch Country Programmable Aid provided as sectoral and budget support (OECD/DAC 2008a). In countries like Uganda, Ghana, Burkina Faso and Mozambique between 40 and 50 percent of bilateral aid consists of budget support (ІОВ 2008a). All in all these figures suggest that project aid is still usual on a global scale, and this applies to the Netherlands as well. In 2005, of all bilateral aid, the Netherlands still spent 40 percent on project aid (Іов 2008a).

Another way of combating fragmentation of aid is for recipient countries themselves to take on the coordination role. This is by no means impossible. For example, in the 199os, Vietnam was already assigning its donors into neat groups, so that it could decide per group who was allowed to talk to which minister and when. Similarly, India has only cooperated with six large donors since 2003. African countries are less well organized and more dependent on aid, and are rarely able to adopt such successful approaches (Whitfield 2009). Less than 25 percent of the countries that received aid in 2007 had a long-term strategy linked to a form of budget distribution, and less than 10 percent had a frame of reference with which aid activities could be assessed and monitored (OECD/DAC 2008a).

\section{Citizens}

The incredibly varied range of aid organizations is further complicated by the recent trend of individual citizens also wanting to play a role which goes beyond contributing to charity and donating to organizations. A growing number of people are keen to 'do something good'. Schools initiate projects to support an orphanage in Ghana. Employees devote their time and energy to help realize a water project in Tanzania. Local authorities and organizations cooperate on twinning projects with counterparts in developing countries. One example is the partnership between the Amsterdam police and the police in Paramaribo. 'Europe's largest employment agency for professional volunteers', PUM, sends mostly retired senior experts out to developing countries for a couple of weeks. On top of this, a growing number of people set up foundations after a holiday. These are referred to as MONGOs (My own NGO). They often focus on straightforward work like building a school or shipping medicine. The people behind MONGOs are usually affluent, well-educated and over-fifty, and often hold the view that existing aid routes via the government and Western NGOs are not efficient enough. They believe that, if they do it themselves they will be certain that 'something will actually get done'. They act on the basis of a feeling of solidarity and often hope that they will gain life experience in return. No one can be completely sure how 
many people are 'doing it themselves'. In a country like the Netherlands there are estimated to be around 6,ooo. There is an increasing organizational focus on support and the combining of these initiatives, for example via large Western NGOs.

The engagement and moral energy of these citizens as regards development policy leads to all kinds of results: "The orphanage has been built, the hospital renovated, the school extended to include three extra classrooms and an income-generating goat project has been started" (Kinsbergen \& Schulpen, 2010: 33). This does not mean that sustainable and structural development is taking place, as shown by research by Lau Schulpen (2007a) into private practices in Ghana and Malawi. New private initiatives can therefore best be regarded as humanitarian aid and not as development aid. Moreover, many of the mistakes made in the past are being repeated. Projects do not link up very well with demand in the countries themselves, the attitude is often one of disparaging paternalism, there are hardly any transfers and very little evidence of sustainability. What is more, people who 'do it themselves' are often not sufficiently aware that other actors play a role, such as local governments. Even if people do realize that their aid increases dependency, they tend to be unaware of what they can do to counter this.

Governments do not really know how to respond to these initiatives. On the one hand they want to encourage citizens to do good. At the same time there are risks. Citizens not only have to realize that their interventions can have inadvertent and damaging consequences, they also have to try to avoid them. Failure to do so means that there is a risk that expectations will be aroused which cannot be fulfilled, and that projects which are not attuned to local governments will violate democratic principles. Despite being difficult to implement, a code of conduct would therefore appear to be a minimum requirement. The problem is that Western countries are not willing to do just that.

\subsection{DELUSIONS OF GRANDEUR: THE CONSTANT LURE OF SOCIAL ENGINEERING}

As shown in chapter 3 , there is no all-embracing theory of development. Academics and policymakers have been searching for such a theory for a long time. The dominant idea was that, if the right buttons of the political and economic system were pressed, countries would develop of their own accord. The question was what 'the right buttons' were. Although development experts repeatedly thought that they had discovered the crucial missing variable for development, in reality it was not as easy as they had thought.

In a review of the first five decades of development after the Second World War, leading development economist Irma Adelman (2001) observed that nowhere had 
so many abrupt paradigm changes taken place in the field of economics as in development economics. She identified seven 'open sesame' factors which, in various partly overlapping periods, were dominant as clarifications of slow development. These were a lack of physical capital (1940-1970), too little entrepreneurship (1958-1965), incorrect relative prices (1970-1980), too little international trade (1980-), hyperactive governments (1980-1996), the quality of human capital (1988-) and, lastly, ineffective governments (1997-).

These paradigms were not only printed in economic journals, they were also repeatedly used as a basis for policy. Only slowly did it become clear that simple frameworks and trendy fads do more harm than good and that it is counterproductive to keep looking for universally applicable policy formulas for development. The dominance of what Adelman calls the 'keep it simple, stupid' (or KISs) principle has had damaging consequences for everything and everyone involved in development. It led to mono-causal explanations which distort history, simple success indicators which do not take any account of contexts and path dependencies, and sustained the entirely false idea historically that development is a linear process (Adelman 2001; Easterly 2001a, 2006; Rodríguez 2007; Rodrik 2007; Thorbecke 2007).

Simple explanatory frameworks are accompanied by the belief in the possibility of social engineering, and therefore the idea that societies can be specifically changed by adjusting a few variables (Scott 1998). That idea is not unique to development policy - a lot of government policy in the West is saturated with it. However, development policy is the most extreme variant: nowhere were the ambitions greater, the theories more limited and the moral rhetoric more compelling. This also has to do with the intellectual order of battle of policy advisors. Policy at organizations like the World Bank was determined for a long time solely by economists and no one else. Gradually, political scientists started to play a role as well when the theme of governance was discovered in the 1990s. Cultural anthropologists do not feature in bodies that determine policy. They appear averse to policy and, conversely, policy does not offer any scope for their insights because they are not easy to translate into generally applicable formulas for action. Rodrik (2007) refers to these large frameworks as presumptive theories.

\subsubsection{CAPITAL AND IMPORT SUBSTITUTION AS A REMEDY}

After the Second World War, newly independent governments in emerging countries primarily looked to economists in the United States and the United Kingdom for advice on how to approach development. The literature on development was dominated by economists who focused on economic growth and paid only scant attention to broader processes of social, cultural and political development. The unsung chroniclers of United Nations intellectual history (Jolly et al. 2004) 
concluded that the focus and emphases would have almost certainly been different if sociologists, anthropologists or political scientists, rather than economists, had been in charge of development policy. However, that was not to be.

The first generation of development economists who appeared on the stage shortly after the Second World War were visionaries and worked with large-scale theories and general macro strategies. These economists were influenced by experiences with the systematic industrialization of the Soviet Union, the economic management of governments during the great depression, the mobilization of sources and resources during the war, and the Marshall Plan support at government level for the reconstruction of Western Europe. On the basis of that experience they centred their ideas on developing countries on structural transformations designed to foster economic growth, with the state being assigned a substantial role. Famous names in that period include Rosenstein-Rodan, Myrdal, Nurkse, Fleming and Hirschman. According to the dominant paradigm, governments of developing states were supposed to encourage the accumulation of capital, ensure that the large reserve of surplus labour was used productively in their countries, develop policy for specific industrialization by using import substitution to counteract the detrimental consequences of the inelastic export yields, and use planning and programming to coordinate the allocation of the available sources.

Within this approach, foreign aid was crucial in order to finance investments since the export of natural resources would, for the time being, generate insufficient foreign currency. The thinking of this first generation of development economists was characterized by external pessimism and internal optimism. Their outlook was sombre as regards the possibilities for export, but they expected rapid expansion of the public sector and development of a broad government policy (Krugman 1993; Lin 2009b; Meier 2001; Yayawardena 1993). Although some of the pioneers (such as Hirschman) were sceptical, planning was fairly generally regarded as an important instrument for development. A UN expert group published a report in 1963 which advocated a role for the state comparable to what would later be referred to in the context of Asian 'wonder countries' as a developmental state. In 1966, the Committee for Development Planning (CDP) started its work as part of ECOSOC, under the leadership of Jan Tinbergen.

Development economists at the United Nations assumed that an exceptionally large leap forwards would be needed to create the initial conditions for development, which they interpreted as being self-perpetuating economic growth. Most attention was therefore paid to initiating economic development, with industrialization at the heart of the process. The pioneers of the development economy often used attractive metaphors to describe their goals: Lewis talked of a 'snowball', Rosenstein-Rodan of a 'big push', and Rostow of a 'take-off'. In particular, 
Rostow's (1960) stages theory of economic growth played a prominent role. This theory propagated the idea that the process towards a developed economy is linear and includes a number of successive stages: the 'traditional society' is followed by the 'conditions for take-off' and then the 'take-off' itself. Rostow, who based this theory on the development of the United Kingdom, believed that other countries ought to adopt the same approach as well. That assertion faded when other researchers voiced theoretical criticism (for example Rostow failed to respond to the question of when a stage exists, and which conditions are necessary for a country to progress to the next stage) and they demonstrated that the United Kingdom was sooner an exception than a rule suitable to be elevated to the status of generally applicable model (Crafts 2001; Jolly et al. 2004).

The 'dependency school', which made a significant contribution to development thinking at the end of the 196 os and the beginning of the 1970 s by approaching development in a less one-sided economic way and along more political science and sociological lines, was similarly critical of Rostow's stages theory and of modernization theories in general. Both the reformist trend within this school, whose proponents included the future Brazilian President Cardoso and the future Brazilian Minister Furtado, and Marxist supporters like Gunder Frank and Dos Santos, adopted the viewpoint that Latin America was held in a situation of 'dependent capitalism' due to its position in the international division of labour. The periphery would only manage to put an end to the exploitation if it were to detach itself from the centre. Dependency could be avoided through (in the words of Samir Amin) de-linking from the world economy and introducing a subsequent development pattern based on self-sufficiency. The assumption that only de-linking would generate opportunities for growth, turned out to be too pessimistic, since some countries in the periphery certainly did experience a process of rapid accumulation without becoming isolated. In the meantime, however, the dependency school had put the importance of external causal factors for underdevelopment on the agenda. It would feature in the debates on a New International Economic Order (see below) and in the work of UNCTAD.

The models and policy recommendations of the first generation of development economists came in for fierce criticism when a number of limitations and problems became clear. For example, the concentration on physical capital accumulation turned out to be too restricted and investments in productive workers (human capital) through the expansion of knowledge, healthcare and skills were placed on the agenda. Experiences with negative consequences of government interventions also caused many economists to become disillusioned about the possibilities of programming and planning development since unemployment turned out to be persistent and poverty continued to exist on a large scale. A lot of economists blamed governments' market-disruptive policies for these disappointing results. These policies paid too little attention to agriculture, supported ineffi- 
cient state companies, and ignored the negative consequences of industrialization on the basis of import substitution. At the end of the 1960 and the beginning of the 1970s, some former supporters of development planning therefore started talking about a 'crisis of planning'. They highlighted deficiencies in many of these plans, the often faulty information, unforeseen disruptions to national economic activities, and institutional weaknesses in developing countries. The first generation of development economists regarded government interventions as an essential remedy against market failure but, in the meantime, many economists had started concluding that those interventions often resulted in market failure.

\subsubsection{THE WASHINGTON CONSENSUS}

The second generation of development economists that emerged from the end of the 196 os onwards lacked the vision of the first generation, and was "almost moralistic, committed to a sombre realism based on fundamental principles of the neoclassic economy" (Meier 2001). Aggregated macromodels fell out of favour and were replaced by the new standard of disaggregated microstudies with production units and households as the basic units of analysis. The famous names from this period included Bauer, Bhagwati, Harberger, Lal and Krueger, who was chief economist at the World Bank from 1982 to 1986 and who, sometime later, served as (vice) president at the IMF. Governments of developing countries were now told to rectify every price disturbance - 'get prices right' - but also to ensure that all their policies were in order - 'get policies right'. The very diverse performances of developing countries were no longer explained on the basis of differences in initial conditions, but were considered to be the result of differences in policy. Unfavourable external circumstances were no longer a valid explanation of the lack of economic progress, which was seen as a consequence of inadequate internal policy. Consequently, countries were required to break with inward-oriented strategies for development, to liberalize their trade, privatize state enterprises and submit themselves to stabilization programmes according to the dominant consensus of the 1990s.

The policy considered necessary for this would be based on stabilization, liberalization, deregulations and privatization. The idea was that the IMF would contribute by imposing strict conditions (conditionalities) on loans, while the World Bank would do the same by linking loans to structural adjustment programmes. In the process, the Bretton Woods institutions gratefully benefited from the fact that many developing countries were forced to approach them when they were hit by the international debt crisis in the 1980 os (Solomon 1995). This crisis came about in the aftermath of wholesale changes in the world economy in the years after the 1973-1974 oil crisis. The international shift towards neoliberal policy dates from this time, but the problems for a lot of developing countries became truly sizeable when the central banks of the rich countries - led by the 
United States - drastically increased interest rates in October 1979 in order to counteract increased inflation. Mexico has the dubious honour of having initiated shockwaves on the international financial markets in August 1982 with the announcement that it was the first country no longer able to pay its debts. Other developing countries followed, and the IMF and the World Bank were put in charge of the 'creditors' cartel' in which banks and creditor countries were represented (Krugman 1993; Meier 2001; Toye \& Toye 2004; Treillet 2002). The structural adjustment programmes (SAPs) usually boiled down to the marketization of government services and reducing bureaucracy. This policy turned out to be disastrous for African countries in particular, since the government apparatus's ability to act ended up falling below the level it was already at, and the population's level of education also dropped (Easterly 2006; Evans 2004; Fukuyama 2004; Mkandawire 2001; Molenaers \& Renard 2007). On top of this, privatization increased corruption in a lot of places and turned the government and politics into more of a business opportunity. Numerous countries which the IMF and the World Bank had ordered to privatize were already privatized because they were owned by the president and his supporters. The fact that, without a legal framework, privatization can have huge disruptive effects became painfully clear in the 1990s in Russia. The situation in Africa was no different - just more poorly documented.

Of course there were also counter movements. Within the United Nations there continued to be scope, even in the 1970s, for criticism of the dominant paradigm and less orthodox approaches to development. The well-known economists who worked within the UN on behalf of countries from the South included Kalecki, Kaldor, Prebisch and Singer, and Jan Pronk in the Netherlands. The developing countries within the UN started to cooperate more and more, with the important turning point being the setting up of the United Nations Conference on Trade and Development (UNCTAD) in 1964. The increased capacity of countries from the South to act within the UN culminated in proposals for a drastic restructuring of the international economic, financial and political relationships into what became known as a New International Economic Order (NIEO) (see table 5.1).

Proposals and initiatives of the G77 developing countries for realizing an NIEO dominated the North-South agenda in the first half of the 1970s. Eventually this did not lead to much because most developed countries wanted nothing to do with real reforms of the world economy. Instead of achieving the stronger position they hoped for within a fairer world order, the developing countries found themselves facing an international neoliberal agenda in the 1980 s. The contrast could scarcely have been greater. While, after the Second World War, the focus was on national sovereignty and control of one's own economic activities, the emphasis shifted to abandoning national policy in the 1980s, and this at precisely the moment that countries in the South wanted to take control (Jolly et al. 2004; see also Toye \& Toye 2004). 


\section{Table 5.1 Programme of Action for the New International Economic Order (1974)}

- Increasing sovereignty over economies and natural resources

- Increasing control over the level and nature of foreign investment

- Maintaining or increasing the purchasing power of raw material and commodity exports

- Increasing access to markets of developed countries

- Reducing the cost of technology transfer

- Increasing the flow of development assistance

- Reducing the debt burden of certain developing countries

- Increasing the decision-making power of the developing countries in the UN and the Bretton Woods institutions

Source: Jolly et al. 2004

The alternative popular in UN circles therefore continued to be mainly an intellectual exercise - just as the UN always used to be more of a source of ideas in the field of development aid than a powerful political actor. Practical policies, at least at multilateral level, were shaped by the World Bank and the IMF and were referred to as the Washington Consensus (see table 5.2). From the end of the 1980s, international financial institutions (IMF, World Bank) and Western countries not only propagated this package as 'the way to go' for developing countries, but imposed it on them where possible. Alternative models supported by developing countries had little chance of success in the international economic climate of the time, and the same applied to the Independent Commission on International Development Issues which, under the leadership of Willy Brandt, published a report in 1980 in which core elements from the previous programme of action for a new international economic order were linked with peace and disarmament.

Table 5.2 The original Washington Consensus
1. Fiscal discipline
2. Reorientation of public expenditures
3. Tax reform
4. Financial liberalization
5. Unified and competitive exchange rates
6. Trade liberalization
7. Openness to DFI
8. Privatization
9. Deregulation
10. Secure Property Rights 
The Washington Consensus is imbued with the neoliberal spirit of the times. John Williamson, who coined the term Washington Consensus and formulated the core points of this new orthodoxy, observed that it did not feature any of the ideas of the first generation of development economists. These days, supporters of this 'consensus' are few and far between. Economic historians have shown that none of the rich countries observed all the points in the consensus during their development. In fact, while the developing countries that did observe the Washington Consensus in recent decades - and these were located mainly in Africa and Latin America - experienced no or very little growth, countries like China, India and Vietnam, which followed their own course during the same period, actually turned into growth paragons (Adelman 2001; Bairoch 1993; Chang 2002, 2007; Reinert 2007a; Rodrik 2002, 2007; Williamson 2008). South Korea went on to score a five out of a total of ten, and Taiwan probably a six (Rodrik 2007).

What is more, a lot of important issues are not covered by the Washington Consensus. When Joseph Stiglitz, who later won the Nobel Prize for Economics, was appointed chief economist at the World Bank at the beginning of 1997, he wanted to expand the original ten points of the consensus with more regulation of the financial sector, competition policy, and transfer policy for technology. He also proposed expanding development goals to include sustainable development, democratization, and a more egalitarian distribution of income. The then Minister of Finance in the United States, Laurence Summers, was unhappy about Stiglitz' ambitions and made his departure from the World Bank a condition for US support for a second term for James Wolfensohn as World Bank President. Consequently, Stiglitz resigned from the World Bank in November 1999. Seven years later, in an Initiative for Policy Dialogue task force, Stiglitz and colleagues summarized the problems with the Washington Consensus as follows: too limited goals (focus on price stability), too few instruments (emphasis on monetary and fiscal policy) and an excessive focus on markets (Stiglitz et al. 2006; Toye \& Toye 2004; Williamson 1990). By then, however, the Washington Consensus had long lost a lot of its sheen.

From the end of the 1990s onwards, when it became clear that the original 'Washington' package of reforms was not working, and sometimes even had negative effects, multilateral bodies and policy economists started adding all kinds of 'second generation reforms' with a more institutional character to the package. This created even longer lists of reforms, which were considered desirable and which went under names like 'post-Washington Consensus', 'Washington Consensus plus', and 'augmented Washington Consensus'. The lists can differ from source to source but the box below contains a representative selection. 


\begin{tabular}{|c|c|}
\hline Original Washington Consensus & $\begin{array}{l}\text { Augmented Washington Consensus } \\
\text { the previous } 10 \text { items, plus: }\end{array}$ \\
\hline 1. Fiscal discipline & 11. Corporate governance \\
\hline 2. Reorientation of public expenditures & 12. Anti-corruption \\
\hline 3. Tax reform & 13. Flexible labour markets \\
\hline 4. Financial liberalization & 14. WTO agreements \\
\hline 5. Unified and competitive exchange rates & 15. Financial codes and standards \\
\hline 6. Trade liberalization & 16. 'Prudent' capital-account opening \\
\hline 7. Openness to DFI & 17. Non-intermediate exchange rate regimes \\
\hline 8. Privatization & 18. Independent central banks/inflation targeting \\
\hline 9. Deregulation & 19. Social safety nets \\
\hline 10. Secure Property Rights & 20. Targeted poverty reduction \\
\hline
\end{tabular}

Source: Rodrik 2002, $2007 a$

An initial review of these issues immediately raises the question of what is missing. The authors notably ignore the problem of sustainability. The improved package of reforms is also impossibly broad and undifferentiated, and still does not take any account of local context and needs. One obvious question is whether all twenty points are even important, or whether indeed a sequence can or should be applied to how the various elements are approached. This list is basically a message to developing countries that they have to become like Denmark or the Netherlands without anyone saying how they should do that. It is like a random burst of buckshot, which is little help to governments or developing countries in weighing up the various possible policy options. It can also be seen as a kind of lucky dip from which international organizations and donors can derive conditionalities before they allow countries to become eligible for aid or a loan (Felipe \& Usui 2008; IEO 2007; Maxwell 2005; Rodrik 2007; Stiglitz 2008; WRR 2001).

Key donors also realized that, although such an approach was analytically more satisfying, from the point of view of policy it provided less direction. As an initial step towards a new long-term strategy, the World Bank therefore published a report in 2007 (World Bank 2007) compiled by a team led by the bank's former chief economist, François Bourguignon, which reveals the contours of a new approach. According to this publication, the most important principles for development strategies are now less doctrinal than in the past. The authors call this "a major evolution from the days of structural adjustment and the Washington Consensus". According to this report there is now international agreement on six principles. 
1. Growth is critical to poverty reduction.

2. Sustainable growth and poverty reduction require attention to the distribution of income and opportunity.

3. The main agent for growth is the private sector, but the public sector has an essential facilitating role.

4. Openness and a dynamic export sector are powerful drivers of development. But debate persists about the best way to obtain this result and about the factors facilitating export development. And there is recognition of the costs from liberalization to some population groups.

5. Good governance and institutional capacity are critical to sustainable development, but there is no unique governance trajectory.

6. There is no unique template for development. It is also recognized that growth does not always result from a linear combination of 'basic determining factors', as postulated in the familiar linear growth regression model. Some elements may be especially important at some times and in some cases, making the model highly nonlinear, complex, and essentially country specific.

Source: World Bank 2007

The grand finale to the demise of the Washington Consensus would appear to be the publication of the report by the Commission on Growth and Development, which was established in 2007, in which famous policymakers and scientists, under the leadership of Nobel Prize winner Michael Spence assess the current state of affairs. This was a signal that the Washington Consensus was de facto dead and buried. The report identifies "five striking points of resemblance" between every very successful economy: (i) exploiting the world economy through openness; (ii) maintaining macroeconomic stability; (iii) keeping high rates of saving and investment; (iv) using markets to allocate resources; and (v), having committed, credible, and capable governments. However the Commission also establishes that the specific characteristics and historical experiences of countries have to be reflected in the realization of these stylized facts in a strategy for growth, and that there is no generic formula which policymakers can use. The Financial Times (22 May 2008) saliently summarized this Commission's report as follows: "The 'Washington Consensus' - stabilize, privatize and liberalize - is dead. Long live the new pragmatism" (Commission on Growth and Development 2008; Ho 2009; Lin \& Monga 2010; Rodrik 2007; World Bank 2005). However, traditions and routines are hard to break and the additional problem that, in practice, there are not many tried-and-tested alternative approaches means that not much tends to change in the practice of donors and international institutions like the IMF (Van Waeyenberge et al. 2010; Weisbrot 2010). 


\subsubsection{GOOD GOVERNANCE AND DEMOCRACY AS A REMEDY}

The idea behind the Washington Consensus was that governments in developing countries had blocked, rather than stimulated, development of their countries (Burnside \& Dollar 1997). Initially therefore the suggestion was to ban government interference in the economy entirely wherever possible. 'Bad governance' would become 'no governance': less government and more market forces. When that proved not to work, the importance of the government was rediscovered. Instead of less governance, good governance became the new mantra. Good governance refers to several connected principles on the functioning of government and the political system. Transparency and accountability are key: government structures must be transparent and there must be reliable procedures for accountability. The best way to achieve this is through democratic principles. Once this ideal had taken hold, countries were only to receive money from loans if they fulfilled the criteria for good governance, since otherwise the aid would only be used ineffectively and leak away through corrupt government systems. Many donor countries complied with these requirements formulated by the World Bank, although determining the limits turned out to be far from easy. However, there was broad endorsement of the idea that encouraging good governance was eminently important. The UNDP now spends 46 percent of its budget on good governance programmes, such as training staff for elections. The World Bank also spends a considerable amount of its funds (a quarter) on 'state capacity building' (Moss et al. 2006).

Was the promotion of good governance then the key to development? The WRR (2001) showed, in an earlier report on development cooperation, that a peculiar paradox exists - an idea which has since been steadfastly reiterated in all kinds of international publications (see also Hout \& Robinsons 2008). Countries which fulfil the criteria for good governance hardly need any development aid since, if they manage to fulfil these criteria, their economies will usually be in good shape 'of their own accord'. Countries which do not fulfil the criteria, do not receive aid but are unable to achieve the desired situation without it. As gradually became clear, if countries do not have a system of good governance, this is usually due to deep-rooted reasons. In many developing countries there is a complex interweaving between state, market and society, of which patronage systems are an example. The good governance requirements mean little more than the reinvention of society, the economy and the state. "Skipping straight to Weber", is how Pritchett \& Woolcock (2008) describe these unreal expectations. It is becoming ever clearer that transferring governance ideals like democracy or transparency (let alone imposing them from outside) is an almost impossible task - in any event in the short term. 


\section{Fragile states}

The idea that the key for development lies in creating good governance was given an impulse from an entirely different angle when, at the end of the Cold War, all kinds of violent internal conflicts occurred, or rather mushroomed, since most had already been smouldering for a long time. It was not always immediately clear what repertoires of activity the new situation demanded. These wars, often civil wars, required a different approach, by both the military - which were strongly focused on wars of conquest - and the world of development aid. It soon became clear that the range of intervention options has to be much wider than the standard set of instruments. How, for example, can calm be restored immediately after military interventions? The importance of security sector reform soon became clear. Although appropriate guidelines were developed, such as those of the OECD, which started tackling the theme at a relatively early stage, there was no international organization sufficiently equipped to structure post-conflict situations in an adequate manner. The Western aid community therefore had to learn by trial and error how to intervene sensibly in post-conflict areas, with some degree of success, for example in Cambodia and Sierra Leone (Manor 2007).

The experiences acquired in this way were combined into studies on what came to be known as 'fragile states'. This generated some interesting insights since the different UN peace operations were quite easy to evaluate and compare (see for example Paris 2004 and Voorhoeve 2008). At the same time a familiar mechanism occurred in that the notion of fragile states was transformed into a recipe which was regarded as applicable in all sorts of situations.

The first consequence of this was the increase in the number of countries referred to as fragile states. Soon the focus was no longer just on post-conflict countries but on almost all countries whose governments, according to the definition of DFID, were not able to provide what its citizens wanted - DFID therefore counted forty-six fragile states. These were very varied and included countries which were really not adequate states, such as the Democratic Republic of Congo or Somalia, countries in which the government did not have an actual presence in all parts of the country, such as Uganda where the North was troubled by the Lord's Resistance Army, as well as countries with a federal structure in which a lot was decentralized to regions, such as Nigeria, and countries where the government can only fulfil its role through large-scale repression, such as North Korea. Then there are countries whose governments only had a limited capacity to act due to a large number of factors, such as Pakistan, and lastly countries which have, to a large extent, been 'constructed' and which have very varied populations, such as Syria and Iraq (Kaplan 2008).

The broadening of the term led to a decrease in its explanatory power. After all, very different situations were lumped together, and it gradually became more and 
more confusing how any intervention should take place (see also: Chandler 2006; Duffield 2007; Kaplan 2009). Nevertheless, several authors started tackling the concept of fragile states. For example, in 2008 the former Afghan Minister of Finance, Ghani (together with co-author Lockhart, director of the Institute of State Effectiveness), published a book entitled Fixing Failed States. A framework for rebuilding a fractured world. The title can be interpreted ironically but the impartial reader cannot draw any other conclusion than that the authors really mean it - for example the chapter 'Reversing History' includes the statement that it is perfectly possible for a government to relieve its country of its misery by concerted action. Those who find that book too complicated can always opt for the publication by the Rand Corporation entitled The Beginner's Guide to Nation Building (Dobbins 2007). In just 284 pages it provides an exact description of how to build up a country. For advanced readers there is the Social capital building toolkit (Sandler \& Lowney 2006).

\section{Democratization before everything?}

The basic idea behind the good governance approach and the toolkits which are intended to get fragile states back on their feet is that a liberal democracy is the condition par excellence for development. The policy consensus was that democratic systems, with a properly functioning market, will contribute to the pacification of internal conflicts, and that this is a basic condition for development. In this context Kahler (2009) even refers to the "New York Consensus". The United Nations - based in New York - started to make more and more of an effort over the course of the 1990 s to build up states which had previously functioned poorly, based on the idea that building up liberal democratic institutions should precede the creation of an active civil society or a properly functioning economy. This idea was a source of great inspiration to the American government, as is shown by their military interventions in Iraq and Afghanistan and the huge sums of money available for organizations that promote democracy, like the National Endowment of Democracy (NED) and Democracy Assistance.

The question is whether the export of democracy indeed turned out to be the key to development. Although peace operations have certainly led to a reduction in violence in a number of cases, a lasting democratic transition appears to be difficult to achieve. More and more frequently, analyses are showing that democracy can only be created to a certain degree and that progress is incremental. At best you can deepen an existing democratic tradition, and at worst your interventions can have damaging consequences. According to Carothers (2002), democratization only has a chance of success if a number of conditions are fulfilled, but this is only rarely the case. Important internal conditions are a history of democratic institutions (if those institutions once existed, it will be easier to restore democracy), sufficient support for democratization within a country (sufficient political reformers), divided and weak authoritarian rulers, and regional peace (unrest among neigh- 
bouring countries causes tensions at home). Influence from outside only works if the country is not too big (so that the aid does not become too scattered) and the aid is extensive and varied. Countries must also have something to gain from democratization. This explains why the democratization processes encouraged by the EU in Eastern Europe got off to relatively good starts (see also Diamond 2008).

The transition period is almost always a period in which democratization is accompanied by widespread ethnic or other conflicts. An analysis and evaluation of eleven peace operations Paris (2004) showed how an emphasis on democracy can add fuel to the fire. In a large number of conflict countries the process of democratization led to an intensification of social conflicts, in others it reproduced traditional sources of violence (see also Van Bijlert 2009; Van der Borgh 2009; Carothers 2002; Mann 2005; Mansfield \& Snyder 2001). In particular the emphasis on speedy elections - the faith in elections - has often proved to be damaging since electoral competition can act as a catalyst for conflicts. Elections often stir up smouldering unrest. Paris (2004) therefore concluded that elections should not continually be regarded as the starting and finishing points of democracy. Democratic elections do not have to be abandoned entirely, but can only take place when other crucial functional political institutions are properly in place, such as the rule of law and a properly working bureaucratic organization. In other words, the political system must have a certain degree of legitimacy before elections can take place. For example the transition in South Africa took place peacefully because all the institutions were already in place: the constitutional state, a parliament, and a rational Weberian form of state bureaucracy. Burundi, by contrast, where the organization of elections in 1993 was forced through by international donors, had none of these institutions, and within a couple of months after the elections 100,000 people had been killed as a result of ethnic rivalries (Mansfield \& Snyder 2001).

It is becoming more and more obvious that institutions that work well as regards pacifying conflicts in Denmark or the Netherlands (political parties, NGOs and a parliament) do not automatically have the same degree of success elsewhere. In most developing countries the parliament does not control the government. It is usually an acquiescent machine comprising loyal parliamentarians, or a substitutes' bench where ambitious people wait their turn to 'take to the field' (Molenaers \& Renard 2007). Audit institutions or offices are also powerless and political parties rarely have deep roots in society, often being concentrated more around people than ideas and with many not even having a manifesto. Elections are won with beer and T-shirts, not with long-term policies. In Kenya, Raila Odinga has been Prime Minister since April 2008 and has been a member of ten political parties. A political party often does not allow another party to win because of a lack of confidence that they will regain power next time round. In particular winner-takes-all systems, like the ones in the United States or the United King- 
dom, often malfunction elsewhere because the parties in power do not know how to deal with 'loyal' opposition (Barbone et al. 2007; Chabal \& Daloz 1999).

\section{Good enough governance}

These days, thinking has moved on and, like the Washington Consensus, the New York Consensus is being replaced by a subtler variant. Researchers like Grindle (2004), who supplements neoclassic political economy with sociological insights, and Fukuyama (2007) propose a focus on good enough governance.

That not only implies a lot more modesty regarding the goals which can be set, but also assumes that the legitimacy and responsiveness of a state can take on various guises. Democracy is not regarded as some kind of holy grail, and the fact that citizen participation and representation will have its faults is acknowledged. The 'good enough governance' approach therefore focuses on the development of effective but limited government. Whereas the supporters of the good governance thesis have a consistent belief in progress, the principle of good enough governance emphasizes the fact that development never takes place uniformly, that there are negative consequences, and that changes can only come about through political alliances and not through contracts. In the meantime, the World Bank has also adjusted its standpoint. In its "broad agreement on six core principles" for its future strategy (see table 5.4 above), the bank now also states that "good governance and institutional capacity are essential for sustainable development, but there is no unique governance process".

It has gradually become clear that the good governance agenda is not the silver bullet it was hoped to be. Donors have learned that, although it may be possible to build up political institutions in a formal sense, this does not yet mean that much has changed in a material sense. In particular, African leaders have demonstrated that they are good at dealing with this state of affairs. Under pressure from Western donors they introduced formal changes (usually forms of multi-party democracy), but that only led to very limited changes to the neo-patrimonial power structures, despite examples of successes, such as Ghana where the elections of 2008 appeared to have a real impact. Although a term like good enough governance is more suitable, it does raise the question of how exactly it should be applied in practice. If every donor starts following their own strategy, the capacity to act will be very limited. However, the question is when is 'good' good enough, and how do you organize the political process between the donors to acquire a joint answer to that question? In 2009, even the beginnings of an answer to these questions were lacking, and the good governance approach had lost a lot of its shine as the ultimate key to development.

\section{Creating a better world}

Perhaps the greatest task facing modern policy systems is to fathom what policy is, and is not, able to achieve. It is an inherent feature of political systems that they 
claim to be able to create a better world, with governments and scientists providing the required instruments. The problem is, however, that ambitions and pretensions often tend to run away with those instruments. It is perfectly possible that import substitution will be useful in some countries in some circumstances, and that privatization will be productive on some occasions. It is equally clear that, in certain circumstances, democracy can contribute to a society's development. Nevertheless, no matter how understandable and tempting it is, the idea that these formulas always work in any situation, and that a simple intervention can raise a society to a higher plane is not only untenable but also damaging, as the history of sixty years of development aid has taught us.

\subsection{LACK OF INTERVENTION ETHICS}

A fourth problem development policy has to face is that there is nothing, or scarcely any thing, that resembles intervention ethics tailored specifically to development aid. Put simply, there has not been enough reflection on when and when not to intervene, in light of what aid interventions actually do with aid recipients. This is indeed a thorny issue. Anyone who visits a developing country for the first time realizes the importance of developing a code of behaviour with regard to beggars. The conclusion is usually that begging children get nothing (if they are given money they will have no reason - and no time - to go to school), but that the situation is different as regards handicapped and elderly people (after all they no longer have any other option). Anyone who visits a developing country a second time will discover that the children are also becoming more professional. In popular locations like Timbuktu in Mali, the churches of Lalibela in Ethiopia or the slave forts on the Ghanaian coast, children approach tourists and tell them that they 'of course' do not want any money but that they cannot pay for their geography books. The tourists are then asked to purchase one for them in a shop, after which the children (when they think that no one is watching) resell the book to the shop. It has not yet been possible to generalize these insights in a good donor strategy.

Another way of putting it is that the implicit idea about aid clung to in the West for more than sixty years now is that it is always good. If only it were that simple. The effect of aid is certainly not, by definition, positive. Aid not only has 'first order' effects, in the form of a school, a clinic or fertilizer subsidy, it also has a 'second order' effect, in the sense of a dependency relationship. Aid goes beyond the alleviation (or not) of a problem. It also constitutes a new relationship between people, creating expectations and dependencies, establishing habits and teaching people how to act, whether they want it or not (Chatterjee 2004; Lewis \& Moss 2006; Li 2007). 
The problem is that donors do not know exactly how they should deal with this. Although attention is paid to a number of negative effects of aid, such as the possible environmental effects of a dam, or the disruption caused by a road being built through an area which is home to 'indigenous' people, there is no focus on how to take account of how aid changes the world view of the people involved. The 2005 Paris Declaration is a good illustration in this respect since it reduces the problem of aid to one of suboptimal 'effectiveness'. Nowadays it is widely recognized that not all aid funds achieve maximum impact. That is one reason why almost every policy document in recent years has emphasized effectiveness as a priority. Donors only want to give effective aid and increasingly report on this issue. These approaches assume that, if one form of aid or another achieves the specific desired effect, everything is fine. The possibility of other, less desirable effects occurring is ignored. People restrict themselves to measuring how the use of resources can be optimized in such a way as to achieve maximum yield. 'Side effects' are not measured, nor traced in any other way.

Very little systematic research has been done into the negative effects of aid, with most focusing on humanitarian aid in crisis situations (Anderson 1999; Polman 2010) and the monetary effects of aid (Moss et al. 2008; Rajan \& Subramanian 2007). This is partly due to the fact that people within the world of development aid rarely want to be confronted by the idea that aid can have a negative effect, and partly also due to methodological problems. The difficulties of determining whether aid leads to development also trouble research into the issue of negative effects. All in all this has meant that, while the website of the World Bank contains more than 1400 research papers, not one of them has been devoted to aid dependency in the past decade. The publication which comes closest concludes, after carrying out certain calculations, that "aid is a bigger curse than oil" (Djankov et al. 2007).

In the meantime, numerous popular publications have appeared which use a range of examples to illustrate the view that aid is bad. One famous example is Dead aid by Dambisa Moyo (2009) which, within six months, made her one of the hundred most influential women in the world, at least according to Time. The book's empirical underpinning is not commensurate with its popularity but it would be foolish to use this as a reason for ignoring its message. There are comparable books Hubbard and Duggan (2009) even talk of a charity trap - and better thought-out formulations of the same standpoint (Glennie 2008; Mwenda \& Tangri 2005). In addition, the issue is receiving more and more attention in Africa itself (Ayittey 2006; Tandon 2008). In Malawi, to name one example, parliament recently swept the agreements the government had made with the IMF from the table, arguing that the country wanted to be in control of its own future. 


\section{Aid creates a new reality}

Which unexpected, adverse effects of aid have been revealed by the limited research that has been done to date? One that is relatively easy to identify is the macroeconomic effect of aid. In countries in which development aid (or debt relief) constitutes an important part of the income, upward pressure is exerted on the exchange rate. This has negative consequences for export opportunities (the famous Dutch disease). Even countries with good macroeconomic policy found it very difficult to counteract this effect thanks to measures like the allocation of foreign currency to pay for imports or the increase of productivity (Hussain, Berg \& Aiyar 2009). At microeconomic level, the importance of aid is also unclear and there are many examples of microcredit programmes which have tended to disrupt the local market rather than improve it.

However, the influence of development money goes further, placing the relationships within a country on a different footing. Particularly in fragile states it often proves difficult to spend aid money effectively on concrete activities and an entire society then focuses on the question of how to benefit from all the available donor funds, with all the associated disruptive effects (Feeny and McGillivray 2009; Gibson et al. 2005). In other developing countries, money from donors affects the incentive to charge tax (Sindzingre 2007). For example, in Uganda, Museveni abolished local taxes just before the presidential elections of 2006. Such a move has an economic effect - unless the donor is prepared to make good the deficit, which is often the case - but also a psychological effect, because it relieves citizens of the feeling that they are financing the government and, as a result, they tend not to place themselves in a position in which they hold the government responsible for achieving results. Conversely the government focuses on donors instead of on citizens. Cultural anthropologist Chabal (2009) refers to historical continuity: in the colonial age the colonies were governed by giving local leaders the positions, resources and backing of the colonizers. A selective approach helped these leaders to substantiate their positions of power. The current structure still displays this basic pattern in which benefiting from external support and power over the people in the country itself have become more and more interwoven because responsibility extends upwards and not downwards.

Another ambivalent transformation is the NGO-ization of developing countries. The time has gone that Western NGOs do everything themselves in developing countries. Now they prefer to use local NGOs. This has resulted in specific donor behaviour in the form of a persistent search for local NGOs. Fowler (in Hearn 2007) refers to this as a new "scramble for Africa". If large-scale resources are used to search, they will always find something. In the 1990s, numerous new NGOs were set up in the countries in the South. Although they use the increased democratic space, they are still, to a large extent, an artefact of the available donor funds. It is difficult to define to what extent, but a cautious estimate has revealed that in 
countries like Uganda and Ethiopia around 60 percent of local NGOs are primarily donor-driven, that around 15 percent are political groups, usually members of the opposition, and around 25 percent can be regarded as authentic and more or less directly representative of local groups. The latter includes, for example, a large number of women's groups.

Local NGOs are often held more accountable to their Western sponsors than to the local population. Against this background it is understandable that the Ethiopian parliament adopted a law in December 2008 which severely restricts local NGOS that receive more than 10 percent of their budget from Western donors, because it is regarded as a form of foreign interference in domestic matters. Ethiopia may well be an extreme case since it has a strict regime and the government also has less noble motives for restricting the work of local NGOs. In that respect it can be added to the list of countries where the activities of NGOs are restricted under the pretext of improving the security situation. This list includes Russia, Brazil, Egypt, Cambodia, Uganda and, most importantly, the United States (Edwards 2009b). However, other African countries are also considering regulating NGO growth. Even in Afghanistan, two years after Western troops had driven back the Taliban, a proposal was made in parliament to reduce the number of NGOs, whose number had risen to 1400 .

Another noticeable development is the influence the presence of Western aid organizations has on the intellectual cadre of a recipient country. The NGO market has often become the most interesting labour market for smart people in their twenties. Some do substantive aid-related work, but many find that their command of English or French enables them to find work as a driver or jack-of-alltrades for Western NGOs, even if they have been trained as doctors or engineers, because the Western organization almost always pays better. This leads to a brain drain within the country, as talented young people from developing countries disappear into Western aid organizations (Rajan \& Subramanian 2005). These days, NGOs rarely function as a 'refuge' for intellectuals, as was the case in the 1980 in Latin America. Usually they are simply the most generous employer.

\section{Mutual dependencies}

A subsequent problem with classical development aid is that it unintentionally tends to undermine the state rather than support it. Instead of realizing that they have an effective government, citizens see successful projects with donors' flags on their local school or clinic. In this way, the government loses some of its legitimacy. An alternative is to have aid organized via governments and for donors not to be visibly present - albeit that USAID, the World Bank and the German organization GTZ still work almost exclusively under their own flags (Bräutigam 200o). However, providing direct support to governments also has its problems. That support makes governments dependent - in countries like Uganda or Mozam- 
bique almost half the government's income consists of contributions from donors. As we have already seen, this can lead to recipient countries feeling more answerable to donors than to their own populations. However, donors, in turn, often have their hands tied as well: what can they do if a recipient country does not act as agreed? A logical step would be for donors to threaten to provide less budget support. Yet this is not the usual response. For one thing it does not fit in with the donor culture. "Donors are softies", is how Molenaers \& Renard put it (2007: 146). When it comes to the crunch they are keen to give money. That is why they are in Africa, Latin America or Asia. The money has to be set aside, not least to fulfil international agreements. Development aid is still primarily a moral activity. Donors want to relieve poverty, not to act like businessmen, and shy away from the human consequences of shutting off the supply of aid funds. That also means having to wait on the sidelines, and that is something donors do not like doing. A major additional problem is that donors are rarely able to present a united front (Renard 2006).

Withdrawing aid has proven a poor sanctioning instrument. Although budget support was stopped following Meles Zenawi's corrupt involvement in the 2005 elections in Ethiopia, it is still de facto present in the form of sectoral support. In 2005, the Ugandan president Museveni wanted to extend his term, in contradiction of the constitution and donors' wishes. The Netherlands, one of the many donors in Uganda, reduced the aid budget slightly, as if that would change Museveni's mind. More recently, following a debate in the Netherlands, the Rwandan development budget was also cut back. This happened after a draft report by the United Nations had designated Rwanda as a possible troublemaker in the conflict in East Congo. The Netherlands also recently imposed a reduction on aid to Pakistan. All these sanctions were a result of Dutch national politics, and had nothing to do with foreign policy. In fact, such politically correct interventions undermine the negotiating position of the Netherlands in the country itself and hamper the process of setting out a long-term development strategy. Their small scale alone means they have no effect on the recipient countries. Six decades of development aid have shown that there is little point imposing ex-post conditionalities and that sanctions of this scale, imposed retroactively, have little effect (Collier 2007; Molenaers \& Renard 2007; Moss et al. 2008).

A comparable problem occurs in the context of combating corruption. Here, too, donors should dose the aid effectively, but have difficulties in doing so. Research has shown that corrupt regimes have received just as much money before as after the introduction of measures to combat corruption (Collier 2007). Although demands were imposed, donors were keen to spend their money, making the imposition of demands usually no more than a formality (Collier 2007; Easterly 2006; Moss et al. 2006; Paris 2004; WRR 2001). A typical example is that of Kenya, which repeatedly asked for, and received, money despite it being common knowl- 
edge that it did not meet Western conditions. Corruption has systematically gone unpunished. Researchers like Birdsall (2007) and Molenaers \& Renard (2007) therefore contend that the problem of development policy is that conditions are imposed too weakly with donors not making adequate use of the exit option.

The donor community has therefore manoeuvred itself into a difficult position in many African countries. A substantial number of countries have since acquired presidents who, for a long time, were successful in achieving economic growth, and who were popular with the people and donors as a result, but who then gradually started to exhibit autocratic tendencies. Ethiopia, Uganda, Rwanda and Cameroon are obvious examples, but there are others. The question is what can be done about it. In practice, donors do not always seem to break free. They move neither forwards nor backwards. It seems as if a new patronage system has come about in which donors and recipients hold each other captive (Mwenda \& Tangri 2005).

\section{'Ownership' and 'participation'}

Giving aid is a complicated activity which assumes that the givers permanently take account of the effects of their interventions, and use these experiences to adapt their behaviour. This applies to every form of aid, including development aid. Within the world of development aid that problem is usually addressed in terms of 'ownership' and 'participation'. The question is what value those terms have.

The basic idea behind ownership is that countries themselves determine as much as possible how they see their future. The West must not act in a veiled neo-colonial way by deciding for other countries what is good for them. In addition, so goes the reasoning, it is arrogant to claim that others can be the owner of the development of specific countries - development can only be brought about by the countries themselves. In 1999, as an instrument for giving substance to ownership, the World Bank and the IMF determined that loan and grant activities would, in the future, have to take place on the basis of a Poverty Reduction Strategy Paper (PRSP), a document in which countries detail their future plans, referred to in French-speaking countries as a Cadre stratégique pour la croissance et la réduction de la pauvreté (CSCRP). The PRSPs defined the ownership of the development perspective. Because Western donors also wanted to impose demands on the extent to which these plans were sustained, design criteria were formulated, including the obligation to draw up the texts in a participative way. There is now a series of PRSPS with all kinds of different names. Some countries are already engaged in their third generation of PRSPS. The question is what does this all mean? 
Research has shown that most PRSPs, certainly those of the first generation, were compiled by Western consultants. Burkina Faso initially had its PRSP written by the World Bank and even Niger's second PRSP, which dates from 2007, was still written in Washington. Only the more 'robust' African countries, such as Tanzania, write their own. The interactive component is usually restricted to the organization of a round of consultations whereby, in many cases, the participants are also paid to be present on the day the plans are presented. In Afghanistan this consultation session was actually held while the Afghan National Development Strategy was already being prepared for print. In the second generation of PRSPs the word participation was sometimes even replaced by 'partnership', while 'ownership' was replaced by 'demand-driven'. The main reason for using such terms was to say what Western donors wanted to hear (Cheru 2006; Cornwall \& Brock 2005, IOB 2008a; Molenaers \& Renard 2007; Rombouts 2006). Public 'participation' usually amounted to little more than a technocratic legitimacy session (Hickey \& Mohan 2008; Kamruzzaman 2009). There was rarely room for dissident opinions. On paper, the construction of PRSPs is a step towards achieving another balance between givers and recipients. However, in practice, that is very limited (Grant \& Marcus 2009).

Ownership is also problematic in other ways, certainly in the context of developing countries. One question is who is the owner of the country? Sometimes this is the president and his supporters, but that is then because he has appropriated a lot of assets of the country, which is not exactly what is meant by ownership. 'The people' is a similar abstraction, since it is seldom able to express itself in its entirety. Parliaments function insufficiently as the voice of society and political parties are usually opportunistic coalitions. On top of this, choosing specific groups - for example parties in government - is always a choice which excludes other groups.

In their turn, donors are partly responsible for the erosion of the term ownership. Many donors still attach a lot of conditions to their aid. First of all, recipients are less free to spend the aid than is suggested. After the deduction of debt relief, the costs of students from developing countries studying in donor countries, the costs of caring for asylum-seekers, the part of technical assistance hired in from the donor countries, the share of tied aid and administration costs, the portion of worldwide official aid that can be spent freely (referred to in the jargon as 'country programmable aid') was around 50 percent in 2009 while, two decades earlier, it was still around 80 percent. Secondly, a lot of donors interfere in the substantive choices made. Many Western donors are keen to emphasize ownership, but also believe that attention must be primarily paid to women, rural development, civil society, the poorest or the judiciary. This is illustrated by the confrontations which take place every year between the priorities of the donors which are, or should be, passed on via the embassies and the wishes of the recipient countries. Western 
donors also determine the investment programmes during the board meetings of the World Bank or budget discussions in their own countries.

Ownership is therefore problematic in two ways. On the developing countries' side there are rarely any bodies which can be regarded as representative owners. On the donors' side, there is a tendency to continuously make permanent substantive demands on how aid is spent. The problem with all this is not, first and foremost, that recipient countries are simply not able to implement their own development processes, or that donors have ideas about how to spend the aid. The problem is actually that it does not help to batter such forms of complexity with slogans like 'ownership' and 'participation' - terms which suggest the existence of problem-free aid relations. Strikingly enough all this is a source of some irritation, but not of more profound reflection.

It may well be useful to start borrowing from theories created in other practices. Birdsall (2007b) suggests adopting the 'primum non nocere' theory from the world of medicine: only do something if you know for certain that it is going to work. This is an appealing thought but it ignores the fact that aid can work well on one level and have negative effects on another. It also fails to answer the question of who is really the 'owner'. However, the idea can also be borrowed from the healthcare sector that the contact between patient and doctor should not just be about a party with demand communicating with a party with supply - although this market metaphor is becoming increasingly popular in healthcare as well - but rather a party with a question and a party with an answer. That answer then simultaneously implies a judgement regarding the question and even includes a counter-question and an invitation to engage in a dialogue - which is what good doctors do.

\section{Accountability}

The donor response as regards an intervention ethic does not usually go beyond indicating the presence of accountability mechanisms, although this too is debatable. Development aid is an intervention on another's territory. That requires accountability to the country in question, and that is something that rarely occurs in practice. It is Western citizens who vote and give money; citizens in developing countries have little say. Development organizations are also more motivated to please Western voters than to give account to the people they are actually supposed to be helping. This applies both to the many NGOs that receive their financing from donor countries, and to the IMF and the World Bank (Easterly 2008 b). It is ironic that the goal of much development aid is democratization, while aid can actually imply a weakening of democratic relations. Mkandawire (2001) calls this the 'democracy paradox'. Parliaments, civil society organizations and the media in developing countries should be offered an active insight into the aid provided, its goal, the method used and its consequences. In this context, it 
cannot simply be assumed that the authorities or government represent the voice of 'the people'. It is therefore important for donors to discuss their intervention policy actively and to search for ways in which to involve citizens in developing countries, without undermining democratic structures and relationships.

The outcome of this accountability cycle ought to weigh heavily in political decisions in donor countries. Although the importance of mutual accountability was emphasized in the Paris Declaration (2005) and later in Accra (2008), its significance is primarily that governments need to be mutually accountable, and, in practice, this principle still has too few operational mechanisms (OECD/DAC 2008a). Existing examples show primarily how difficult it is to develop good instruments, and this sometimes leads to a specialist and technical process (as in Vietnam), and sometimes to the creation of a new parallel structure in the form of a 'parliament' of stakeholders set up alongside the existing structures (as in Mozambique) (Steer \& Wathne 2009). Incidentally, the World Bank is also intending to take this latter course of action. In addition, donors could experiment more with new forms of accountability: why, for example, could they not use evaluation reports by local ombudsmen?

The Western donor community really has no adequate intervention ethics. 'Anything goes' is still the adage for aid to Africa, with each project being a welcome addition. Western concepts like participation and ownership are borrowed, but turn out to be either interpreted in a technocratic way, or to have little material significance, or a combination of both. Sometimes the use of language is even expressed in ideological terms, for example in the use of the term 'demand-driven'. In a world in which people are short of everything, there is demand for everything. Another specific problem is that people always ask for things they know, and not for what they do not know. As Henry Ford once complained, if you ask a cowboy what means of transport he wants, he will ask for a fast horse. There is therefore little point talking about aid as being 'demanddriven'. The question is how aid can most adequately respond to what is needed, and how it can be given in a way that makes a maximum contribution to the capacity of recipient countries to solve problems themselves. For this a different vocabulary is needed.

\section{5 .5 COMPARTMENTALIZATION: UNDERESTIMATING OTHER INSTRUMENTS}

The interdependencies between countries and issues are increasing and, as a result, development aid is becoming more and more tied to broader issues. The question is what this means for classical aid and for the development dimension of policy in other areas. The institutional system of development aid has been struggling with this problem since its inception. Originally it was still relatively easy to 
deal with, as Western countries regarded development aid purely as a task for multilateral organizations. Those organizations, in particular the UN, appeared to provide the perfect framework for tackling almost all major global problems. However, the UN lost its capacity to act, aid started to be organized more and more bilaterally, and the need to look beyond the classical limits of aid became more and more obvious. In the Netherlands in 1990 this led to former minister Pronk making a daring attempt to link classical development aid to other themes and issues (Ministry of Foreign Affairs 1990). However, the broad picture he sketched of the interwoven nature of themes and countries turned out to be very general. In practice, therefore, policy aimed at development increasingly turned into development aid policy. "Instead of being part of a coherent policy approach to development processes, development aid has progressively evolved into something individual, separate from war and peace, from climate and the environment, from migration, and from religion and culture. (...) This is what development aid and development cooperation were meant for: to contribute to a developing country, from the inside, to help them to progress. (...) It was never ever the intention to achieve all this directly via the development aid itself." That was how Jan Pronk, in his Evert Vermeer lecture (2008: 182), reflected on what has happened to development aid. It has become too much of an enclosed space.

\subsubsection{NEW THEMES}

Since then the need to link aid and cross-border policy in other fields more with each other has only increased. That has taken place via a number of dimensions, some of which are discussed below.

\section{Migration}

Even if we limit ourselves to remittances, there can be no doubting the importance of migration for development (Birdsall et al. 2005; Lavenex \& Kunz 2008; Skeldon 2009; World Bank 2008b). The total quantity of money involved in cash transfers by migrants to their families in their countries of origin has been much greater in recent years than official aid by donors to developing countries. What is more, the effects of migration extend further than financial transfers alone and, for example, include knowledge transfer and the creation of cross-border networks. However, the idea that migration can be a development instrument exists primarily in countries in the South: Turkey and India even have separate ministries for their diaspora (compatriots who have gone to live in other countries). In the West, the debate on this theme still has to get off the ground.

\section{Trade}

Trade and development are inextricably linked in a similar fashion and, although there has been some degree of success, defining appropriate consequences for policy has proved a difficult process. Trade liberalization has been high on the 
agendas of many policymakers and NGOs for a long time now. Opinions differ as to whether the large wTO consultation round (the Doha development round) can still achieve much for developing countries. However, poor countries can still benefit from preferential access to more markets, as this helps them to diversify their economies and become less dependent on the export of natural resources. Some work still has to be done to achieve the full tax and quota-free access to rich countries for all export products promised to the least developed countries in the UN Millennium Declaration of September 200o. Although the Everything But Arms (EBA) initiative offers the least developed countries more possibilities to export almost anything - except weapons - without levies or quotas to the EU, the strict rules of origin are still an obstacle. Collier referred to an example in 2008 that, according to these rules, a Ugandan fishing boat on which a Kenyan is employed is no longer allowed to export fish under the EBA programme. Attention also needs to be paid to the development-friendliness of the international trade regime, and to finding a balance between free trade and fair trade. The ultimate aim is to help developing countries benefit from participation in the international trade system (Gallagher 2008; Khor 2008; Stiglitz \& Charlton 2006; Wade 2003).

The International Assessment of Agricultural Knowledge, Science and Technology for Development (IAASTD) report, entitled Agriculture at a Crossroads (2009), is interesting in this context. Modelled on the structure and method of working of the Intergovernmental Panel on Climate Change (IPCC), a report was compiled after more than four years' work by around four hundred experts, organized by a geographically evenly balanced bureau with representatives from thirty governments and thirty private parties, including NGOs, producers and consumer organizations. The report highlighted the fact that the current international trade regime for agricultural products generates too few benefits for small-scale farmers, while excessively rapid trade liberalization can permanently disrupt the rural sector. Without any suitable and sufficiently operational institutions and infrastructure, large-scale opening up of the markets will wipe out small local producers, thereby causing them to miss out on the new opportunities on the world market. The conclusion was that the poorest countries will be the net losers of most liberalization scenarios.

\section{Financial stability}

Financial stability is a third issue linking development policy and other policy, since developing countries have less resilience when it comes to coping with the consequences of financial crises. Following the financial crises in Latin America in the 1980 os and Asia in the 1990s, many developing countries armed themselves against financial instability by maintaining high official reserves, but that has opportunity costs. Rodrik calculated that these countries jointly lose one percent of their gross national product every year (Stiglitz came up with an even higher amount), because they maintain large monetary reserves, often in low-interest 
American government bonds, while the potential yield of investments in the economy of these countries is itself much greater. This insurance against financial instability - which also helps to keep the IMF wolf from the door - can cost countries more than the funds they have available for poverty reduction. The interests of developing countries should therefore receive serious attention in international financial fora responsible for drawing up policy. Unfortunately this is only achieved with difficulty (Ocampo \& Stiglitz 2008; Patomäki 2001; Rodrik 2006; Rodrik \& Subramanian 2008; Stiglitz 2006; UN 2009b; UNCTAD 2009d; UNIDO 2008; World Bank 2009a).

During the current crisis it again became clear how big a problem it is that there are no mechanisms for promoting the coherence, consistency and coordination of global economic and social policy, let alone mechanisms in which developing countries can participate. All countries suffer from a lack of coherent policy, but the economic and social problems are particularly large in developing countries with few resources and a limited capacity to moderate the consequences of the crisis. One of the consequences of this is that the crisis will considerably reduce the - already quite remote - chance of the millennium goals being achieved by 2015. In the meantime, various parties are advocating setting up a better socioeconomic governance framework. For example, Joseph Stiglitz advocated the creation of an elected and representative Global Economic Coordination Council as part of the UN, with annual meetings of heads of state, to assess and promote the development process and to function as a "democratic representative alternative to the G2O” (Dervis 2005; Handley 2009; Rueda-Sabater et al. 2009; UN 2009a, 2009d). The realization of such a Council is not a foregone conclusion, however.

Clearly, the fate of developing countries cannot be seen separately from the way in which the Western world deals with the system of regulating financial markets. More and more of the large developing countries are being admitted to international fora. However, the vast majority of developing countries have no real influence in the G7, G8, G2O or other ad hoc fora set up to host general negotiations on the policy response to the consequences of the crisis. They thus run the risk of developed countries devising new rules and reforms, which are subsequently imposed as global international standards without any account being taken of the specific situation and interest of countries with much smaller and less sophisticated financial sectors (Frenkel \& Rapetti 2009; Lin 2009a; UN 2009a, 2009b).

\section{Fiscal coordination}

In the wake of the financial crisis, the international fiscal system has been placed higher up the agenda of, among others, the G2O. Not only rich countries are missing out on the tax revenues because of the possibilities offered by international monetary transfers, but so too are developing countries, which have less welldeveloped fiscal systems and fewer resources. The many definition and data prob- 
lems make it difficult to determine exactly what amounts are involved. Various experts assume, however, that illegal financial transactions, the existence of tax havens, tax evasion and transfer pricing by multinationals (more than half of international trade takes place within companies) are causing developing countries to miss out on revenue which is many times greater than the amount of aid provided worldwide. In a recent testimony before the Committee on Financial Services of the American House of Representatives, expert Raymond Baker calculated that for every dollar Western governments give in development aid "crooked Western banks, businesses and middlemen of various descriptions have been taking back up to ten dollars of illicit proceeds under the table". Without international action and agreements, nothing can be done to stop this, so actively helping to bring them about can actually do more to fight corruption and stimulate development than a tenth of a percentage more or less of aid (Baker 2009; Bhat 2009; Christian Aid 2009; Cobham 2005; Kar \& Cartwright-Smith 2009; Oxfam 2009; Task Force on Financial Integrity and Economic Development 2009).

\section{Food}

The next example we can take is food, since it too is an issue via which development aid interferes with other policy. The pressure on food supplies will rise along with the increase in the world population and the changing diets of millions of Asians, Africans and Latin Americans. In order to ensure that 9.1 billion people can still be fed in forty years time, agricultural production has to increase by 70 percent, and in developing countries by even 100 percent. Achieving this target is beset with problems. Some of these can be traced back to the political and economic interests of rich (and therefore primarily Western) countries. However, they are also related to the political, institutional and technical infrastructure in developing countries. Large marginal rural areas in Africa and Asia currently lack technology and markets, while their populations are growing and are dependent on local food production. In many places this results in the inefficient use of land and water, and often even overcropping. This leads to exhausted soils and even more food scarcity, generating a spiral of ever-decreasing sustainability. By linking these areas to markets and thereby offering the population the opportunity of cultivating and selling high-quality cash crops in addition to food crops, a surplus can be created that can be invested in fertilizer use and better agricultural technologies. This makes it possible to break out of the downward spiral and retain millions of hectares of fertile soil for the future. Only then will these areas no longer be dependent on food aid, and only then will it be possible to contribute efficiently to world food supplies via a system of specialization in appropriate high-quality export products. Consequently it is in everyone's interest that people in areas with marginal agriculture production start changing their production strategies and link up with a suitable market (FAO 2008; IAC 2004; Rabbinge \& Bindraban 2005). 
What we are currently facing is an exceptionally fragile global food system. The regulations governing the market for agricultural products, which oscillate between protectionism and accelerated liberalization, the possibilities of speculating with the prices of agricultural products, the growing importance of biofuels, the policy on intellectual property (which means that more and more crops are being patented), the need for strategic coordination and the imminent threat of shortages of water, soil and fertilizer mean a global perspective is required, and a development policy that reaches much further than the classical ODA instruments (Fresco 2009).

\section{Climate}

A final example of the need to link development aid to other themes is climate policy. Ideally, national and international efforts would focus on rich and poor countries together determining climate and development goals in which industrial policy in, and the transfer of technology and knowledge to, developing countries is made a priority, alongside effective mechanisms for emissions trading and the preservation of production and consumption in Western countries. On top of this, adaptation and mitigation need to be integrated into what the World Bank refers to as a "climate-smart development strategy that increases resilience, reduces the threat of further warming, and improves development outcomes". The negative additional effects of mitigation also need to be examined since they can hinder the realization of development goals. In this context the World Bank calls the reduction of $\mathrm{CO} 2$ through the use of grain biofuels questionable, and points out that the United States and the EU have diverted fertilizer for food to the production of biofuels and, by doing so, have contributed to higher food prices and increased poverty.

It is clear that all this goes beyond what classical development aid is capable of. It involves knowledge policy and transfers and technology policy, funds for technology transfer and capacity building in developing countries (as previously via the successful Montreal Protocol to counteract damage to the ozone layer by CFCs), intellectual property rights and the negotiations at the WTO about Trade Related Intellectual Property Rights (TRIPS), actual and potential conflicts between WTO trade rules and Multilateral Environmental Agreements (MEAs), techniques and systems for energy saving and for the generation of sustainable energy, new financing instruments with non-governmental parties and governments (proposals for international taxes and redistribution have been circulating for years), the setting up of adequate and inclusive international institutions, and the promotion, both internationally and nationally, of policy that is coherent as regards its effect on development. It is impossible for a minister for development cooperation to create and monitor the overall agenda needed for this in the coming decades. Consequently, just as for other global issues, new institutional and administrative arrangements will have to be developed. 
In addition, the organization and design of development aid will have to be such that it supports developing countries with the necessary long-term planning required in the context of, among other things, reductions in the physical and financial consequences of unpredictable and extreme weather conditions, changes in healthcare, the establishment of insurance policies and social protection for the most vulnerable in society, infrastructural planning, a 'climate-intelligent' approach to urban development, ensuring governments remain solvent in countries affected by disasters, adequate food production, and the transformation from energy supply to energy consumption. In recent reports both the UN and the World Bank underline the fact that a generally applicable model for this is even more unlikely to be available than in the case of other development policy because the differences between countries are considerable and very little is still known about how adaptation can be properly designed. The international aid architecture is insufficiently equipped for this, since, according to the UN in its World Economic and Social Survey 2009: "Despite the demonstrated effect of the Marshall Plan framework in Europe in the 1940s, 'aid' has developed over the years into a mixture of assistance for an assortment of specific projects and ad hoc responses to unexpected shocks with little apparent coherence, in respect either of the countries that receive it or of its global distribution. Donor conferences are driven more by what donors want to promote than by the desire to support specific multi-year national programmes. It is difficult to see how aid can ever be really effective without an articulation of macroeconomic objectives and detailed programmes for infrastructure investment, etc. and without a coherent account of priorities - what should be done and in what order - and a sense of the necessary complementarities among different investments and projects" (see also Lee et al. 20o9; Ockwell et al. 2009; OECD 2009, Srinivas 2009; UN 2009c; UNCTAD 2009d; World Bank 20ogb).

\subsubsection{SEARCHING FOR COHERENCE}

Cross-border issues and the relationship between aid and other policy have always received a certain amount of attention within the world of development aid. In policy terms, issues like 'policy coherence for development' have gradually moved up the agenda. The basic idea is, on the one hand, to prevent the positive effects of development aid from being undermined by the negative effects of policy on other areas such as trade, migration or environmental policy and, on the other hand, to ensure that policy in other areas has positive spillovers for developing countries.

In practice, however, policy coherence for development is by no means easy to achieve. Finding good instruments proved difficult. This had to do with the functioning of policy systems (which work better with policy issues that each have their own organization and budget), with conflicts of interests, as well as with the complexity of the material itself. Coherence issues are also so international in 
nature that it is difficult for individual countries to create their own policy. For example, trade policy in Europe is the exclusive competence of the European Union, while climate and financial and fiscal systems are also international matters. Coherence therefore plays a very explicit role in international fora, despite individual countries also having possibilities to make a substantial contribution. The problem is that they often have no idea how to do that.

In 2005, the Commission and the evaluation departments for development policy of the EU member states jointly tried to acquire an insight into how to apply the principles for coordination, complementarity and policy coherence. This revealed that coherence for development clearly features on the agendas of the various member states, and that a reservoir of practical experiences has since been built up as a result of them adopting a pragmatic approach to the issue. However, there turns out to be no real systematic approach. A key conclusion in the synthesis of these evaluations was that promoting policy coherence continues to be a work in progress requiring permanent political support at the highest level in the European Union and in the member states (ECDPM and ICEI 2006; EUHES 2007).

The Netherlands is one of the leading nations in this respect. The coherence unit, which has existed at the Ministry of Foreign Affairs since May 2002, has been presented as a shining example to other countries in many international comparisons. The Netherlands has headed the Center for Global Development's annual Commitment to Development Index for several years now, although the index itself can be called into question: the Netherlands' leading position is due not only to its high score on the aid index, but also to above-average scores on some of the other six indicators. Like other countries, the Netherlands regularly publishes a memorandum on progress in achieving coherence, and these show that, within the framework of concrete dossiers, attention has been paid to the development dimension. However, the relationship between development policy and other themes is, for the time being, primarily an academic issue. Many of the debates conducted are predictable in nature. The Minister for Development Cooperation is keen to become involved in broader themes. However, other ministries are not so keen on the idea. Furthermore, as soon as the question is asked as to whether part of the 0.8 percent of GDP reserved for development cooperation can be used for these areas, the willingness to debate soon dissipates (Engel et al. 2009; Ministry of Foreign Affairs 2006, 2008).

Another country that serves as an international example is Sweden. In 2003, it came to the conclusion that development cooperation has to be structured along three main lines: classical aid, policy coherence and international public goods. In March 2008, the new Swedish government sent a memorandum entitled Global challenges - Our responsibility to parliament with the intention being to tackle observed deficiencies in the implementation of policy coherence for development. 
The initiative was greeted with broad political and social support. Improvements are being sought in the field of management, organization and follow-up, knowledge and analysis in the ministries, cooperation with various Swedish actors, and the EU's work in the field of policy coherence. This has led to the introduction of contact points in ministries, interministerial working groups on a number of prioritized themes, and a special unit within the Ministry of Foreign Affairs.

Although progress has been made, institutional structures do little to alleviate the problem of conflicting interests. Sweden is, for example, a major arms exporter, but this issue is not referred to in government memoranda on coherence (Government Offices of Sweden 2008; Odén 2009; Odén \& Wohlgemuth 2007).

\section{European coherence}

As with other policies, creating coherence policy within the European Union is complicated because of the many procedures involved. However, the European Union is in an excellent position to give the policy real substance, and has recently become more active as regards the coherence dossier. Article 178 of the Treaty of Maastricht (1992) already contained a slightly vague phrasing to the effect that, as regards the execution of policy which is "likely to affect developing countries" the Union has to take account of the development goals formulated in Article 177. Campaigns by NGOs (with the support of French and German development ministries) against export subsidies for meat (1993) and for fishing agreements (1996) (again with support from the German ministry) pressurized the Commission to publish a report on coherence issues, but this did not produce any real results. All in all, little progress was made on this dossier in the 1990 os. However, things have changed over the last few years, and there is now a serious focus on coherence policy. In its first document on policy coherence for development, the European Commission (2005) states that aid is important but insufficient to enable developing countries to achieve the millennium goals. It selected eleven areas for special attention in the coherence field - including trade, agriculture, fisheries, transport and migration - and, after the General Affairs and External Relations Council (GAERC) added climate change to make twelve, the ambitions of the EU as regards policy coherence for development were laid down in the European Consensus for Development, which the Council, the European Parliament and the Commission ratified in December 2005 (Official Journal C46 of 24.2.2006).

Despite all the good intentions, however, policy coherence has had little impact on development in practice up till now. This became clear when Europe decided, in February 2009, to raise dairy subsidies again. It is precisely these kinds of agricultural subsidies which are the casus belli for many NGOs and academic researchers. They accuse the West of hypocrisy by demanding in negotiations on trade liberalization that developing countries open up their markets while, at the same time, they support their own agricultural sectors with subsidies. The rich countries 
jointly spend around 700 million dollars a day on agriculture subsidies, and during almost all of the past twenty-five years, the OECD countries spent more on agricultural subsidies than the total gross national product of Sub-Saharan Africa. In 1995, agreement was reached at the WTO to abolish all agricultural export subsidies, and in 2005 it was agreed in Hong Kong that this should be realized by the end of 2013. It is very doubtful whether this will be the case. Until that time national producers in developing countries may be confronted, in any event, by unfairly subsidized competition from countries which already have a head start because their productivity is much higher (Bourguignon et al. 2008; Bretherton \& Vogler 2008; Carbone 2008; Dearden 2008; Egenhofer et al. 2006; Olsen 2008).

European intentions as regards policy coherence also appear to have been forced into the background in the negotiations between Europe and 77 poor countries on the updating of trade agreements in the form of Economic Partnership Agreements (EPAs). A group of developing countries in Africa, the Caribbean and the Pacific have maintained preferential trade relations with the European Union since 1964. On 23 June 2000, the ACP-EU Partnership Agreement was signed in Cotonou. The agreement came into effect on 1 April 2003 for a term of twenty years. As the Cotonou agreement is not in conformity with WTO rules - the ACP countries are given preferential treatment over other developing countries without an 'objective criterion' - the EU has divided the ACP countries into six regions to enable negotiations to take place about regional trade agreements, also known as EPAs, which are WTO-proof. The EU wanted to conclude these negotiations by 20 December 2007 but only thirty-five of the seventy-seven ACP countries were prepared to sign an agreement at that juncture. To date, only one EPA is almost ready, between the EU and CARIFORUM (the Caribbean area), while interim agreements have been entered into for the other regions. Many ACP countries and NGOs were critical of the stance of the EU in the negotiations, for example because it applied pressure on developing countries to agree quickly, it wanted to broaden the negotiations to include issues which go beyond the wTO treaties (the liberalization of trade in services and the 'Singapore issues' in the areas of competition policy, foreign investments, tenders and trade facilitation). The EU also wanted a restriction on the possibility for ACP countries to tax exports, despite this being important for these countries' incomes, and on the possibility for ACP countries to protect economic sectors (infant industry clauses). An ICCO report (2008) shows that nine of the thirteen ACP countries questioned were of the opinion that the EPA negotiations would provide no support for regional integration. The negotiations on full EPAs are currently ongoing and it is unclear when they will be completed. The ministers of finance and trade of the African Union want to review a number of stipulations in the provisional agreements in the light of their own policy space. Moreover, the harmonization of the EPA process with initiatives for regional integration continues to be a problem (Draper 2008; ECDPM 2009a; Lui \& Bilal 2009). 
Coherence at European level is therefore easier said than done. This is also demonstrated by the Commission's two-yearly reports. In the first report of September 2007, the criticism of the member states was that there was too little involvement in coherence for development on the part of ministries other than those responsible for development cooperation. In many countries the mechanisms for policy coherence for development were still insufficiently systematic and poorly institutionalized, and there was also a lack of transparency and accountability in this field. The evaluation assessed progress at European level as satisfactory. In its recently published second evaluation the Commission again states that progress has been made at European and national levels, but that the lack of awareness regarding development in line ministries is an obstacle within the member states, while it is also often difficult to acquire a clear insight into the eventual impact of non-development policy on developing countries. According to the Commission these problems at national level often make themselves felt at European level, and vice-versa. In the coming period the Commission no longer wants to monitor the previously selected twelve policy fields but rather focus strategically on five key development challenges (European Commission 2007, 2009a, 2009b). For some this does not go far enough, however. In a critical report on policy coherence, for example, European NGOs argue in favour of broadening rather than restricting coherence for development to include, among other things, measures for combating food speculation and tax evasion (CONCORD 2009). This debate is ongoing and, after consulting the member states and the relevant stakeholders, the Commission aims to establish a specific and operational work programme for policy coherence for development in 2010.

\section{Global regulation}

Difficult as it is to formulate coherent policy within the European Union, it is an even greater challenge to achieve that on a global scale. This again became painfully clear during the recent financial crisis. The crisis makes two things clear: the regulation framework for financial markets is inadequate and there is no good system for global economic governance. The crisis of the 1930s, when protectionism had its heyday and countries tried to shift problems onto their neighbours, led to the belief that a crisis like that should never be allowed to happen again. At the end of the Second World War this resulted in the establishment (1944) of the Bretton Woods institutions: the World Bank and the IMF. The UN system came later but never really got off the ground in the economic and social sense. When the UN was set up, the economic and social council (ECOSOC), which met for the first time in January 1946, was intended to function as a coordinating body for economic and social policy. The IMF and the World Bank - unlike, for example, the ILO which was set up in 1919 - however, never wanted to be clustered under the ECOSOc umbrella. Separate systems developed for, on the one hand, economic regulations, with a central role for the World Bank, the WTO and the IMF, and, on the other hand, security issues, with a central role for the Security Council. The 
organizations which make up the economic system never really became part of the UN system and acquired their own governance structures. UN organizations active in social and economic areas, like Unesco, Unicef, ILO, WHO, UNCTAD and UNDP, operate at the periphery of the socioeconomic institutional system, while the IMF, the Wто and the World Bank make up the heart of it. As a result, the social agenda has not been properly mandated and the security and economic agenda function separately from each other.

The idea that broad themes are important is widely accepted in the world of development aid. However, the process of finding suitable arrangements has not been sufficiently developed to date. This has to do with political will but, of course, also with the complexity of the material - there are no simple ways of giving substance to coherence and global regulations and it is no easier to do justice to the development perspective in the context of complicated issues.

\section{Conclusion}

Over a period of sixty years development aid has grown to become an extensive and complex system. That system has acquired specific characteristics: poverty reduction in the form of direct aid has become increasingly important while specific support for growth has receded more and more into the background. The focus on direct aid has partly been the reason for the enormous proliferation in organizations. In so far as large-scale programmes for change are advocated, they are characterized by a very optimistic belief in the possibility of social engineering and the idea that simple and universal answers exist for developing countries as a whole. Neither is there a detailed perspective on the question of when intervention is useful and sensible, and when it is not. Lastly, the links with non-classical policy fields which are relevant to development have not really got off the ground. All this has generated a substantial agenda for change. 


\section{THE TASK AHEAD}

The history of sixty years of development aid can be described as a struggle during which citizens, governments and multilateral organizations searched, with only partial success, for ways of getting to grips with an extremely complex phenomenon. The question is what conclusions can be drawn from this with a view to future policy. A gloomy assessment about what has been achieved may lead to the conclusion that continuing development aid is not desirable or sensible, while the fact that development is a difficult task can quickly become a licence for continuing along the same, chosen path. The material presented in the previous five chapters implies, however, that we should neither give up nor blindly carry on. This chapter is devoted to formulating a more poignant conclusion.

\subsection{LINKING WILL BECOME INCREASINGLY UNAVOIDABLE}

Why do we provide development aid? In chapter 2 we discussed two types of motives: moral motives and motives which can be traced back to collective selfinterest. Moral motives have always played a major role for individuals, as reflected in the work of missionaries, modern-day benefit concerts and individual aid initiatives. The question is, however, to what extent Western governments should allow this motive to play a part in their policy. Although it can be argued from a normative perspective that governments also have a moral duty to show solidarity or charity, that argument makes allowances for political assumptions. Whether moral reasons are sufficient for granting development aid is then a political choice. This is less clear-cut in the case of collective self-interest: the government has to ensure that the interests of Western citizens can also be guaranteed in the long term, as laid down in the constitution. Western countries are becoming more and more reliant on the international order to realize those interests. Collective self-interest can therefore be a powerful argument for development aid. However, it does have to be clear where that interest actually lies.

An argument often put forward in this framework is that a more equal distribution of opportunities in the world would prevent large migration flows. However, there is insufficient empirical evidence for that reasoning - in fact, there is more to support the opposite argument (Bakewell 2008). It is a myth to think that migration will decrease as developing countries develop. It is precisely in countries which continue to develop that farmers gravitate to the cities, while city dwellers migrate to richer countries. For the time being, therefore, any progress by developing countries is more likely to result in more migration to the West rather than less (Adepoju et al. 2008; Faist 2008; De Haas 2007; Skeldon 2009; UNDP 2009). Re-migration will only reoccur in a later phase, once expectations with respect to opportunities have increased significantly in the home country. For example, a lot 
of Greeks and Italians who had emigrated to the Netherlands in the 1950s returned home fifteen years later. In recent years, a comparable process seems to be taking place among young adult Dutch citizens of Turkish origin.

The argument that development aid helps the fight against terrorism is similarly questionable. While it may be the case that extreme poverty can contribute to terrorists being difficult to locate, this is more likely to be down to the lack of a good government apparatus than any causal role for poverty. Poverty itself is rarely the primary cause of terrorism, or even of insurrection. Research has shown that recent terrorism has its roots in a feeling of discrimination which is sooner sociocultural than economic (Burke 2007; Rashid 2006). That is also why the leaders usually have middle-class backgrounds - Osama bin Laden is even a member of the Saudi Arabian elite. The same applied, incidentally, to the many revolutions that occurred in Europe in centuries past.

Development aid will therefore do little to counteract migration flows or terrorism, at least in the short term. However, the interests of Western countries extend a lot further. For example they - and certainly those with an open economy - have an economic interest in a properly functioning world market. In the long run, Africa could be an interesting sales market, and is already a key supplier of natural resources. However, the essential interests of Western countries go a whole lot further. In the short term they lie in making agreements on climate objectives, in the slightly longer term in the global management of energy and food, and in the even longer term in a stable world order. After all, climate objectives cannot be realized without countries from the South, and energy and food will inevitably have to feature on the international agenda as well. Although the energy problem is still being discussed in terms of the environmental burden, the focus will soon shift to the problem of scarcity. In theory the earth can still produce enough food, but that will require much more careful global coordination. Lastly, water scarcity, biodiversity and the use of increasingly scarce resources are becoming more and more pressing international problems.

In the longer term the world order itself will be precarious. The world is becoming so much busier and richer that people will have to start living together on the basis of much stricter conditions. While the world population was 2.5 billion in 1950, by 2050 this is expected to have risen to 9.2 billion, almost four times as many people. What is more, if current developments continue, these people will be a great deal richer. The average gross domestic product per global citizen in 1950 was 2,109 dollars; in 2000 it was 6,029 dollars (both expressed in the dollar rate of 1990, see Maddison 2009). No one can predict with any certainty whether incomes in the first half of the twenty-first century will again rise by a factor of three, but it would be administratively and politically prudent to allow for this. This means we have to assume that, by 2050 , there will be four times as 
many people on the planet who, on average, are nine times richer than in 1950. An administrative and political response will have to be found to these substantial changes because it is clear that, in a world as busy as that, we have to share space and resources with more people and it is essential to search for mechanisms to limit the unavoidable mutual tensions. History has taught us that reinforcing mutual dependencies is probably the best approach. This is how flammable employment relations were pacified at the beginning of the twentieth century in the West, and how the tensions between Germany and France were channelled after the Second World War through the setting up of the EEC. It would be playing for high stakes not to exercise the same caution at global level. Not only for moral, but also for functional reasons, policy must focus on keeping countries and people together wherever possible. We cannot afford to settle for less.

\section{Embedded globalization}

It has become clear that scrupulous globalization will be impossible if globalization continues in the same form as in past decades. The financial crisis has made it obvious to former globalization cheerleaders that global economic development cannot simply be left to markets and companies. World leaders like former British Prime Minister Brown and American president Obama have now declared the Washington Consensus dead in the water, and all kinds of national and international fora have started reflecting on how globalization can be organized in a manner which is less risky and less vulnerable to crises. One example is the months-long discussion in The Financial Times on "The future of capitalism". The focus is no longer solely on better and more effective global agreements and supervision. At least as important is the question how - with a new popular concept - 'the resilience' of national states can be increased so that they are better able to cope with contagion by crises (climate, food, financial) and global (economic and other) shocks (DFID 20ogb; Evans et al. 2010). This leads to important follow-up questions. The sudden return of governments, bailing out banks and state-owned companies and trying to counteract the lack of demand by means of fiscal policy, "has reinforced the truism that without the state, market economies would not be able to thrive. Without public authorities capable of exercising legitimate coercion, capitalism would be impossible" (Hemerijck et al. 2009).

The question is along which lines a new world will take shape. During the period that is often referred to as the golden years of capitalism - the post-war period of historically unprecedented economic growth which ended with the oil crisis of 1973 - the most important role in the world system was allocated to national states. The decision to liberalize trade was taken during an international conference organized in the Mount Washington hotel in Bretton Woods in July 1944, which was intended to prepare the structure of the post-war international 
economic system. However, to prevent a new world crisis like that of the 1930s, countries were given room to make their own policy choices - for example setting a lower interest rate in order to generate more employment. Cross-border movement of capital, now sometimes referred to as 'hot money', was strongly regulated and controlled. To Keynes, currently enjoying a resurgence in popularity in the wake of the financial crisis, but back then a leading figure at Bretton Woods, those capital controls were the most important outcome of this conference.

These agreements were a clear response to a previous period. In his famous publication entitled The Great Transformation (1944), Karl Polanyi argues that the economic liberalism of the 1920 s with its belief in a self-regulating market mechanism had resulted in the elimination of "all interventionist policies which interfered with the freedom of markets", and had disembedded the economy from society. The ensuing increase in inequality, instability and insecurity resulted in the recession of the 1930 and the rise of fascism. To Polanyi, "the notion of embeddedness underlines the fact that economic activity is created and shaped by political decisions, social conventions, and shared norms and understandings. Although free markets are often misperceived as natural, sovereign, selfcontained, and self-regulating, a market economy cannot exist independently of the society and rules in which it is located". John Ruggie, professor of international political economy at Harvard, therefore referred to the hey-day of capitalism since Bretton Woods as "the compromise of embedded liberalism”.

This post-war structure started to reach its limits during the international recessions of 1973-1974 and 1981-1982, and the golden years of post-war capitalism were followed by the neoliberal decades of Thatcher and Reagan and the Washington Consensus, which were characterized by lower growth figures. We are now in a transnational phase in which global markets are becoming more and more disembedded from societies and national states due to new technologies and liberalization, privatization and deregulation. In recent years, more attention has gradually been paid to the downsides of this, and to actual and potential losers in the increasing internationalization of trade, financial flows and production (see for example the World Commission on the Social Dimension of Globalization 2004). The financial crisis and imminent climate and food crises are like salt in the wound.

Acknowledging that globalization is not fatal but (re)shapeable throws up fundamental questions about the architecture of international economic and political relationships (Findlay \& O’Rourke 2007). Two parallel movements can be observed here. Although they appear to be contradictory at first glance, closer examination reveals that this does not necessarily have to be the case. On the one hand there is a proliferation of proposals to regulate and organize more at global level - for example monitoring national economies and codes of conduct for the 
financial sector, appeals and modest initiatives to tackle tax havens, proposals for global taxes such as a tax on airline tickets or a levy on financial transactions or Tobin tax (Schmidt 2009), research by the IMF into an obligatory insurance premium for banks to pay compensation for problems they cause, a proposal by the governor of the Chinese Central Bank to introduce a new global backup currency (instead of the dollar), the agreement by the G2O to allow the IMF to issue new 'special drawing rights' (SDRs), and last but not least activities by various UN organizations to realize a global "social protection floor" (ILO \& WHO 2009). On the other hand more space is being created by countries to protect them individually from the negative consequences of globalization. Examples include measures to protect companies or economic sectors and new initiatives for industrial policy, measures to limit speculation and the negative consequences (higher exchange rates) of volatile international financial flows - hot money - as implemented, for instance, by Brazil and Taiwan in November 2009 (Coelho \& Gallagher 2010; Ostry et al. 2010), and lastly the increased focus on regional cooperation, integration and fundraising for mutual financial support and more policy space with regard to global organizations and within the world economy (for example the Chiang Mai initiative by the ASEAN countries, the Andean Reserve Fund, the Latin American Reserve Fund).

These attempts to embed markets more powerfully again at national level and to give national states more policy space to protect themselves against international crises and their consequences without losing out on the real or potential benefits of globalization, together comprise a complicated balancing act with numerous uncertainties and unknown outcomes. No one knows yet what this 'embedded globalization' is going to look like. That will be thrashed out in the coming period and we ourselves will be involved in the process. However, because autarky is not an option and no one expects to see a federal world state come about in the short term, were that to be desirable at all, new international coordination mechanisms need to be developed so that interdependencies can be managed more effectively, global public goods provided, cross-border problems solved, and rules of the game agreed which give national states sufficient policy space to solve the problems globalization can cause for some or all of their people.

In the near future it will be worthwhile exploring this general point of departure in more detail and also, in that context, to ascertain the exact nature of the longterm interests of specific countries and what these imply for the way in which the international order can best be shaped. In that respect one could follow the example set by Norway which recently adopted a theme-based approach to establishing its long-term interests. It is telling that this exercise was undertaken by a minister for development aid who wanted to find an answer to the question before starting to write a policy document on aid. His conclusion was that investing in the world order is both necessary and sensible and that development aid can serve as an 
instrument for achieving this. In that respect we must, as Nobel Prize winner Stiglitz put it, go beyond "the shame of enlightened self-interest". The development task is no longer something we do out of kindness, but because it is unavoidable.

\subsection{THE TASK: TO BE MORE DEVELOPMENT-ORIENTED, MORE SPECIFIC AND BROADER}

How can this task be fulfilled? First and foremost it is important to be clear about what development aid is supposed to achieve. This can be determined in three ways, at least in an analytical sense. Aid can be aimed firstly at improving direct living conditions, secondly at encouraging the development of people and countries and thirdly at safeguarding and providing global public goods. Each goal has its own type of legitimacy. Aid aimed at improving direct living conditions can be defended in moral terms, as can the pursuit of development, although the latter also creates conditions for a more stable world order and, in that respect, is a form of enlightened self-interest. Finally, working on global themes is a clear form of collective self-interest.

It seems necessary to give greater substance to the second and third types of aid. Increasing the self-reliance of developing countries and promoting common, global self-interest ought to be a more central element of Western development policy. In abstract terms this is a statement which many will whole-heartedly agree with. The problem is, however, that development aid has been institutionalized in such a way that attention focuses systematically on the more 'palliative' types of aid. Aid has become increasingly characterized by the desire to achieve attractive results which get plenty of positive media attention. This has led to a strong focus on the social sectors, often with no specific development strategies which are, indeed, difficult to develop at a time during which the emphasis is on attractive results and achieving rapid political successes. We need a different approach, one which breaks with a number of the historical mantras of development cooperation, such as the primacy of poverty reduction, the direct focus on the poorest, and the strong belief in the unconditional importance of investing in provisions like drinking water, primary education and healthcare.

The need for a clearer accent to be placed on development and global themes does not deprive direct poverty reduction of its raison d'être. However, choosing between development aid goals always means choosing between the here and now and the future (Barder 2009a). Poverty reduction relates to things which are visible now while development relates to future possibilities. Weighing up acute needs and future possibilities is an essential feature of political systems. All governments have to weigh up the interests of the current population against the interests of future generations and find a balance between the two. Experience has 
shown that political practice in most developing countries often leads to a choice being made in favour of the short-term division of often scarce resources among a variety of needy population groups, with long-term development taking second place. However, the same can be said of many Western countries. Neo-patrimonial structures contribute to the tendency to focus on the present. The development battle will therefore always have to be fought to some extent in a field of practice which is more inclined to use resources for (re)distribution among the current generation. Incidentally, making distribution issues a priority is sometimes not only politically opportunistic or easily defensible on normative grounds, but also functional. After all, a more equal distribution of wealth helps to maintain social stability, a goal which is, in itself, important in order to facilitate development. In more general terms, excessive inequality tends to be bad for economic growth and is not conducive to development (Nissanke \& Thorbecke 2006).

All this encompasses the task for development aid in the future. Although it is sometimes necessary to invest in stability or desirable to reduce poverty directly, the challenges lie in stimulating long-term development and addressing global issues. Clearly this is far from easy, but that is no reason not to try. After all, policy in Western countries is also a question of trial and error. When applied to the organization of development aid this means that movement is required in two directions simultaneously. In order to contribute more effectively to development, interventions must be more tailor-made and that means a shift towards locally defined country perspectives. By contrast, global issues require a broader approach. That calls for instruments which, at the moment, hardly feature in the ODA repertoire.

On the one hand, therefore, it is necessary to move towards professional customization. Universal ideas on development do not provide a good basis for local aid. Responses regarded as generally applicable have all too often produced little of value. Anyone who compares the country-specific and complex nature of development as a phenomenon (chapter 3) with the policy-related responses (chapter 5) can only conclude that there is a substantial mismatch. This is understandable because, after all, there are both moral and self-interest motives underlying the desire to further development, and the pressure to act is considerable. The point of departure of any politician confronted with an urgent task is that it is 'better to have a weak policy theory than to wait for the right response'. In the meantime, however, this mismatch has become uncomfortably large. An even bigger problem is that the system of development aid is insufficiently oriented towards permanent self-adjustment. Making mistakes is forgivable, not learning from them is not.

While the more detailed specification of aid implies a reduction in scale, on the other hand an increase in scale is also needed. Development is not only country- 
specific, it also depends on global relationships, rules and agreements. In extreme terms, aid runs the risk of becoming little more than a plaster on the wound, with developing countries being allocated resources to compensate for what they are simultaneously denied in other ways. To take one example: Mozambique is losing almost as much as a consequence of the EU sugar policy as it receives in European aid. This implies that there is a lot more development benefit to be gained outside the world of classical development aid than within it. At the moment there are imbalances in the world trade system, in the system of fiscal controls, in the way in which financial flows are regulated, in the climate agreements and in the free (or restricted) movement of people. The effects of this on development are much greater than those of direct aid, as revealed in chapter 5 . As a consequence, development aid not only has to become more specific, but also broader.

\subsection{THE FIRST CONSEQUENCE: BEING MORE DEVELOPMENT- ORIENTED}

No matter how morally defensible and politically understandable poverty reduction is, it should not be the direct or primary goal of development aid. As Mkandawire reminds us (2010b), development was always about more than poverty. Although the greater degree of attention for poverty is a welcome antidote to the dominant stabilization policy of the 1980 os and 1990s, he argues that "in correcting a narrow policy agenda the new focus pushes a good point too far when it focuses attention only on the proximate causes of poverty and narrows the development agenda." According to Mkandawire, in countries which have successfully combated poverty, the most important policy measures were not explicitly poverty-oriented: "the eradication of poverty is always embedded in social and economic development." The accent of government development aid has to be on increasing the development possibilities and on the self-reliance of countries and regions. Stimulating employment to help people earn their own livelihood and to generate inclusive growth are therefore important parameters in development policy, as are reinforcing economic sectors and the productive and innovative capacity of countries, diversifying the economy, the quality of institutions, and strengthening local capacity to find solutions.

\subsubsection{GROWTH}

The fact that growth is badly needed in developing countries is not down to it being inherently good or a goal in itself, but rather to the general idea that societies are only able to develop constructively if there is the prospect of 'more' (see Stiglitz et al. 2009). Although it is perhaps possible to justify the idea of Western countries still being able to develop mainly because of an improved distribution of the available resources, and the idea that the development of the world as a whole is increasingly becoming a question of (re)distribution and of sustainability and 
less related to growth (Jackson 2009), that option is not open to developing countries because they need growth to shape further modernization and improve material provisions for citizens. This was a point reiterated recently by Martin Ravallion, head of the research department at the World Bank (2009b). He started by asking the question of whether developing countries could end absolute poverty (according to the most recent World Bank standard this is an income of 1.25 dollars per day, in 2005 PPP) by means of internal redistribution. Redistribution then ought to be carried out by imposing on people who earn more than what is considered poor in the United States (13 dollars per day) a higher marginal tax rate (MTR) for all income in excess of those thirteen dollars per day. The tax incomes generated in this way could then be used to try to banish absolute poverty from the country concerned through income transfers and/or social programmes. Ravallion concludes that there are currently two categories of countries: in middle-income countries redistribution can be productive while, in most countries (and that certainly applies to the least developed countries) with an average income of less than 2,00o dollars per person per year, growth is needed first and foremost to finance social programmes. In concrete terms Brazil would only need a marginal tax rate of 1 percent in order to redistribute, and China 37 percent. However, if China really wanted to progress beyond the wider poverty line of two dollars a day, an MTR of 100 percent would be needed. Even a MTR of 100 percent (which is, of course, impossible) would allow India to eliminate just 20 percent of absolute poverty. In short, growth is an absolute condition for combating poverty in most developing countries. If the average income is as low as it now is in a lot of poor countries, redistribution could lead at most to, in the words of Amartya Sen "the redistribution of misery" (Krueger 2009).

\section{More or more effective economic activity?}

For the sake of their own development and to combat citizens' poverty in the long term, countries must reinforce their economies, and shape and upgrade their productive sectors to create national production and innovation systems (Cimoli et al. 2009). Although this sounds logical, there is no generally applicable answer to the question of how it should be done. The government of a poor African country which proposes improving its own competitiveness and investment climate in order to boost economic growth will be able to count on both international and national approval. Yet how are they going to achieve this? The World Economic Forum assesses the competitiveness of countries in its Global Competitiveness Report using more than one hundred indicators, while the World Bank marks the quality of the investment climate in countries on the basis of the Doing Business Index using a total of more than one hundred variables. Competitiveness is a complex business. Moreover, these kinds of league tables do not provide any certainty and their composition is open to all kinds of criticism (IEG 2008; Moore \& Schmitz 2008). What is more, it is impossible to assess all the low scores that developing countries achieve in indexes like these at the same time, and a list does 
not clarify what the priorities should be in a specific country. As a consequence, priorities for reforming the governance of processes with which capital accumulation, technological progress and diversification of production can be promoted, and for building up institutions for the accumulation of productive skills and industrial development, are often determined on the basis of what is fashionable in the international development community or what is currently considered best practice, without any specific account being taken of the local situation. It would be more effective first to make a diagnostic analysis to determine the key problems at a specific place and time, to then seek tailor-made solutions, and to leave additional problems for later. The key bottlenecks will change over time, making development a dynamic and sequential process. Only by experimenting and learning from successes and failures will it be possible to find strategies which work in one concrete context or other (Cimoli et al. 2009; Hausmann 2008; Hausmann et al. 2008; Rodrik 2007; Wade 2009b).

A country cannot achieve development without investment. Although the financial crisis recently resulted in a relative decrease, foreign direct investment (FDI) has increased enormously worldwide since 1980. Between 1982 and 2008, the value of FDI rose from 58 billion to 1,697 billion dollars, or by roughly 30 percent per year (UNCTAD 2009c). The number of multinationals has now grown to around 82,00o. In principle, this is good news since economic activity is crucial for development and FDI is particularly important in this respect. Foreign direct investments are more stable than other financial flows and are the most important external source of funding for developing countries, which, incidentally, benefit from this funding very unequally. Portfolio investments, which represent large flows of funds into and out of countries, are more likely to result in bubbles and fluctuations, while FDI is usually aimed at sectors in which a country has comparative benefits and brings technology, management, access to markets and social networks (Lin 2010).

One crucial point is, however, that not all investments are equally good for development. Developing countries benefit not only from more investment, but above all from better investment. As UNCTAD concluded (2007), the involvement of multinationals in commodity extraction industries can have both positive and negative effects on developing countries. On the one hand, these companies can contribute to "higher levels of efficiency, productivity and innovation in the industries concerned. On the other hand, their activities may also generate or increase economic, environmental and social costs." It is possible to earn a lot of money in developing countries without this leading to development, and this applies not only to extraction industry (Collier 2007; UNCTAD 2005). In Economic Development in Africa: rethinking the role of foreign direct investments, UNCTAD (2005) makes the point that the African continent is commonly misunderstood as being unattractive to investors. The main problem is that a lot of these invest- 
ments do not result in economic development. Development-oriented investments involve the sustainable transfer of skills, technology and innovation, and strengthening economic activities by increasing returns to scale, dynamic comparative advantages and rapid technological progress. To all intents and purposes this aspect is ignored in a lot of African countries which try to attract investors with tax benefits or by offering companies a privileged status.

The experiences in a number of Asian countries which have benefited from FDI have shown that foreign investments are primarily worthwhile if they were part of a wider industrial and agricultural strategy focusing on promoting, diversifying and upgrading endogenous economic activities. According to Justin Lin, chief economist of the World Bank, it is crucially important to accept that economic development is a continual process which cannot be divided into rigid or specific stages - as suggested by Rostow (1960) - and certainly not into a dichotomy between 'poor' and 'rich' countries. Each stage of economic development is "a point in a wide spectrum from a low-income, subsistence agrarian economy to a high-income industrialized economy", and given the endogenity of the industrial structure of a country "at each state of development, the targets of industrial upgrading and infrastructure improvement in a developing country should not necessarily refer to the industries and infrastructure that are in place in highincome countries" (Lin 2010).

In more concrete terms, least developed countries (LDCs) scarcely have any largescale industry and any industrial production that does take place is largely related to low-technology and labour-intensive products: in 2006-2007, an average of 90 percent of industrial exports by LDCs consisted of low-quality commodities like food, drinks and textiles. In itself this is not that strange, because it is relatively straightforward for a producer to diversify 'nearby', for example from shirts to overcoats and, generally speaking, rich countries export goods which have been produced on the basis of higher wages, while poor countries export low-wage goods. The challenge for proactive industrial policy is to develop a country's exports more in the direction of sophisticated goods, while bearing in mind both the considerable potential benefits and the potential problems and risks (Rodrik 2007b; Wade 2009b).

UNCTAD therefore states that international and national policymakers have to realize that structural changes are needed in least developed countries to facilitate dynamic growth and increasing returns to scale. This requires appropriate knowledge and innovations to continue developing endogenous economic activity and other than was thought during the hey-day of the Washington Consensus - an active role for the state. Industrial policy (Rodrik 2007b; Wade 2009b; Zarsky 2010) and an ensemble of 'infant nurturing measures' (Cimoli et al. 2009) have historically been used by countries that have undergone successful development, 
because national systems of production and innovation cannot come into existence of their own accord. The role of the state in the context of industrial diversification and upgrading concerns, for example, the coordination of related investments for new industries by various companies, support for new industries with incubation, and the direct fostering of foreign investment (Lin and Chang 2009). In addition, the state has to play a more classical leading role in improving the 'hard' infrastructure-such as energy, transport and telecommunication systems - and the 'soft' infrastructure - for example the financial system, education system, social networks, and legal structure (Lin 2010). The policymakers in these countries have to be given the time and space to set priorities, discover which policy mix works best in their situation, and adapt institutions and behavioural conventions to changing circumstances and evolving political and social preferences (UNCTAD 2009b). An important additional related aspect is the elaboration of regional cooperation to facilitate common activity in and between countries wherever possible.

\section{Trickle down?}

Without economic growth there will not be enough wealth to distribute. However, and this cannot be stressed enough, growth is not a goal in itself but a means for facilitating development, in the form of accelerated modernization. Growth is measured on the basis of national income. Although this provides an indication of the volume of resources available in a country to increase the population's prosperity, it says nothing about the extent to which a society succeeds in sharing that potential wealth. Therefore, specific measures and institutional safeguards are needed to ensure that the majority of the population actually benefit from economic growth, employment levels increase, and inequality is reduced (Stewart 2003; Malamed 2010). Scientists and UN organizations like UNCTAD, UNEP, UNDP and the ILO have worked to define the distribution of growth in more detail and expand the definition of 'growth' to include concepts such as fair growth, shared growth, pro-poor growth, growth with equity, inclusive growth, sustainable growth and growth with specific attention for women and environmental limits. Incidentally, it is by no means always clear what exactly this means (Birdsall 2010). In one of the variants of pro-poor growth, for example, a country that undergoes 1 percent growth with an average income rise for the poor of 2 percent is pro-poor, while a country that experiences 6 percent growth and generates 5 percent more income for the poor is not, because of the increase in social differences (Negre 2010).

Growth can help to deal with income differences, but there is no necessity that it will do so. In recent years, for example Angola has experienced enormous growth thanks primarily to oil exports, but this growth has mainly benefited the elite minority. Assessing the income distribution effects of growth is a complex matter. For some time the maxim was based on the famous words of World Bank researchers Dollar and Kraay: "Trade is good for growth and growth is good for the 
poor”. However, research supporting this claim was roundly criticized on methodological and theoretical grounds. As a consequence, policymakers and scientists currently believe there is no automatism, and that the postulated trickledown process has by no means always resulted in practice, or was too slow to have a sufficient effect without supplementary measures. Kraay (2004) concluded on the grounds of a cross-country study that the growth in average income of countries explains 70 percent of the variation in poverty reduction in the short term and 97 percent in the long term, and that a large proportion of the rest of the difference is determined by distribution.

Whether the poor in a country also actually benefit from more growth is dependent on, for example, the agricultural and industrialization pattern: economic and social policy improves the situation of the poor if it is aimed at raising the income they generate from working, in many cases in agriculture or from unskilled labour. An inherent element of this is one of the major problems with development in Africa: a lot of growth relies on the extraction of natural resources and rising commodity prices. The related industries are capital-intensive and it is the owners who primarily benefit. What is more, job creation is still too infrequently a spearhead of development policy - Amsden (2010) refers to "dementia over jobs" to indicate how little employment is actually referred to in development literature. Growth in labour-intensive activities affects a much larger group of people and leads to more employment. As Ravallion (2009c) observes, in India, China and Brazil "the sectoral pattern of growth mattered to poverty reduction, independently of the overall rate of growth". In short, it is not growth in itself, but the type of development in a country and the policy pursued that determine the outcomes for the poor (see also Adelman 2001; Demartino 2000; Dollar \& Kraay 2001a, 2001b; Donaldson 2008; Jolly et al. 2004; Kaplinsky 2009; Kniivilä 2008; Nayyar 2003; Nissanke \& Thorbecke 2006; O’Connor \& Kjöllerström 2008; Rodrik 2000; Saad-Filho 2007; Sen 1999; Son \& Kakwani 2008; Stanton 2007; Stewart 2003).

In recent years, a number of attempts have been made to assess in more detail the effects of various types of growth on poverty reduction (on the basis of capital intensive raw materials extraction, labour intensive industrial production and more efficient agriculture). As might be expected, there are no general formulas available. However, some general guidelines do apply. "Inclusive development and the ending of social exclusion require focusing on the development process as one of structural change and transformation that shifts economies from low-productivity, low-technology paths of development to technologically dynamic, skillsintensive paths towards the generation of equitable growth and development that benefit all", is another very general, but not unimportant conclusion by the Department of Economic and Social Affairs (DESA) at the United Nations in its report entitled Rethinking Poverty (UN 2010). Van der Hoeven (2010) refers to 
research that shows that "high employment levels reduce inequality, and, especially for developing countries, high employment levels in the industrial sector reduce inequality."

However, agriculture must not be neglected in the process. In the 2008 World Development Report entitled Agriculture for Development the position is taken that a rise of 1 percent in GDP growth in the agricultural sector will lead to a 2.5 percent rise in income for the poorest groups. Later studies show that this percentage can increase to 4.5 percent, but that this mainly applies to people who have to make ends meet on 1 dollar a day, with people who earn 2 dollars or more a day benefiting more from growth outside the agricultural sector (Christiaensen, Demery \& Kuhl 2010). The argument is that this is where the opportunities lie, particularly for Africa. After independence, Africa was for a long time self-sufficient as regards food. Agriculture was neglected partly under the influence of donors, with the hope that a new stage of development would soon be reached. To date, no real green revolution has taken place in Africa - partly because of institutional factors and the mediocre quality of the soil, and partly because of the low population density, which resulted in an expansion rather than an intensification of agriculture (with more new land being used). Gradually, however, the population density in some African countries reached the same level as in some Asian countries when they experienced the green revolution (Kuyenhoven 2007). This makes agricultural improvements in Africa a real challenge, even if the way in which that revolution took form in Asia -state-driven, market-mediated and small-farmer based - is not easy to imitate in the African context (Ruben, Pender \& Kuyenhoven 2007). What is more, the green revolution in Asia started during a period of high agriculture prices, which then dropped systematically from the 1990 os onwards, leading in turn to a considerable weakening of incentives for African farmers.

Different forms of growth have different effects. This applies not only to the extent to which rich and poor benefit from growth, but also to other groups. Boserup (1970) pointed out that women do not benefit from development in the same way as men, although here too, it is not possible to draw simplistic conclusions. It depends primarily on how countries develop and what sort of economic activity takes place. In South and Southeast Asia, particularly Malaysia, as well as in Latin America, women especially are benefiting from employment opportunities in the emerging manufacturing industry. Many globalization-related economic activities offer women more employment opportunities than men. Tourism is a good example, where 46 percent of formal jobs are fulfilled by women. Women educated to higher levels are finding work in call centres and data entry jobs in India and the Caribbean in particular. It is also becoming easier for women from developing countries to find work in the Western services economy, although that not only generates useful income in the countries of origin but also creates social problems. Where development is mainly accompanied by informal- 
ization of work, however, the position of women tends to weaken. The prospects of domestic workers employed in countries like Singapore, the US, Dubai and, to a lesser extent Europe, are often poor (Momsen 2010). More often than not the work is not performed in factories, but in small workshops or at home, to keep costs as low as possible and to ensure maximum flexibility (Pearson 2007).

The question of what kind of policy and what type of growth are effective in reducing poverty structurally in a concrete context cannot be answered in abstract terms. Based on a comparison of the reduction of poverty in Brazil, China and India, Ravallion (2009c) concludes that countries can sometimes learn a lot from each other but that "a country's initial conditions matter to understanding the specific strategy it takes for fighting poverty", and "as those conditions change so too should the strategy." How a country deals with preferences and social differences is first and foremost an issue for the inhabitants, interest groups and social movements of that country itself. If we look at the forty-nine least developed countries, the poorest countries in the world according to the United Nations, with jointly around 800 million inhabitants, UNCTAD annual reports show that growth in these countries since 2000 has had very few significant positive consequences for poverty reduction. According to UNCTAD, this is because growth in these countries primarily depends on exports, and has not resulted in an increase in consumption. Other causes are the significant increases in the population and especially the working population. For example, Breman (2001) observed that, in the case of India, integration into the global economy has to date not led to a reduction in the divide, with a process of informalization on the underside of the economy causing a deterioration in the standard of living. Growth will therefore have to be accompanied by a form of (re)distribution of wealth in order to have an actual positive effect on reducing poverty. However, no general statements can be made on the trade-offs which then apply and which need to be assessed on a measure to measure basis in each country, and which will also change in time as circumstances change (Birdsall 2010).

\subsubsection{WHAT ABOUT WATER SUPPLY, EDUCATION AND HEALTHCARE?}

Many people regard placing less of an emphasis on social sectors as counterinstinctive. After all, such a focus would appear to be on in-depth investments in a society's development. The question is whether this is really the case.

\section{Drinking water and irrigation}

A classic example of the tension between investing in improvements to living conditions and investing in development has to do with water. Anyone who builds water infrastructure to a far-off village in a developing country can do two things: use it to supply water for household use or to establish an irrigation system. The usual choice is to supply water for household use, in line with MDG 
7c. A number of leading water institutes, including the International Water and Sanitation Centre (IRC), recently published an empirical study showing that investing in a water supply which can also be used for agricultural production, has a much greater impact on local development than drinking water and sanitary services alone. Using eight case studies in Asia, Africa and Latin America, they demonstrate that investing in a water infrastructure which can be used for both household and communal production purposes leads to higher income, more sustainable production and eventually less poverty and better hygiene and drinking water. What is more, a water supply like this, which goes beyond supplying 'services' and which is also important for family incomes, is looked after better. Furthermore, poorer population groups themselves proved to regard water for production purposes as being more important than water for hygiene. As a result, drinking water services are, in practice, often used for production purposes for which they were not designed (Van Koppen et al. 2009).

Irrigation is a driver for agricultural production. Numerous studies have shown that the multiplier effect of an investment in irrigation on agricultural productivity is often between 2.5 to 4 , with the additional income from outside agriculture even growing twice as quickly as the growth within the sector itself. This positive impact is visible in the form of increased employment, affordable food prices and more reliable harvests (Molden 2007). It is therefore no surprise that empirical proof from forty countries shows that 1 percent growth in agricultural productivity in the past also pulled i percent of poor people up over the poverty line (Irz et al. 2001). It is interesting in this context to note that only 4 percent of the agricultural acreage in Sub-Saharan Africa is irrigated. This means that agricultural production is still only a fraction of what it could be with widespread irrigation. In many cases the problem is not the absence of water, but the lack of adequate investments in institutional and physical infrastructure (World Bank 2008a).

Water supply is still dominated (too much) by a humanitarian perspective: it seems more important to drink water than to earn from it. The same applies to ideas on how to deal with waste water. For example, the prevailing notion now seems to be that everyone in the world is entitled to a water closet connected to a sewer system. People are all too keen to elevate the Western model to a universal standard. Yet there seem to be plenty of indicators that such technology is certainly not the most sensible strategy in thinly populated areas - and that means in large areas of Africa. Water closets require a great deal of water and sewer systems are expensive to construct and maintain. There are often better options available which, however, are rarely chosen (Mara 2008; Massoud et al. 2009).

\section{Education}

It seems to go without saying that education always leads to development. Education is therefore a key focus of Western development efforts, with a relatively large 
portion of the budget being assigned to primary education. One of the MDGs also relates to universal access to primary education. The argument is that, if all children attend school, the rest will follow automatically. Unfortunately, this is not the case. Almost every country in the world has expanded its education system substantially since 1960 , but not every country has also exhibited growth. Moreover, growth figures fluctuate significantly in time, while investments in education have exhibited a clear upward trend. In other words, there is no visible correlation (Pritchett 2009a). Education sometimes contributes to growth, but sometimes growth depends on other factors. If there are no jobs, a properly trained working population has no additional value, at least not in an economic sense. Cuba is a prime example. In a number of cases there may even be too much education: if the employment market cannot provide work for educated people, this will mainly lead to frustration. This can be seen on a daily basis in many African towns, especially those with universities (Dietz \& Van Zanen 2009).

Modern macro approaches aimed at stimulating economic growth by developing countries' endogenous productive and technological capacities - such as 'new structural economics' (Lin 2010), or 'new developmentalism' (Zarsky 2010) demand a much more specific focus on the extent to which the development of human capital is an important factor for a country's overall development strategy. According to chief economist Lin of the World Bank, improvements in human capital "should be commeasurable with the accumulation of physical capital and the upgrading of industry in the economy. Otherwise, human capital will either become a binding constraint for economic development if it is undersupplied because of inefficient investment, or the country will have many frustrated highly-educated workers who cannot find adequate jobs if investment in training, knowledge and learning is not consistent with the speed of industrial upgrading in the economy" (Lin 2010).

It is also clear that not every form of education contributes equally to development. In that respect, the emphasis on primary education - the MDG 2- has actually caused a great deal of harm. A lot of countries (and NGOs) focus on getting as many children as possible to attend school without devoting much attention to whether they learn anything and what they learn. Attending school can therefore mean that a child ends up in a class with 200 other children. In some Sub-Saharan African countries, primary education is more like a form of childcare. Neither is it completely certain that a teacher will actually turn up to teach: in many African countries teacher attendance is less than 20 percent. Moreover, if a teacher is actually present, the quality of the teaching is often very poor. The educational impact is then measured by the number of children attending school rather than what they actually learn. It would have been better to have called the Millennium Education Goal the 'Millennium Learning Goal' (Pritchett 20ogb). 
Rather than education itself, it is the quality of education that is linked to development (Hanushek \& Wößmann 2007). The question then is what good education is and what type of education can stimulate development. Education can increase human capital and therefore productivity, or improve the innovative capacity of the economy, or the transmission of existing knowledge within a society (Helpman 2004). Education can also contribute to the formation of a critical middle class, which can bring pressure to bear on democratic and government institutions (Kapur \& Crowley 2008). However, the current education system in many developing countries is not oriented around this. Lant Pritchett, a leading education economist, has expressed his amazement at how similar education is wherever he goes, no matter whether it is Bangladesh, Vietnam or Ghana - everywhere there are children in classrooms learning things by heart. Education all over the world is oriented around preparing children for jobs as civil servant or for Western-styled production processes, with new workers coming off the education production line ready for a future in the factories.

The question is whether this education model is the most suitable. Developing countries have different economies and different institutions, and it is now more than 100 years since the introduction of classrooms with rows of desks. How can education in developing countries be adapted to local development opportunities? In the few years that they attend school, poor children in the villages of Mali learn how to use the 'accent aigu' correctly but nothing about sustainable agriculture. It is therefore no surprise that the emphasis on primary education has barely resulted in development. In that context it is interesting to note that the focus of the most recent five-year plan of the government of India - a country with a high percentage of illiterate people - is on improving children's skills instead of trying to realize universal access to primary education. The emphasis is on what people learn rather than where. Education can be a great deal more productive if it is combined with work and job prospects. A functional perspective on education like this ought to be adopted by Western donors, something they have failed to do to date. Bodies like the World Bank and the UN become fixated by the MDG, and with that by general access to primary education, while Unesco focuses primarily on high culture, and the ILO on terms and conditions of employment. Donors have failed almost entirely to invest in ICT on behalf of education and in the central production of good teaching materials.

Education can lead to development if it links up with a society's needs. If development is the goal, attention needs to be paid to vocational education and to tailoring education to the employment market. In addition, there generally has to be more of a focus on tertiary education. Take, for example, the green revolution. It was much more successful in Asia than in Africa because the local technological capacity was much greater there - local universities and research groups were able to adapt the new technology to local conditions (Kapur \& Crowley 2008). Despite 
worldwide interest in the 'knowledge economy', bilateral donors and the World Bank overtly discouraged developing countries to invest in higher education: they believed that Africa first had to ensure universal access to primary education. Partly as a consequence of this, the quality of higher education has drastically declined in many developing countries, and especially in Sub-Saharan Africa. What is more, only 5 percent of the population there had completed a higher education in 2006. Although this is a lot in comparison to the 1 percent in 1965 , it is only as much as in the Western world forty years ago (Bloom et al. 2006). Very few African countries have the minimum number of scientists needed to create a functioning scientific community. Fewer than one in a thousand inventions and one in two hundred scientific publications come from Africa and, in so far as research capacity exists, it is concentrated in a couple of countries, in particular Egypt and South Africa (Pouris \& Pouris 2009). What is more, the programmes offered by African universities are rarely attuned to what is needed for national and regional development.

In many developing countries, in so far as higher education is available, it often links up poorly with the employment market. While 50 percent of university students in China or Korea graduate in science subjects, a technical subject or business administration, in Africa this is 20 percent. A country like Ethiopia needs graduates in life sciences and agriculture management, while most students want to study business administration. In Ethiopia, therefore, limits were recently introduced to ensure that 60 percent of students choose a science subject. The problem goes beyond this, however. Just as primary education is modelled on nineteenth-century Western classical education, universities are modelled on nineteenth-century Western universities. Education acquires the form of classical knowledge transfer from teacher to student. Whereas Western universities use all possible means to establish links with the world around them - no Western university is complete without a Science Park - a lot of African students do not even go on work placements. Universities and R\&D institutions in developing countries are far removed from the practice of development, production and marketing. The problem is exacerbated by the fact that innovation in Africa is rarely the result of research and development, but usually of existing knowledge being tailored more effectively to one specific target group or other. Productive knowledge development which links up more directly with areas where knowledge is actually needed is therefore extremely important (Juma 2006).

\section{Healthcare}

Like education, healthcare can be important for a country's human capital, but this does not apply by definition. Significant breakthroughs in public healthcare, disease control and - often most importantly - better and varied food (WHO 2001) may have underpinned major take-offs in economic history like the rapid growth of England during the Industrial Revolution and of Japan at the beginning 
of the twentieth century, and the dynamic economic changes in Southern Europe and Eastern Asia in the 1950s and 1960s, but they were not the causes. As the Commission on Growth and Development (2009) concluded: "Historical research, cross-sectional analysis, and innovative ways of integrating household factors into cross-country studies have pushed the methodological envelope, but the results remain inconclusive". Research shows that growth often leads to better health; it remains unresolved whether the opposite is the case (Jack \& Lewis 2009).

A wide range of microeconomic studies show that good health can affect a country's development. Children who attend school learn and develop less if they are undernourished. Healthy employees are more productive. This seems trivial. When the French, led by the man who had also built the Suez Canal, Ferdinand de Lesseps, started to dig a canal through Panama in 1882, they lost around 22,000 employees over a period of six years to yellow fever and malaria, and they even had to cut short the project. The Americans eventually finished the canal in 1914, after first tackling the mosquitoes. The question is, however, whether such a situation also applies on a macro level in Africa. There is no shortage of human capital in many countries in Africa. Even the recent AIDS outbreak that has hit Africa, and which particularly affected the working population between the ages of fifteen and fifty years, appears to have had only a very limited effect on the economic functioning of the majority of countries (Bloom \& Canning in CGD 2009). There are regional differences, however, and the effect is more noticeable in some sectors than in others. Some companies in southern Africa sometimes find it difficult to find quality employees, and there is also a shortage of public sector workers, particularly teachers. The AIDs epidemic in Africa has stabilized since 2000, particularly in southern Africa (South Africa, Swaziland, Botswana, Zimbabwe), although it is still at a high level. In that area approximately one-fifth of people aged between fifteen and forty-nine is infected.

Growth cannot, therefore, be stimulated automatically by promoting better health, just as health improvements cannot be automatically stimulated by investing in good healthcare. Improving healthcare is therefore primarily important from a humanitarian perspective, and in that respect certain improvements definitely need to be made. There is for example considerable tension between a vertical, illness-related approach and a more horizontal approach in which the general healthcare infrastructure is improved.

Almost all the considerable health-related successes which have been achieved in Africa, such as the eradication of smallpox, tackling river blindness and the development of dehydration programmes for children with diarrhoea, are the consequence of vertical programmes organized per illness. The problem with a vertical approach is that it may solve an illness, but does not improve people's general 
health. Sometimes vertical programmes even override the existing infrastructure, as was noticeably the case with a number of capital-rich AIDS programmes (Easterly 2008a). Organizations like the World Bank and the WHO therefore argue against a vertical and in favour of a horizontal, integrated approach, preferably aimed at universal primary healthcare. Incidentally, this approach also has a downside: in many middle-income countries it leads to demand for secondary and tertiary care being left entirely to market forces. To avoid a situation in which a publicly financed system of primary care is accompanied by a privately financed system of hospitals, attention needs to be paid to the development of publicly initiated or subsidized insurance systems which provide cover for a broad range of care expenses. Numerous experiments are being conducted especially in West and Central Africa. The Ghanaian government, for example, is even actively encouraging the national coverage of local communitybased insurance. It is not yet clear how tenable those constructions are. The idea of insurance is often far removed from the perception of a lot of the residents of countries in the South. Many either expect healthcare to be provided by the government, or the money they pay in to be repaid after a certain period of time.

\subsubsection{AND WHAT ABOUT SECURITY AND STABILITY?}

In the context of aid, the assumption is that, in any event, there is a sufficiently stable environment in which aid can thrive. This is not always the case. What does it mean to pursue a more development-oriented policy in areas in which there is hardly any security and stability? Classical concepts from the development world are insufficiently equipped to deal with such situations (Voorhoeve 2007). The good news is that there appears to be a reciprocal relationship between the number of publications on fragile states and the fragility of states. Certainly after the large number of armed conflicts in the 1990s, and the subsequent UN peace operations, an impressive series of studies appeared which reflect the events of this age and the West's role in it - and the end does not yet appear to be in sight: the World Development Report 2011 is also going to be dedicated to fragile states. At the same time the number of countries in conflict situations is decreasing significantly. The majority of developing countries are more or less stable, although only the future will show how stable that is. None of this alters the fact that there are areas still torn by conflict: Somalia, the Central African Republic, Southern and Western Sudan, Southern Chad, the Democratic Republic of Congo. While the number of inter-state and intra-state conflicts is gradually declining - a process that has been going on since the 1970s if you regard the conflicts which flared up at the beginning of 199os as 'delayed conflicts' - the international community has become increasingly willing to intervene. The number of UN peace missions doubled between 1987 and 1994, and the UN has continued to be involved in conflict situations since then as well. Currently it has a presence in eighteen countries. 
People are gradually realizing that peace operations have to be embedded in a broader package of measures, including structural development. The $3 \mathrm{D}$ concept (Defence, Diplomacy, Development) was introduced to deal with this. It has considerably increased the complexity of the task. Building up institutions in post-conflict situations is a laborious process. Experience has shown that it is much more difficult to restructure countries which undergo enforced regime change, like Iraq and Afghanistan, than many had thought because institutions cannot be set up overnight. Kaplan's evaluation (2009) of the American experiences in Iraq is telling: "The significant reduction in violence in Iraq since the middle of 2007 has been based largely on four years of hard-won knowledge of Iraq's complex tribal and sectarian politics that allowed local commanders to follow a template for governance in Iraq that has existed for centuries and which even dictators like Saddam Hussein had to rely on." The same applies to Afghanistan. For a number of years the international community has been working without any major success on formulating plans and strategies for 'fixing the failed state of Afghanistan'. As Van Bijlert (2009) records, the work is carried out as if the state is a tabula rasa. No attention is paid to the reality of the existing institutional structures, cultures, traditions and memories. There is an idea of what the state should be like in Afghanistan, based on the enlightened leadership of King Abdul Rahman Khan and memories of the communist system with its coupons and subsidies. Yet this notion does not tally very closely with that of a Western liberal democracy. Neither can a Weberian bureaucracy simply be introduced into a country with a strong patronage system, where everyone tries to have the right (read: most powerful) contacts (wasetas) and where it is indeed unethical not to provide services to clan members, family members, and also neighbours and colleagues who need them. What is more, the political system is saturated with an insider-outsider logic which is not commensurate with a liberal democratic state as inclusion depends mainly on threats and shows of strength. This is how the old warlords and commanders have been included in the political system, for example as members of parliament or ministers. They then use their influence to exempt their legal and illegal trade or acquire personal control over parts of the security system, often thanks to their capacity to mobilize large numbers of armed men. "Fixing Afghanistan has thus largely become an intellectual exercise, with intelligent people drafting project designs - on issues such as governance, institutional reform, counter-narcotics, anti-corruption, social outreach or gender-equality - which possess an internal logic, but have very little relation to the realities on the ground" (Van Bijlert 2009: 166). There is good reason why, in 2007, once the expected successes failed to materialize, DFID started an Understanding Afghanistan project, flying in cultural anthropologists with sufficient local knowledge of the population and language to describe how the country 'really' functioned. 
In the meantime, the debate is growing about whether it is at all possible to build states by means of military interventions. The successful involvement of the allies in state-building in Japan after 1945 served as a shining example for a long time. However, it is arguable whether the same process can be repeated elsewhere. The question then is what has to be done in conflict and post-conflict situations? Some now argue against any kind of military intervention in failing states, and leaving local actors to settle conflicts themselves, even if it means war (Duyvesteyn 2009), or at most separating the warring parties, and avoiding state-building activities completely (Hellema 2007). In their view, it is an illusion to think that order can be brought to Afghanistan - or any comparable country - by a Western power that is only present in the country for a few years. It requires either a long and emphatic presence or adjusting and tempering the initial objectives.

This is the lesson Western donors need to learn. Achieving stability is an important contribution to development - but is also a very difficult and troublesome one. It requires a much better assessment process than the one currently in use. Sometimes, with a great deal of effort, it is possible to separate warring parties as demonstrated by, for example, the experiences in Cambodia where, incidentally, Vietnam should be given most of the credit for taking action in 1979 and ousting the Pol Pot regime, making it possible to start the rebuilding process with international support. That is, however, a long and difficult process which takes a great deal of time and effort. Often donors appear not to have the required patience and expect everything to be sorted out in just a couple of years. This was already referred to in the famous Brahimi report (2000). Based on an evaluation of a number of disastrous UN peace missions, the report recommended that peace operations should only be conducted if there was a clear mandate, limited goals which can be achieved within a reasonable period of time and based on a professional approach and a consensus in the Security Council. Although those points of departure still apply today, there is still no proper assessment framework for when and how to take action in fragile states and (post)conflict situations.

One huge problem associated with drawing up such a framework is that, in the coming years, the way the options are viewed will be determined by the experiences in Afghanistan and Iraq. It would seem certain that Afghanistan is going to serve as a model for the impossibility of rapid, externally-managed society building based on a Western model. This could well result in Western societies being so unwilling to create stability through military intervention that, at least for a number of years, no action will be taken in conflicts in Africa, where it might well be meaningful to do so. In African countries the situation is often fundamentally different. The interventions in Iraq and Afghanistan were primarily based on geopolitical and security motives, with the development dimension being added for good measure. In Africa, stability can usually be achieved at a much lower level on the violence spectrum. There, shows of strength are sometimes enough, as 
shown by the British Operation Pallister in Sierra Leone. The operation involved little more than occupying the airport and firing a few warning shots. In that specific context, that proved sufficient to restore calm. In Afghanistan and Iraq the focus was on Development to achieve Defence, while in Africa it was on Development by Defence.

It would be regrettable for military interventions in Africa to be banned because there are a great many more possibilities for successful action in African countries than in the extremely complex situations in Iraq and Afghanistan. Collier (2007) suggests that it would have been good for the West to have 'practised' military interventions in a country like Togo. Togo has 6 million inhabitants and has been the scene of a number of coups, latterly in 2005. Collier also makes other far-reaching suggestions in a later book (Collier 2009). In his eyes, the most effective instrument would take the form of a guarantee by the international community to take action if the stability of a country in Africa or elsewhere is jeopardized. This appears to be a more rigorous interpretation of what has been referred to for some time in UN circles as the responsibility to protect. In theory there is a lot to be said for this, but in practice it is rarely straightforward to make a proper assessment of when action should be taken. This is borne out by the experience gained during the UN peace missions. For example, during the genocide in Rwanda, the French sided for a long time with the Hutus, long after the Canadian UN commander Dallaire had asked them to take action. Many Rwandans have never forgiven the French for that, and it was a key motive behind the recent decision by President Kagame to change the country's official language from French to English although the formal reason was that it would improve trade relations with neighbouring English-speaking countries. Foreign interventions aimed at bringing stability often help to define the dilemmas of intervening more distinctly than those focusing on development, raising the question of how dirty your hands should get in the pursuit of what goals?

Smaller Western countries should not aspire to bring stability on their own - it is a task that really needs to be fulfilled by the international community. Nevertheless, it would seem prudent to take proper heed of recent experiences. One lesson is that it is unhelpful to make a contrived distinction between stability and development. Another is that the possibilities of exporting democracy should not be approached too simplistically. The gravity of the intervention must be attuned to the objectives: there is no point trying to build up a country almost from scratch and then leaving it to its own devices after only a couple of years. It is therefore important to make a proper prior assessment of whether it is possible to stay in a country for a number of decades during the period of relative calm that may follow a military intervention. If this is not possible, any intervention must have a more modest goal from the beginning. 


\subsection{THE SECOND CONSEQUENCE: BEING MORE SPECIFIC}

Development aid requires tailor-made interventions: the development problems in the various countries concerned must be the point of departure, rather than the umpteenth universal development theory (based on infrastructure, civil society or good governance) or impressive sounding goals agreed by the UN (such as the MDGs). Such goals formulated at global level are important in achieving an international consensus and can also have a mobilizing effect, but they go too far if they result in a one-size-fits-all approach. Aid-related thinking is slowly but surely being influenced by the realization that an approach like this is unsuitable for tackling the very diverse problems facing countries in the South. Unfortunately, however, too few conclusions are still being drawn for policy.

\subsubsection{COUNTRY AND REGIONAL DIFFERENTIATION}

Development issues must be approached in a more differentiated fashion and the same applies to developing countries. The term 'third world' should be banned forthwith. Specific development policy requires a more appropriate differentiation between countries. The question is how exactly should countries be grouped and classified? Answering this question is far from easy. Some classifications are based on income, others on different national performance league tables. In 2008, the UNDP already counted 178 different indexes compiled by various organizations and institutions. However, none of these do justice to the complexity of development and the nature of the differences between countries (Harris et al. 2009). In its long-term strategy, the World Bank, long the paragon of GDP-based thinking, identifies Sub-Saharan Africa, fragile states, inclusive development in middleincome countries, and global and regional public goods as the four critical challenges facing global development. Each of these challenges is based on a different way of dividing the world.

The focus then has to be on establishing different relationships with different countries. Germany, which reduced the number of partner countries in its development policy from 120 to 75 at the end of the 199 os (and then later to 6o), has now identified fifteen 'anchor countries' (including China, Brazil, Turkey, Egypt and Nigeria), based on economic weight and political influence, which require a special approach because they are important for reducing poverty, sustainable economic development, peace and security, global governance, and global public goods. Other Western countries will also have to differentiate their relationships on the basis of key characteristics. Relationships can be established with countries in Southeast Asia and Latin America based on the mutual exchange of knowledge, and agreements on climate, trade, the diaspora and other relevant factors. In this approach the transfer of funds is inappropriate - and is mostly considered as such by the partner countries in question. While the relationships with these countries 
will be oriented primarily around organizing transfers of knowledge, people and goods, there are also countries for which it is predominantly important to build up a relationship oriented around key geopolitical issues. For example, China is crucial for the procurement of global public goods. Within Africa it is equally important to be as specific as possible. The differences between African countries are considerable and there is no simple template which provides answers to the question of which type of relationships should best be entered into.

Although most people in Asia still live below the poverty line, a simple 'aid relationship' is no longer appropriate to most of the countries in the continent. Governments feel responsible for their own poor, and are unwilling to tolerate external interference without good reason. Poverty in which Western governments might play a more direct role in alleviating is becoming increasingly concentrated in Sub-Saharan Africa. Of the thirty countries at the bottom of the UNDP's Human Development Index, which encompasses all the countries in the 'low human development' category, only one is not in Africa (East Timor, a country with 1 million inhabitants). It should be noted, however, that no score is allocated to Afghanistan due to the exceptional situation there. What does this mean in more detail?

Since 1980, China has managed to extract 600 million people from poverty and, at the current rate of growth, a basic subsistence level will be achieved for the majority of the population within one and a half decades. This does not apply to India which, in effect, consists of 29 countries. Although India is experiencing growth, this is primarily increasing the contrasts between the rich west and south of the country on the one hand and the poor east and north on the other. This problem will persist for some considerable time to come because, for the time being, population growth in India is expected to be substantial - in 2030 it is expected to surpass China as the country with the most inhabitants. There is not much to do for Western donors in India, however, not because there are no problems but because the Indian government does not appreciate Western donors labelling India as a developing country. In 2003, it explicitly asked the Netherlands to withdraw as a donor. India regarded the Dutch approach to be too arrogant, certainly in proportion to the amount it donated.

Other countries in East and Southeast Asia are undergoing rapid development: South Korea and Taiwan have a Western level of income, Thailand and Malaysia have a substantial middle class, while countries like Indonesia, Vietnam, Cambodia and Laos are well on the way to reaching that stage. The Philippines is still lagging behind, partly because the revolution by the middle class against Marcos in 1986 has not been followed by a more equal distribution of wealth, in particular land. Bangladesh still deserves most attention, if only because it is home to 160 million people - even though, if present trends continue, it will be a middle- 
income country in around 2020. The circumstances in Afghanistan and Iran are unique. In principle the 'Stans' (the former Soviet republics in Central Asia) have more than enough raw materials to look after themselves. In Turkmenistan, petrol costs less than water: water scarcity, excessive grazing and pollution are the most pressing problems facing the population there, the majority of whom live in remote areas. Most of the regimes in the region are very repressive and are preoccupied with safeguarding their own interests, meaning that redistribution and structural development fail to get off the ground. In short, despite the wide differences between the countries, in Asia development aid in its classical form will only apply to a very limited number of countries. The word in the corridors of the World Bank is that bank staff enjoy going to Asia because successes can still be achieved there; the bank has a presence there primarily because it has to be seen to be successful, rather than out of necessity.

Latin America also has numerous middle-income countries, which are increasingly going their own way. Bolivia and, to a less extent, Colombia and Ecuador are not growing sufficiently and Haiti is a special case, but, in general terms, Latin America is carving out a place for itself on the world stage. However, the development of the local regional organization, Mercosur, is not as advanced as other regional partnerships. This is partly because it has a less distinct mutual orientation than, for example, ASEAN, the Southeast Asian regional organization, and partly because of considerable political differences (Chavez is not universally popular) and the predominant role of Brazil. Many countries in Latin America are characterized by considerable income differences, although there are indications that this inequality is decreasing. Between 2000 and 2006, the Gini coefficient in twelve of the seventeen Latin American countries dropped thanks to, among other things, a reduction in the income differences between educated and poorly educated employees (as a consequence of the quantity and price effects) and progressive government cash and non-cash transfers (Lopez-Calva \& Lustig 2009).

Then there is Sub-Saharan Africa, a strongly underpopulated continent, with an economy the size of that of a country like the Netherlands or a city like Chicago. There is much less growth there and plenty of indications that it will be some time before the continent will be able to look after itself. Africa got off to a false start and nations are having to be built on the basis of arrangements which do not, or scarcely, fit in with existing social relationships. The institutional structure left behind by the colonizers was, in many cases, too weak to support the countries. Political parties have little meaning and almost all governments are overtly patrimonial. In addition, the nation and state-building process is by no means complete. For example, a number of African countries are still expected to collapse, starting with Sudan in 2011. However, the conditions for aid are improving in Africa because the situation there is becoming more stable. At the beginning 
of the 1990s, twenty-six African countries were involved in wars or large-scale violence against the state. At the start of 2007, five conflicts were still raging and there was more or less permanent fighting in two (Darfur and East Congo). A number of countries appear to be making impressive progress (Ghana, Tanzania, Mozambique and Rwanda), though there are also examples of setbacks (in 2009 in Madagascar, Zimbabwe, Guinea and Gabon).

Additional differentiation needs to be applied in Africa as well. A small number of countries have de facto failing governments, and the involvement of individual Western donors is modest - and primarily aimed at providing humanitarian aid, via NGOs or more ambitious channels - and based on multilateral attempts to build states which have a reasonable basis in the country's own social structures. Nevertheless, the majority of countries in Africa are building institutions in a way which creates some stability. Development aid could play a significant role in these countries, if done in the right way.

\subsubsection{DIAGNOSTIC APPROACH}

Contributing to development means first of all making accurate assessments of how countries are developing so that tailor-made initiatives can be taken. At the moment, development aid is insufficiently context-dependent and countryspecific. Institutional reforms propagated by international organizations - and often followed by bilateral donors - are still grafted onto a best practice model. This assumes that it is possible to devise a single unique set of suitable institutional arrangements based on successful practice and prescribe it elsewhere. This quickly results in a demoralizing list with adaptations, all of which are important. Although that makes it easier to make comparisons between countries and to benchmark, it does no justice to the complex reality and the differences between and within countries. The development processes of rich countries (Chang 2009a) and six decades of development policy have shown that there are no examples or generally applicable formulas which can simply be copied and applied to development. Assuming that this is the case can all too easily backfire (Fukuyama 2007; Grindle 2001, 2004; Rodrik 2008a).

However, this does not mean that nothing sensible can be said about fostering development. Between universal claims and 'anything goes' handy guidelines are available for economic policy and 'good enough' institutions which can be developed in a variety of ways - not only ours. Knowledge about development in other places and times is important, but professional development aid needs contextual interpretations which take account of countries' specific history, circumstances and path-dependencies. In other words, professional development aid requires tailor-made solutions based on a proper understanding of the complex or even chaotic systems which are the object of intervention (Adelman 2001; Chang 2002, 
2005, 2007; Evans 2004; Ho 2009; De Lange 2010; Mansfield \& Snyder 2001; Paris 2004; Rodrik 2007, 2008a, 2008b).

The difficult question is then: how do we know which interventions contribute to a country's continued development? Wherever development aid is caught in a paralyzing 'everything is linked to everything else' ideology, it spreads out in all directions and aims at the general transformation of entire societies. Choices are therefore inevitable in order to concentrate the effort in terms of time, money and knowledge. Instead of a charitable attitude - all aid is welcome - a pragmatic approach is desirable based on an assessment of which initiatives will be most effective.

\section{Diagnostics}

Professional 'aid for development' is comparable to the way in which good doctors go about helping their patients. To start with it is important to diagnose professionally, with a trained eye, per country or region where the most essential pain is and what is causing it, to be able to reflect on what effective resources could be used to bring about change (Collier 2007; Hausmann et al. 2005; Hausmann et al. 2008; Lindauer \& Pritchett 2002; Pritchett \& Woolcock 2008; Reinert 2007b; Rodrik 2007; Sachs 2005).

A 'diagnostic' approach to development therefore means trying to define, as accurately as possible, the greatest barriers to development in a country. These may be related to the economic situation (for example too limited availability of credit for companies or a lack of proper infrastructure), at the level of government and the state (for example a lack of safety, or insufficient rule of law) or within society as a whole (for example insufficient people with the right training, or a lack of trust or social capital). The next step is to determine which of these binding constraints is the most important and needs tackling first. The issue then is to assess how this can best be tackled in a specific context. All in all this approach makes interventions more specific and leads to sequencing and timing instead of everything appearing to be equally relevant or urgent and being tackled in a uniform manner.

The situation in the developing country therefore becomes the point of departure for development aid, rather than the wishes, experiences and preoccupations of donors and voters in the West. In practice, this is by no means a foregone conclusion. In the 1950 s and 1960 s, for example, the focus of much aid was on supporting farmers, including those in Europe. However, in recent decades development aid has neglected agriculture and has been primarily invested in social sectors - just as happened in the West. Development policy is also characterized by trends, as a consequence of the ineradicable habit of wanting to provide general responses, even if the problems are specific. It is, however, high time to say farewell to this approach. A country-specific strategy facilitates the specific use of knowledge, 
money and other resources and takes account of the differences between and within countries, with the added benefit that developing countries do not have to change everything simultaneously: Djibouti is not required - nor is it at all capable - to become a kind of Denmark or the Netherlands. Other than in the case of the not overly successful - large utopian adjustment and reform programmes which dominated the development agenda of the 1980 os and 1990s, the focus in the near future will be on the development of a precise and specific effort based on modesty and realism.

Various examples of such a diagnostic approach can now be found in both scientific literature and policy practice. In addition to researchers, various international institutions - such as the Asian Development Bank (ADB), the World Bank and the Inter-American Development Bank (IADB) - and donors - like the Millennium Challenge Corporation (MCC) set up by the United States and DFID - have started using growth diagnostics. The logical structure developed by the pioneers of this approach is depicted in the decision tree in figure 6.1. The idea is that, if you read the tree from top to bottom, you will identify the most important obstacle to growth at this moment in time and in this context. Is the problem an excessively low return on investments or excessively high financing costs? If there are indications of low returns, this will be because the social returns on investments are too low (if this is the case, the question is what this is due to: a poor infrastructure or a shortage of human capital?) or because private returns for investors are too small (in this case the question is whether this is due to market failure or government failure?). If it is more plausible that the financing costs are too high and there is insufficient affordable capital available, the question then is whether this is due to inadequate access to international capital markets, or to domestic problems (a low savings quota, for example, or an underdeveloped financial sector). Many of these problems are present in most developing countries, but not always simultaneously, nor to the same degree. As a result, they are not always equally restricting, nor a problem at all in some cases. Dani Rodrik (2010), one of the pioneers of growth diagnostics, organizes executive programmes for senior World Bank economists at the Harvard Kennedy School and uses the above decision tree to discuss South Africa's binding constraints. "Every year," he writes, "I am surprised at how quickly these practitioners dismiss some of the conventional culprits that typically preoccupy them in their country work (such as poor governance, macroeconomic instability, bad infrastructure, lack of openness to trade) and come to focus on a few problem areas (typically, lack of competitiveness in tradables and high cost of labor)." Specific research into binding constraints and discussions with the various parties involved can clarify what are the biggest problems and where something has to be done as a priority to increase the chance of more and sustainable growth. 


\section{Figure 6.1 Growth diagnostics}

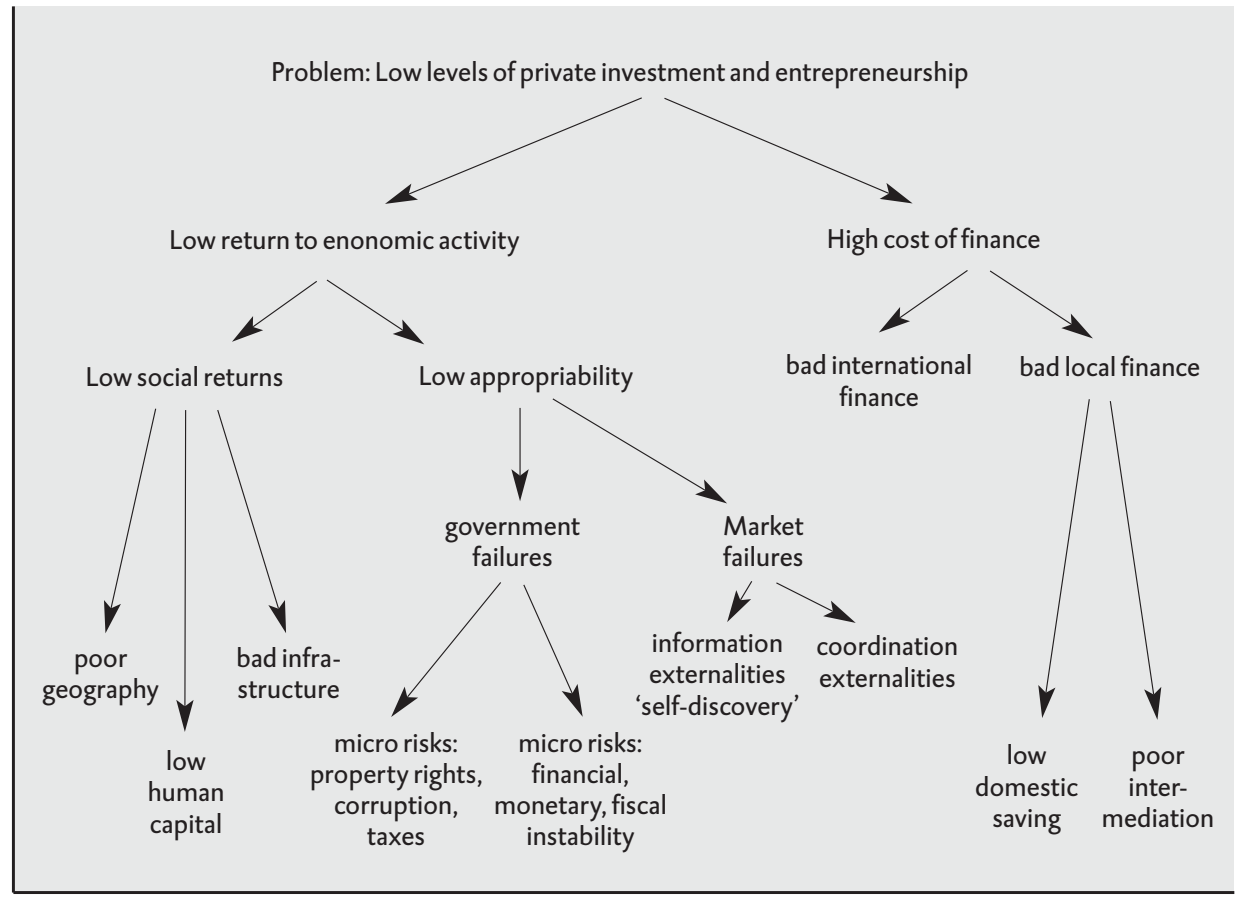

Source: Rodrik 2007a

To avoid misunderstandings, it is important to realize that this decision tree is not the only conceivable one, and certainly not a magic wand which can be used anywhere and anytime to identify key obstacles to development. The chance that tackling one large binding constraint can solve all the problems that exist in a particular country is, in any event, zero and it is also likely that "complementary or interrelated policy adjustments" are needed to achieve an optimal result (Misch et al. 2010). What is more, it will always be necessary to identify new obstacles and tackle them sequentially. Neither can all questions and problems be accommodated in one schema.

This schema relates to economic growth, but diagnostics can also be used for subanalyses like the one used, for example, in Trade Diagnostic Integrations Studies (see www.integratedframework.org), and they can also be useful in the political and institutional fields. In fragile states, in particular, everything appears to be a priority: infrastructure, sanitation, food, maintaining order, employment, education ... everything is a problem. The many international actors therefore work simultaneously on all fronts, but it is impossible to realize all the items on their overfull development agendas (Cousens \& Kumar 2001 in Van der Borgh 2009; Patrick 2007). According to Grindle (2007), it is becoming increasingly clear that 
the first priority has to be to set priorities. As shown in Figure 6.2 this can be done by, for example, first taking a careful look at the form of a failing state (is it, for example, a post-conflict state or dictatorship?), assessing the possibilities for change and then estimating how much effort every individual change will cost. Here too countries do not have to rush to fulfil the norm that applies in the Netherlands or Denmark: good enough governance is good enough.

\section{Figure 6.2 Political diagnostics}

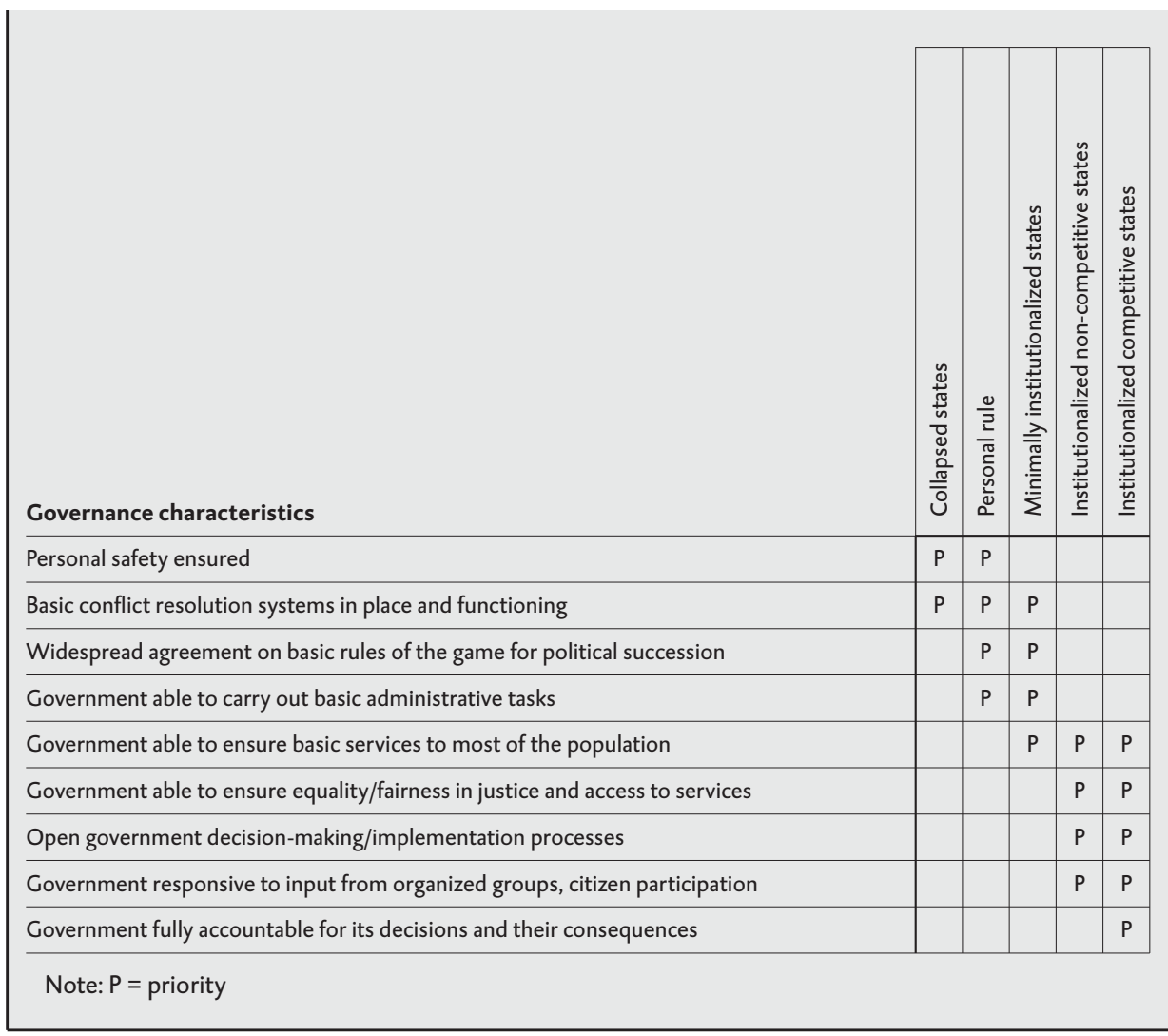

Source: Grindle 2007

In addition to being useful in the economic and political fields, diagnostics can also help to make well-reasoned choices and set social priorities. Again, everything appears to be equally important: child mortality, education, healthcare, clean water, malaria, HIV/AIDS - it is almost unethical to choose. The MDGs imply a general approach for all countries in a multitude of social dimensions, and are therefore really the antithesis of choice. Neither can instruments used by the World Bank and bilateral organizations be regarded as having a social diagnostic 
function. Although the Poverty Reduction Strategy Papers (PRSPs) which developing countries have to draw up improve every year, most are primarily spending department wish lists, particularly for education, healthcare and agriculture. PRSPS are often poorly thought-out and far removed from being clear-cut development strategies. In the words of researcher Whitfield (2009) they "tend to be an aggregation of existing government and donor sector strategies and projects, rather than an ideological coherent national strategy for achieving growth with poverty reduction in the next ten years and prioritized, concrete steps to achieve it”. The PRSPS of different countries also appear to be suspiciously similar, with all the fields of social development being covered, and almost all of them stating that the government wants to improve education for girls in remote areas. They do not include analyses of the distribution of capital, assets, income and power, nor proposals relating to administrative and political organization. There is almost never any attention for the private sector, nor for the role of decentralized governments. Lastly, the paragraphs on implementation usually lack content.

The Asian Development Bank is now also experimenting with social analyses and has developed an analysis tree to identify the binding constraints for social inclusion to ensure equal access to opportunities for all and poverty reduction in the event of growth. The tree has been applied in, for example, Nepal, the Philippines and Papua New Guinea (see figure 6.3). A conceptual framework like this makes it possible to investigate structurally where the greatest hindrances are to raising the population's standard of living and reducing inequality, and to acquire a wellreasoned insight into the question of whether it is, for example, actually worthwhile, in a concrete context, to reduce poverty by focusing on 'safety net policies' which offer protection against risks, or on 'cargo net policies' which increase the productive possibilities of the long-term poor through specific education or healthcare. Tricky trade-offs may be necessary between helping more people or a smaller group. As Barrett et al. (2006) explain, "For example, cargo net asset transfer programs that are 'a mile wide and an inch deep' may be predictably ineffective in the presence of critical wealth thresholds".

\section{Not a technocratic exercise}

Economic, political and social diagnostics can be used to help to design a countryspecific development strategy, but they are not a technocratic instrument which will produce the 'right' outcome without discussion. Neither should they be viewed in isolation because education and healthcare, for example, are not only important for people's personal development and self-reliance, but can also be of consequence for the quality of 'human capital' and also, in certain circumstances, for a country's economic development. Diagnostics is not an exact science: to start with, situations can be assessed in different ways. Here too, an analogy with medical diagnostics provides greater clarity since, while the degree of objectivity in medical diagnostics is greater than in the case of development diagnostics, the 


\section{Figure 6.3 Diagnostic framework for inclusiveness}

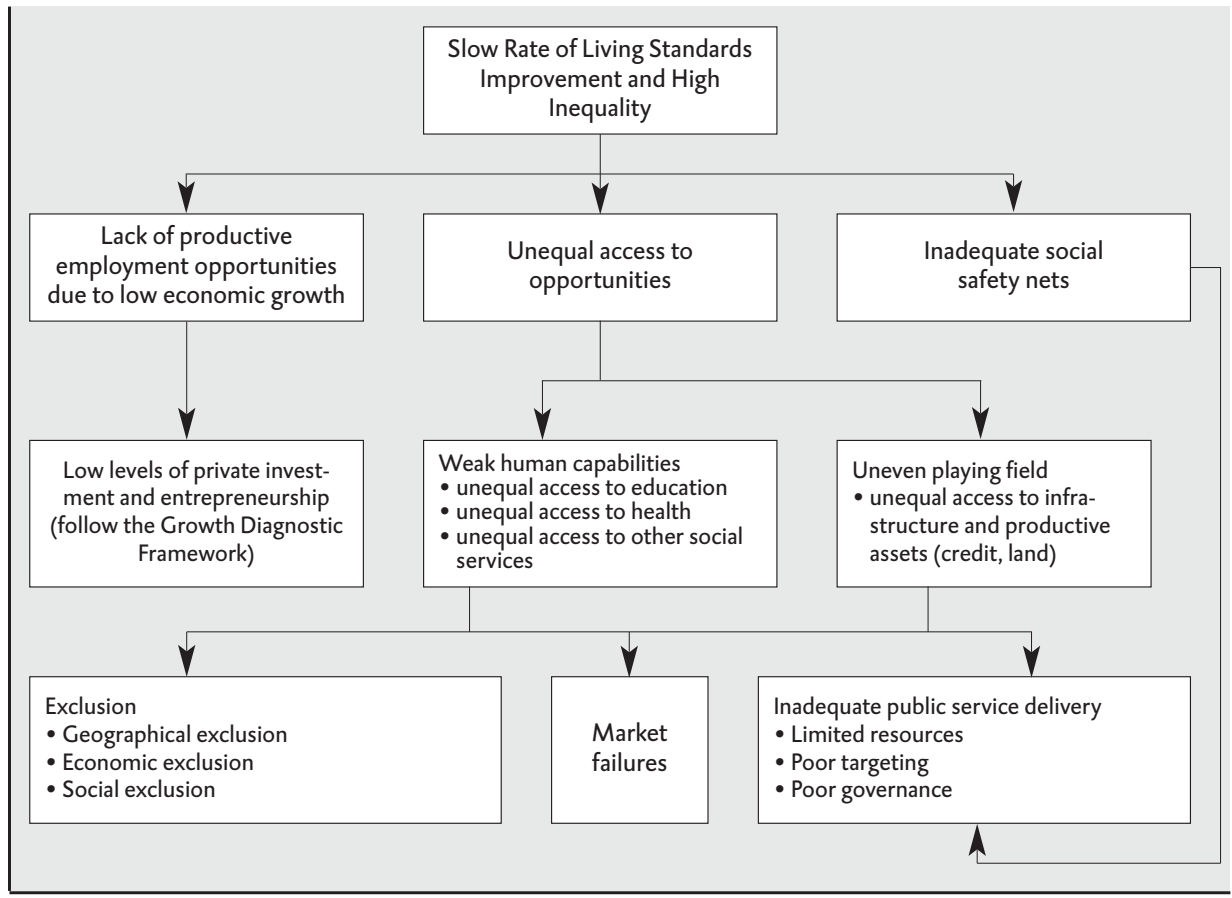

Source: Khan 2010

possibility of a second opinion is still regarded as a fundamental right. Analogous to this, it is essential to find an adequate structure to compare various diagnoses. A diagnostic approach must also enable alternative interpretations and models to be submitted to the various parties involved, to inspire them and allow a more effective analysis of the trade-offs and risks of the different ways of tackling the diagnosed problems. It cannot be stressed enough that diagnostics is therefore not a search for some kind of holy grail, but a way of setting deliberate and specific priorities, and weighing up what constitutes a good country-specific development strategy. The priorities in Mali will be different to those in Burkina Faso, simply because their concrete problems and political and institutional situations are different, even though they are neighbouring countries with many similarities.

In a growth diagnosis for Cambodia, one World Bank researcher concluded that this can be difficult enough in practice: "Looking for one or few binding constraints is (...) politically counterintuitive. First, in the Cambodian, Buddhist context, there is a view that everything should be improved at the same time, a theme that echoes that of a 'balanced growth' path. Second, given the uncertainties (conclusions are often based on signals or hints, rather than being firm), the 
rapid changes of the economy, and the time it will take to address constraints that might emerge only in the future (e.g. skills), it would be unwise to 'put all one's eggs in the same basket'. This suggests a process-oriented diagnostic that enables adjustments over time. Third, whether within Government or a multi-sector organization like the World Bank, radical prioritization at the expense of a sector or issue is challenging" (Guimbert 2010). Which of the possible solutions for prioritized binding constraints is eventually chosen will usually be the subject of debate, and evoke resistance and sometimes also conflict. A diagnostic approach is therefore not an alternative to a political process. Its primary goal is to substantially improve the quality of the political debate on development to permit the various considerations to be weighed up.

\subsubsection{CHOICE OF INSTRUMENTS}

Every few years, the world of development aid adopts a different trend, which is then invariably replaced, some years later, by a new one. That mechanism comes about because general solutions and instruments are continually propagated for specific problems. Convincing examples can always be given of situations in which such a solution or instrument works, but these are soon followed by counterexamples of situations in which they have detrimental effects. After a while someone will present a new general concept, based yet again on new examples, and the cycle starts from the beginning.

At very regular intervals, for example, the point is made during the development debate that it would be sensible to focus primarily on the government as a source for development. Unexpected reflections on this view can be found in the recent encyclical letter entitled Caritas in veritate by Pope Benedict XVI, which advocates re-evaluating the role of the state in areas in which this is functional for development. However, whether governments are the deciding factor in providing healthcare and education, or whether the initiative comes from civil society or private parties, is a question which cannot be answered in general terms. The answer depends on the country in question, and can vary over the course of time. It is also directly related to the question of whether aid has a productive or destructive effect. In a country with a fragile state structure it is, for instance, often sensible to place the building of a system of healthcare and education primarily in the government's hands because setting up parallel structures will quickly erode the government's legitimacy. However, if governments excessively serve specific political or ethnic groups, it may actually be better to build healthcare and education structures without the government's involvement. It is also a good idea to distinguish between a government's various tasks. In many African countries, a distinction between the government's role as financier and implementing party could have a positive effect on the quality of healthcare or education. 
Similarly it is important not to think too simplistically about how to stimulate economic activity. Although it may start with companies, this is not always the case. Sometimes the government may have to create facilities for companies - such as attractive credit facilities for small and medium-sized businesses which are often absent in African countries - and sometimes it will mainly be physical infrastructure that is needed, or legal infrastructure, or something entirely different. If we can learn something from sixty years of development policy it is that it is important not to adopt often fairly ideological positions unquestioningly but to examine specifically what the most important bottleneck is in a concrete countryspecific context and how it can be removed.

Interventions will therefore have to be carefully selected. In a small number of cases this is a relatively straightforward process. Countries with natural resources do not primarily need money but support with managing those resources, including the building of an institutional system which is able to do this, and focusing on diversification of the economy because the quantity of natural resources is finite. In some cases it is a better idea to invest in agriculture. Countries with fertile soil, and there are many in Africa, have often failed almost entirely to develop their agricultural potential, either to feed their own populations or to develop an export market. There are good reasons for the latter: the resource-rich Middle East has a severe lack of good quality farmland, as does China where only 7 percent of the soil is suitable for arable farming.

For agriculture, too, it is important to establish the right approach. Investments in fertilizer, irrigation and better crops, in hygienic food storage, in electricity and roads, and in a sound financial sector are obvious steps to take, including the development of trade chains. Sometimes, however, it is better to place the emphasis on knowledge development and diffusion. Since the introduction of new agriculture technology in Asia, Latin America and Africa in the 196os and 1970s (the green revolution), few large-scale innovations have taken place in Asian agriculture, while the failure of this revolution in Africa meant there were no large-scale increases in food production there at all. This relative stagnation can only partially be attributed to the impossibilities presented by the physical environment or technological limitations: it is primarily down to a lack of applied knowledge development, in particular the lack of a scientific network which facilitates local innovations (IAC 2004). The emergence of large centralized knowledge institutes like the International Rice Research Institute and the International Maize and Wheat Improvement Centre (СІМмYT) laid the foundation for innovations in cultivation techniques which provided a basis for the green revolution in Asia but meant that innovation in agriculture became increasingly centralized and scientific, and thereby even more removed from the possible users of knowledge and techniques. The centralized scientific knowledge became detached from the various everyday practices, and knowledge and technology developments therefore frequently fail 
to link up with the specific conditions of agricultural practice. Conversely the many small-scale innovations by farmers in the field are not sufficiently identified and facilitated through appropriate scientific embedding on a sufficient scale (Maat 2008).

Knowledge development and diffusion also assume a tailor-made approach. For a green revolution in Africa, or rather for large-scale growth in African agricultural production, more is needed than centralized technology intervention. Due to the seriously fragmented character of African agriculture with its dozens of cultivation systems and many hundreds of sub-cultivation systems, each adapted to specific environmental factors, it is important that innovation is coproduced by science and practice. Scientific researchers will have to identify the bottlenecks and the opportunities facing production increases for each cultivation system, and will have to understand existing local innovations in order to link up with developments in scientific technology (Richards et al. 2009). The context-specific nature of such innovation will be fundamentally different from the one-size-fitsall innovation on which the green revolution in Asia was based. The many specific agricultural contexts in Africa require a wide range of local revolutions in order to increase African agricultural production (IAC 2004).

\subsection{THE THIRD CONSEQUENCE: BEING BROADER}

Western development policy is often two-faced: we give countries financial and other support but, at the same time, pursue policy that can undermine development. The key question ought therefore to be how to avoid the positive effects of development aid being undermined by the negative consequences of policy in other areas such as trade, migration or environmental policy. Unfortunately, this implies more than a simple technical policy adjustment. At national level there are often opposing interests at play and, in addition, much of the policy in question cannot be changed at national level. For example, trade policy is governed by the EU, and environmental policy by global level agreements. Policy coherence, since that is what is at stake, can generate more development for developing countries than aid, but giving it concrete form is a difficult task.

The importance of (joined-up) cooperation with parties outside the classical development domain in order to contribute to development and solve global problems has now also been broadly acknowledged. The question is, however, what form this is going to take. As was described in chapter 5 , not much progress has yet been made as regards the practical implementation of policy coherence. At the same time, the possibilities are enormous. The European Commission recently called on the member states to provide extra financing for development, with the idea being that every euro assigned to development aid should mobilize five euros for activities which were officially not development aid but which involved, for 
example, the transfer of technology, trade financing or private investments. This is intended to create 'development leverage', and that is at the very least an intriguing idea (European Commission 2009a).

The consequence of this reasoning is also that the ODA concept has to be applied in a less forced manner than has been the case to date. Non-development actors, who often have better contacts with specific international fora than traditional development organizations, should also carry out development tasks and could, therefore, also partially be funded from oDA resources. In this context there is considerable international interest in the operation and impact of Norway's International Climate and Forest Initiative, and Germany's International Climate Initiative, which link climate policy and development, and are partially funded by ODA. However, according to Paul Engel, director of the European Centre for Development Policy Management (ECDPM), an important lesson to be learned from previous experiences has to be, in all these cases, that "development objectives should be leading, or at least demonstrated beyond reasonable doubt. No matter what other objectives international actors may define for their cooperation, development impact must be the single criterion guiding the use of ODA". A good plan therefore needs to be accompanied by options for a continuing dialogue on the results between all the parties involved, with donors also having to give account of their actions (ECDPM 2009b; European Commission 2009a, 2009c).

\section{Global public goods}

Broadening development goes beyond the involvement of new policy instruments in development work because developing and Western countries also increasingly have common interests. After all, we all stand to gain from 'global public goods' such as a stable climate, knowledge, and financial stability.

More and more of the wide range of cross-border issues do not relate to interests which conflict (or potentially conflict) and therefore have to be moderated by means of coherence policy, but rather relate to common interests. These interests offer possibilities for linking development policy to themes which are also in the interest of rich countries. UNDP put this issue on the international policy agenda in 1999 by introducing the concept of global public goods. International public goods are not about sharing or transferring cross-border consequences of domestic policy (spillovers or externalities), but about benefits for everyone in the world (in the case of global public goods) or in the region in question (in the case of regional public goods), which can only be realized or retained through specific action and cooperation.

Within national states, public goods have been a recognized category of services and goods for some time, from which no one can be excluded (non-exclusivity) and whose use by one party is not detrimental to use by others (non-rivalry) - 
peace and good macroeconomic policy are well-known examples. Such public goods do not become available in sufficient quantities via the market of their own accord because everyone can benefit from them free of charge (free riders). Without coordination, a 'collective action problem' arises, whereby everyone waits for others to act, with insufficient supply as a result. The 'public' element of public goods lies in the fact that they, in principle, affect everyone, or ought to be available to everyone, but this says nothing about the way in which public good will be provided. How this happens can differ from case to case, and can become the task of both private and public parties, individually or jointly.

In the meantime, the national nature of public goods no longer corresponds to the world in which we live, because cross-border public goods like counteracting global warming and safeguarding financial stability are becoming increasingly important for our collective welfare. In addition, globalization has created new international public goods. Examples are the prevention of global public bads' like internet crime and fraud, the spread of diseases by trade and travel, and global public goods like the international regimes for cross-border transport and communication, trade, international monetary policy, or harmonized fiscal policy. Only specific action or cooperation will make it possible to halt global warming or avoid the negative consequences of interdependencies, like for example the spread of infectious diseases through international travel. This cross-border perspective not only gives us a different relationship with developing countries, it also means we have to focus our attention more on global governance (ITFGPG 2006; Kanbur 2001; Kaul et al. 1999; Kaul \& Conceição 2006; Kaul \& Mendoza 2003; Morrissey et al. 2002; Rajan 2009; Sandler 2002b; Went 2010).

Linking the development agenda to other fields is, in itself, not new but offers more opportunities and is more urgent than ever before now that potential global and regional shortages (water, food, natural resources) and the increasing importance of international public goods (climate, financial stability, preventing pandemics) are with good reason high on the national and international agendas. Within the context of an international cooperation agenda, development policy is increasingly expected to help tackle global issues whose solution is not technical, and is disputed by various players. There are differing views on the desired policies on trade, security, migration, climate, governance, food or the global financial sector and considerable interests are at stake. This offers new opportunities for development policy based on positive synergy with other policy and for increasing the basis of support for such policy.

All countries in the West - and elsewhere - are currently struggling to define their position in the world, and how they want to cooperate in establishing transnational arrangements. Given the increased interdependencies, Western countries are finding a focus on global development more and more inevitable. Although 
this search will still take some time, it is already clear that development policy has to be an essential part of the process. Playing on several boards at the same time will be a core requirement development policy will increasingly have to fulfil. If collective self-interest is made to count, in addition to moral motives, the development task will become increasingly unavoidable, and that will make greater demands on how it is designed.

\subsection{A DUAL STRATEGY FOR DEVELOPMENT}

Development policy must become more development-oriented, and that can be achieved in two ways. On the one hand it has to become more specific - more tailor-made - in and for developing countries and focus on the spot where development needs to acquire specific content. It must not be based on expansive Western schemes, but be related to specific situations. On the other hand, policy has to become more general, with development also being implemented in fields in which 'non-development actors' have traditionally been active. The answers will not only, or primarily, lie in the spending of ODA resources which can, at most, be used cleverly to bring in other parties. Development policy will therefore become more specific and broader or, from a different perspective, both smaller and larger.

What does this mean for the structure of Western aid policy? The most important implication is a dual strategy. The dominant image of development policy is still mainly one in which Western countries support individual countries - and are keen to receive appreciation for this to show their taxpayers that useful things can be done with the resources they provide. It is much less clear how development policy can be shaped in a broader context. In an intellectual sense, many acknowledge the importance of global issues in the specific promotion of development. However, in most Western countries there has been scarcely any response to the question of how to deal with this. Here and there attempts are made to give substance to policy aimed at coherence or global public goods, but these have to date been little more than finger exercises. For some time, a number of NGOs have also been calling for attention to be paid to the development dimension of global issues - and sometimes with some success. However, this too is sooner the beginning than the end of a development.

While perceptions have focused primarily on the first pillar of development policy, there are many indications that the second pillar must become the most important one. The space for classical development policy, whereby donors support individual countries locally, can be expected to diminish in the coming years. In the near future it will certainly still be worthwhile contributing in that way to the development of a number of countries, primarily in Africa. However, if these countries can maintain the same rate of development that they have exhibited in recent years in the coming decade, they will want to take a very different 
position in respect of Western donors in around fifteen years time. The focus will then no longer be on classical development aid, but on partnerships which are comparable to the relationship which Western countries currently have with countries like Indonesia. Exit classical aid. On the other hand, these countries will become increasingly interrelated in a world order in which all parties become more and more dependent on each other. As a consequence, development will be determined more and more by the way in which global issues are dealt with.

As far as Western donors are concerned, all this implies a restructuring of their development policy. Nowadays, ministries are still predominantly organized around the implementation of aid programmes, while the emphasis must increasingly be placed on the way in which countries deal with broad issues. This does not mean that sudden changes have to be made to the organizational design but that, over a period of say fifteen years, the structure will have to become fundamentally different. It is therefore important to start introducing changes now: the country-specific pillar must be made more development-oriented and gradually decrease in importance, while the global pillar must start acquiring form and content.

The following chapters deal with the issue of how to design both pillars. Chapter 7 explores how aid can be made more specific and outlines the way in which Western governments can continue developing their existing system of aid to ensure that it is genuinely aimed at development based on local situations. Chapter 8 assesses what it means to adopt a wider view and, with coherence policy and a strategy for international public goods and global governance, to take cross-border issues as a reference point. 



\section{BEING MORE SPECIFIC: PROFESSIONALIZING AID}

What is required to make a serious contribution to development? As we have seen, there is no Big Answer to that question. Societies cannot be 'fixed'. Development aid should aim to increase self-sufficiency, and be tailored to the specific situation and problems in the country concerned. Anyone who takes this as a serious starting point will not act on the basis of yet another grand, universal theory of development, but on a heterogeneous, better substantiated and targeted collection of local policy practices.

\subsection{APPROPRIATE AID MODALITIES}

Asking how to shape development is to ask not only what, but also how. The debate on 'what' is many times more intensive than the question of 'how'. Aid presupposes a thorough reflection on which instruments to deploy, but that is a surprisingly neglected issue. There has been little systematic reflection on how aid can best be provided. To be more precise, there is a whole body of literature on specific intervention variants - for example, the various forms of microcredit have been evaluated extensively - but the question of how this aid relates to the "political economy' of a country is almost invariably ignored. At micro level there is a wide range of insights into the exact design of aid projects, but the issue of whether aid can better be provided through NGOs or local government is much less systematically examined. Choice of instruments is often a matter of preference, with some people believing that governments are the best channel, and others placing their trust in multilateral organizations, NGOs or the private sector.

This neglect is partly based on the implicit assumption that all aid is worthwhile. As long as it is aimed at reducing poverty, every person who is alleviated from poverty is a positive result, no matter who provides the aid. When the objective shifts to increasing the self-sufficiency of countries and peoples, it is necessary to ask what kind of aid is best suited to achieving that. In addition to increasing selfsufficiency, it is also important to address ways of avoiding negative side effects of aid, such as the unproductive perpetuation of neopatrimonial structures. The existence of such structures is a reality in many developing countries, and it is important to determine how aid relates to them.

How are we to approach this problem? Nearly all donors have to ask themselves this question nowadays. Anyone who aims to make a recipient country self-sufficient, and sees aid as a temporary measure that should be rendered unnecessary as soon as possible, is faced with a serious dilemma. History has taught us that it is an illusion to assume that modern states can be built up without a properly functioning government. It has also taught us that governments in Africa are always 
inclined to use aid for their personal benefit or that of their immediate group rather than for the country as a whole. Donors cannot build on governments with complete confidence, but it is equally difficult to act without them.

It is therefore crucial to seek forms of aid that aim to avoid negative side effects from the start. In theory there are many possibilities. The option of limiting the aid in scale and/or time could in any case be considered. To prevent too much aid dependency, the volume of aid could be restricted to a certain level, for example 15 percent of a country's GDP. It is equally possible to limit the duration of the aid. A country can make it clear in advance that it wishes to be a donor for a specific number of years, perhaps somewhere between five and ten, and to prevent dependency in that way. The striking fact that neither of these options is used very often is an indication of a failure to address the effects of aid.

Another rarely applied method to avoid recipient countries becoming excessively dependent on a donor is to make greater use of the option of not making funds available to the central government, but to see regional and local authorities as the primary recipients of aid. Most donors are inclined to focus primarily on national governments. That reflex is understandable and there are often also good reasons for it. However, it is also possible to focus primarily on other authorities that are willing and able to deal with aid adequately - and this leads to a reward system within a recipient country. Such a step also links up well with the growing need to invest in the development of quality of regional and local authorities, which are becoming increasingly important tiers of government with the strong increase in urbanization.

It is also possible to introduce slightly stricter conditions, and focus more on results. One example is through a 'matching budget' system, whereby donors double the revenue a country collects through some form of taxation. This performance-based approach also includes variants of 'cash on delivery', in which aid funds are provided once a previously agreed objective has been reached. All of these variants have their advantages, but often look better on paper than in practice. Governments in many developing countries are insufficiently equipped to deal with output financing as an incentive.

There is also room for improvement in avoiding aid dependency when designing aid programmes. The productive safety nets in Ethiopia - a variant of the Food for Work projects which have been successful for so long elsewhere - are a good example. In recent decades, Ethiopia has been confronted by periods of severe drought, which were serious enough to make the front pages of Western newspapers. To be prepared for subsequent droughts, it was very tempting for donors to build up large stocks of food through the UN World Food Programme. However, a more intelligent concept has since been developed, based on the wide variety of 
local needs in areas where drought occurs on a regular basis. A scheme has been developed, for example, which provides farmers with paid work on infrastructural projects if they cannot work on the land because of drought. They can then use the money they earn to buy food themselves. That makes it unnecessary to keep food in reserve, as there is plenty on the market. However, it does mean that there must be workable plans for infrastructural projects, as well as the tools and materials required to carry them out. This makes aid funds twice as productive and ensures that the aid does not make people passive. They retain their pride and dignity and the local market is not paralyzed by large quantities of free food.

In short, there is a wide variety of ways to provide aid in a way that minimizes the risk of dependency. However, there are no simple answers. Aid is dirty business, and it is wise to keep that in the back of your mind. Not only can aid have undesired effects but, even in the best case, it means making choices. Whenever a road is laid, an economic sector is supported or a region acquires extra schools, there is always another road, sector or region that does not benefit. Implicitly a choice is always made for (and therefore also against) specific groups. Some political groups also benefit more than others. These are usually the groups in the government, because they can present the results as their own successes. In that sense development aid is itself unavoidably political. There is no point in denying that, just as there is no point in claiming that Western donors never give money to corrupt regimes. What is worthwhile is to work hard to design aid in a way that its positive effects outweigh its negative ones. There is no watertight formula for that, but it is important to be continually aware of it. That includes seeking and continuing to seek appropriate aid modalities, which will differ from country to country. In general terms, these can be divided into five strategies.

\subsection{SUPPORTING GOVERNMENTS}

The first strategy consists of providing development aid primarily through governments. That is no simple task. In developing countries political and government systems are often dysfunctional. Political elites with an unclear pedigree cannot always be circumvented, and there are very few developing countries without some form of corruption. Half the people of Cameroon, Liberia, Sierra Leone and Uganda indicate that they have paid bribes over the previous twelve months, and there is not a single developing country where the figure is under 6 percent (Transparency International 2009). There are neopatrimonial structures, governments are heavily bureaucratic, or a large number of factions vie for power. Developing countries are by no means populated only with pitiful people who need urgent help. They comprise a wide variety of groups, each of which pursues its own interests, including elites out to enrich themselves and shadowy warlords (Van Bijlert 2009; Chabal \& Daloz 1999). At best, in addition to pursuing its own interests, the elite may also wish to develop the country, and there may be coun- 
tervailing powers that function to some degree, but these are almost never fully effective. In many developing countries, the parties that donors have to negotiate with are often not in a position themselves to influence ministries or other important players. Saying "yes" and then doing nothing (or not being able to do anything) is a strategy that is frequently used (Whitfield 2009). It means that donors have to become involved in local power relations, and development aid always takes place within a political force field.

Nevertheless, it is possible to provide aid directly to governments. The most common forms of direct aid are general budget support and sectoral support. Both of these variants make the recipient government primarily responsible for spending the funds provided. Donors see it as their task to agree on frameworks that give them sufficient guarantees that the money will be spent wisely, but in principle the responsibility lies with the recipient government. General budget support is in theory the best strategy within this approach, as sectoral support always involves donors in making choices about which sector deserves support. The distinction is, however, primarily optical, as governments can easily move funds around within their budgets. If donors want to provide money for education, that releases funds for sectors they are less enthusiastic about, such as defence. The distinction is therefore more significant for the donating country, which can assure its public that the money is being used for worthwhile purposes, than for recipient countries.

Although only a limited part of the aid budget is reserved for this form of aid (in 2008 that was 15 percent of aid to Africa) it leads to heated discussions in donor countries. Some consider budget support the ideal form of aid, as it allows countries to make their own choices and frees them from good intentions tinted with neocolonialism. Others see it as the most dangerous, because it makes governments lazy, given that they are no longer required to act responsibly towards their own people or account for their actions through taxation and elections. The Ugandan president Museveni referred to budget support - presumably when he himself was in a more favourable position - as "a life-support system for brain-dead regimes” (in Ellis \& Ter Haar 2004).

With this form of aid, donors rely heavily on 'budget tracking'. Systems have been developed, often with the support of technical specialists from the World Bank, to enable the monitoring of expenditure and results. Yet these also encounter problems. Good systems of public finance management are difficult to implement because they assume, for example, that there is a competent ministry of finance. Local governments must also provide information efficiently and keep people up to date on the building of clinics and schools, despite this being more difficult to achieve at local level. 


\section{Accountability}

Some donors prefer to extend accountability beyond the classical financial instruments, for example by improving accountability practices in the countries themselves. It is significant that DFID, which often takes a lead in the policy debate on development aid, announced in a recent policy memorandum in the summer of 2009 that it would reserve 5 percent of the budget of all future projects to achieve accountability. That is no longer a matter of simply counting and measuring. Other forms of accounting are at least as important, including supporting organizations that use internet to make government spending (and what they should spend) transparent, meaning that the directors of schools in remote towns can see whether their schools are actually receiving the agreed amount of funding. There is a much-quoted example from Uganda. Every time the Ministry of Finance allocated money to a school, it informed the local media of the exact amount and sent a poster to the school so that everyone could see how much it should be receiving. As a result, less of the money got lost en route. This approach has proved to work better if people are more vocal and can at least read (Hubbard 2007). Projects in India went even further, sending text messages to schoolchildren at random moments asking them to take a photo of their teacher with their mobile telephones. If the teacher was not present, the school did not receive its funding. Another strategy is to allow users to assess the quality of public services. In 2001, for example, Korea introduced a Citizen Audit Request System, under which people can request audits of public services which they consider to be inadequate (UN 2007). Bangalore's Report Card System is another example. For more than ten years, the local newspaper has been publishing the scores the city's residents give to municipal departments. The scheme was the initiative of a small group of active citizens (UN 2008).

\section{Political nerve}

Budget tracking and other accountability systems have a significant Achilles heel. The results they produce by no means always lead to action. Donors are not in a position to take any decisive measures on the basis of their findings. Partly because of increasing donor pressure, they have little scope for negotiation and are rarely important players in individual developing countries. The World Bank and, to a lesser extent, the UNDP are often major players, but their negotiators seldom dare to take up political positions. In the case of the World Bank that is because they are not permitted to do so by their headquarters, whereas the UNDP is a UN agency and the recipient countries are also member states and tolerate no intervention in their internal affairs. In most developing countries, the EU also has little influence. In addition, there are more complicating factors. Because they are by definition willing to be generous, donors are in a vulnerable position from the outset. Furthermore, they have the tendency to compete. Everyone wants to provide aid in a country where they can achieve easy results. Since the emergence of new donors in the past decade, the situation has become even more complex. China's 
capacity to invest in developing countries is so great that the World Bank sometimes feels that its influence is negligible. Moreover China does not impose irritating requirements. Lastly, where donors do have sufficient negotiating power, it is not always easy to use it. Even in Surinam, where - to compensate for its long colonization of the country - the Netherlands was by far the largest donor for many decades, it was not always possible to exert even subtle political pressure.

It is striking that, while donors make so little progress in developing a good political strategy, developing countries do seem to be making progress in their 'emancipation process' as aid recipients. African countries are looking at the way Asian countries have already taken control of where and how donors provide aid. The donor effort is increasingly managed by recipient governments in Southeast Asian countries. The same process is rapidly taking place in Africa, with governments becoming more self-confident and daring more and more to stand up to donors. They are prepared to risk cuts in aid, knowing that it is mostly temporary, and that it will not make so much difference anyway.

Donors are conspicuously reluctant to develop instruments that go further than transparency. Joint donor strategies are few and far between. Most individual donors therefore try, above all, to be pragmatic. They form alliances, do not make empty threats and develop sharp insight into the strengths and weaknesses of the other party. After all, political systems and governments in developing countries are by no means monolithic.

It is also striking that individual countries do not wish to accept the consequence that they should develop a more appropriate funding model. The model currently used by most Western donors is based on budgeting annual funds that are no longer made available if they are not used. This annual pressure to spend has a distorting effect on decisions on the progress of aid. It would seem more logical to treat money provided for development aid as a kind of investment fund. It could be provided for a longer period, perhaps five or even better ten years, with decisions about when it is made available being made at local level. What happens if money is not spent quickly enough became blatantly clear shortly after the establishment of the Millennium Challenge Corporation by George Bush Sr. The organization was set up as a counterbalance to USAID and only provided governments with money once they had presented a sound plan, with a transparent but tough assessment of quality. Consequently, plans were submitted less quickly than had been hoped and funds remained unspent, causing political unrest about the low level of expenditure.

Budget support has another important shortcoming, which is less often discussed but equally evident: it is primarily aimed at spending departments, and particularly at the social sectors. Budget support fits in with a kind of aid which focuses 
mainly on supporting social policy. Anyone with other priorities must consider other instruments. For example, if you want to improve the provision of financial services to small and medium-sized enterprises, sectoral support is of little use (the financial sector is not a sector in the sense of being a separate budget item that is centrally financed). Support for this sector therefore has to be provided through other mechanisms than budget support. Budget support is more suitable for a development policy aimed at improving living conditions.

Here too, however, generally applicable positions are not appropriate. There are countries that have shown in recent years that they can cope well with budget support (Ghana is the best example), while it remains to be seen how it will turn out in others (for example, Tanzania and Uganda).

\subsection{OTHER ACTORS: NGOS FOR DEVELOPMENT}

After it became clear in the mid-1980s that development interventions aimed at the state did not produce the desired results, hopes were increasingly focused on civil society. The scientific underpinning was provided by the social capital

\section{Figure 7.1 Percentage ODA to NGOS}

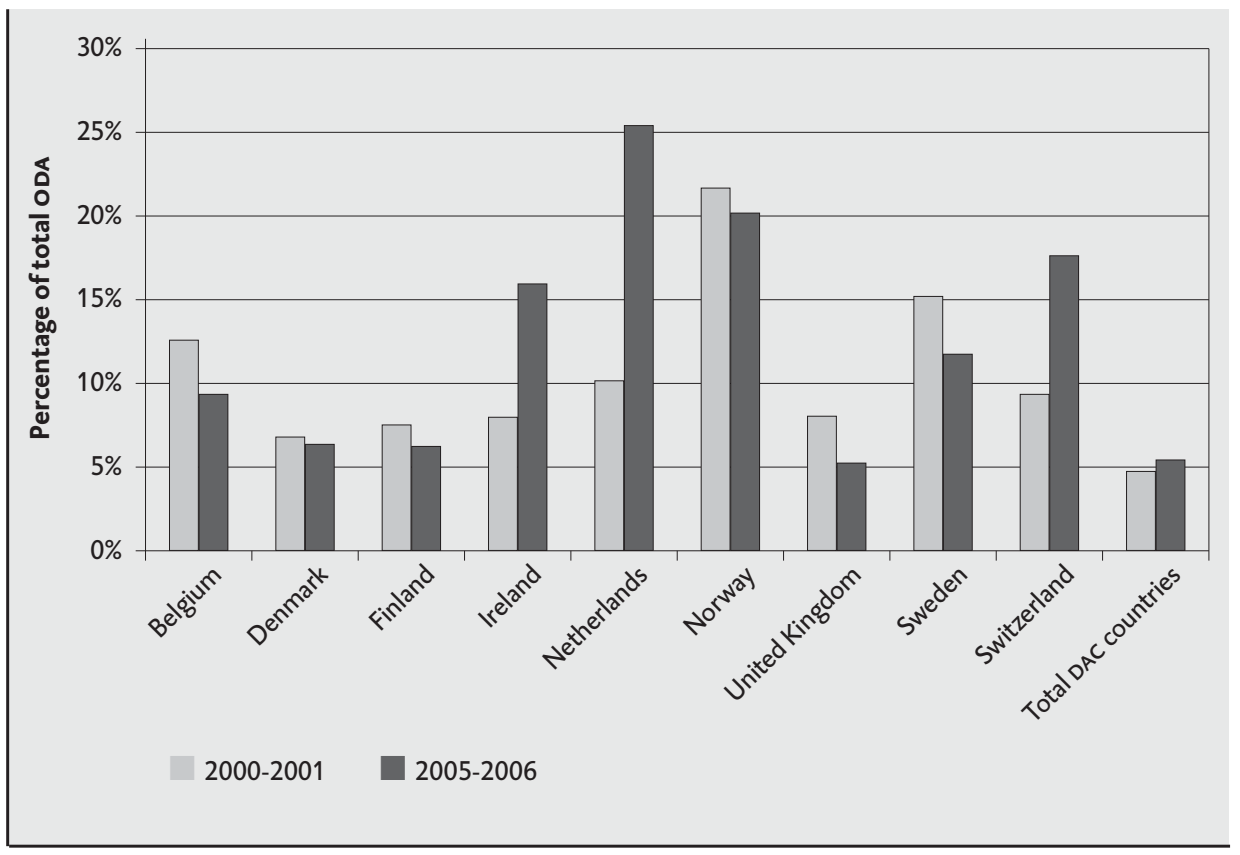

Source: Nijs \& Renard 2009 
theory, which emphasized that a robust civil society was a condition for democratization and development. This heralded the start of two golden decades for NGOs in both the North and the South. They received money in large quantities from individual citizens, celebrities and national governments. Now, no less than 30 percent of all the public and private money provided for aid is spent through NGOS (Riddell 2007).

Despite the great financial and non-financial confidence in NGOs, many - especially those in the West - are struggling with their task, form and function (Bebbington et al. 2008; Biekart \& Fowler 2008; Grotenhuis 2009; Lister 2004; Riddell 2007; De Wal 2009). That is primarily a consequence of changes in the South. There has been, for example, an enormous increase in Southern NGOs. Furthermore, the distinction between Western and Southern NGOs is becoming less clear. For example, the Bangladeshi NGO BRAC is active in nine countries, and Oxfam recently set up Oxfam India to allow Indians to support aid to their own country (Lewis \& Kanji 2009; Lister 2004). Capacity development of NGOS in the South is also having an impact. Southern NGOs no longer always need their Western counterparts. They increasingly receive funding directly from other sources, for example from philanthropists, vertical funds or their own governments. This is now partly the case in India and Brazil. Now Southern NGOs are becoming stronger, it is important to ask what added value Western NGOs can offer.

Changes in donor countries also play a role. In recent decades, Western civil society organizations, and especially those that have received funding from the government, have been emphatically required to render account for their expenditure and activities. Many organizations were pleased to do this to illustrate their legitimacy. However, the emphasis on presenting results, monitoring and selfevaluation can also have negative effects. NGOs become more bureaucratic rather than more professional. After all, professionalization means having enough room to manoeuvre to be able to respond to the changing situation in countries themselves, to experiment, to be part of a learning system, and to render account for the main framework of their interventions, rather than the details. Southern NGOs funded by Western NGOs have also sometimes suffered under this burden of accountability, which has forced their development objectives into the background (Lewis \& Kanji 2009; Bebbington et al. 2008). Moreover, there is a tendency to finance existing, larger organizations, especially if they are able to demonstrate their successes. As a result, institutional logic seems to triumph over the logic of development (Edwards 2004).

Institutional logic also requires that Western NGOs show that they have support in their own societies. That means that, in addition to the thick reports of 'expected results' they have to submit to the ministry, they also have to present their West- 
ern publics with images of children living in pitiful circumstances - or smiling and happy after receiving aid. 'For just a few euros a year you can send Shanti back to school' - appeals like these demonstrably deliver the largest number of new donors. Riddell (2007) calls this approach 'the greatest lie in development aid'. Unlike the picture presented by the sales pitches, development is a capricious and unpredictable process, and most NGOs know that. They are often not helping Shanti at all, but are dealing with the local ministry of education or village heads. The question is what effect dissemination of this 'lie' as a means of gaining public support has on Western NGOs. How do their efforts to create societal support in donor countries relate to other objectives, like greater professionalization and seeking legitimacy in developing countries (see also Dietz et al. 2006)?

The emergence of Southern NGOs, advanced bureaucracy, and a hybrid mandate in the West have all raised questions about the future of Western NGOs. How these questions are answered will depend on whether these organizations are able to contribute to global development in the future, and whether they will still have their own added value.

\section{Being more specific}

Answering the question of the added value of Western NGOs means first examining their significance in developing countries themselves. As with earlier paradigms, the civil society paradigm has proved not to be a panacea for development problems. Studies have increasingly shown that the role of NGOs must not be underestimated - but also not overestimated (Bebbington et al. 2008; Biekart 2008; Bräutigam 2000; Edwards 2004, 2009b; Lewis \& Kanji 2009; Molenaers \& Renard 2007, 2009; Rahman 2006; Riddell 2007; Roy 2008). Civil society and social capital cannot simply be considered synonymous with NGOs. NGOs do not by nature do 'good' (Grotenhuis 20o9).

The first question is what civil society should be taken to mean. It is an extremely heterogeneous category or, as Carothers (1999: 20) puts it: "Civil society everywhere is a bewildering array of the good, the bad and the outright bizarre". Claiming to work with 'civil society' does not say much at all, without stating whether your partners are pro or anti military, pro or anti birth control, etc.

The next question is what an NGO has the capacity to do. Like states, civil societies cannot be built up from the outside. You then need to ask how NGOs can contribute to civil society, and what organizations can make a difference. A lot of Western NGOs primarily have contact with Southern exponents of Western social movements, and they are often by no means the most important groups. It is not uncommon for Western NGOs to completely miss the social dynamics in developing countries. One source of dynamism may be religious groups, like the Pentecostal church or Islamic communities, which Western NGOs have little contact 
with (Edwards 2009). Many NGOs also focus their activities in the cities and therefore miss the social dynamics of the countryside, which can often be a source of development.

Donor financing of Southern NGOs can even lead to an artificial civil society in which money attracts entrepreneurs. That can sometimes lead to improbably high numbers of NGOs: for example, Bangladesh and Nepal both have more than a hundred INGOs (international NGOs) and 1,800 and 5,978 local NGOs respectively (Mayhew 2005). This not only raises questions about unworkable donor pressure and lack of efficiency, but also about the binding of these organizations to the societies in which they work. In Uganda, where there are 7,00o registered NGOs, it is said that they have hijacked civil society. In addition, the concept of NGO used by Western financiers is not appropriate to all societies. There may be forms of social dynamism that cannot easily be fitted into an easy to subsidize organizational form. In other cases, some organizations - like Islamic or clan-based organizations - may not fit in with the Western picture of a 'good' civil society, yet they can in some cases make substantial contributions to development (Edwards 2004, 2009b; Molenaers \& Renard 2009; Rose 2009).

Another factor is that governments in developing countries can by no means always work well together with the NGOs in their countries. The theory of social capital presupposes that trust is learned within NGOs so that a healthy yet charged relationship develops between society and the state. However, it is arguable whether people really learn to trust if governments - like those in Iran or Ethiopia - primarily project mistrust. Governments that are too weak, or too authoritarian, do not allow themselves to be influenced by NGOs (Radelet 2005; Gaventa \& McGee 2010). The Right to Information Act in India, for example, only makes sense because there is a state. India has an enormous bureaucracy, strongly based on the colonial art of keeping records and files, which generates retrievable information (Baviskar 2010). The contribution made by NGOs to development is therefore not equal in every country and at all times. In several countries that have developed rapidly in recent decades - like Botswana, China or Taiwan - NGOs hardly played a role of any significance. In countries like Brazil and South Korea after democratization, on the other hand, NGOs did play a part. Like the market or the state, NGOs cannot transform societies on their own, as there are many different forces at play (Bräutigam 200o; Chabal \& Daloz 1999; Edwards 2009b; Molenaers \& Renard 2007; Rose 2009).

To estimate the contribution that NGOs make it is important to distinguish between the different functions they can fulfil, even though these can often overlap. Three immediately come to the fore: service provider, watchdog and supporter of social processes. Other authors also emphasize the importance of differentiating functions for understanding the role played by NGOs in developing 
countries, but use different categories, often with slightly different meanings (Edwards 2004; Fowler 2000; Korten 1990; Ministry of Foreign Affairs 2009a; De Wal 2009).

NGOs can fulfil the role of service provider in developing countries by, for example, distributing food or setting up a hospital. This role resembles their old mission, and the way NGOs have functioned in continental Europe in the past two centuries. This function was especially dominant in the 1980 os and 1990 os when a lot of aid was provided on a project basis. Service provision is particularly effective if a government fails in its obligations or if specific groups are difficult to reach. Some governments acknowledge this. In India, for example, the government has quadrupled funding for NGOs in the last decade to improve service provision to marginalized groups (Riddell 2007).

However, there is also criticism of service-delivery NGOs. They can become part of patronage systems, or undermine the tasks and responsibility of governments. In some countries parallel systems evolve. For example, in Uganda in the 199os, healthcare was kept afloat by NGOs (Bräutigam 200o). The same applies to BRAC, from Bangladesh. This NGO not only has 97,00o employees, but also provides nearly the whole population with healthcare, making it a kind of quasi-governmental organization (Thomas 2008). Critics from within and without these countries believe that, because such NGOs primarily focus on service provision, and often (without criticism) take over the role of the government, too little is done to change the structural causes of underdevelopment (Edwards 2004, 2009b; Fowler 2000; Molenaers \& Renard 2009; Rahman 2006; Riddell 2007).

Through external criticism and self-reflection on this sort of service provision many NGOs have assumed different roles (Thomas 2008). One of these is the newer, more Anglo-Saxon role of watchdog and of influencing policy. NGOs in developing countries try to follow national government policy and administration, preferably to change them. In addition NGOs are increasingly acting as watchdogs in respect of local and international companies, and are especially monitoring corporate social responsibility. These organizations are more politically minded and try to change policy. The keywords for watchdog NGOs are transparency, responsiveness and accountability. They also frequently focus on research and information provision and set up budget-tracking systems. These critical NGOs try to give a voice to as yet nascent middle classes.

According to Riddell (2009), NGOs are relatively effective in terms of institutional development, especially in comparison with bilateral efforts. Yet they cannot be certain of success in all countries. For example, governance in a number of Indian states has not improved despite substantial pressure from a large number of NGOs (Roy 2008). The paradox is that a critical watchdog function is only valuable if 
there is a functioning state apparatus which is ready and willing to change in the long term (Molenaers \& Renard 2009; Radelet 2005). It is therefore no coincidence that watchdog NGOs have mainly contributed to social rights and civil society building in Latin America (Biekart 2008).

The last function that NGOs fulfil is that of supporting social processes, usually referred to in the international context as community development. This embraces a wide range of tasks that have changed considerably over time, often because donors have imposed other priorities. For example, in the past a lot of effort was made in the agricultural sector to support farmers, frequently through cooperatives. In the 1980 and 1990 os, the focus shifted to the empowerment of deprived groups, such as women and ethnic minorities. In recent years, NGOs have devoted greater attention to development of the private sector, particularly by supporting small producers and arranging microcredit (Helmsing \& Knorringa 2009). There is also growing attention for conflict mediation. In ethnically or religiously fragmented societies, NGOs that play a functionally binding role, such as football clubs or trade unions, are important in, for example, preventing violence, as an Indian study shows (Varshney 2002). Religious organizations, whether Muslim or Christian, also increasingly play a conciliatory role, while the importance of their function as service provider is declining (see also Biekart 2008). Yet here too it is important to note that if NGOs focus too much on bonding rather than on bridging - as in Rwanda - they can themselves fan the flames of conflict (Narayan 1999).

NGOs therefore have different roles to play, and whether and how they can contribute to development will depend on the country and the context in which they operate. That means it is necessary to examine each case specifically to see whether NGOs can play a role in the further development of a country and, if so, what role that should be. Each role has its own assessment framework. A serviceproviding NGO will generally have added value in a fragile or weak state. A tendering model is best suited to finance service provision in states like this, with NGOs competing with others for specific assignments which can also be expressed in terms of tangible results, such as the number of people the service reaches, the quality of the service and, in the context of preventing the unintended consequences of aid, what needs to be done to eventually transfer provision of the service to the local or national government. As mentioned above, an NGO can only operate effectively as a watchdog if there is a reasonably well-functioning state. In such cases, tender-based financing is not appropriate, as the embedding and legitimacy of the NGO are of major importance. The accountability framework must therefore be based on those criteria. Finally, the role of supporting community development should reflect not the wishes of the donor community but existing development in the local community. Conflict mediation is especially required in societies that are ethnically or religiously fragmented and where the government is 
not conciliatory (Narayan 1999), while the empowerment of women is only worthwhile if there is already considerable activity aimed at achieving it. In the latter case, the assessment framework will have to be based mainly on broad support and quality.

\section{The future of Western NGOS}

What does the future hold for Western NGOs? As they should only provide services where governments genuinely fail to function, they are then in effect temporary substitutes, offering services that governments should provide themselves. This role should therefore be restricted to a limited number of cases. There is more scope to contribute to a properly functioning social system by keeping a close eye on the government and helping to bring about productive social relations. However, these are major tasks, so great that it is arguable whether they are achievable at all. A lot of NGOs are proud of these major tasks, but few address the problem of what it means to tackle them with limited resources. Here, more than ever, it is important for NGOs to concentrate on what they are good at. They could focus on a limited number of countries with and in which they have longstanding and far-reaching contact. In this way, they will build up good country-specific knowledge. A second option is to specialize in themes.

Incidentally, it is striking how little systematic knowledge is available on how investments in civil society can contribute to development. However, there is hardly any exchange of knowledge between development organizations or initiatives. With the exception of a few recent initiatives, there is a serious shortage of horizontal feedback (see also Dietz et al. 2006). Developing a policy theory on social development is therefore an important point for attention.

\subsection{OTHER ACTORS: BUSINESSES FOR DEVELOPMENT}

Aid can be directed at governments or NGOs. It can also be aimed at economic activity. After all one of the major challenges of the twenty-first century is to devote greater attention in African and other least developed countries to knowledge that can contribute to growth and development. For example, studies have shown so far that growth and structural transformation is often facilitated if an economy is diverse and not only based on industrialization. An important question is then how to make better use of the interaction between domestic and foreign capital (UNCTAD 2005, 2009b; Wade 2009b). Investments can lead to development if they have a positive, catalyzing effect on the existing economic infrastructure and small and medium-sized enterprises (SMEs). However, they do not necessarily have such a positive impact. After all, business linkages in all directions can have both positive and negative consequences (UNCTAD 2005). Multinationals can create employment for SMEs in poor countries and transfer technology and knowledge to these companies, but they can also compete local SMEs out of 
the market. Moreover, while transnational companies can offer consumers cheaper products, they can also contract supply (Coghlan \& Poskitt 2009). To assess whether investments are development-related, it is necessary to examine the entire chain. This is incorporated in the OECD directive and the ILO statement on corporate social responsibility. The sustainability of chains is also receiving more attention. "A promising way to improve the sustainability of production chains", says the Netherlands Environmental Assessment Agency (PBL) in a recent report "is by international agreements between companies, NGOs and governments to set criteria for the sustainability of these production chains" (Netherlands Environmental Assessment Agency 2009b).

Economic activity is usually stimulated in two ways. Western donors can try to regulate their own multinational corporations so that their activities benefit countries in the South. However, it is also possible to support economic activity in Southern countries, in particular by contributing to a good business climate.

\section{Engaging international companies}

Encouraging Western companies to contribute to the development of countries in the South usually occurs in the context of corporate social responsibility (CSR). CSR takes a variety of forms. According to Van Tulder \& Fortanier (2009), development-related business practices are the most far-reaching form of corporate social responsibility. They distinguish four different approaches to CSR: inactive, reactive, 'active-go-it-alone' and proactive. American companies generally tend to adhere to the more inactive and reactive variants. That means that they donate part of their profits to aid projects on, for example, microcredit or HIV/AIDS. This has more to do with public relations than development. Most of the projects, if they have any impact at all, may help reduce poverty. In Europe, there is more of a tendency to be proactive, and to integrate social objectives with the profit motive. This is more promising and gives rise to the question of how companies can be supported in this development-related approach and how governments, in turn, can make better use of what companies have to offer.

Governments try more and more to involve businesses in pursuing development objectives. Since the World Summit on Sustainable Development in Johannesburg (2002) there has been an increase in cross-sector partnerships. At the end of 2006, the UN secretariat registered more than 300 bipartite and tripartite partnerships, yet little is known about their nature, dynamics and effectiveness. It is clear that they can help fill gaps in governance, knowledge and investment but - as the capacities and competences required to achieve development are diverse - they are not able to replace all other actors in the development field (see also Edwards 2009a). Governments can sometimes play an initiating role in the relatively new field of partnerships for development. 
The policy of most Western governments on corporate social responsibility is based on self-regulation, cooperation and facilitation. The basic principle is that companies should primarily fulfil their obligations regarding CSR and the associated socially responsible chain management in their own way in dialogue with their local communities. Transparency and consultation with stakeholders is considered to be of great importance. 'Soft law' approaches to CSR can count on more support than regulations and legislation. A good example is the Global Compact, initiated by the UN in 2002 with the words: "There was great potential for the goals of the United Nations - promoting peace and development - and the goals of business - creating wealth and prosperity - to be mutually supportive" (Therien \& Pouliot 2006). By the end of 2005, around 2,400 companies had signed the Compact. They undertook, within their sphere of influence, to endorse voluntarily ten principles distilled from four major international agreements, including the Universal Declaration of Human Rights. A lot of UN agencies have now adopted an approach based on private sector partnerships (Ruggie 2007; UNCTAD 2008a). The considerable emphasis on self-regulation is not without its critics. Western NGOs insist that voluntary and binding corporate social responsibility are not mutually exclusive and argue that CSR should be embedded in national legislation, international regulations and widely accepted principles of good governance and socially responsible behaviour.

Gradually a normative framework for international CSR is emerging on the basis of a series of international declarations, directives and recommendations by the ILO, OECD and the International Chamber of Commerce (ICC), and national organisations like the Dutch Accounting Standards Board. It is essential not only to endorse the normative framework laid out in the Social and Economic Council's Statement on International Corporate Social Responsibility (SER 2009) but also to render account for it. That calls for transparency, independence and a system for dealing with complaints.

Insisting on and facilitating soft law is a task for the government if the private sector itself shows insufficient initiative. A number of initiatives have been taken in this respect in recent years. For example, together with the private sector and NGOs, the British government introduced the Extractive Industry Transparency Initiative (EITI), which aims to prevent illegal trade in natural resources from Africa. Another example is the Dutch Sustainable Trade Initiative (IDH), set up with the support of the Dutch government, which has now created eight publicprivate partnerships to promote sustainable trade. These PPPs involve over 100 organizations which are expected to invest 425 million euros in the sustainable production of cocoa, tea, tropical timber, natural stone, tourism, soy, cotton and aquaculture between 2009 and 2015 . 
The government can go a step further and ensure that companies comply with the law. In this respect it could be more proactive in tracing illegal capital transactions. This problem urgently requires greater attention and action now that there is growing evidence that developing countries are suffering massive damage as a result of illegal financial flows, tax evasion and the use of 'creative' transfer prices within multinationals (Ministry of Foreign Affairs 2006, 2008, 2009d). A report by the Commission on Capital Flight from Developing Countries (2009) set up by the Norwegian government makes the interesting recommendation to explore the possibility of making it compulsory for multinationals to include more details in their annual reports on the scale of their activities, the number of staff, and the taxes paid as a percentage of the taxable profit in each country in which they are active. According to the commission, companies that already engage in CSR can start doing this on their own initiative without waiting for the government to introduce legislation.

The decisions by the G2O to take action where necessary against tax paradises may bring about changes in favour of developing countries. However, they also represent a missed opportunity in that the G2O did not also insist on transparency about bank accounts, especially those of African leaders, in Switzerland and other countries that maintain banking confidentiality. That could have helped change the situation in a number of African countries. Transparency International calculates that African elites keep some 700 billion dollars outside their countries (Glennie 2008) and Acquaah Gaissie (2006) reaches a similar estimate. Nigeria's Economic and Financial Crimes Commission alone has recovered more than 5 billion dollars and convicted 82 people since 2003. That required a lot of time and effort and was only the tip of the iceberg: it took a great deal of pressure to persuade Swiss banks to repay most of the money stolen by Nigerian dictator Abacha in the 1990 .

\section{Increasing business opportunities}

Economic activity can be promoted more directly by stimulating investments in countries in the South. The traditional instrument used by many Western donors to achieve this is still to offer Western companies grants, credit facilities and guarantees. However, it is debatable how worthwhile it is to use such financial instruments to encourage the private sector to operate in developing countries. First of all, the effect of these instruments should not be overestimated. Schemes set up since the 1960 s to persuade Dutch companies to invest in developing countries have primarily been used by smaller businesses, and then only piecemeal, while the private sector itself has never come up with creative proposals to be more proactive in favour of developing countries. It is highly unlikely that a Western agrarian company will enthusiastically invest in the high plains of Ethiopia, for example, just because it will receive a grant to do so from Western development funds. Most companies that decide to make such an investment would of course be pleased to receive a financial contribution, but would make their ultimate decision 
on other grounds. Companies making decisions about where to invest crucially need to know whether a country has clear laws governing, for instance, property rights or legal procedures, an effectively functioning labour market, and a state that can guarantee physical safety. Western development efforts should focus on these areas if they aim to encourage investment in, for example, Sub-Saharan Africa.

Financial stimulants should only be used if they lead to more and better investments in developing countries. Positive effects on employment and the possible transfer of knowledge and technology that strengthen the productive capacity of the country concerned could be relevant parameters in decisions to provide guarantees and loans, especially given the positive evaluations of Western development banks. The question then is whether it is better to seek general schemes that invite the private sector to invest broadly in developing countries, or to devise more specific instruments. Since we have repeatedly argued here that development policy should be based on the specific situation in specific countries, it would be logical also to make instruments specific. Whereas it may be worthwhile in one country to invest in, for example, the transport or food sectors, in another country these may not be a development priority at all.

\section{Credit facilities}

As we saw in chapter 6 , the core of the effort to develop economic activity in developing countries must lie in strengthening indigenous activity and promoting the diversification and upgrading of local production. After all, development aid is not intended for Western companies but to strengthen and develop the economy of the recipient countries. It seems that, in any event, extra attention is needed for a system that provides sufficient financing instruments for companies in developing countries. Currently this is still often insufficiently developed: frequently there is no proper banking system and high-risk investments on a scale between microcredit and FDI are difficult to realize. The policy of developing countries often favours large banks and the equity market, irrespective of the structure of their national economies, while many donors and NGOs focus on microfinancing. As Roodman \& Murdoch (2009) remind us, the attraction of microcredit, "is manifold. It is at once radical in its suggestion that the poor are creditworthy and conservative in its insistence on individual responsibility. It offers, as the cliché goes, a hand up, not a hand-out. Because its currency is currency itself, microcredit makes supporters feel that their hands are reaching out directly to the poor. And it is seen as demonstrably lifting people out of poverty, especially when channeled to women." There is, however, scant real knowledge on whether microcredit is an efficient way of combating poverty or stimulating growth. This is the focus of more and more research, but that by no means always generates clear conclusions. 
Karlan and Zinman (2009), for example, investigated the impact of microcredit on small entrepreneurs in Manila. They examined the effects of expanding the issue of credit to micro-entrepreneurs by the First Macro Bank (FMB). Of the 1,601 applications for loans from this group, 1,272 were approved at random, while the other 329 applications were rejected. A survey of all 1,601 applicants a year later surprisingly concluded that greater access to credit had not resulted in more business investments, but did lead to an increase in profit, in particular - contrary to what is often claimed - among men with a higher income. Another quite unexpected outcome of this research is that no evidence at all was found for a positive effect of more microcredit on subjective well-being, and it may even have caused a slight decline. However, in an equally well-structured study, Banerjee et al. (2009) draw entirely different conclusions. In their randomized evaluation microcredit was introduced in half of 104 slums in Hyderabad (India) and not in the other half. They concluded that "microcredit does have important effects on business outcomes and the composition of household expenditure. Moreover, these effects differ for different households, in a way consistent with the fact that a household wishing to start a new business must pay a fixed cost to do so." While, in this instance, microcredit had positive consequences for expenditure by households and for the creation and expansion of activities, the researchers found no effects on healthcare, education or the empowerment of women.

The debate on microcredits therefore continues. Some people are even highly sceptical. For example, Bateman (2010) defends the position that "microfinance is largely antagonistic to sustainable economic development and social development, and so also to sustainable poverty reduction." He points out the undesirable disadvantages and risks which can result from the place and role of microfinance within the financial system, such as underestimating the importance of scale effects and investments in small and medium-sized businesses, including in agriculture, the well-known 'fallacy of composition' (for individual street vendors it is rational to purchase larger stocks at lower prices, but if everyone does the same the market will become saturated and prices and incomes will decline), and the driving up of interest by commercial parties rushing to become involved in microfinancing. According to Bateman (2010), the key point is that we have to "accept that it is not simply the quantity of finance available, which determines the rate of growth and sustainable development, but also how, where, when and in what form financial resources are deployed." For the time being it would seem to be difficult to draw general conclusions on the effect of microcredits. It will continue to be necessary to establish whether, when and under what conditions microcredit can have positive effects on growth, development and poverty reduction.

The existing industrial structure, the average size of companies and the main types of risk these companies face are important factors in determining the opti- 
mal financial structure at a certain level of development. It goes without saying that countries with a low income opt for a financial system whose backbone comprises small local banks rather than trying to copy the financial structure of advanced industrial countries. These might include financial and credit cooperatives, community and state development banks or subsidized SME loan and credit programmes. It is essential that adequate financial services can be offered to small businesses in agriculture, industry and the services sector (Lin 2009a, 2010).

There are, however, encouraging trends. Researchers from the IMF, World Bank and the Nederlandsche Bank have ascertained that banks from developing countries are also becoming increasingly active in other Southern countries (Claessens et al. 2008). In Sub-Saharan Africa, the proportion of Southern banks in the total number of foreign banks rose from 37 percent in 1995 to 43 percent in 2006. In 2006, the largest bank in Madagascar was the Bank of Africa from Benin, while the Bank of Africa and Ecobank (from Togo) are among the six largest banks in Burkina Faso. The main driving forces behind this pattern of investment include the similarities in the political, economic and business environment in the various countries: "Ecobank, for instance, understands the size and the significance of informal businesses in these countries and works to develop African solutions to address these problems. It puts a lot of emphasis on SMEs and focuses heavily on retail banking. These banks seem to be better able to digest the uncertainties of the business environments in the host countries than some of their high income counterparts" (Claessens et al. 2008).

Private equity is also becoming more readily available, although not enough. The whole private equity industry in Africa was set up by investment banks, but the Dutch FMO and other bilateral and multilateral investment banks only make up a part of the shortfall, despite doing very useful work. There are a number of additional possibilities that have not yet been explored, or not sufficiently. If Western countries wish to make an extra contribution in this respect it might be interesting to explore whether a subsequent step could be taken, in consultation with Western pension funds, by setting up a 'fund-of-funds' to invest in commercial investment funds in developing countries, especially if it focuses on the agricultural sector and SMEs. Pension funds have experience with, and a growing interest in, direct investment in emerging markets, are already investing in microcredit and sustainable energy, and have already proved themselves willing to show their social face when it emerged that some of their funds were invested in the arms industry. Investment funds could also be developed in which private capital funds participate. Such revolving fund constructions are not part of the standard repertoire of development aid (nor do they count as ODA, because they are in principle aimed at making a profit), but can be very effective and offer considerable leverage. Lastly, in the same context, the possibility of giving individual citizens more 
opportunity to participate can also be considered, for example by expanding the existing fiscal incentives to invest in social and ethical funds in developing countries.

\subsection{OTHER ACTORS: CITIZENS FOR DEVELOPMENT}

Development is not the exclusive domain of governments, NGOs or companies. Development policy can also directly affect individual citizens, in both the West and the South. In the West, it focuses primarily on the role of citizens as consumers, a role in which they are increasingly concerned with development. Fair trade, for example, has become a progressively widespread concept since the 1950s. In 2008, 28 percent of Dutch households bought one or more fair trade products, and the market has grown by 55 percent since 2006. At the moment it is mainly people from the higher social classes who support development in this way, and the market share for fair trade products remains small (Hamers \& Mathijssen 2008). For example, even after twenty years, the Max Havelaar label has only acquired 3 percent of the coffee market and 2 percent of the banana market in the Netherlands. In the United Kingdom and other countries that percentage is higher (Quak 2009).

Consumer pressure is therefore not yet that high, but it is becoming more and more important for companies to acquire and maintain a good image, not only because consumers otherwise choose other products, but because the companies wish to inspire loyalty from their middle and senior management. People do not like working for companies that are known for pollution and exploitation. Moreover, more and more businesses are seeing the advantages of, for example, using sustainable raw materials even though they may not themselves carry the fair trade label. Lastly, campaigns and internet sites increase the pressure on companies to preserve a good reputation, as they offer a greater insight into the extent to which their policies are sustainable and take account of development.

Despite the increased availability of information, it is not always easy for consumers to know what products are responsible purchases and what are not. Not all information is reliable and it can sometimes be difficult to make a wellconsidered decision. For example, is it contributing to development if you buy products made in a factory that pays its workers the statutory minimum wage, if that wage is not enough for them to live on? In addition, sustainability and development can sometimes be at odds with each other. It might, for instance, be inadvisable from an environmental perspective to export agricultural goods from Africa by air, while marketing products in Europe may indeed be good for the continent's development (Quak 20o9). 


\section{Migrants}

Migrants are a completely different category of engaged citizens. On a global scale migrants send three to four times as much money to developing countries in the form of remittances than all official aid put together. From a small country like the Netherlands, migrants sent remittances home to the value of 6.7 billion dollars in 2006; that is as much as countries like Bangladesh or Indonesia receive in total remittances every year (World Bank 2008b). This financial influx accounts for a considerable proportion of the GDP of some developing countries, and is less subject to fluctuations than other financial flows (World Bank 2006). Migrants are indispensable in improving living standards (humanitarian aid), even more so as they tend to send extra money if their home country is in need. During the financial crisis, compared to ODA and foreign investment, remittances fell relatively little (UNDP 2009), showing that transnational family ties are considerably more reliable than bilateral or multilateral relations between countries.

However, migrants alone cannot ensure the development of their countries, with the possible exception of a number of small countries that depend to a large extent on remittances, such as Tajikistan (45\%), Tonga (35\%) and Lesotho (29\%). Often the transferred money is spent on consumption, while the countries that need the income most, especially those in Sub-Saharan Africa, receive the least. The Matthew effect ('For to all those who have, more will be given, and they will have an abundance; but from those who have nothing, even what they have will be taken away') clearly applies here too (see figure 7.2). That is because it is usually not the poorest who leave, but those who are a little better off, and they generally do not come from the poorest countries. Money is therefore largely sent to countries where the migrants have been successful and where development is already under way, such as India and China. Furthermore, if money is sent home to be invested, that usually occurs when the situation in the recipient country is favourable and there is a clear prospect of economic prosperity. After all, it is better to sow seeds in fertile than barren ground. That is also why migrants prefer to send remittances to the city than the countryside, which is poorer (Adepoju et al. 2008; De Haas 2007; Faist 2008; Mazzucato 2008; Skeldon 2009; World Bank 2006).

The money that migrants send home does therefore not necessarily lead to development, but they do contribute to development in two other ways. They often function as bridge-builders in global knowledge networks, and are frequently good at finding knowledge in the international context to fill in gaps at local level (Saxenian \& Sabel 2008). South Korea, for example, acquired technological knowledge through its diaspora networks, and Indian businesses in the service sector have benefited from close contacts with friends and family members in American companies (Kuznetsov 2006). In addition, migrants often drive institutional reforms in their home countries, promoting values like accountability, democratization, transparency and responsibility. This is most evident among transnational 


\section{Figure 7.2 Remittances to developing countries}

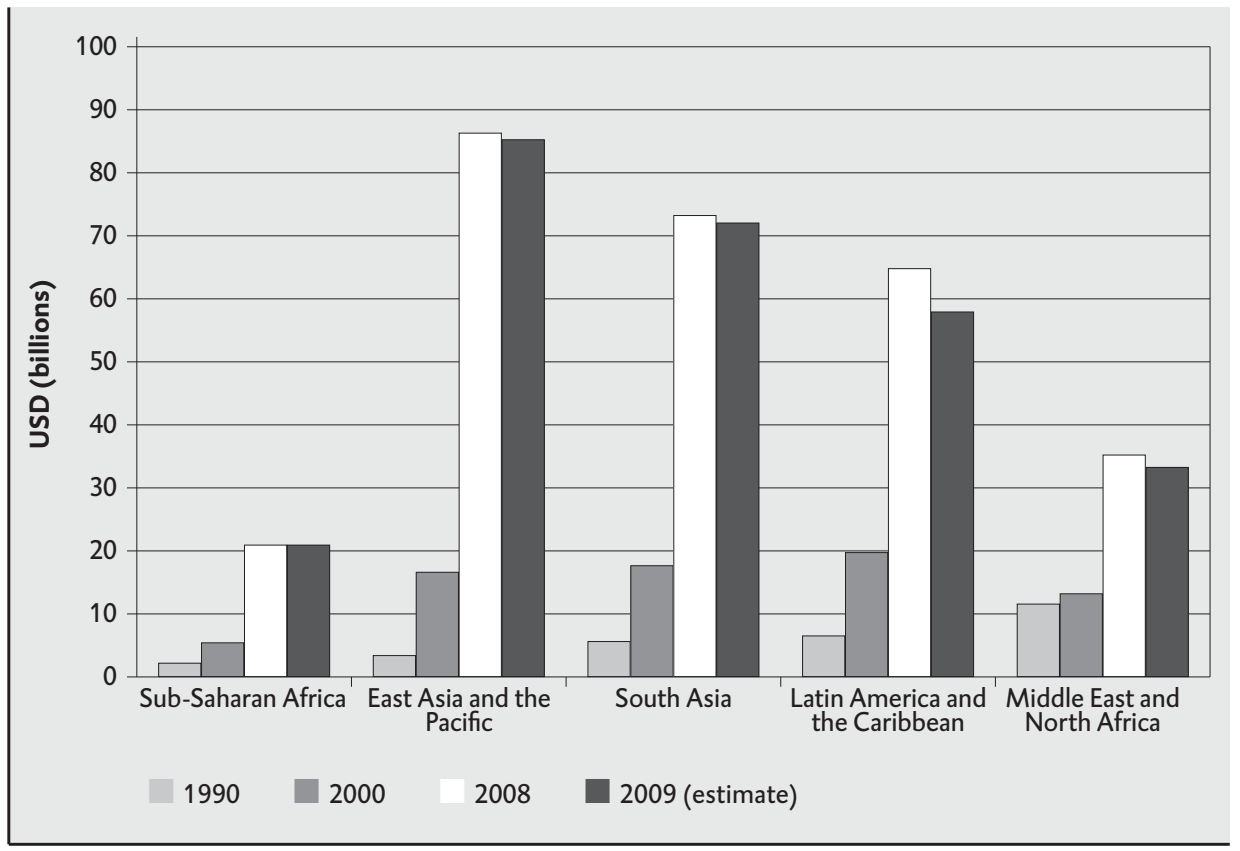

Source: Own calculations based on World Bank data

migrants who not only send money to their family members but also invest in companies in their countries of origin. Many banking systems have improved under pressure from migrants involved in business activities, and in India the transnational IT branch has successfully lobbied for transparency and effective regulation, especially at local political level (Global Commission on International Migration 2005; UNDP 2009; World Bank 2006). Diaspora communities can also exert pressure on democratization processes. Exiles in Zambia and Tanzania, for example, helped bring about the departure of president Hastings Kamuzu Banda in Malawi, while those from Liberia and Sierra Leone succeeded in getting blood diamonds on the European, American and UN agendas (Ellis \& Van Kessel 2009). However, diaspora communities can sometimes have a negative effect on development (Kapur 2007). They can use their money and ideas to keep conflicts going, as we have seen with Israeli, Palestinian, Irish and Tamils living abroad. Because they themselves do not have to pay the price of the conflict, members of the diaspora sometimes seek confrontation more easily than people living in the countries themselves and have been referred to as "the nursery of nationalism" (Faist 2008).

Migration is currently considered to be primarily beneficial to development. For many years, that was not the case, and it was associated with the brain drain. This 
is, however, only a problem in a small number of countries like Malawi and Zambia, and in Surinam. For the majority of labour-exporting countries it applies to less than 10 percent of the educated population, a similar percentage to the number of Britons or Americans who work elsewhere (De Haas 2007; Skeldon 2009). A larger problem is brain drain in specific sectors, especially healthcare. It is estimated that around 12 percent of doctors trained in India work in the United Kingdom, while only a third of the doctors trained in Ghana stay there, and half of those trained in South Africa have left the country (World Bank 2006). In these same countries unemployment among academics is often high, while few wish to work in the healthcare sector because of the poor working conditions. Brain drain is therefore more a symptom of failing systems than a cause (De Haas 2007; Skeldon 2009; UNDP 2009).

Some attempts have been made to reduce the 'care drain', especially in the United Kingdom. For example, the National Health Service (NHS) has decided not to recruit people actively in certain countries and areas, and to adhere to an ethical code in taking on staff. In 2003, the British ministries of health and foreign affairs and DFID signed an agreement with the South African government to regulate the flow of health workers from the country to Britain. The objective is to make the British healthcare system self-sufficient, instil the relevant actors with ethical awareness, exchange information and knowledge, provide South Africa with technical assistance, promote cooperation between health institutions, and support exchanges of staff for limited periods of time. The programme has not yet been evaluated, but the percentage of South African nurses and midwives in the United Kingdom fell considerably between 2000 and 2006 (Chappell \& Glennie 2009). Another way of reducing the detrimental effects of brain drain (already proposed by Baghwati in the 1970s) is to make migrants pay tax not only in the country where they live and work, but also in their countries of origin. The Philippines tried the system for a while, but it proved unworkable and unfair, as many migrants had paid for their own educations, and were already sending a lot of money back home.

To preserve the advantages of migration and combat the negative effects of brain drain, a number of international organizations and academic researchers have suggested a form of 'rotation' or brain circulation (Global Commission on International Migration 2005; UNDP 2009; World Bank 2006). The idea is that people go to developed countries to upgrade their skills and knowledge, and then return to their home countries to contribute to development. It is a brilliant idea, on paper. However, in practice, once migrants have had a taste of a good salary, services and security, they find it difficult to return (Adepoju et al. 2008; Faist 2008; De Haas 2007). That does not necessarily mean that they cannot contribute to development in their countries of origin, as the transnational transfer of knowledge, values and ideas can take many forms. In other words, migrants do not need to rotate to have 
a positive impact on development, if there are opportunities for cross-border movements. Transnational families, hometown associations, knowledge communities of experts and academics, and diaspora knowledge networks are often very functional for development (Faist 2008; De Haas 2007; Saxenian \& Sabel 2008).

A logical consequence of this is that Western countries should take a long hard look at their policies on migration and integration in the light of their development objectives. That does not mean that they should immediately throw open their borders, but that there should be more scope for selective migration by those with a better education. The challenge is to involve as many people as possible from Sub-Saharan Africa. Other Western countries already have interesting bilateral migration programmes focusing on development: New Zealand has a temporary migration scheme in the agricultural sector, Canada and Jamaica have an innovative programme based on local quotas, and Spain is setting up a coproduction project for development with its main migration partner countries (Pritchett \& Fanjul 2009). In the Netherlands, very modest experiments are also being conducted with migration projects from a development perspective (Ministry of Foreign Affairs and Ministry of Justice 2008).

However, current bilateral programmes have their limitations, if for no other reason than their small scale. It can be argued that labour and study migration would be better organized as part of a system of global agreements. Migration policy should not only be part of national or European efforts to achieve policy coherence, but the free movement of persons should be the subject of global engagement. There is good reason why many Southern countries argued at the Doha round of WTO talks for better regulation of labour migration within the General Agreement on Trade in Services (GATS), while Western countries primarily insisted on free service provision and wanted no free movement of persons. Proposals were also made to set up a global organization for migration, more wideranging than the current International Organization for Migration (IOM), to develop a General Agreement on Labour Migration and set up a more fluid and educational system to which multiple parties (migrants, trade unions, employers) can contribute, in addition to governments (Pritchett \& Fanjul 2009). Interesting developments in this respect are the Colombo process, started in 2008, and the Abu Dhabi dialogue aimed at concluding regional agreements between South Asian countries and the Gulf States (UNDP 2009).

It is important that migration can take various forms. Migrants should have rights, but this should not necessarily imply them gaining full citizenship of their host countries. The development of countries in the South benefits particularly from recognizing transnationalism and the importance of cross-border movements. That implies that it should be easier to travel back and forth, to allow more exchanges of knowledge and ideas. It would also be a good idea to give diaspora 
networks more support with development in mind. This would include not only political but also commercial and academic networks of migrants, who are not only engaged but talented (Kuznetsov 2006; see also UNDP 2009). The Norwegian government has already taken steps in this direction and is currently compiling a diaspora database so that it can explore whether and how the development relationship with selected countries can be deepened.

\section{Citizens as recipients of aid}

Citizens can also be direct recipients of aid. If a government does little more than spend aid money on a bad system of agriculture, healthcare or education, it may be better to give the money directly to those who most need services in these sectors. In Latin America, there have been successes with cash transfer programmes, in which citizens receive money if they, for example, send their children to school. This creates a direct link between aid and results: no school attendance means no money. Similar programmes have been set up outside Latin America in the past ten years. Cash transfers are now given to more than 110 million families in at least 45 countries. Each programme is different, ranging from general child support in Mongolia to pensions in Africa. Sometimes the monthly amounts are small - only a few dollars - but some can be up to 100 dollars or more. In Latin America and the Caribbean, these programmes now reach more than 12 percent of the population (Hanlon, Barrientos \& Hulme 2010; Fiszbein \& Schady et al. 2009; ILO \& WHO 2009; Valencia Lomeli 2009). Schemes in which citizens receive vouchers they can use at a school or clinic of their choice go a step further (Easterly 2001a, 2008b). Such schemes apply pressure to those offering the services, though they only work if there is a real choice of providers. This is often the case in urban environments, but rarely in rural areas.

Cash transfers and vouchers are forms of aid in which citizens are the direct recipients. There are of course other ways to involve citizens more directly in spending aid funds, for example in the form of participatory budgeting. In its most advanced form this means that citizens actually decide on how budgets are spent. Here too Latin America is often a good source of inspiration. In 1988, a project of this kind was set up on a large scale in the Brazilian city of Porto Alegre, with a population of over 1 million. Evaluations show that there are disadvantages associated with this approach - for example, marginalized groups had less say - but these proved to be far outweighed by the advantages, especially the dismantling of patronage systems. In Brazil itself, 100 other municipalities have followed the example of Porto Alegre, and the approach has now been applied in many other parts of the world, including Thailand, India and South Africa (Shah 2007). Participatory budgeting is not only significant for governments, some donors also see it as an excellent instrument. For example, in the context of community-driven development in Indonesia, the World Bank placed a large part of the budget in the hands of local municipalities. 
Another form of aid that goes directly to service users is the setting up of mutual insurance schemes to cover, for example, the costs of medical treatment or accidents. Such schemes are difficult to achieve, are not possible everywhere and take a lot of time. Citizens are often reluctant to participate in them as they have learned that they can demand that their governments provide them with healthcare. They also rely on the existence of a more or less homogenous group with a high degree of cohesion, which is often not the case, especially in urban areas. However, they do contribute to a social policy that is no longer based on one-off gifts from donors, but becomes part of a consistent national policy. There are parallels to the way in which social policy was first set up in Europe some 100 years ago. Continental West-European countries have a tradition in which small mutual insurance schemes evolved to cover workers and farmers for the costs of industrial accidents and medical treatment. This was later extended to invalidity and old age, and later still to unemployment. Over time, these mutual insurance schemes became increasingly comprehensive - which was necessary from the perspective of risk pooling - and after the Second World War they were nationalized and made into general systems that also applied to non-employees. In a similar way, social policy in Asian countries has also become part of wider policy in recent decades and is increasingly recognized as an investment (Mkandawire 2004).

Yet another form of direct support is investment in citizens' networks. With the aid of new technologies, like mobile telephones, email and the internet, people are coming together in looser networks and in networks of networks. These technologies enable people to contact each other fast and in great numbers. Good examples are the green movement in Iran, the Orange revolution in the Ukraine, and the protests in the Philippines in 2001. They also help to make information public. For example, in Kenya there is an internet platform called Ushahidi - which means 'witness' in Swahili - which gives individual citizens the opportunity to report complaints, incidents, and cases of fraud and abuse of power online. Development policy can also support platforms and technology that can bring citizens together rather than subsidize institutionalized, well-organized NGOs.

\subsection{PROGRAMME AID}

Aid can primarily be based on providing money, as in the case of budget support, or on building up civil society organizations or the private sector, or supporting active individual citizens. All of these methods can make a difference. However, it is also possible not to make a choice between them, but to be aware that effective interventions can best be achieved if these elements are combined in a productive way. Changes can seldom be brought about by a single actor. If a government persistently tries to introduce a change, but does not have the support of nongovernmental parties, there is a good chance that it will give up after a few years. 
Achieving sustained changes often means playing on several boards at the same time.

This implies not only involving more actors in effecting a change, but also deploying multiple instruments. In addition to money, this often means knowledge, and sometimes commitment and process management as well. Money is not always unimportant - even the organization of a good system of land rights or the development of a trade chain costs money - but is often not as important as people believe. Knowledge is frequently more important. In the past, the emphasis was often on transferring specific insights and skills to concrete individuals, ranging from the best way to build a chicken run so that the birds remained healthy to designing forms for the clerk of a court. That form of support is progressively making way for knowledge at system level, varying from the way water management is organized to improving the quality of teachers, and consists mainly of supporting a country in its efforts to upgrade these activities to a higher level. Furthermore, engagement is equally as important. Many development projects succeed not because donors give money - which they often do - or provide expertise - which they also often do - but because they manage a process of change in a way that local parties, hampered by all kinds of traditions and conflicts of interest, are unable to do. This applies particularly where multiple stakeholders have to be brought together. The result is what we might call programme aid.

Programme aid implies long-term relations in which sufficient specific expertise and a range of instruments are deployed in a coherent way. For example, to develop agriculture it may be necessary to maintain relations with knowledge organizations in both the donor and recipient countries, not only for the purposes of research and development, but also at various levels of practice and schooling, if necessary right down to primary education level. It may also be advisable to reduce trade-related obstacles, which will require interaction with ministries and sometimes with legal experts in the field of import restrictions on markets. Furthermore, it may be a good idea to expand transport possibilities or devote attention to the availability of fertilizer and seeds. Other relevant partners are private firms that pack or process food or serve markets, and local farmers' organizations. It may be essential to work with them to find out how to organize cooperatives or set up insurance schemes. In addition, if you want to move from a classical agricultural policy to a value-chain approach you will need to generate knowledge of the market that farmers can use in deciding what to produce (OECD/DAC 2009C). In short, it is important to approach the market in its entirety or at least a substantial part of it.

Programme-based development aid calls for far-reaching expertise and long-term involvement of local actors, and goes further than only giving money. It is a form of aid that is becoming increasingly popular, and developing countries, especially 
middle-income countries, will request donors to provide this type of aid more and more. In short, money itself is becoming less of a problem, and good organization of expertise more so. In this respect it is significant that the Inter-American Development Bank has decided to replace a few hundred people with knowledge on loans with experts on the organization of large-scale programmes. The reasoning behind this was that the money could also be found on the international capital market (although this has become more difficult as a result of the financial crisis). The underlying idea is that it is more worthwhile for donors to add something substantive than to focus on primarily providing a financial contribution. A small financial share in large projects may be sufficient as a guarantee that will help persuade private investors to participate. The shift towards seeking expertise can also be seen among low-income countries. For example, China is no longer interested in money from the West, but in knowledge exchange and the supervision of pilot projects in the field of institutional reform. It is interested, for instance, in the pros and cons of the Dutch system of land registration (Ho 2009). Vietnam, which is designing a system of water management, is no longer interested in who will give it money for nothing. It would rather pay for services it really needs than be given something with little added value. Countries like Uganda and Ethiopia are also increasingly interested in contributions that combine money with expertise.

This all stands or falls with the ability to manage relationships within both the recipient and donor countries. It becomes more a matter of involving the right parties at the right moment than doing everything yourself. That means bringing together a variety of initiatives, both ODA and non-ODA. Programme-based cooperation between ministries has mostly proved difficult, and this form of working requires cooperation with many more parties, including civil society organizations, universities, banks and insurance companies. For most donors it is difficult to find that best way to make an appropriate substantive contribution. However, the contours required of such a contribution can be clearly outlined.

\section{Knowledge}

To make choices and good diagnoses and to be specific, it is first of all necessary to have knowledge about the development processes and the social, political and economic situation in a country. Furthermore, interventions must be accompanied by knowledge development about what is being done and what changes it brings about (Easterly 2006), and that all has to be recorded and made accessible. It is a matter of organizing the institutional memory. The question is what the level of ambition should be. Within other social sectors, like healthcare and education, considerable amounts of money are invested in research and development. In healthcare, at least 6 percent of public and private investment is spent on R\&D, and that has been the case for a long time. As development aid is a much more exploratory activity, 6 percent should be a minimum, which is rarely the case. In 
that respect, many donors can take a lead from DFID. The British development agency finances research centres affiliated to universities that contribute to its development strategy. There are knowledge centres on governance (University of Manchester), the future state (University of Sussex) and the new International Growth Centre knowledge network. DFID has high expectations of diagnostic growth analyses and will be spending 10 million pounds annually on growth research alone between 2008 and 2013. According to the British research strategy, DFID's total research budget for this period is a billion pounds.

Knowledge development is not only a matter for donors, however. In a programme-based approach it is primarily in the interest of recipient countries. This means that adequate programmes always have to devote sufficient attention to knowledge and how to perpetuate it. To some extent this is a matter of making country and sector-specific arrangements. Donors will therefore not only have to invest in their own or European institutions and networks, but also help build up the knowledge infrastructure in individual developing countries. The knowledge infrastructure has become especially fragile in Sub-Saharan Africa and former and current conflict areas (Wagner 2008). Good development diagnoses and professional interventions in developing countries are only possible if the level of knowledge, and with it the capacity to adjust their own policies on the basis of evaluation, is improved. Development can, after all, not be puzzled out in Washington or New York. It has to be done on the spot. In this context Hausmann \& Rodrik (2006) refer to self-discovery, meaning that countries have to 'discover' their own specific paths to development.

Instead of becoming channelled into 'disciplines' like those that evolved in the West in the nineteenth and twentieth centuries the knowledge infrastructure to be built up in these countries needs to be multidisciplinary and varied. Economics and anthropology, knowledge on agriculture and social medicine are often required parallel to, and in combination with, one another. Investments in this interdisciplinary knowledge infrastructure can take different forms. A donor can simply finance knowledge institutions and networks in the South, but it is also possible to do more to promote cooperation. For example, the Netherlands has SANPAD, an innovative cooperation project with South Africa, in which African academics study problems that are relevant for development in South Africa, together with counterparts at Dutch universities, and follow an extensive training programme (Box 2009). Similar variants can be found elsewhere. These relationships transcend the obsolete notion of 'knowledge transfer': innovation arises from learning by seeking local applications of methods developed elsewhere and feeding back these lessons. The current expanded possibilities for access to international knowledge are accompanied by a much greater demand for contextspecific knowledge and innovation, but the supply is limited. To address this problem, professor of innovation Soete (2009) proposes linking Western univer- 
sities to universities in the South, or at least to make development one of the objectives of all universities. This is already practice in Belgium, where part of the development budget is allocated to development cooperation by universities.

A knowledge strategy should also take account of the fact that it is not only NGOs, officials of ministries and international organizations, and scientific researchers who produce knowledge, but also service-users, businesses and others. Every sector requires a different 'type' of knowledge and a different search pattern: trade calls for technical expertise, while improvements in education benefit from consultation (Jones et al. 2009). Private sector parties are crucial to industrial and agricultural policy, and it is important not so much to ask the direct question of what activities should be encouraged or what instruments will work the best, but how best to give shape to discovering worthwhile objectives and devising appropriate instruments. The challenge is to learn how to give producers constant incentives to diversify, upgrade and work together with foreign companies (Hausmann 2008; Hausmann et al. 2008; Lin 2009b; Rodrik 2007b; Wade 2009b).

Lastly, diversity also deserves more attention. Development benefits from dissonant voices and different development paradigms. Countries in the South must be able to consider different development paths and elaborate on them or change them as they see fit. In this context the Centre for Policy Research in Delhi speaks of the need for a broader 'conceptual infrastructure'. In practice, the World Bank now often has a quasimonopoly on the pallet of policy options from which developing countries can choose. In the words of Ha-Joon Chang they offer countries the "Henry Ford principle of diversity". For their part, many bilateral donors are too oriented towards Washington, often in the absence of an alternative. In both Europe and developing countries, thinking on development is dominated by Anglo-Saxon authors. There is little or no knowledge of alternative development paths and corresponding interventions. There is therefore a great need for greater plurality in research work and the supply of advice available to international institutions, donors and experts.

\section{Organization}

What is the implication of this programme-based development strategy for the implementation structure? Professional development aid is not possible without a professional system of aid provision, and that is what most donors try to achieve. The majority have their own implementation structure, with a clear division between policy and implementation. Good examples are the Swedish and Norwegian aid agencies. Their country offices are responsible for diagnosis and strategy. Day-to-day political work is also left to professionals on the spot.

The country offices have a certain amount of autonomy from their embassies, but there is always some tension in the relationship. A certain distance is useful for the 
professional development of the organization. This argument was also used to justify the decision to split the DFID from the Foreign and Commonwealth Office (FCO) in Britain in 1997. The move is still widely seen as positive, though it has led to new tensions in recent years as issues like trade and security have moved higher up the agenda. The new Conservative-Liberal government that took office in 2010 therefore decided that DFID, which many see as a Labour invention, should once again strengthen its ties with the FCO. In the United States, when Condoleeza Rice announced in 2006 that she wanted to gradually integrate USAID into the State Department, it led to fierce protests and contributed to the resignation of the agency's director (Pickard \& Buss 2009). Most Western donors accept this tension and either already have two organizations or intend to set them up. Canada recently announced its intention to make its aid departments more autonomous from the other departments at its embassies. Some countries have a different model. For example, the Danish development agency DANIDA is only a virtual organization, as its work is conducted completely within the Danish Ministry of Foreign Affairs. The Netherlands also has no separate development organization, and the integration of aid within the Ministry of Foreign Affairs has resulted in much less attention to professionalism.

Although a separate organization is important, the working method is more so. A new organization must not be bureaucratic and official, but professional and geared towards learning. Country offices should ideally exchange experiences of interventions between and within themselves, with the ministries behind them acting primarily as brokers and knowledge conduits, both internally and externally. This will require restoring the prominence of country-specific knowledge and the long-term involvement of professionals. What is more, a lack of engagement is not very conducive to professionalism. Knowledge is acquired through long-term involvement and endurance, so that insights can continually be reviewed. It is not only a matter of knowing a country, but also of being known. Professional development aid requires building up trust by a long-term presence and a thorough knowledge of the situation. Currently the personnel policy of many of these organizations is founded on rotation rather than specialization. Often, they have copied the personnel policy of the foreign ministries, but this is not appropriate to a professional development organization.

Lastly, contributing to development means being able to navigate between local practice and development theory. Creative ways must be sought to try out existing ideas and distil new ones from practice. In a professional organization it is important to nurture what Scott (1998) calls metis. Compare a chef to someone who follows a recipe in a cookbook: the chef will know the 'rules' of cooking but will continually adjust himself to the season, his guests and his inspiration. Similarly, people who work in developing countries cannot blindly follow rules or best practices; copying existing recipes without question will lead to bad interventions. It is 
therefore crucial for organizations to allow scope for experiment and to take on personnel with creativity and nerve.

\section{Selecting and specializing}

How does a programme-based approach to development aid best fit into an international aid architecture that displays more and more fragmentation? In the 2005 Paris Declaration, donors agreed to harmonize and coordinate their efforts, divide up their tasks and designate a lead donor per country. One practical consequence of this would be that donors would provide their financial contributions for some sectors through other donors, thereby also relinquishing control over political decision-making on the money. In practice, little progress has been made in this respect and, to the extent that donors have joined forces, this is primarily operational and not political. Pooling resources is somewhat different to transferring political control. Actual transfer of authority - known as joint strategic behaviour is difficult to achieve. Donor capitals have trouble accepting strategic agreements made at country level. The fact that accountability still occurs at national level does not make this easier (Hoebink 2010; OECD/DAC 2008a; Whitfield 2009).

If there were a single fund with a single office for each developing country, there would no longer be fragmentation, duplication and undirected interventions. Donors could then speak to the representatives of the country with one voice. Riddell (2007) proposes this as an escape route from the current aid monster, as does Birdsall (2008), though she is reluctant to completely exclude the principle of competition. However, establishing a single multilateral fund for each country is an ideal that faces a lot of national and international political obstacles, and has little chance of becoming reality for the time being. Nevertheless, it would not be a bad thing for a donor country to seek like-minded donors who might wish to work together towards achieving this ideal.

What can an individual donor country do to become more effective as long as there is not yet a joint development strategy specific to each recipient country? The answer is logical: make strict choices between countries and issues, so that it is possible to enter into long-term relationships, with knowledge of the subject matter and of local relationships, with a limited number of countries. In each country a wide variety of instruments can be deployed, and a wide variety of parties can play a role. This will generate more political leverage and individual donor countries will automatically contribute to a better division of labour between donors. Figure 7.3 shows that a lot of countries still fragment their aid substantially (Acharya et al. 2003; see also Easterly \& Pfutze 2008). 
Figure 7.3 Donor proliferation index (average 1999-2001)

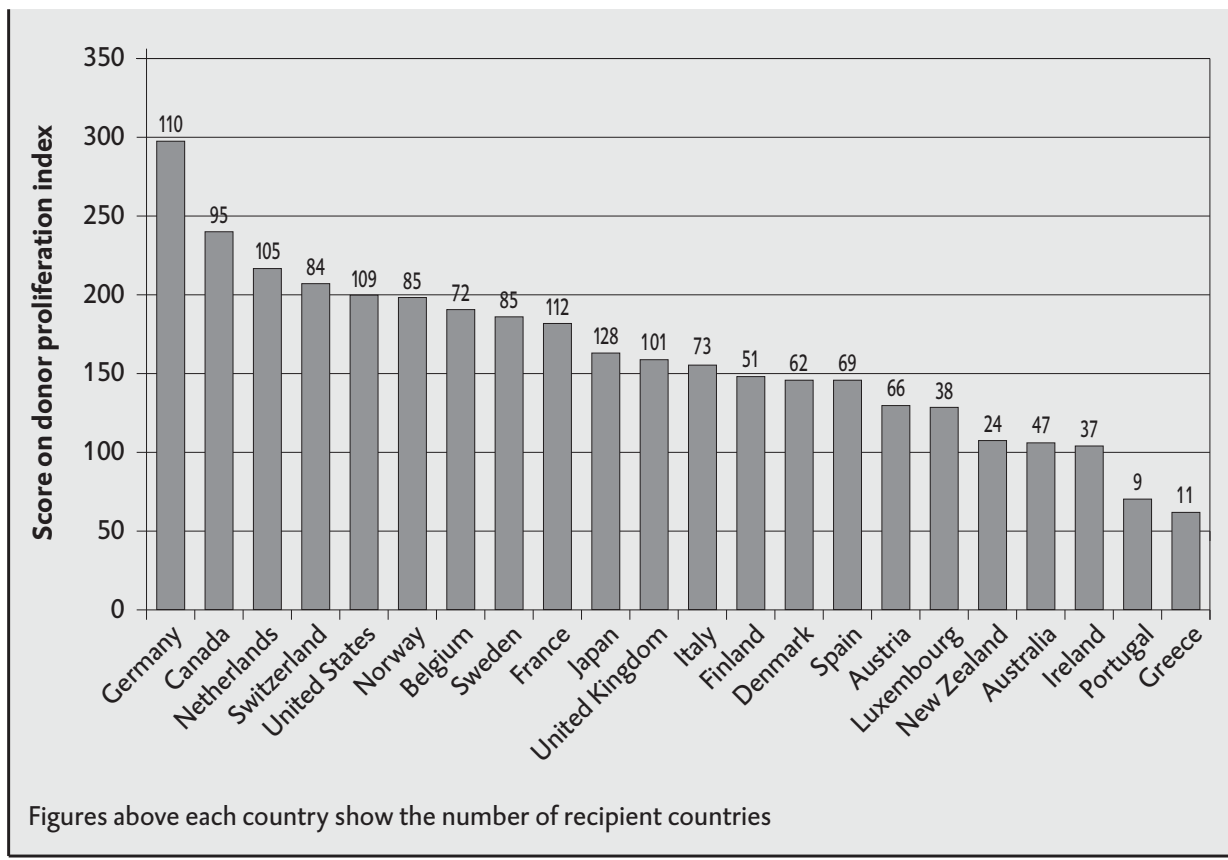

Source: Acharya et al. 2003

Note: The donor proliferation index is the reverse of a Theil index, multiplied by 100 to avoid decimals. There is more donor proliferation (aid distribution) if the aid from a donor is allocated to a large proportion of the potential recipients, and when each recipient has a relatively equal share of the total aid received from the donor.

The dilution of aid funds and the mismatch between expertise and financial contributions have negative consequences on both sides of the fence. They reduce political effectiveness in the developing country and the capacity of donor countries to specialize and acquaint themselves sufficiently with the social, cultural, political and economic structures of a country. There is therefore a lot to be said for individual countries specializing: aid is most effective when it is based on knowledge and other expertise. Norway has already taken steps in this direction, specializing in peace and reconciliation, and leaving healthcare and education to others, though it does sometimes provide financial support in these sectors. That means that in many developing countries peace and reconciliation is almost automatically left to the Norwegians. The distribution of labour agreed in Paris (and later in the EU) and which is so difficult to achieve, takes shape itself if, like Norway, donors themselves take resolute steps in the right direction. These substantive choices mean that Norway is primarily active in the Middle East, Sudan, Sri Lanka and Guatemala. In addition to areas in which they consciously build up targeted 
knowledge, the Norwegians also specialize in issues with which they have considerable experience in their own country. This is why they have an extensive Oil for Development programme, through which they exchange their own home-grown knowledge with that of oil-rich developing countries. Donors like Sweden, Denmark and Canada have expressed similar intentions. It is logical to seek ways of coordinating these efforts and to tailor them as a whole to the wishes of countries in the South.

\section{Learning}

Programme-based aid is professional development aid. That assumes that those implementing aid activities are given sufficient room for manoeuvre and have to give a general account for their actions to the appropriate political fora, both here and there. That in turn assumes that there is mutual professional accountability, and that lessons are learned from what goes well and what does not. After sixty years of aid, you would expect there to be some kind of ethic for professional intervention, offering some idea of when you may intervene and when it is better not to. However, in the aid sector, there is a shortage of professional exchange and critical reflection on interventions. How can we best give shape to this learning capacity?

In the United Kingdom there is discussion on codes of conduct for development organizations, particularly to counteract the unintended negative consequences of aid. One issue is whether local staff employed by NGOs financed by donors should not be paid more than government officials. It is important to make mutual agreements on these and similar questions, and that should be done in an international context. Even more essential is that accountability should contribute to the learning process. Interventions can only improve by learning from both successes and failures, and that means checking time and time again whether they indeed produce the desired results. If that does not prove to be the case, it is necessary to investigate why and what has turned out differently than expected. This is known as vertical feedback, because knowledge and experience from local practice must be continually fed back 'upwards'. Feedback from the recipients of aid is also part of this learning process, but this is often still forgotten. Aid recipients are rarely asked for feedback - they are simply assumed to be grateful (Dietz et al. 2009; Easterly 2006, 2008b; World Bank 2003). In addition, exchange between development organizations and initiatives, or horizontal feedback, is important as it enables an insight to be acquired at aggregate level of what works in a specific context. Because of the fragmentation of aid, it is increasingly difficult to learn from each others' experiences, and even Western development organizations rarely have mechanisms to exchange experiences at country level, even though this is where development begins (see Dietz et al. 2006).

A learning system must also leave open the possibility of making mistakes. After all, learning means not only evaluating and adjusting methods, but also develop- 
ing new ones. It involves what Argyris \& Schön (1978) call single loop and double loop learning. With development aid unorthodox policy initiatives are sometimes the most successful, but it is impossible to say in advance which will produce the best results. To safeguard the scope for experimentation and learn new things, there must be feed-forward mechanisms that offer space for innovation. Furthermore, faith should be placed in those who are prepared to experiment (see WRR 2006a). In other words, mistakes are not a problem as long as we learn from them. In this respect Easterly (2006) talks about 'seekers'. His description of them has a little too much of the 'innovative loner', but seeking is essential. A culture of accountability is only professional if it offers space for institutionalized seeking, where errors are made before progress is made.

\section{Evaluation}

An essential part of learning and accountability is evaluating what has taken place. There is often a lack of independent study of the consequences of aid interventions. Birdsall (2008) calls this one of the seven deadly sins of development aid, and is not alone in this (Banerjee \& He 2008; Duflo \& Kremer 2008; Easterly $2008 \mathrm{~b}$; Gunning 2005). A lot of time and money is spent on independent studies of Western education or healthcare, but the same does not apply to aid. There are various reasons for this lacuna. Sometimes it is not politically opportune to conduct a thorough study of aid, as it might lead to criticism of decisions that have been taken. In addition, significant institutional and other interests may be at stake, such as employment in the sector or the continued existence of NGOs. In addition, as we saw in chapter 4 , it is often a complex matter to evaluate the effects of aid properly. The charity-based nature of aid is also an obstacle as money spent on evaluation is seen as better spent on helping the poor. Yet independent evaluation is of great importance. It is necessary to determine whether the aid provided is of sufficient quality, and to feed the political debate in both donor and developing countries. Good independent evaluations can lead to better decisions on the contribution we can make (Savedoff \& Levine 2006).

What makes a good evaluation depends on what the objectives of aid are. If it aims to improve living standards, it is primarily a matter of measuring output; if development is the aim, the evaluation must focus on impact and outcome. Studies of the latter are scarce, although there is growing demand for them. Most international organizations do not have effective evaluation systems, with the World Bank, the Asian Development Bank and the IMF as honourable exceptions (Banerjee \& He 2008). Many people call for this kind of evaluation to be conducted jointly. This is in line with the Paris Declaration, which calls for more aid to be pooled, and therefore for more collective programmes. That will make it increasingly difficult to isolate the contributions of individual countries (OECD/DAC 2009b). Birdsall (2008) also argues for a collective solution to the 'evaluation problem', using independent international funds. Multilateral organi- 
zations could set up a fund with contributions from donors, and bilateral donors could do the same for programmes. In addition there is much to be said for allowing impact analyses to be conducted more often by researchers and organizations in the recipient country itself (Savedoff \& Levine 2006).

Programme aid has advantages: frequently knowledge is at least as important as money. Countries can best project themselves on the basis of their added value, an increasingly important factor in a world in which recipient countries can choose between more and more donors, and in which they increasingly want to direct the aid process themselves. This approach has the added benefit that aid will once again acquire the appearance desired by many people in the West: by linking it more strongly to our own knowledge and traditions, we bring it closer to home. That is also an important advantage at a time when the legitimacy and added value of aid is increasingly being questioned in most northwest European countries.

\subsection{DOING GOOD CAN AND MUST BE DONE BETTER}

If military interventions were to take place in the way development aid is organized, the Pentagon's instructions would be "Go and shoot some Iraqis", according to a former architect of USAID. Development aid is currently comparable with throwing confetti: well-intended but mainly a matter of pot luck. However, aid is also not an activity which can facilitate a series of planned changes by means of simple and specific action. Neither the logic of the confetti, nor that of the magic bullet, apply to interventions in the field of development aid. Planned changes always take place within a complex network of relationships, require a great deal of insight and tact, and rarely turn out exactly as originally thought. Despite all this, however, they can still work out well in the end. A purely arbitrary or a simple systematic approach has to make way for a well thought-out attempt to bring about change in systems.

Change is not linear. Rather, it occurs slowly and unpredictably and needs support from insiders and outsiders. "Successful policy change occurs not through professional advocacy alone, but involves complex and highly developed mobilizing structures which link national reformers to local and faith-based groups, the media and repositories of expertise. Such structures are built over time, deeply grounded in the societies where they are found, and linked to the biographies of those who lead them. Alliances between social actors and champions of change inside the state are critical to make policy change happen. Social mobilization structures provide opportunities for state-based reformers to generate change from within, just as political opportunity structures provide spaces for social actors to do so from without."(Gaventa \& McGee 2010) 
Development is a complex and country-specific process that is not compatible with universal theories and a bureaucratic implementing organization. Instead, aid has to be professionalized to learn from experience and allow action based on expertise. A new, professional system will reflect the importance of context and country-specificity and will be based on the understanding that furthering development means making choices. A diagnosis will have to be carried out in each country to establish where the most essential problems are, so that a tailor-made remedy can be sought. Experimenting, permanent learning and multiform knowledge are the conditions for achieving an effective development strategy. Implementing parties must have the scope to engage in a dialogue with those around them and assess which approach will achieve the best results. Lastly it is important that professional aid actually be able to make a difference, on the one hand by exerting political influence and, on the other hand, by contributing expertise. This is very important given the field of influence in which development aid operates: donors compete with each other and the relationships in developing countries are often a minefield.

At the same time it is impossible to say in advance that there is a preferred intervention method. To some donors general budget support is the best possible variant. Although this might be the case from the point of view of ownership, it may not be so in terms of added value or preventing aid dependency. Others prefer programme aid, especially those who believe that the organization of knowledge eventually has more added value than money. At the same time, programme aid can too easily send existing power relations in the wrong direction. Aid via NGOS sounds like a safe bet but their capacity to act is usually limited and their added value is often based more on assumption than evidence or reason. Companies do not allow themselves to be easily persuaded to invest, and investment-related decisions often follow once other conditions are in place. Citizens are becoming an increasingly important reference point for development policy. Much AngloSaxon literature and the policies of donors like the World Bank often place great faith in the potential of individual citizens to bring about change: people who are aware of their citizenship rights will force authorities to function more effectively. Here, the key words are monitoring, transparency and accountability. Citizens must show authorities the way and demonstrate what providing good services means. Often this overestimates the possibilities that citizens have, and sometimes it is important to invest in stability first.

It is very tempting to exacerbate the differences between the various methods of working, but there is little point in doing so. Preferences are not just contingent: the different mechanisms are not mutually exclusive. There is, for example, a frequent tendency to position citizens and civil society on the opposite side of the fence to the business community and the government. NGOs in particular increasingly see themselves primarily as watchdogs and are especially anxious about 
being hedged in by the government. This often liberal attitude fits in with a Western interpretation of citizenship, but is not always fruitful. Change does not come about primarily in society or in the state but in the relationship between them. Civic driven change (Biekart \& Fowler 2009) is more likely to occur when different actors jointly and reciprocally play a role. This was evident, for example, during the agricultural reforms in the Philippines. They were only possible because the progressive state secretary, Ernesto Garilao (1992-1998), entered into an alliance with experts from the leading NGOs in this field, as a result of which he was able to shape his policy against the wishes of his conservative government and land owners. As Gaventa \& McGee (2010) report, this is why donors should not so much subsidize NGOs, which are often urban and middle-class, but instead try to support coalitions between state actors, media, technical experts and national and local actors.

In the end, sustainable change can only come about "by winning hearts and changing minds", and in order for donors to play a positive role in this, thorough knowledge of the situation and power relations is indispensable (De Lange 2010). DFID has designed a Drivers of Change analysis to increase its understanding and that of other donors of how change takes place in developing countries, precisely because they noted that donors usually have a better understanding of what has to be changed than how it should happen. However, being more critical on the how of development appears to be far from simple. According to Unsworth (2008) an increased number of political analyses have scarcely led to any changes in donor behaviour. This is hardly surprising given that it often has to do with power relations and acquired positions, as Hausmann et al. (2008a) point out in a Mindbook on the setting up of growth diagnostics: "Big constraints on growth are there for a deep reason and they are not always easy to affect, even when they are clearly identified. Vested interests may be present and the political economy of change may be difficult" (see also Asian Development Bank 2007). However, the ultimate task of high-quality development policy remains to search for mechanisms to initiate self-reinforcing processes of endogenous change. 


\section{A BROADER PERSPECTIVE: LOOKING BEYOND AID}

Development aid can take the form of direct aid from one country to another. However, aid in this form will gradually decrease in importance in the years to come. As development questions become increasingly interwoven with broader global and regional issues, the focal point of development activities will also have to shift in the same direction. That shift does not have to be made too hastily. For a number of developing countries, bilateral aid is still of vital importance and can be useful under certain conditions. However, that applies to a decreasing number of countries. If the pace of development between 2004 and 2008 continues, by 2020 classical developing countries like Bangladesh, Ethiopia, Ghana, Kenya and even Chad will be middle-income countries, at least according to current methods of measurement. The fate of these countries will then depend less on what financial support individual donors still wish to give them and more on how they respond to the opportunities they find and take for themselves in a globalizing world.

The question is how development issues can gradually be placed more and more in such a global perspective. Donors are still making heavy weather of this shift in focus, and most of them have not yet even reached the conclusion that it is necessary. This chapter describes how to achieve this change in three stages. The first is how more aid can be provided through multilateral channels, which offers greater opportunities to address development issues from a broad perspective. The second stage relates to how national and European policies in areas that do not belong to the classical development domain can devote serious attention to their impact on development-related issues. After addressing coherence for development, the third step is to examine how development issues fit within an approach based on international public goods. This also means examining the implications for global governance of the increasing need for coordination and strategic integration of policies with cross-border consequences.

\subsection{MULTILATERAL AID}

Addressing development issues in a way that goes beyond classical bilateral aid can first be achieved by placing aid in a multilateral context. That has a number of advantages, including less need for coordination, greater effectiveness, lower transaction costs for recipients and donors, but especially more opportunities to tackle issues from a broader perspective. We first examine the extent to which attention is devoted to the latter possibility.

\section{European Union}

Does the European Union perhaps offer an appropriate context within which to provide a framework for the aid provided by member states? Since the 1992 Treaty 
of Maastricht, development aid has been the shared responsibility of the European Community and its member states, and there has been a European development policy alongside national development policies (Van Schaik \& Maes 2008). Ten years ago, the British Minister for International Development, Clare Short, described the European Commission as the "worst development agency in the world", but since then reforms of management and strategy have substantially increased the effectiveness of European aid (Barder et al. 2010). Only a little over 20 percent of EU aid passes through the European Commission, but through the contributions of its growing number of member states, the EU has become the second largest donor, after the World Bank, and the combined aid provided by the EU and its member states accounts for some 6 o percent of the global development effort.

In theory, the European Union could take on a prominent role. In the first place, this might take the form of coordination, by clustering the knowledge and financial resources of the member states. There are limitations to such a role, as not all member states are leading donors, while some major donors - like Switzerland, Norway and Canada - are not members of the EU. At the same time, however, it is worthwhile exploring the opportunities that do exist. One good reason for assigning the EU this role is that, certainly in comparison with France and the United Kingdom, it is seen as 'politically neutral'. More importantly, however, the EU intervenes in areas that are crucial to development, including migration and trade. The European Commission negotiates on behalf of the member states at the WTO and conducts free trade negotiations with countries and regions, while migration policy is also increasingly becoming a Europe-wide issue. The EU possesses a wide range of instruments - loans and, more especially, grants - which make an integrated approach possible.

However, there seems to be, as yet, little political will among the member states to attribute the EU a prominent role in development aid. In practice, rather than being an umbrella organization or a body that pursues a coherent policy, the EU has become much more an additional donor, contributing to the further fragmentation of aid. For the time being, it seems likely that the EU will play little more than a limited role in harmonizing and coordinating policy. Some progress, however, can be noted. At its 2974th External Relations Council Meeting on 17 November 2009, the European Council succeeded in agreeing, in an Operational Framework on Aid Effectiveness, on a division of labour stating in which developing countries which of fourteen member states and the Commission should be lead facilitator or supporting facilitator. What will become of this in practice remains to be seen. Attempts to go further than this appear to enjoy the support largely of civil servants, and of the Commission, but rarely of the European Council. Those attempts are by no means meaningless - on some points they go much further than agreements made within the DAC, in which the most impor- 
tant donors are represented. The EU has, for example, published a number of innovative documents, including The European Consensus on Development in 2005, the Code of Conduct on Division of Labour in 2007, and comprehensive reports on policy coherence in 2007 and 2009. The impact of these documents is, however, limited, not only within the member states but within the EU itself. More intensive coordination between the European member states will take much longer, if for no other reason than differences in orientation: the new member states, for example, prefer to focus on Central Asia more than on Africa, partly because they want to reduce migration from that region, and also because their own recent history makes them familiar with what the countries in the region are currently experiencing.

The Lisbon Treaty can give European foreign policy a new momentum, with a recognizable, politically responsible figure (the new High Representative of the Union for Foreign Affairs) and with its own offices in other countries (European External Action Services). What this is all going to mean, however, will only become clear in the next few years. Many fear that the EU will for the time being remain primarily a 'large Switzerland' when it comes to foreign policy, because Germany, France and the United Kingdom do not seem prepared to subordinate their own foreign policy to that of the European Union as a whole. The role of development policy in relation to classical foreign policy (security and trade) will also have to be specified in greater detail - some even fear that development aid will be used as a bribe to achieve foreign policy objectives.

In the field of development cooperation, as in other areas, Europe remains for the time being largely a promise. There are, however, clear opportunities. First of all, knowledge, policy and instruments can be better coordinated, for example by creating a sort of European version of the World Bank, which would undoubtedly be called the Europe Bank. More than eight billion euros a year are already provided through EuropeAid, making the European Commission the second largest donor of humanitarian aid and the third largest of development aid. That expanded role is, however, not linked to a good knowledge infrastructure, like that of the World Bank, or to large-scale credit provision - that is the responsibility of the European Investment Bank (ЕIB), which primarily operates within Europe, and the European Bank for Reconstruction and Development (EBRD), which focuses predominantly on the former Soviet States, and is distinct from the policy of EuropeAid. Combining and expanding these European banks offers considerable opportunities for creating a genuine European development policy.

A next step could be to take serious steps towards adopting a coordinating role at the level of individual recipient countries. Combining the role of coordinator of member states' policy with being the 28th donor is not workable and leads to much friction with other donors in recipient countries. Focus on its coordinating 
role could be combined with a concentration on the themes and areas in which the EU clearly has added value, and which European citizens consider legitimate issues for the EU. In that respect, the EU still appears to have difficulties accepting the signals that European voters sent out en masse during the process of ratifying the Lisbon Treaty: that Europe should primarily focus on what the member states cannot do themselves. The EU development policy has for a number of years already favored what are considered 'less political' domains, such as infrastructure and regional economic development (Grimm et al. 2005). That trend should be continued, and the EU should specialize on issues with a regional (that is: supra-national) character. That means no interventions in healthcare or education, as many (perhaps too many) other donors and funds already do that, but making know-how and resources available to set up and further develop regional public goods and regional economic and political cooperation. The EU has recognized experience in these areas, citizens see them as its legitimate tasks, and African countries in particular have much to benefit from them (UNCTAD 2009e).

\section{World Bank}

If the EU proves unable, in the near future, to combine the forces of its member states, will aid then have to be left more to global multilateral organizations? Until 1963, with the exception of aid to former colonies, the lion's share of Western aid was provided through the multilateral channel. However, immediately after the Second World War, expectations of intergovernmental institutions were running high: "At Bretton Woods in 1944, John Maynard Keynes and the British delegation proposed a monetary fund equal to half of annual world imports, while Harry Dexter White and the American side proposed a smaller fund worth one-sixth of annual world imports" (Weiss \& Thakur 2010: 19). Although the world is now much more interdependent than back then, around a quarter of the Netherlands' development budget is currently transferred to multilateral organizations like the World Bank and the United Nations. The United Kingdom spends nearly half of its budget through the multilateral channel and Italy more than half, while countries like Denmark and Sweden devote a greater share of their budgets to multilateral organizations than the Netherlands, which plays an important role through its high total level of ODA. The question is whether these organizations are the best bodies to combine and coordinate aid efforts and thereby to address supra-national issues.

The World Bank has a number of clear advantages: it has extensive macroeconomic knowledge and is good at managing, for example, budget support and infrastructural projects. More than other organizations, the World Bank gives priority to knowledge development, and it conducts internal and external evaluations. Having said that, there are still too few feedback loops between the knowledge and research departments and country desks, and the Bank does not give sufficient account of its interventions to aid recipients. 
The World Bank also has a number of clear limitations. Firstly, because of its history, some developing countries distrust the Bank, especially for the one-sizefits-all policies it pursued in the past. The IMF also struggles with an image problem. That is not so surprising since, for a long time, both organizations worked along exactly the same lines, with the World Bank only providing support if the IMF issued a statement that the country concerned fulfilled the set requirements. Although their policies have diverged somewhat, the link between the two organizations remains very close, even at the most practical level with the staff of the Bank able to use their passes to enter the IMF building, and vice versa (the buildings are on opposite sides of the street and are joined by a tunnel). The World Bank is still closely associated with the Washington Consensus. This reputation is not entirely deserved, as the practice of the different country offices varies widely. However, it is a fact and, given the sluggishness of institutional change, it is unlikely that this image will change very quickly. The second disadvantage is that the World Bank implements its own policy, and combining its tasks of architect and main implementing agency is troublesome.

The main point, however, is that while the World Bank - which likes to present itself as a 'knowledge bank' - possesses more resources and an almost complete knowledge monopoly compared to regional development banks and more heterodox researchers and institutes, the failure of its one-size-fits-all approaches calls specifically for great diversity and plurality in knowledge, ideas and research for development. Countries differ from each other in their history, culture, traditions, institutions and level of developments, and paths to development are specific to each. Policy choices are political as well as technical and often no one knows what works best or how to create 'good' institutions. That is why "(p)olicy diversity [is] as important for development as bio-diversity is for the survival of the ecosystem" (Storm 2005). The implication of this is that we should abandon attempts "to spread a single variety of capitalism through the WTO, the IMF and the World Bank" (Wade 2009a).

The consequences of this for policy are that existing international institutions should not have a monopoly. Development benefits from a mosaic of organizations in different regions, that compete with each other at the level of ideas, but which are also linked together in networks and learn from each other (Sabel \& Reddy 2007). In addition, the quality and robustness of the generated knowledge can also be called into question: after analyzing the knowledge on the recent food price crisis produced by the international financial institutions, Cuesta (2010) concluded that "perhaps the current IFIs may be more cautiously described as knowledgeable institutions rather than knowledge banks." The world does not therefore benefit from a single World Bank functioning as a global knowledge institute, but needs three or four 'knowledge banks' with a similar mandate to that of the World Bank: knowledge, financing and project implementation. There is 
much to be said for having one of these banks in Africa and one in Asia. This could be achieved by merging the regional offices of the World Bank with the existing regional development banks, and making them responsible for the main functions currently performed by the World Bank, such as providing loans.

\section{United Nations}

In theory, it seems more logical to make the United Nations lead the way in development aid. Unlike the EU or the World Bank, the UN embraces all countries, including developing countries. In addition, its legitimacy is less controversial. The UN is particularly important in generating attractive and critical concepts and influential ideas (Jolly et al. 2009), like the Human Development Index and the concept of global public goods, has proved valuable as a norm entrepreneur in formulating and setting global standards, and has in some cases played an important role in coordinating worldwide humanitarian efforts after disasters like the tsunami in December 2004. Nevertheless, the UN still seems limited in its capability to take on the role of director.

The UN has a crucial part to play in global governance, defined as the whole of laws, standards, policies and institutions that define, constitute and mediate relations in the international arena between citizens, societies, markets and the state. But the gap between the global character of many present-day problems and solutions that are currently available is very wide. Weiss \& Thakur (2010) identify five 'gaps in global governance' that are reflected in the UN: knowledge gaps, normative gaps, policy gaps, institutional gaps, and compliance gaps. The UN is not a world government, nor are the specialized UN agencies departments of a global authority, and although "such distinguished commentators as Nobel laureate Jan Tinbergen and the World Bank's former president Robert McNamara have declared the need for the UN system to have some of these powers, such a goal remains elusive, highly contested, and very far from being accepted politically, even as a distant objective" (Weiss \& Thakur 2010: 35 ).

For all kinds of reasons, the UN is unfortunately not very effective as a political and directing force. A broader directing role for development aid is therefore, for the time being, a bridge too far. It still remains to be seen whether the Development Corporation Forum, set up in July 2007 to combine development efforts within the UN, will become more than just a discussion platform. In recent decades, instead of adopting a more directing role, the UN has focused more on implementation. A wide spectrum of implementing bodies has developed within and under the wings of the UN, each inevitably with their own institutional interests. Adebayo Adedeji, former executive secretary of the UN Economic Commission for Africa (ECA) noted that "once you establish an institution, in this society of ours in the world in which we live today, they are like cemeteries. You can't remove the graves" (Weiss \& Thakur 2010: 48). The UN has become a fragmented organiza- 
tion in which a growing number of institutions - often with too limited resources - all follow their own paths, notwithstanding all efforts to create 'one UN'. International institutions that focus on specific problem areas or issues and operate on the basis of norms and a consensus accepted by the member states - like the International Atomic Energy Agency (IAEA), Unicef, or the International Telecommunication Union (ITU) - are generally considered worthwhile. However, that was not the case with, for example, the former Commission on Human Rights (CHR). Implementing organizations like UNDP have, to put it mildly, achieved mixed results. It would have been more logical to have made UNDP a directing rather than an implementing agency, as was the original intention. It would have fitted in with the UN's position as an umbrella organization.

It seems sensible to safeguard and support the stronger aspects of the UN and its specialized agencies (FAO, UN-DESA, UNCTAD, UNDP, UNEP, UNICEF, UNIDO, UNRISD, etc.) - for example, generating ideas, conducting thorough analyses, tackling failing collective action on issues like climate, trade and security, and formulating worldwide standards - and only to assign it implementing tasks where it clearly offers added value or can operate better or more effectively than bilateral donors. Besides, the UN should certainly be the first option for providing aid in the case of disasters: it is better not to leave emergency aid to a multitude of individual NGOs and individual countries. The UN can direct the effort, especially if the government of the affected country is not politically involved in the cause of the disaster and has no major, biased interests in the way aid is provided - as is often the case with 'classical' natural disasters. With man-made disasters, interventions are usually more politically charged, which restricts the UN, as it obviously has to deal with governments. In such cases, interventions are better directed by large professional international organizations like the Red Cross or Médecins Sans Frontières.

Donor countries should develop criteria to determine what they see as the core of multilateral organizations, to avoid a proliferation of financial contributions to international organizations so that in the end no one knows which organizations are being supported and why (and which ones are not and why not), and what the concrete objectives of doing so are. That calls for a more serious evaluation of how these organizations function than current, often rather diplomatically formulated monitoring. A clear idea of the core roles of these organizations and of the desired international structure is an important aspect of this exercise. In that respect it will be interesting to see what comes out of the large-scale review of multilateral organizations announced in June 2010 by the new British government, which spends three billion pounds a year through them. 


\subsection{COHERENCE FOR DEVELOPMENT}

Development dimensions also play a role in policy that does not strictly fall within the sphere of development policy. Despite good intentions expressed at meetings and laid down in statements and reports, the concrete results of coherence policies for development have so far been disappointing. Without detracting from what has been achieved, it must be said that many of those involved believe that the potential benefits have only been realized to a very moderate extent. A major obstacle is that creating coherence is a relatively new objective, with which no single country has a great deal of experience. However, that is not the only problem. While holding a former position, the current chief economist at the British Department for International Development (DFID), Alan Winters, wrote that coherence is an emotional concept which no one can resist: who wants to be accused of incoherence? According to Winters, hard reality teaches us that a certain degree of incoherence is unavoidable, because coherence policy involves considerations and choices in which different objectives and interests are at stake (Winters 2001).

It is fashionable to consider practically everything as a win-win situation, but with many coherence issues that is not always possible. Complete coherence is unrealistic in a pluralist society in which different interests, perceptions and values coexist. Whether coherence has been achieved in a given situation depends on your viewpoint. A ban on trading arms with poor countries is coherent with the effort to achieve stability, but not with the interests of employers and employees in the arms industry, or of ministries wishing to promote international trade. In some cases there genuinely is a win-win situation - for example, in the field of knowledge, science and innovation policy (AWT 2009) - but generally speaking incoherence cannot be avoided and legitimate interests can often clash (Carbone 2008; Odén 2009; Winters 2001).

This can be made more concrete by looking at current practices. The choices that are made between the various interests involved are not necessarily those that would be made if development interests were given priority. There is good reason why, during the run-up to the last European elections, a coalition of large NGOS placed a number of themes on the web - including trade in illegally harvested timber, medicines, migration, military export credits and arms transit - through which, in their view, individual member states and the EU were damaging the interests of developing countries. There is also tension between keeping a country attractive as a location for multinationals and the price they pay for that in other countries. Researchers at the Centre for Research on Multinational Corporations (somo) estimate, for example, that thanks to the Netherlands' fiscal regime, developing countries lose out on some 640 million dollars (or 15 percent of the Netherlands' aid budget) per year in resources that they would otherwise be able to spend 
on healthcare, education or other public goods and services (Weyzig \& Van Dijk 2008).

Coherence policy for development is, in short, not a technical exercise, but a political process in which policymakers often have to weigh up conflicting interests and widely varying estimations of the potential consequences of policy against each other. By allowing development interests to prevail in this process more often, rich countries can make a greater contribution to growth, development and structural poverty reduction in poor countries than is possible with classical aid. The continuing asymmetrical relations between rich and poor countries and the great differences and inequalities between countries can be invoked to justify this, but whether that actually occurs is a political decision. This can be - and is - the cause of differences of opinion and political conflicts.

In light of the above, the institutional design of coherence policy for development is decidedly difficult. Experience so far shows that four interconnected issues play an important role in this respect: political commitment, coordination between and bridgeheads with material experts at the various ministries, building up knowledge and expertise and, last but not least, monitoring and evaluation (Odén \& Lundquist 2007). We shall examine these four issues in turn.

\section{Political commitment}

Without political commitment at the highest possible level the aim of achieving more coherence for development will never get off the ground - that much is clear from international experience so far. Because there is no one in the relevant policy bodies who directly represents the interests of developing countries, there is little incentive, without sufficient political pressure and engagement, to take them into account. In Sweden, for that reason, there were proposals to make coherence policy the direct responsibility of the prime minister, though the idea was eventually abandoned for practical reasons. Coherence policy has now been placed under the Ministry of Foreign Affairs, though opinions continue to differ about whether that is a wise decision. A coordinating role for the prime minister fits in well with the expanding role of heads of government in international fora and more generally with the theming of global issues. It is problematic for a prime minister to take direct responsibility for all major global issues, but one thing is clear: coherence policy will only seriously get off the ground if it is placed high on the political agenda. There are, however, no ready-made answers to the question of how that can best be achieved.

\section{Coordination and bridgeheads}

The second requirement for achieving an effective coherence policy is an adequate architecture. This calls for transparency and flexibility. It is important to be able to adapt quickly to changed relationships, identify instances of incoherence, and 
develop a culture in which sectors work together, enter into dialogue and settle disputes amiably rather than fighting them out. That can take a number of different forms. In Finland, one minister is responsible for both trade and development. Some countries are experimenting with combined departments. The United Kingdom, for example, has a joint directorate of the trade and development ministries, which concerns itself with trade policy and the British standpoint at the WTO talks in Doha (International Development Committee 2007, 2008), and a Stabilization Unit that coordinates the efforts of foreign affairs, development cooperation and defence ministries in countries like Iraq and Afghanistan. Sweden has taken the lead internationally with an integrated perspective on global development based on 'whole-of-government approaches', in which policy coherence is a government-wide responsibility. Norway, too, has taken the first steps in this direction. The European Commission also wants to move towards a 'whole-of-the-Union' approach, but it is not yet very clear what that precisely entails (Anten et al. 2008; Carbone 2008; European Commission 2009b, 2009c; OECD/DAC 2008b; OECD 2009). In the Netherlands, coherence policy has been addressed dynamically by a small unit at the Ministry of Foreign Affairs. The unit scores well in international comparisons, but there are limits to what six people, no matter how dedicated they are, can do to make government policy more coherent with development policy. In the near future it would seem logical to set up contact points or coherence units with material experts at other ministries, which can build up knowledge and identify issues at an early stage. A unit at the foreign ministry, with more manpower, could play a coordinating role. The unit would have direct access to the Cabinet through the Minister for Development Cooperation. The resulting government-wide network could also be used to discuss coherence issues with developing countries with which the classical aid relationship is being phased out.

Sweden is currently running an interesting pilot project exploring, together with the countries concerned, ways in which it can contribute to development in countries where it is phasing out their financial aid. The first reaction when terminating a donor relationship is to look at trade opportunities, but there are all kinds of other cross-border movements that can promote or hamper development - flows of money, people or information - and there will be increasing demand in developing countries for tailor-made knowledge in specific areas. It is therefore a matter not of simply leaving a country, but of a subtle change in the nature of the relationship.

There are also benefits to be acquired by exploring ways of making coherence issues and the trade-offs that they entail more visible. One logical example of this would be to integrate accountability for development spending in a broader process of accountability including policy in other areas. That would be practically feasible if it were combined with the policy proposed in the previous chapter: resolute concentration on a small number of countries or regions. The policy 
pursued in each country or region would then be mapped out, not only in terms of expenditure of ODA funds, but also of policy on trade, migration, knowledge, climate, etc. Addressing binding constraints on the basis of a diagnostic analysis can require a combination of complementary activities in various policy areas.

Policy coherence benefits from NGOs that not only expose existing incoherence between, for example, policy on migration and the arms trade, but also offer alternatives. Michael Edwards (2008), former director of the Ford Foundation, considers this a much more important task than activities that focus more on developing countries (as described in the previous chapter). In his view, the main task of NGOs is to contribute to the formation of a vocal civil society with the aim being to modify international rules, agreements and standards that are a more important condition for a resilient development policy. It is a matter of creating a fairer playing field, giving people from the South a voice, and generating a support base that can help achieve global changes in consumption patterns.

The obligation to address the issue of coherence in every dossier is a kill-or-cure remedy that can easily lead to more bureaucracy and yet another item on the checklist of requirements that have to be met by documents sent to parliament and the Cabinet. On the other hand, such a formal rule can help civil society organizations identify coherence issues at an early stage and exert influence on them. According to a recent evaluation, a similar way of working during preparation of the Netherlands' standpoint on new proposals by the European Commission which does not take place in public - has had a positive impact (Engel et al. 2009).

\section{Building knowledge and expertise}

Material expertise and involvement on the part of ministries is the third indispensable factor for coherence policy. Two successive evaluations by the European Commission have shown that a lack of these elements is often a major obstacle to building up coherence policy (European Commission 2007, 2009b, 2009c). Expertise on the relationship between different policy areas and development will therefore have to be accumulated and deepened 'on the job'. Generating and mobilizing relevant knowledge also requires more links with knowledge institutes, scientists and civil society organizations with expertise in specific areas, both here and in developing countries. It is crucial not to forget the latter, as stakeholders in developing countries themselves have so far had little opportunity to contribute to donors' coherence policy. The European Commission recently announced that it is going to make a greater effort in this respect for the Union in the coming period, a step which is also logical at national level.

Building up more expertise also means actively promoting countervailing power. Greater transparency on trade-offs and the choices made in coherence dossiers and debates on coherence can mobilize knowledge available on these issues in all kinds 
of places. It also involves NGOs, citizens, interest groups and experts more closely in policy, and this countervailing power is important because interest groups that operate in or on behalf of developing countries are not themselves present around the table when civil servants and politicians in donor countries discuss and make decisions on coherence issues.

\section{Monitoring and evaluation}

Because expectations about the intended or unintended consequences of policy that play a role in coherence dossiers are often controversial, monitoring and evaluation are the final indispensable elements in an effective approach to coherence policy for development. They not only enable us to learn lessons for the future, but also enable us to modify an ongoing course of action if it proves to have unexpected negative effects. The Norwegian Minister for International Development provided a good illustration of this in 2006 when he decided, unilaterally and unconditionally, to cancel the equivalent of eighty million dollars in Norwegian kroner in debts owed to Norway by Egypt, Ecuador, Peru, Jamaica and Sierra Leone. These countries had used the loans to buy ships from Norway, assuming that they would contribute to their development. An evaluation, however, showed that this was not the case (Ministry of Foreign Affairs Norway 2008).

In addition to monitoring individual activities, it is useful to commission an independent evaluation of coherence policy as a whole, for example every two years, to help keep policymakers on their toes and to learn from successes and failures. In its recent peer review of Sweden's development policy, the DAC reminds the Swedish government of this recommendation. Like many other donor countries, Sweden has not yet introduced such an independent review. Furthermore, experts from developing countries should play an important role in general evaluations of coherence policy (Odén 2009; OECD/DAC 2009c).

\section{The next step}

In coming years, donor countries and the EU will continue to seek ways of formulating good coherence policy. In most Western countries a logical next step would first of all seem to be to interweave all the activities of the line ministries that have a substantial development component with the Ministry of Foreign Affairs. Obvious models for achieving this are joint departments that report to two ministers or programme departments, but other organizational forms that go much further than the friendly exchange of information are conceivable. It would also seem logical to set up a bridgehead at each ministry with expertise on coherence policy for development, and to strengthen the monitoring and evaluation of coherence policy. 


\subsection{INTERNATIONAL PUBLIC GOODS}

International public goods are becoming an increasingly important reference point for international policy, and more and more relevant to the possibilities and room for manoeuvre available to national states. That raises the question of how best to give substance to their development dimension (Wijffels 2008). All kinds of goods, perhaps sometimes too many, are considered to be global public goods and not all are equally relevant to development. Donors and recipient countries therefore need to devise strategies to prevent budgets and energy from becoming fragmented, and to promote the internal coherence of development policy. For donor countries such strategies should, in any case, contain four elements. First of all they need to find a balance between national, regional and global public goods to help ensure that developing countries do not jump out of the frying pan into the fire. Secondly, they have to examine ways, perhaps together with others, of taking catalyzing initiatives. That will often mean, thirdly, developing new funding mechanisms. Lastly, it is important to render account for the action they take and other choices.

\section{Public goods on different scales}

It is important to seek the right balance between public goods on different scales, as they are mutually dependent (Hettne \& Söderbaum 2006) and the available funds can only be spent once. Little will be gained if the funds used for global public goods, such as climate policy or protecting biodiversity, are taken from budgets already allocated to national public goods in developing countries, like education or border controls, or to regional public goods, such as water management or regional infrastructure. Nor should developing countries be pressurized to sacrifice efforts relating to regional public goods (for example, to clean up a lake) in favour of global public goods (such as combating global warming) just because donors believe the latter should have top priority. Development countries need public goods at national and regional scale not only for their further development, but also to benefit from and contribute to global public goods.

National public goods in developing countries, as in rich countries, are indispensable for economic growth and development (UNCTAD 2009b) and, in principle, donors are already aware of them. If countries can diagnose where the main internal obstacles to development exist, it is possible to help remove them, for example with money or knowledge. In this way, where national public goods fall short, they can be supplemented. It is more difficult if a country's development is held back because it has insufficient access to certain global public goods - for example, land is drying out because of rising temperatures caused by climate change (Care 2010) - or regional public goods - such as an inadequate infrastructure linking it to neighbouring countries. Unilateral action by national government is generally not sufficient to ensure access to these public goods. It requires cooperation with other 
countries, calling for something different than the country-based approach traditionally applied in development cooperation (Arce \& Sandler 2002; Estevadeordal et al. 2002; Kanbur 2002; Te Velde et al. 2006).

\section{Taking catalyzing initiatives}

What role can an individual donor country play in all this? History shows that catalyzing initiatives are of great importance in facilitating and creating global and regional public goods. Such initiatives can be taken by governments or multilateral organizations, or by companies and other non-governmental parties. The legal framework for human rights, for example, is not only the result of the activities of national states, but also of the efforts of the United Nations and of civil society organizations like Amnesty International and Human Rights Watch that promote human rights. For international norms and standards in the field of labour rights, the tripartite (government, employers and employees) International Labour Organization (ILO) has been playing an indispensable role since 1919. For the prevention and treatment of HIV/AIDS, in addition to national specialized organizations and the UN, non-governmental groups like the Rockefeller, Ford and Bill and Melinda Gates Foundations and countless NGOs also make an important contribution. Biodiversity is preserved thanks to the efforts of national states, multilateral institutions and a large number of non-governmental actors, like Greenpeace and the Worldwatch Institute. The landmine treaty was a success thanks to cooperation between a number of middle-sized countries and NGOs. And, as a final example, businesses and investors can play an important role, together with NGOs, experts, governments and multilateral organizations, in bringing about international covenants and global norms and standards, like the Global Reporting Initiative (GRI), the Extractive Industries Transparency Initiative (EITI), and the Kimberly Initiative for diamonds (Collier 2007; International Task Force on Global Public Goods 2006; Zadek 2008). According to Klaus Schwab (2008), founder of the World Economic Forum (WEF), businesses, governments and civil society should join forces on Global Corporate Citizenship: "Corporations must engage on global issues while understanding that the business community cannot, on its own, solve global problems such as poverty, poor education, and inadequate healthcare. Governments and multilateral organizations cannot be discharged from their responsibilities to deliver such public goods."

In the field of global regulation, NGOs have also achieved a number of demonstrable successes (Edwards 2008; Lewis \& Kanji 2009; Riddell 2007). In 2005, for example, after sustained pressure from NGOs, the British government changed its standpoint on tariff walls and trade protection. It now recognizes that a one-sizefits-all approach to trade can be disadvantageous for some developing countries (Riddell 2007). International organizations, too, can be sensitive to pressure from NGOs. The World Bank admits that it became 'greener' in the 1980 os and 1990 os thanks to NGOs, and that international NGO campaigns for debt cancellation led to 
the HIPC (Heavily Indebted Poor Countries) initiative on debt reduction. Moreover, the chroniclers of the United Nations conclude that, over the years, NGOs have gradually but steadily increased their influence within the UN system. They even describe 'NGOs and consultants' as the 'third UN' alongside the first (governments) and the second (international secretariats) (Jolly et al. 2004; Jolly et al. 2009; Stokke 2009). There are, however, still a few challenges facing NGOs. They are, for example, better at addressing 'soft' themes like poverty or landmines, than forcing change in 'hard' areas like the economy or defence, and it remains difficult to propose innovative or workable alternatives (Lewis \& Kanji 2009). The power of civil society organizations is often that they can link country-specific problems to global themes - a link that needs to be made more often. They are excellent, for example, at showing how the economic situation of a farmer in Uganda is clearly related to agreements at the WTO, or that specific climate agreements are necessary for a region of Bangladesh. That is also why civil society organizations are well positioned to contribute to further elaboration of international public goods and strengthen their development dimension (Florini 2005; Edwards 2008; Grotenhuis 2009).

For donor countries wishing to contribute to development, giving high priority to promoting development-relevant international public goods means not only a lot of hard work in international fora and institutions, but also looking for possibilities to instigate relevant initiatives, either independently or together with likeminded countries and other parties. Preferences and possibilities will differ from country to country, and whether that can best be achieved by focusing on a small number of niches in which public and private expertise and resources can be combined productively is a question that has to be addressed when developing such a strategy. That will also require organizing and mobilizing more capacity for research and expertise.

\section{Developing new instruments}

Funding is often, though not always, necessary for international public goods. How this is organized differs from case to case, as public goods come in all shapes and sizes. Take, for example, public goods from which everyone - including nonpayers - benefit, such as measures to combat global warming. Financing these measures calls for initiatives by the international community, for example in the form of taxes or subscriptions. The situation is different for what are known as 'weakest link' public goods, which are very dependent on the activities of those who make the least effort (for example, measures to combat infectious diseases). In such cases, one option is to set up partnerships between public and private parties, so that all stakeholders make an acceptable contribution. These partnerships can also provide funding for 'best shot' public goods, from which everyone benefits once measures have been taken at a single location (for example, vaccines). A final example is 'club goods', whereby it is possible to exclude people 
from the benefits of the good concerned (e.g. satellite communication). Here the incentives lie elsewhere: the 'members of the club' (users) can form a private collective that provides the financing (Arce \& Sandler 2002; Sandler 2002a, 2002b, 2006).

These examples illustrate that it is necessary to think carefully about the concrete dimensions of an international public good. Not all global public goods are the same or need to cost a lot of public money, and it is not always necessary to wait until all countries wish to participate before taking initiatives. Global contracts and charters can sometimes be very effective without costing a great deal of money, and it is important to respond cleverly to incentives that can encourage governments or non-governmental parties to contribute to regional and global public goods. Should it prove necessary to organize funding for public goods, experience so far suggests three possible strategies, which can also be applied in combination.

- Better mobilization of resources. International agreements on the distribution of costs, with which everyone complies, and which take account of the widely varying capacity of countries to contribute, and with the way the benefits of the public good are distributed. This assures international organizations that provide the global public good concerned of predictable incomes.

- Cooperation with the private sector and civil society. Governments can do more to tap into and strengthen the specialized knowledge of the private sector and civil society and, with regulation frameworks and incentives, to facilitate and stimulate new initiatives in healthcare, environment and knowledge.

- Innovative financing mechanisms. There are ideas for generating additional funds for development and global public goods which have not yet been put into practice to any significant degree. These include, for example, the proposals for a tax on financial transactions (which the IMF has also recently started looking into), the issue of global development bonds, the British idea for an International Finance Facility that would make funds directly available by issuing bonds on the basis of long-term pledges by donors, and new financing mechanisms like advanced market commitments, which are used to provide vaccines for people in poor countries and regions. The latter appears to be a promising innovation and is examined in a little more detail below.

Advanced market commitments (AMCs) offer an answer to the problem that, compared to the social demand, little research and development (R\&D) is devoted to vaccines and medicines to tackle diseases in poor countries, like malaria or tuberculosis. A much-quoted statistic from the World Health Organization (WHO) is that half of the R\&D in the health sector in 1992 was conducted by the private sector, but that less than 5 percent of that was devoted to diseases that are specific to poor countries. Biochemical and pharmaceutical companies that have to turn a profit are reluctant to invest in R\&D into these kinds of diseases if they are afraid that they cannot market the vaccines at a price that will allow them to 
recover their costs. Michael Kremer, Bill and Melinda Gates Professor of Developing Societies and Economics at Harvard, devised a solution to this problem by focusing on the demand side, which had always been seen as hopeless. The basic idea behind his proposal to tempt manufacturers to conduct more R\&D into vaccines for the poor is that one or more sponsors commit themselves to pay a minimum price for each person who is effectively rendered immune to a specific disease by a newly developed product, until a certain number of individuals has been reached. This means that, if the manufacturer does not succeed in developing an effective vaccine, they receive no payment. AMCs have now been endorsed by the World Bank, former British prime minister Gordon Brown and the pope, to mention but a few of their more well-known supporters. In addition, the governments of several countries, including Italy, Canada and Norway, and the Gates Foundation have raised 1.5 billion dollars for the first AMC project, research into lung diseases, in the hope that this will lead to vaccines that will, up to 2030 , prevent the deaths of 5.8 million children. Meanwhile, the discussion on the pros and cons of this approach continues (Berndt et al. 2006; Light 2009).

Where donor countries can have added value depends on a variety of factors. It seems logical, for example, for a country like the Netherlands, with a quite strongly developed financial sector, to see a role for itself in helping to develop new financing mechanisms for international public goods. But more and more global funds are being established, for climate policy, healthcare and other public goods, and that brings with it the risk of fragmentation. As a consequence it is first necessary to examine where opportunities and needs lie and, although more and less well-known global public goods deserve attention, specific attention also has to be paid to less high-profile regional public goods, because funding them is especially difficult. Regional public goods can be difficult to organize because it is unclear how the benefits will be distributed among different countries, and therefore how the costs should be divided up. Furthermore, because donors focus on countries and 'ownership', there is a risk that both recipient countries and donors consider regional public goods to be less interesting than global or national goods. It can therefore be necessary to devise creative solutions, if there is no regional entity that can contract or provide security for loans for regional public goods, for example in cooperation with regional development banks and joint ventures between countries (Birdsall 2006; Estevadeordal et al. 2002; Kanbur 2001; Sandler 2005, 2007; UNIDO 2008).

\section{Accountability}

The final component of a more intensive approach to international public goods for development is the need for donor countries to establish appropriate forms of accountability for the deployed funds. As the available funds are limited, it is crucial to consider carefully where the extra financial resources for global and regional public goods must come from. Sometimes they will be 'new' or 'addi- 
tional' funds that do not come from the existing budget for development cooperation, but they can also be allocated at the expense of funds reserved for the direct improvement of living conditions in poor countries or for national or regional public goods in developing countries. To ensure that this occurs in a well-considered manner, it has been proposed that countries should keep a record in their national budget mechanisms of how much they spend on global and regional public goods. The OECD could then include this information in its statistics, as it already does for development aid. If donor countries were to take up this suggestion in the near future, it would not only become possible to obtain a clear picture of the contributions they make to international public goods and how they change, it would also give a signal to the international community and lead to the establishment of new standards (Dervis 2005; International Task Force on Global Public Goods 2006).

Following on from this, it is an interesting challenge to start thinking about what should follow the Millennium Development Goals. Gradually, an international discussion is gathering momentum on the agenda for development after 2015, when the MDGs should have been achieved. Partly because of increasing doubts that many of the MDGs will be achieved, a number of fundamental questions are being raised, some of which have been raised before. We have already seen, for example, that the relationship between the MDGs and economic growth and development is unclear, and their relationship to international public goods is equally obscure. Furthermore, there is still a lack of clarity as regards the scope of the MDGs, and about who actually 'owns' them, or should own them (DFID 2009a; Manning 2009). Developing a reference framework that is better structured conceptually and in which well-founded links can be made between international objectives, the application of different instruments (including ODA and international public goods) and the growth and development of countries, is not simple, but certainly badly needed.

\section{The next step}

International public goods are not only important for development policy, and require specific substantive knowledge from case to case. It is therefore not logical to give general responsibility for these goods in donor countries to a single minister and to the ministry of development cooperation. It would appear more sensible for line ministries to be responsible for international public goods in their own specific areas of work and, as not everything can be addressed at the same time and as priorities will have to be set, a political and official coordination point will have to be established at high level, which can set priorities and account for them. In addition, since it is not going to happen automatically, the interests of developing countries must be explicitly defined. It is logical that the ministry of the prime minister or president will have to take more explicit responsibility for this coordination function, if for no other reason than that different cross-border themes will 
increasingly be linked to each other in international fora like the G2O and institutions like the United Nations. Whether the coordination point will take the form of a sub-cabinet of ministers for global development, or a new entity, or take some other form completely, is a matter of further elaboration and will depend partly on the specific structure, tradition and culture of the administrative organization of each country.

\subsection{GLOBAL GOVERNANCE}

In the past sixty years, most Western governments have offered no, or almost no, critical reflections on the functioning of multilateral organizations. That is increasingly becoming a sore point. Today's world calls for a far-reaching review of these organizations - slight adjustments here and there will not suffice. Tectonic changes in the global configuration of influence and power have led to a multipolar world no longer dominated by a single superpower. The increasing influence of Brazil, Russia, India and China (the BRIC countries) and other developing countries will sooner or later lead to new relations between and among international organizations, and to new forms of, and ideas on, global governance. A country that does not want to lag behind but to help design the new world, will have to develop innovative ideas and proposals.

A new vision is required on Western countries' place in the world, and what contribution to the international order is appropriate on the basis of that position. That is a long process. On a development agenda for the future, however, there are three issues that donor countries clearly need to address seriously: the composition of international fora, the lack of multilateral coherence in economic and social policies, and the relationship between global and regional coordination mechanisms. We briefly examine these issues below.

\section{Composition of international fora}

The first issue that can no longer be avoided is the basis on which the composition of major international fora is determined. In the UN General Assembly - the G192 - all countries, large or small, have equal power, while in the IMF and the World Bank it is the size of their economies and their financial contribution that determine how much power each member state can wield. Although the G2o may be more representative than the G7 or G8 and more than 8 o percent of the global economy meets there around the table, a considerable proportion of the global population is not represented. Proposals have therefore been made recently to determine the weight of countries in multilateral organizations by a combination of the size of their economies and of their populations, and possibly also to take account of the extent to which countries make a contribution to global public goods. It is high time for a fundamental debate on how we wish to address this issue (Dervis 2005; Rueda-Sabater et al. 2009). 
In addition, a country like the Netherlands can no longer evade questions about its own position at the IMF and the World Bank. Since mid-2010, when the quota was adjusted, the Netherlands (with 2.16 percent of the votes) has had almost as much voting power at the IMF as the much larger India (2.44 percent of the votes) and more voting power than Brazil (1.78 percent). It is also overrepresented at both the World Bank and the IMF, with a director on the board. With nine of the twentyfour seats on the board and more than 30 percent of the votes, the European countries jointly are also heavily overrepresented at the IMF. That representation will have to be reduced to allow more space for emerging countries. If we take our support for more representative multilateral organizations seriously and want the rest of the international community to believe that EU members understand that the world really has changed, it will not be possible to avoid giving up certain positions in favour of emerging countries that are currently underrepresented. That means, for example, that the European Union will have to settle for one or two representatives on the boards of the IMF and the World Bank. An added advantage of this is that the representation and the standpoints of the EU in multilateral organizations will receive greater attention in national and European policy preparation and the debates in national parliaments and the media.

\section{Global coherence}

Secondly, from the perspective of development, global coordination and coherence (or the lack of them) of economic and social policy are important for stability in developing countries. This is also an important issue for the rest of the world - we need only to think of the financial crisis (UN 2008). At the moment, none of the multilateral institutions have either the position or the legitimacy to move this forward: ECOSOC does not have sufficient bite and has no influence on the IMF, the World Bank or the WTO, which in turn have a legitimacy problem. The vacuum between weak international institutions and the growing need for global governance is filled by an assortment of informal institutions, publicprivate, government and NGO arrangements, and specialized organizations. That is to a considerable extent unavoidable as long as there is no effective world government - as we have seen, the UN is far from that - and only very few people see that happening or even consider it an attractive prospect. That does, however, have a downside, as it leads to a proliferation of international, regional and subregional standards and initiatives that far exceed the absorption capacity of many countries. Where rich countries, with their extensive resources and hundreds of officials, think-tanks and lobby groups, already have serious problems in overseeing the many governance fora, picking their way through them and trying to bring about coherence in their policies, poorer countries, with their much more limited capacity, are faced with an impossible task. According to Cilliers (2008), the implication for countries in Africa, for example, is that regional organizations must operate more rapidly and selectively if they are not to become irrelevant, and that governments must set much clearer priorities and 
become much more intelligent and more competent if they are to find their way in the changing world.

Initiatives to promote multilateral coherence can only start in the participating national states. The inherent problem with this is aptly formulated by Alan Winters, currently chief economist at the British DFID: "Individual governments do not define precisely what they want from the world system and so the various organizations end up with conflicting goals or, at least, conflicting weights on different goals" (2001). A task force set up by the UN General Assembly, led by Nobel Prize-winning economist Joseph Stiglitz, has proposed establishing an elected Global Economic Coordination Council within the UN to replace the G2O and G8. The Council would be responsible for promoting coherence and consistency in the multilateral system, for example at annual meetings of heads of state and government. Despite plenty of good intentions, this has not yet led to much in practice, but the discussion continues and, given the increasing interdependence of various international problems and crises, proposals of this nature will be tabled more and more frequently, demanding responses and initiatives (UN 2oogd; Went 2009).

\section{Both multilateral and regional}

A third issue that needs to be fundamentally considered, and not only from a development perspective, is the scale on which coordination and cross-border initiatives can best be organized. The current trend is to address as many topics as possible multilaterally at global level, which seems logical in light of globalization and the increasing interdependence between countries. After all, the national level is insufficient to address cross-border issues. The global level is, however, often too badly organized and politically heterogeneous to take any kind of effective action at all. That makes it easy to underestimate the extent to which regions and forms of regional cooperation are, or should be, playing an increasingly crucial role in tackling cross-border problems and challenges. African countries have much to gain by more intensive regional economic cooperation (UNCTAD 2009e), although EU negotiators on EPAs do not yet seem to have realized that sufficiently (see, for example, South Centre 2010). In chapter 6, we already drew attention to the increased importance of regional funds (e.g. the Chiang Mai initiative of the ASEAN countries) in strengthening mutual financial support and policy space in respect of global organizations and within the global economy.

Following the recent financial and economic crises, there is little left of the euphoria about the assumed capacity of globalizing markets to regulate themselves, and around the world, think-tanks and governments are seeking ways to re-embed markets more deeply at national level, and give states and regional institutions more policy space to protect themselves against international crises and their consequences without unnecessarily losing the potential and actual benefits of 
globalization (see, for example, Rodrik 2010b). Strengthening regional cooperation can be interesting not only in the context of embedded globalization, but also because it is easier to mobilize political will and joint action at that level. The EU is a case in point. When global coordination does prove necessary it can perhaps be organized, depending on the issue, through cooperation between regional institutions at different levels. If we also take account of the fact that providing regional public goods often encounters specific problems, it is clear that it is necessary to develop a new pragmatic vision on the relationship between the multilateral, regional and national levels (Hettne \& Söderbaum 2006; Hettne et al. 2008; Ministry of Foreign Affairs 20ogb; Ocampo 2002; UNCTAD 2009e).

Shallow rather than deep integration should be the motto of multilateral institutions and cooperation, to give countries sufficient policy space to make their own choices. Here, too, the EU provides a good example of the way in which collective action is combined with the sovereignty and policy freedom of individual member states. Developing countries need that to 'learn-by-doing' and where necessary to be able to take protective measures, perhaps temporarily, to be able to develop new dynamic economic sectors (see also George 2010). National development strategies can only work if international regimes and governance structures and mechanisms facilitate and promote sufficient policy space and flexibility and, for example, allow exceptions to general rules and standards. The question as to how globalization can be combined in a more productive and less destructive way with national states that have sufficient policy space, and with regional institutions, has been on agendas around the world since the financial crisis. Closer reflection on the form and content of what we have described above as 'socialized or 'embedded' globalization, is unavoidable (UNCTAD 2009b; UNDP 2003).

\subsection{BEYOND 'INTERNATIONAL COOPERATION'}

The world has changed radically. In the past, international relations were 'Newtonian' by nature: states were sovereign, settled disputes with might, and were measured by weight - the size of their territory, population, industry, natural resources and military power. In the current era the situation is different, in that states can no longer be considered autonomous isolated entities, are losing their monopoly on economic, political and military power, and increasingly have to share them with transnationally operating organizations like multinationals, NGOs, political multilateral organizations, not to mention criminal and terrorist organizations. Global interdependencies are increasing and the internationalization of trade, financial flows and production (economic globalization), cross-border communications and global challenges are forcing countries that compete with each other also to seek areas of common interest. That is taking place in a world that is no longer dominated by a single superpower, but is multipolar and has, to an increasing degree, different regional and national power centres (Gu et al. 2007). 
As a consequence, development objectives are becoming more interwoven with other policy areas, and development policy is more frequently expected to contribute not only to 'pure' development goals, but also to be a partner in international cooperation in pursuit of other aims, and therefore to work with nontraditional development actors in the North and the South. Ideally, this can mean that the leverage of development aid can be used more effectively to find solutions to global issues in other policy areas which are positive for development, but that is by no means self evident. It may lead to cofinancing and the joint deployment of development aid and financial resources from other sources, but that may also have consequences for what can be considered official development aid (ODA) (ECDPM 2009b). It is important to examine this closely, but constructively (Severino \& Ray 2009). How donor countries approach the 0.7 percent standard for ODA, agreed at the UN in 1970 and reconfirmed on many occasions since, is seen internationally as an "indication of the preparedness of governments to comply with internationally agreed commitments relating to the social and economic development of developing countries" (Stokke 2009: 512). Definitions of ODA are, however, not set in stone and should reflect thinking on what a responsible development strategy entails. They have therefore changed several times since the DAC first agreed in 1969 what expenditure could be regarded as ODA. The discussion on the definition of ODA still continues. This debate will, however, reach a completely new phase once policy coherence and global public goods issues are also brought in the equation.

\section{Global development}

While the term 'international cooperation' was appropriate in an era when the relationship between states was based on sovereignty, 'global development' expresses the fact that national policy increasingly has an impact in other countries, that issues and problems on national agendas are more frequently coloured and influenced by developments and activities across the border, and that development takes place in a global context in which a variety of actors operate. Because, after sixty years of development cooperation, we are now sadder and wiser about what can be achieved from outside, and know that for the majority of developing countries the importance of aid is much more relative than we thought, issues like financial stability, trade policy and migration are becoming increasingly significant to the development agenda. A focus on global development does not mean that we should adopt the megalomaniac pretension that we have to develop the entire world, but that we have to be more systematic in identifying the cross-border consequences of our policies and actions. That will enable us to take a more conscious approach to coherence policy for development and in providing targeted support and initiatives for international public goods. Striving to take that challenge seriously, through trial and error, is a long-term investment in effective mechanisms to stimulate and direct efforts to achieve a new world. No single country knows as yet exactly how that is to be achieved. 
It calls for a radical re-think of the relationship between domestic and foreign affairs and, by extension, of the institutions designed to give shape to that relationship (see, for example, Evans et al. 2010). In particular that means continuing to develop the way the Ministry of Foreign Affairs is structured and how it operates. Maintaining relations with foreign powers and defending the national interest through a single institution is a nineteenth-century construction from a time when states were still autonomous, isolated entities, and diplomatic processes were largely dependent on the speed of the mail coach. Ministries that 'do overseas' and labour under the misconception that they direct or even control all crossborder relations, are no longer appropriate to the issues that the world now presents us with. Many international organizations, too, work in a way that dates from a time when air travel, internet and telecommunications did not exist.

It is not possible to draw up a blueprint for a new system to manage cross-border relations, and experimentation and further development will remain necessary. It is a very logical step, however, to streamline external representative and multilateral institutions and transform them into networks in which national and international experts work together on the basis of their specialized knowledge and expertise, and make use of new organizational forms and technologies. Instead of diplomats, agricultural experts would exchange proposals and information on subjects that they know about. That is not only more cost effective, but also good for the quality of the exchange of ideas and decision-making in international organizations. They will become substantively more valuable when diplomats no longer read their pre-written interventions to each other, and experts in the field in question work together to solve problems. Diplomats can then do what they are good at: indicate how the process of cooperation can best be structured.

What remains is the question of how to achieve the coordination and strategic integration of the mosaic of cross-border relationships and networks that is gradually evolving. A Ministry of Foreign Affairs concerns itself with professional diplomacy, but can no longer play a substantive role in many areas. It is therefore logical to look for better ways of organizing cross border issues. One obvious step would be to modify the portfolio of the Minister for Development Cooperation. The new minister would have two important areas of responsibility: organizing and providing aid itself, and a globalization agenda in which aid, coherence policy and international public goods would be approached in an integrated manner on the basis of a vision of global development. This minister would then function, like the Minister of Foreign Affairs, primarily as an extension of the prime minister, and less as someone with their 'own' domain. Following on from this, it will then be necessary to re-assess the entire division of labour surrounding the theme of 'foreign affairs' to determine whether it is appropriate to meet the challenges of the twenty-first century. 


\section{Thinking more broadly}

"The ones most likely to 'save Africa' are Africans themselves", concludes William Easterly (2008a) in a comprehensive evaluation of Western attempts to save Africa. Everyone agrees that countries and peoples can only develop themselves, and that financial aid from outside can at most help them to do that and should be designed to render itself unnecessary as soon as possible. Of great and sustained significance for possibilities for development are the international context in which poor countries have to try and find a place for themselves, and the cross-border consequences that they encounter from actions conducted in the rest of the world. Development policy therefore has to devote considerable attention to well-functioning and stable financial markets, coordination of efforts to combat tax evasion, migration policy, knowledge transfer and sharing, a development-friendly trade regime, and policy space for countries to determine their own paths to development. Yet, in most donor countries, nearly all attention is still devoted to the expenditure on the official budget that the Minister for Development Cooperation spends every year, the material evidence that we wish to contribute to a better world. Public, political, official and media interest in other mechanisms with which we have a positive or negative impact on development continues to be far too limited.

In doing that, we are not doing developing countries any favours, as other noncoherent policies can more than cancel out the impact of development aid. In addition, by devoting so little attention to the cross-border externalities of national policy, we are also selling ourselves short, because the active involvement of developing countries is indispensable in the provision of important global public goods that are also in our own interests. Eradicating infectious diseases, combating financial instability and a climate policy to combat global warming, are topical examples that are familiar to everybody. In addition to aid, coherence policy for development, a strategy for international public goods, and a vision of global governance founded on the new relations in the world are indispensable in contributing to global development within a globalization agenda. 



\section{CONCLUSION}

Development aid is the subject of heavy debate. In many ways the world has improved immensely over the past sixty years. However, the question is increasingly being raised as to what contribution aid has made to this development. Progress has primarily become apparent over the last few decades. In the past twenty-five years, life expectancy in all developing countries taken together has risen by ten years, and the percentage of children attending school has doubled. Poverty around the globe has also halved, to a quarter of the world's population. This success, however, has primarily been achieved in Asia, with China alone accounting for three quarters of the decrease. In Sub-Saharan Africa, real incomes have doubled over the past twenty-five years, but the percentage of people living on an income under the poverty line has not fallen. Can these successes be attributed to development aid, or should the lack of success be blamed on aid? The answer to both questions is: 'No'.

Development aid definitely contributed to the massive leaps forward made in Asia, from the economic support to Taiwan and South Korea in the 1950 s to the aid for agricultural improvement provided to India in the 1970s. However, these contributions were limited - all manner of other factors were important. Similarly, the lack of success - in particular in Sub-Saharan Africa - cannot unequivocally be traced back to the failure of aid. A lot of aid, particularly in the 1990s, had geopolitical objectives. Even today, much aid primarily aims to improve the immediate living conditions of the poor instead of bringing about structural development. Moreover, economic, political and social structures in African countries are of a very different order. These countries still clearly reveal the traces of colonialism, with their artificial borders and institutions that are barely rooted in society. Strong governments with a clear view of the future development of their country are rare in Africa, in sharp contrast to Asia.

Simple analogies between development paths in various parts of the world soon become misleading. For example, a parallel between development aid and the Marshall Plan is inaccurate because the latter started out as an attempt to rebuild Europe after the war. It was essentially a matter of reviving a formerly healthy patient, while many of the countries which need aid now have never had a healthy market economy or a functioning state system. The point of departure for the countries in Asia which have achieved rapid development in recent decades was very specific. Japan, South Korea and Taiwan were able to integrate into a world market which was many times less regulated and overcrowded than it is today. African countries currently wishing to produce for export not only face fierce competition from China and other Southeast Asian countries, but their products and production processes also have to meet a wide range of require- 
ments. In other words, development paths are pre-eminently country and timespecific.

The first lesson to be learned from sixty years of development aid is that we should be modest. Modesty is due first of all because of the relative importance of aid. Development only depends on aid to a very limited extent. This applies financially: in most developing countries, foreign investments and migrant remittances account for larger flows of money than aid. It also applies institutionally: with the exception of the aid to fragile countries and the very poorest countries, financial transfers are not, by definition, the best tools for contributing to development. In the majority of countries, unilateral trade concessions, more stringent international global tax regulations that also apply to multinationals in the West, financial stability, less strict intellectual property rights, the abolition of tax havens, knowledge and technology for the climate-friendly development of agriculture, companies, transport systems and cities, and the return of stolen funds can make a bigger contribution to development than classical aid.

Modesty would also be good for our thinking patterns. For too long now, we have tried to use all-encompassing plans to provide universal explanations for a multitude of specific situations and to subsequently write out equally universal prescriptions. In previous decades, these were macroeconomic reforms and good governance, while in recent years investments in social sectors have been popular, but every time the prescriptions have been too general. After sixty years of generalizing, it has become apparent that specificity is required because it is impossible to be able to say in general what works best and why. This lesson is unavoidable: countries in Asia, such as China and India, which took little notice of Western economic orthodoxy and worked pragmatically and creatively, have undergone unparalleled development, while growth lagged behind in Latin American and African countries when they tried, partly due to pressure from the IMF, to reshape themselves according to the general guidelines of the Washington Consensus.

Moreover, the world is changing. China, India and Brazil have become important players on the world market. This process has been accelerated by the current financial crisis, which these countries - where the government has a more important role, including in the financial sector - have managed to survive better than their Western counterparts. The world is rapidly becoming more crowded and more interdependent. The global population is expected to quadruple between 1950 and 2050 and, if the current trend continues, it will become nine times as rich. This means that social, physical and sustainability limits will soon come into view. Development will increasingly become regional and global in character. As a result of issues like climate, trade, migration, energy and security, national policy will decreasingly be a sole determinant factor; the pressure to take action and to make agreements at regional and global level will only increase. The principal task 
is to find ways to shape the globalizing world so that the balance between shared interests and the space for countries and people to take control of their own futures is preserved. This will only be possible if every country and people feels that they have a place, that they count and can keep pace with others. In that respect, the development of poor countries is increasingly becoming an unavoidable necessity.

This multiplicity of developments means that the aid sector faces countless major questions, and the range of answers is equally broad. For example, some advocates of aid stubbornly maintain that we could permanently rid the world of poverty for just a few trillion dollars. This is an appealing message which appeals to the good in every human being, and many people are only too willing to believe it - not in the least due to the efforts of many celebrities who want their own 'Bono moment'. However, there is no empirical basis for this claim: if only it were true that we could buy a better world for a reasonable sum of money. It is unfortunately impossible to lift countries out of poverty from the outside in one fell swoop.

On the other hand, there is also widespread scepticism about the value of development aid. Many people are particularly concerned that the preconditions to allow aid to act as a catalyst have not been fulfilled in Sub-Saharan Africa. It is easy to invoke the image of neo-patrimonial structures, with excessive corruption and local elites with a glaring lack of a sense of responsibility. That impression is not entirely incorrect, but is too one-sided. Developing countries vary and are complex entities with all manner of fractions, path dependencies and their own dynamics. The challenge is to align with this intelligently and facilitate the right development processes.

There is therefore no general answer to the question whether development aid helps. Sixty years of evaluation studies also bear this out. The development of countries is influenced by so many factors and is so complex that any attempt to provide a general answer encounters exceptions. On closer inspection, it should come as no surprise that projects and initiatives sometimes fail. In complex situations, intervening is always a matter of trying things out, experimenting. That things go wrong every now and again is not bad, but it is important to learn from these mistakes. That means constantly determining where the most binding constraints lie, and where the best opportunities present themselves. This is not easy, but it is very productive.

\subsection{DEVELOPMENT MORE CENTRAL}

The main task for development policy is to dose and structure development aid in such a way that it makes a difference in a world which is becoming increasingly interdependent. That first of all means being clear about goals and means, and 
creating close links between the two. There is no lack of visionary ideas in the aid sector, nor is there a shortage of possible activities. Moreover, every ideal has its counterpart somewhere in a specific project. A minister for development cooperation can therefore easily demonstrate that he has thought of everything and that his policy covers every possible idea. However, the challenge is to structure aid in such a way that it is systematically aligned with the selected goals. It is therefore also important to make targeted choices and to link them to serious consequences.

Modern development policy should organize itself in accordance with clear objectives. These may vary. Analytically speaking, three types of objectives can be distinguished at this point in time. To start with there is concrete poverty alleviation and the immediate improvement of living conditions. The majority of aid focuses on this and can rely on widespread support in Western societies. It shows that many people are becoming increasingly involved in this type of aid, and are taking the initiative themselves. The government's role is limited. It can help those involved to find out the best thing to do and how they can do it. The government can also try to prevent Africa becoming a playground for irresponsible amateurism. In the UK, work is already under way to develop a code of conduct aimed at preventing abuses in the South. That is an example worth following.

The second objective of aid is development focused on structural improvements in developing countries through sustainable economic activity. The principal preconditions for this are an effective government which can play a facilitating role and a sufficiently stable social climate. Providing aid which aims to make countries self-sufficient is very complicated. To start with, it presupposes that it is possible to determine how development can be stimulated. Secondly, it assumes that this can be achieved from the outside. In addition, the aid should have more positive than negative effects, such as creating aid dependency or reinforcing neopatrimonial structures.

The third important objective for development aid is to contribute to global public goods. Our self interest is clear here: national objectives for climate, food, energy and safety cannot be achieved without active contributions by other countries and should be coordinated at a supranational (regional and global) level. The main problems here are that it is difficult to find an adequate structure for this, and that most donors are not major players.

Not all three objectives receive equal attention in current development policy. Direct poverty alleviation is relatively simple to visualize, and is high on the agenda for moral reasons, but the aid sector's attention has been very strongly focused on this aspect. The lion's share of the budget is currently spent on social sectors, while productive sectors like agriculture and infrastructure, which are 
less likely to produce visible results, but which can alleviate poverty structurally in the long term, receive little funding (though they have been receiving greater attention in the past two years). Part of the investment in social sectors will, perhaps, in time also contribute to development, but the effect is very indirect, all the more because education in many African countries is not only of poor quality, but is also hardly attuned to local needs. In addition, aid is often so fragmented across countries, themes and channels - and often so untargeted that it insufficiently stimulates structural development.

This can and must be improved. The goal of development should once again receive more emphasis. Economic growth is emphatically part of this, because without growth there is nothing to distribute in developing countries. It also means that poverty alleviation should not be seen as a mantra, and that the poor do not always have to immediately benefit from the aid provided - the development of the middle classes is essential to development. It demands that more attention be paid to agriculture - not only for food security, but also for export - to strengthen productive sectors and the importance of market players. That means giving more attention again to entrepreneurship and supporting the provision of credit to developing companies, in particular small and medium-sized enterprises. In addition, the question as to whether job opportunities should be created should become an important parameter for development policy. Economic and social policy improves the situation of the poor if it is aimed at raising the income they generate from working, in many cases in agriculture or from unskilled labour. After all, it is not growth in itself that determines its consequences for the poor but the nature of agriculture and industrialization in the country and the economic, social and labour policies it pursues. This is one of the major problems with development in Africa: a lot of growth relies on the extraction of natural resources and rising commodity prices.

Putting development first as an objective also entails a more emphatic orientation towards regulating global affairs. For example, properly functioning and stable financial markets, fiscal coordination to combat tax evasion, migration policy, knowledge transfer and knowledge sharing are much more important to many developing countries than direct financial aid. In addition, in as much as they are international public goods, they are also to our benefit. In spite of this, when it comes to development aid, many Western societies still devote almost all their attention to the very small percentage of GNP allocated to the budget of the minister responsible for development cooperation.

The implication of this argument is that development policy that is really focused on development will take shape along different paths. The first path is that of classical aid, but then designed in a responsible way. The second path is that of general regional and global policy within which the development component is given 
specific attention. There is much evidence that the first path is increasingly approaching the end of its lifecycle. It is still worthwhile to follow this path in the coming decade but after that, unless very strange things happen, the number of countries that can be helped further in this way will be very small. In Asia there will be hardly any such countries left once Bangladesh, as is expected, becomes a middle-income country in 2020. India will remain a poor country for many years, but is decreasingly willing to accept Western aid in tackling its poverty problem. In most of Latin America, too, classical aid is no longer appropriate. In Africa, it will remain necessary for some years to come, but that need will also decline steadily. In ten years' time, it will probably only be required in a limited number of countries where nation-building remains fragile, such as Congo and Somalia. Development policy will to an increasing extent be shaped within broader regional and global policy. It is therefore an important task for governments to gradually redesign their policy systems (institutions, instruments) with this in mind. How can these two paths be shaped further in the future? Section 9.2 looks at the first path, of direct aid, while section 9.3 examines ways of addressing development issues in a broader context.

\subsection{PROFESSIONALLY ORGANIZED DEVELOPMENT}

Development should once again become central to development aid. Organizationally, this entails a much more pronounced country orientation, combined with substantial professionalization. A more pronounced orientation starts by recognizing that development always comes largely from the inside, and that development paths vary from country to country. Development aid basically means help in developing. At most, and even this is not a certainty, aid can make a small contribution to a country's development process. Where and how this support can be of use, varies from country to country.

A good diagnosis per country is necessary to determine what kind of aid is required. The capacity to provide aid depends entirely on having extensive local knowledge and contacts. Aid is therefore primarily useful as a long-term, programme-based investment comprising a coherent package of interventions, and which is carried out in collaboration with local institutions or actors. To provide a concrete example: there is very little point in trying to develop agriculture in Ethiopia without determining whether there is sufficient credit available for entrepreneurs, whether the infrastructure is of sufficient quality for transport products, whether good seed is available, what the irrigation systems are like, what options are available for university research and development, what skills are taught at primary and secondary schools, what role private investors have or could have, what trade limitations Europe enforces on exports and what wider developments are taking place on the global market in that context. Fully comprehending these kinds of cohesive systems and knowing when, where and what can be done 
in a worthwhile manner presupposes a long-term presence, thorough knowledge and the capacity to utilize a multitude of parties in both donor and developing countries (from good legal experts in the field of agriculture and trade to people who can help set up education programmes and private investors). Finally, all these efforts are only worthwhile if they take place on a large enough scale to really make a difference.

At the moment these conditions are not sufficiently met. Take, for example, the demand that the lines along which the development of a specific country can best be furthered should be clear. It may sound trivial, but such analyses are rare. There is a lot of valuable information to be found on the Dutch Ministry of Foreign Affairs' website or in its budget, but this is usually not the most essential information: i.e. an account of why the Netherlands believes that the contributions it is attempting to make are actually the most sensible ones. In practice, the Netherlands primarily provides a lot of support to education and healthcare because it has always done so: usually there is no more reasoning behind it than that. Investing in primary education is, however, not necessarily the best way to stimulate structural development in every country. In this respect a country like the Netherlands, which is no exception, could learn from other countries: Britain, Sweden and Norway are better at making these considerations more transparent. This enables others also to consider the most sensible contribution in any specific situation. Precisely because there are no simple or general answers to the question of how development can best be promoted, it is important to continually exchange insights on this.

If development aid truly wishes to make a difference, it should also be professionally organized. Sweden has already arrived at that conclusion and created its own development organization. In Britain, the DFID was split from the Foreign and Commonwealth Office in 1997 for the same reason, and Canada is also intending to organize its development aid separately, at some distance from the embassies. In addition, Canada has opted to focus on a substantially lower number of countries and sectors, a route the Nordic countries have also taken. An obvious choice for countries that have not yet taken this path, including the Netherlands, would be to select a limited number - a maximum of ten - development aid units based in the recipient countries concerned. These local organizations would be located somewhere near the embassies in the recipient countries, but would have their own personnel policies, focusing on the professional requirements of a long-term presence and specific expertise. The demand for professionalism is related to the underlying subject matter (if you want to develop the water sector, you really have to know something about it) and to processes (the capacity to involve the right parties at the right point in time, both private and public), but also to being streetwise (being able to deal with local contacts). 
This organizational model proposes that donors stop fragmenting their aid and limit themselves to a small number of locations where they have a proper presence. This is also sensible for three other reasons. First of all, it will make it easier to deal with the negative consequences of aid. After all, aid is never innocent: it places countries in a dependent position and gives rise to all sorts of power politics in which individuals try to benefit themselves and their own people. In that respect, corruption is only one of the problems. Such dependencies should be kept manageable, and two requirements have to be met to ensure this. Firstly, a donor should be a serious player; threatening to withhold relatively small sums scares no one. Secondly, donors should have a wide range of aid tools to ensure, as far as possible, that aid does not create dependency or undermine local accountability procedures. This means constantly weighing up the methods used to provide aid. Aid can be provided entirely indirectly (by improving trading conditions or migration policy) or directly (by transferring funds or knowledge). In the latter case, the channel used is also of importance: through the government or, for example, service users. Lastly, this should be accompanied by removal of the annual pressure to spend the money available and making financial resources available for a longer period of time in the form of a fund.

A second advantage of concentrating only on a few countries is that it makes concrete steps possible to combat the enormous increase in donors per country. All donors, both governmental and non-governmental, endorse the 2005 Paris Declaration on Aid Effectiveness which promised to increase aid coherence, but which has so far insufficiently been put into practice. Donors enthusiastically discuss the importance of good governance, but when it comes to the way in which they themselves structure their aid, it suddenly seems a lot less important. The European Union has done good work by outlining a form of division of labour, but in practice almost no progress has been achieved. It is therefore important for a number of countries to set a good example and start pruning their own activities. This should be done in conjunction with likeminded donors and recipient countries. The time is now ripe.

Finally, a focused, professional organization would also enable us to organize our development aid better as a learning system. If we invest seriously in a limited number of countries and sectors, we can set up a knowledge infrastructure around that comprising both the staff involved and national and international knowledge institutes. A significant portion of the total budget should therefore also be made available for systematic research and development. Six percent of the aid budget is not an excessively high figure, given the constantly investigative nature of development aid. Compare this to the DFID which, as of 2010, will spend over 200 million pounds a year on research and development, and could permit itself to make 34 million pounds available to develop a growth strategy and set up an International Growth Centre, because it feels that this is an issue that it does not know 
enough about. In such a knowledge structure, a form of monitoring and accountability can be developed that focuses on content and the impact of activities, rather than - as is typically the case with current practice - being trapped within an accountant's perspective and confined by the question whether funds have been spent legitimately. Independent research to determine whether it can reasonably be assumed that a positive contribution has been made fits within this framework. It should also include the assessment of stakeholders in the recipient countries. That creates the building blocks for a country-oriented accountability framework that should constitute the basis for consultations between the responsible minister and parliament.

In line with this, it is the task of donors to actively promote the decentralization of knowledge development, i.e. developing countries should be enabled to create their own knowledge infrastructure. The West currently has a quasi-monopoly in this respect. That might be justifiable if knowledge on development were incontestable, but that is not the case. Global variation and selection are required and the best way to do this is to set up three or four 'knowledge banks' around the world which gather knowledge on development and introduce ideas for policy which both learn from and compete with one another. At least one of these knowledge banks should be in Africa and another in Asia. It would also seem obvious to work towards a type of European 'World Bank', bringing together European tools for knowledge, loans, subsidies and policy. Linking the European Development Fund to coordination mechanisms for bilateral aid, credit provision by the European Investment bank and the European Bank for Reconstruction and Development, and with a knowledge function such as the World Bank in Washington already has, can generate improved conditions for strong, effective European development policy.

\section{What about the others?}

An as yet unanswered question is why this type of development aid should be provided through individual donors. Is it not more logical to organize aid mainly within larger forms of cooperation? After all, that would prevent fragmentation and mobilize real political power and implementation expertise. In theory this is true, but in practice it will definitely not be fully feasible for the time being. To start with, it is a political challenge to provide Western taxpayers with sufficient insight into what exactly has been done with their money; it is simply not enough to say the money was transferred to the World Bank and that it is doing good things with it. In addition, multilateral organizations face legitimacy problems in developing countries. The World Bank is burdened by its history and monopoly, and in many poorer countries it is still viewed as the IMF's natural accomplice. In the long term, doing more through the EU is definitely an option, but not in the way it is done now. Instead of an umbrella organization, the EU has become a new donor, active everywhere and in a wide number of themes, thereby exacerbat- 
ing the fragmentation of aid rather than reducing it. It is a missed opportunity that the EU does not concentrate on areas in which it can claim to have special expertise and legitimacy: regional development, integration and public goods.

An equally relevant question is what role Western NGOs can play. Many of these NGOs have evolved into hybrid organizations which work on fundraising, expanding their support base, representing partners' interests, influencing policy, developing projects, subsidizing Southern NGOs, providing direct aid and supporting civilian initiatives in a large number of countries. This is understandable from a historical perspective, but can dilute their contributions to homeopathic proportions and reduce their effectiveness to little to nothing. Furthermore, subsidizing Southern NGOs through Western NGOs is increasingly inappropriate in a situation in which developing countries have their own social organizations. The point of departure for funding should be the situation and actors in developing countries rather than that of Western organizations. Western donors should, in principle, provide support and funding directly to Southern NGOs in accordance with the function they require (service provider, watchdog or supporter of social processes). Western NGOs should profile their added value more emphatically if they wish to be eligible for funding. They can achieve this by, for example, establishing special ties with organizations in countries with which Western governments cannot or do not wish to maintain relations because they are governed by authoritarian or failing regimes. The South will, however, increasingly wish to look after itself, meaning that in some areas Western NGOs will no longer be relevant. On the other hand, they may be able to play a greater role in monitoring the impact on development of policy at national, European and global levels. Developing countries do not take part in meetings of ministries, companies and other organizations that work - or should be working - on policy coherence for development, and Western NGOs can help make sure their voices are heard.

\section{Where and what?}

It is therefore primarily a matter of properly considering what donors can do in the coming decade in Sub-Saharan Africa, a subcontinent with well over 900 million inhabitants, but a gross national product comparable to that of the Netherlands or South Korea. It is underpopulated, making building infrastructure and irrigation much more expensive than in the heavily populated parts of Asia, and in many areas has depleted soil and a one-sided economy heavily dependent on raw materials. Sub-Saharan Africa is also a subcontinent where the majority of countries may have a more or less functioning government, but seldom one which as yet merits full confidence. In many cases, aid will therefore have to be tied to a sensible political strategy and support for civil society. In countries with a state apparatus that hardly functions, such as classical fragile states like the Democratic Republic of Congo and Somalia, the difficult task will be to help shape the state apparatus, often by initially investing in security and stability. Many donors - 
including Sweden, Denmark, Canada, the UK and the EU - have developed a separate African strategy in recent years, and with good reason.

Selecting a limited number of countries does not mean that the relationships with other countries, for example middle-income countries, are no longer important. These should however no longer be made the focus of development aid, but of cooperation using other tools than financial support, aimed at specific goals in the field of knowledge exchange, environmental policy, economic activity, etc. It is becoming increasingly clear that countries which have emerged from the phase of absolute poverty benefit most from the development of knowledge and of a trained middle class. This conclusion has been fully understood by large multinational organizations, but as yet much less so by bilateral donors. For some time, the World Bank has been profiling itself as a knowledge bank, while the Inter-American Development Bank (the development bank that focuses on Latin America, where almost all low-income countries have evolved into middleincome countries) has exchanged a large number of specialists in loan provision for specialists in large project management.

The specific choice of countries can be based on three simple criteria: a country's needs, the extent to which they are already being met by other donors, and the potential added value a specific donor can offer. The latter is new. Until now, most donors have claimed to be able to do everything, but that is becoming increasingly problematic. Good development aid should be designed professionally and that calls for specific expertise. Norway has therefore concentrated its efforts on peace and reconciliation. It also spends a substantial part of its aid funds on a wide-ranging Oil for Development programme, which makes not only drilling and environmental technology expertise available, but also knowledge on how to adequately manage revenue from natural resources, and how governments can enter into contracts with major oil companies. All manner of public and private parties cooperate in this programme. If necessary, countries in the South can conclude a tenyear contract with the Norwegian government, which sets out how the support will be provided in detail. A country like the Netherlands could develop a Water for Development, Agriculture for Development, Justice for Development or Fighting HIV/AIDS for Development programme along these lines, combining the broad spectrum of public and private knowledge available. The choice of themes could be more ambitious. Strikingly little attention is paid to the professionalization of knowledge on the role and significance of civil society. The same applies to regional cooperation - much development is not only about how to help a country function properly, but also about regional cooperation and integration. 


\subsection{BEYOND CLASSICAL AID}

Besides more focus and professionalization, promoting development also entails paying more attention to the management of cross-border interdependencies and realizing global development opportunities. In that respect in most countries we have only just set out on this path. Coherence policy for development proves difficult, and that only tries to ensure that one ministry's policy does not conflict with that of another. It is even more complicated to manage seriously and substantively the coherence between different cross-border issues, and to approach ultimate global development as a strategic task. Whilst the familiar term 'international cooperation' suits the era in which states maintained sovereign external relations with one another, the term 'global development' expresses the fact that national policy also has consequences for other countries, while national agendas are coloured and influenced by what happens outside. This calls for new ways of dealing with other countries and, in that context, the distinction between developing and developed countries will, to a large extent, become outmoded.

The new world this will create demands innovative ways of dealing with the coherence between various policy instruments. For example: a country that is serious about helping to reduce $\mathrm{CO}_{2}$ emissions both at home and in developing countries will have to address knowledge policy and transfer, technology policy and transfer, intellectual property rights and negotiations on them at the WTO, technologies and energy saving and sustainable energy-generating systems adapted to local conditions, how to devise and set up new funding instruments with nongovernmental parties and government bodies, adequate and inclusive international institutions, and, last, but by no means least, national and international coherence so that more biofuel here does not lead to higher food prices and increased poverty in the South. There are insufficient good coordination mechanisms for this, both globally and nationally: the existing administrative model in most Western countries for addressing trade, migration, financial stability, climate, food, fiscal policy, energy, knowledge, safety and development issues from a coherent perspective is too ineffective, with coordination mechanisms lodged too much at operational and not enough at political-strategic level.

At global level, more intensive attention to coherence policy and international public goods demands investments in innovation in the shape of funding and regulation, and in new forms of cooperation, consultation and global governance. The UN offers many worthwhile ideas and concepts, but is weak and often very bureaucratic organizationally and in implementation. All manner of associated structures and consultation mechanisms have emerged in many areas and on many issues - the latest being the G2O, which, since the financial crisis, has replaced the G7/G8 as the global coordinating body. In fields like climate, fisheries, trade and healthcare there are often separate mechanisms which are only loosely 
affiliated to the UN system. However, for migration and financial stability for example, they exist only to a limited extent or are not very effective. New forms and structures for consultation, coordination and the exchange of agendas and priorities will have to be developed and tested.

Western countries should take a fresh look at the existing multilateral organizations from such a perspective. The UN has lost some of its authority in recent decades and operates only to a very limited extent as a coordinating body. Many UN agencies have become primarily implementing organizations that, in daily practice, have to compete with other implementing bodies. Concentration in implementation is only logical in specific situations, for example to address fragile states or provide emergency aid. Coordination, knowledge dissemination and standard-setting should otherwise be the focus of UN organizations. The World Bank has not yet shed its Western orientation, while the EU has become the twenty-eighth donor alongside its twenty-seven member states, rather than an organization focusing on regional development.

Furthermore, at national level better tools and coordination systems need to be developed. Suitable tools will to some extent have to be created 'on the job'. As stated, a greater role by NGOs in this respect would be beneficial. Investment in appropriate accountability frameworks should then be the next step. More justice could be done to development policy coherence if - in future - country reports were to juxtapose expenditure on development aid and efforts aimed at other issues. The more inclusive question will then be how to approach, for example, a region in Africa in terms of aid funds, migration, knowledge, trade, fiscal policy, technology transfer, climate, etc. That would be a significant innovation.

It would therefore show suitable ambition also to take another subsequent step and question the importance of the 0.7 percent of national income set aside for development aid. When the standard was devised in the 1960 , it still reflected the estimated need for aid in developing countries. However, since the 1970 it has acquired the character of a politically-based international standard, which is reconfirmed at international summits and conferences. Such a standard however suits an isolated system of aid while development in an increasingly interdependent world depends more and more on other issues. It is more appropriate to this new reality to attempt to formulate a new measure which includes not only aid but also Western efforts with regard to international regulations and global public goods relevant to development policy. This would lead not only to a much more fruitful debate than the eternal question of whether the budget for development aid should be more or less than 0.7 percent of GDP; it would also provide good input for the debate which will undoubtedly emerge about what should be used as an international framework of reference after 2015, when the MDGs expire. 
Lastly, the coordination mechanisms at state and political-administrative system level need to be reviewed. The distinction between a foreign ministry, which is supposed to deal with foreign affairs, line ministries that are 'only' expert in their own fields of policy or are concerned with domestic affairs, and a prime minister, who should primarily view all of this from a distance, is no longer suitable for the twenty-first century. It is a nineteenth-century construction from an era when policy stopped at the border and the internet did not yet exist. In an increasing number of fields, the distinction between national and foreign affairs is less relevant, if not meaningless. International action should primarily be driven by content and the administrative structure will then have to rapidly keep abreast of this new reality. An obvious step would be to systematically dovetail the substantive policies of line ministries with the ministry of foreign affairs by establishing joint directorates, programme directorates and other relevant organizational structures. Furthermore, the portfolio of the current minister for development cooperation should be upgraded to a package of tasks focused on global development and with two distinct components: managing specific aid programmes in a limited number of countries and formulating a globalization agenda which considers relevant global problems in context and develops an appropriate perspective for action.

\subsection{LESS PRETENSION, MORE AMBITION}

Changing the organization and focus of development aid is no easy task. Development aid has to continually tack back and forth between extremes. At home, where television rules, there is a desire for results with immediate appeal. Developing countries would benefit more from long-term perspectives. That is a difficult gap to bridge. In the meantime, public scepticism about development aid is on the increase. A number of countries have recently issued policy memoranda reviewing their development aid strategies. Some of these - like Norway, Sweden, and (it would now seem) Canada - are reorienting themselves by making much more defined choices. Others, with Britain at the forefront, want to do everything they have done so far better: more professionally, more transparently, more responsibly. So far, the Netherlands has not determined its course. Official development policy, including part of the institutional world underpinning it, seems to be unintentionally heading for a radical confrontation with those who now believe that aid might just as well be abolished. That is not a sensible route to take.

In addition, it is not helpful to separate the questions of what and why from that of how. What does help is to make choices and to structure the organization accordingly. The various objectives outlined - providing direct aid, promoting development (directly or indirectly by incorporating development effects in other policies), coherence policy and preserving international public goods - all have their own legitimacy. How much money and energy should be spent on that is, in 
essence, a political decision based on how much importance we should attach to the various issues. Our political decision-making process was designed to answer questions like this. Once we have used this system to determine how much money is available for development policy, we can decide how to divide it up between direct aid, structural development and international public goods. The political debate could gain quality and relevance if it focused more on this. It is then the task of politics to align the structure of intervention with these chosen goals.

Ultimately, this can lead to a development aid practice which can be described as 'less pretension, more ambition'. It is not the quantity but the quality of our contribution to a world in which people and countries are self-sufficient and in which international public goods are adequately safeguarded, that should be the point of departure for what we now still refer to as 'development aid', but perhaps later 'global development'. Global development is about targeted strategies, the capacity to work in various fields at the same time, knowing when to hold back, and differentiating between goals and thereby between levels of intervention. It is about combining ambition with the awareness that you can only play a modest role. 



\section{REFERENCES}

Acharya, A., A. Fuzzo de Lima and M. Moore (2003) The Proliferators: Transactions, Costs and the Value of Aid, IDs Working Paper, Sussex, UK: Institute of Development Studies.

Acquaah, G. (2006) 'Stealing from the Poor: Securing Integrity in African Public Services in the Twenty-First Century', in Konadu-Agyemang, K. Panford (2006) Africa's Development in the Twenty-First Century: Pertinent Socio-Economic and Development Issues, Aldershot, UK: Ashgate.

Adelman, I. (2001) 'Fallacies in Development Theory and Their Implications for Policy', in G. Meier and J. Stiglitz (eds.) Frontiers of Development Economics: The Future in Perspective, New York: Oxford University Press.

Adepoju, A., T. van Naerssen and A. Zoomers (2008) International Migration and National Development in Sub-Saharan Africa: Viewpoints and Policy Initiatives in the Countries of Origin, Leiden: Brill.

Alkire, S. (2007) 'The Missing Dimension of Poverty Data', Oxford Development Studies, 35 (4): 347359.

Allan, J. (1999) 'Productive Efficiency and Allocative Efficiency: Why Better Water Management May not Solve the Problem', Agricultural Water Management, 40: 71-77.

Allan, J. (2001) 'Virtual water - Economically Invisible and Politically Silent: A Way to Solve Strategic Water Problems', International Water and Irrigation Journal, November.

Alston, P. (2005) 'Ships Passing in the Night: The Current State of the Human Rights and Development Debate Seen Through the Lens of the Millennium Development Goals', Human Rights Quarterly, 27: 755-829.

Amsden, A. (2007) Escape from Empire: The Developing World's Journey through Heaven and Hell, Cambridge, Mass.: MIT Press.

Amsden, A. (2010) 'Say's Law, Poverty Resistance, and Employment Neglect', Journal of Human Development and Capabilities, 11 (1): 57-66.

Anderson, M. (1999) Do No Harm: How Aid Can Support Peace - or War, Boulder: Lynne Rienner.

Anten, L., M. van Beijnum and E. Kets (2008) Towards a Whole-of-Government Approach to Security System Reform, CRU occasional paper, The Hague: Clingendael.

Arce, D. and T. Sandler (2002) Regional Public Goods: Typologies, Provision, Financing, and Development Assistance, Stockholm: Expert Group on Development Issues.

Argyris, C. and D. Schön (1978) Organizational Learning: A Theory of Action Perspective, Reading, Mass.: Addison-Wesley.

Arndt, C., S. Jones and F. Tarp (2009) Aid and Growth: Have We Come Full Circle?, Discussion paper no. 05, Helsinki: UNU-WIDER.

Asian Development Bank (2007) Philippines: Critical Development Constraints, Manila: ADB.

AWT (Advisory Council for Science and Technology Policy) (2009) Kennis zonder grenzen: Kennis en innovatie in mondiaal perspectief, AWT advies 3045, The Hague: AWT.

Ayittey, G. (2006) Africa Unchained: The Blueprint for Africa's Future, Basingstoke: Palgrave Macmillan.

Bacchetta, M., E. Ernst and J. Bustamante (2009) Globalization and Informal Jobs in Developing Countries: A Joint Study by the International Labour Office and the Secretariat of the World Trade Organization, Geneva: ILO and WTO. 
Bairoch, P. (1993) Economics and World History: Myths and Paradoxes, Chicago: Chicago University Press.

Baker, R. (2009) The Context within Which Corruption Thrives and How to Curtail the Global Problem, Testimony before the Committee on Financial Services United States House of Representatives (May 19), Washington DC: Global Financial Integrity.

Bakewell, O. (2008) “"Keeping Them in Their Place”: The Ambivalent Relationship between Development and Migration in Africa', Third World Quarterly, 29 (7): 1341-1358.

Banerjee, A. (2007) Making Aid Work, Cambridge, Mass.: MIT Press.

Banerjee, A. and E. Duflo (2008) 'What is Middle Class About the Middle Classes Around the World?', Journal of Eeconomic Perspectives, 22 (2): 3-28.

Banerjee, A., E. Duflo, R. Glennerster and C. Kinnan (2009) The Miracle of Microfinance? Evidence From a Randomized Evaluation, Working Paper Financial Access Initiative and Innovations for Poverty Action, available on http://www.povertyactionlab.org/sites/default/files/ publications/The\%2oMiracle\%20of\%2oMicrofinance.pdf.

Banerjee, A. and R. He (2008) 'Making Aid Work', in W. Easterly (ed.) Reinventing Foreign Aid, Cambridge, Mass.: MIT Press.

Bangura, Y. (ed.) (2006) Ethnic Inequalities and Public Sector Governance, UNRISD, Basingstoke: Palgrave Macmillan.

Barbone, L., L. Cord, K. Hull and J. Sandefur (2007) 'Democracy and Poverty Reduction: Explorations on the Sen Conjecture', in N. Dinello and V. Popov (eds.) Political Institutions and Development: Failed Expectations and Renewed Hopes, Cheltenham, uk: Edward Elgar.

Barder, O. (2009a) What is Poverty Reduction?, Working Paper no. 170, Washington DC: Center for Global Development.

Barder, O. (2009b) Beyond Planning: Markets and Networks for Better Aid, Working Paper no. 185, Washington DC: Center for Global Development.

Barrett, C., M. Carter and P. Little (2006) 'Understanding and Reducing Persistent Poverty in Africa: Introduction to a Special Issue', Journal of Development Studies, 42 (2): 167-177.

Bateman, M. (2010) Why Doesn't Microfinance work? The Destructive Rise of Local Neoliberalism, London: Zed Books.

Bates, R. (1981) Markets and States in Tropical Africa: The Political Basis of Agricultural Policies, California Series on Social Choice and Political Economy, Berkeley: University of California Press.

Bates, R. (2001) Prosperity and Violence: The Political Economy of Development, New York: W.w. Norton.

Bates, R. (2008) When Things Fell Apart: State Failure in Late-Century Africa, Cambridge Studies in Comparative Politics, New York: Cambridge University Press.

Batliwala, S. and D. Dhanraj (2007) 'Gender Myths that Instrumentalize Women: A View from the India Front Line', in A. Cornwall, E. Harrison and A. Whitehead (eds.) Feminisms in Development. Contradictions, Contestations and Challenges, London: Zed Books.

Baulch, B. and E. Masset (2003) 'Do Monetary and Nonmonetary Indicators Tell the Same Story About Chronic Poverty? A Study of Vietnam in the 199os', World Development, 31 (3):441-453.

Baviskar, A. (2010) ‘Winning the Right to Information in India: Is Knowledge Power?’, in J. Gaventa and R. McGee (eds.) Citizen Action and National Policy Reform: Making Change Happen, London: Zed Books.

Bebbington, A., S. Hickey and D. Mitlin (eds.) (2008) Can NGOs Make a Difference? The Challenge of Development Alternatives, London: Zed Books. 
Becker, K. (2004) The Informal Economy: Fact Finding Study, Stockholm: SIDA.

Berendsen, B. (ed.) (2008) Democracy and Development, Amsterdam: KIT.

Berger, P. (2008) 'Faith and Development', Society, 46 (1): 69-75.

Berndt, E., R. Glennerster, M. Kremer, J. Lee, R. Levine, G. Weizsacker and H. Williams (2006)

Advance Market Commitments for Vaccines Against Neglected Diseases: Estimating Costs and Effectiveness, Working Paper no. 98, Washington DC: Center for Global Development.

Bhargava, V. (2006) Global Issues for Global Citizens, Washington DC: The World Bank.

Bhat, G. (2009) Transfer Pricing, Tax Havens and Global Governance, DIE Discussion Paper no.7,

Bonn: Deutsches Institut für Entwicklungspolitik.

Biekart, K. (2008) 'Learning from Latin America: Recent Trends in European NGO Policymaking', in

A. Bebbington, S. Hickey and D. Mitlin (eds.) Can NGOs Make a Difference? The Challenge of Development Alternatives, London: Zed Books.

Biekart, K. and A. Fowler (eds.) (2008) Civic Driven Change: Citizen's Imagination in Action, The Hague: Institute of Social Studies.

Bijlert, M. van (2009) 'Imaginary Institutions: State Building in Afghanistan', in M. Kremer, P. van

Lieshout and R. Went (eds.) Doing Good or Doing Better: Development Policies in a Globalising World, WRR Investigation, Amsterdam: Amsterdam University Press.

Birdsall, N. (2006) 'Overcoming Coordination and Attribution Problems: Meeting the Challenge of Underfunded Regionalism', in I. Kaul and P. Conceição (eds.) The New Public Finance: Responding to Global Challenges, Oxford: Oxford University Press.

Birdsall, N. (2007a) Do No Harm: Aid, Weak Institutions, and the Missing Middle in Africa, Working Paper no. 113, Washington DC: Center for Global Development.

Birdsall, N. (2007b) Reflections on the Macro Foundations of the Middle Class in the Developing World,

Working Paper no. 130, Washington DC: Center for Global Development.

Birdsall, N. (2008) 'Seven Deadly Sins: Reflections on Donor Failings', in W. Easterly (ed.) Reinventing Foreign Aid, Cambridge, Mass.: MIT Press.

Birdsall, N. (2010) The (Indispensable) Middle Class in Developing Countries; or, The Rich and the Rest, Not the Poor and the Rest, Center for Global Development Working Paper 207.

Birdsall, N., D. Rodrik and A. Subramanian (2005) 'How to Help Poor Countries', Foreign Affairs, 84 (4): 136-153.

Birdsall, N. and A. Subramanian (2009) Energy Needs and Efficiency, not Emissions: Re-framing the Climate Change Narrative, Working Paper no. 187, Washington DC: Center for Global Development.

Bloom, D., M. Hartley and H. Rosovsky (2006) ‘Beyond Private Gain: The Public Benefits of Higher Education', in Z. Tadmar (ed.) Transition to Mass Higher Education Systems: International Comparisons and Perspectives, Haifa: S. Neaman Institute.

Boekestijn, A.J. (2009) De prijs van een slecht geweten, Soesterberg: Aspekt.

Bolt, J. and D. Bezemer (2009) 'Understanding Long-run African Growth: Colonial Institutions or

Colonial Education?', Journal of Development Studies, 45: 24-54.

Bolton, G. (2007) Aid and Other Dirty Business, London: Ebury Press.

Borgh, C. van der (2009) 'Postwar Peace-building: What Role for International Organisations?', in M. Kremer, P. van Lieshout and R. Went (eds.) Doing Good or Doing Better:Development Policies in a Globalising World, WRR Investigation, Amsterdam: Amsterdam University Press.

Boserup, E. (1970) Women's Role in Economic Development, London: Allen and Unwin.

Bourdieu, P. (1985) 'The Forms of Capital', in J. Richardson (ed.) Handbook of Theory and Research for the Sociology of Education, New York: Greenwood Press. 
Bourguignon, F., A. Bénassy-Quéré, S. Dercon, A. Estache, J.W. Gunning, R. Kanbur, S. Klasen, S. Maxwell, J.-P. Platteau and A. Spadaro (2008) Millennium Development Goals at Midpoint: Where do we Stand and Where do we Need to go?, Background Paper for the European Commission, available on http://ec.europa.eu/development/icenter/ repository/mdg_paper_final_20o8og16_en.pdf.

Box, L. (2009) Are we Ready for Radical Changes? Preface, in H. Molenaar, L. Box and R. Engelhard (eds.) Knowledge on the Move: Emerging Agendas for Development-Oriented Research, Leiden: International Development Publications.

Brahimi, L. (2000) The Report of the Panel on United Nations Peacekeeping Operations, New York: United Nations.

Brainard, L. and D. Chollet (eds.) (2008) Global Development 2.o: Can Philanthropists, the Public, and the Poor Make Poverty History?, Washington DC: Brookings Institution Press.

Bräutigam, D. (200o) Aid Dependence and Governance, Stockholm: Almqvist \& Wiksell International for the Swedish Ministry of Foreign Affairs.

Breman, J. (2001) Op weg naar een slechter bestaan: Verwijdering van industriële arbeid uit de formele sector van de economie, Amsterdam: Vossiuspers.

Bretherton, C. and J. Vogler (2008) 'The European Union as a Sustainable Development Actor: The Case of External Fisheries Policies', European Integration, 30 (3): 401-417.

Broad, R. and J. Cavanagh (2006) 'The Hijacking of the Development Debate: How Friedman and Sachs got it Wrong', World Policy Journal, 23 (2): 21.

Brown, S. and P. Kaiser (2007) 'Democratisations in Africa: Attempts, Hindrances and Prospects', Third World Quarterly, 28 (6): 1131-1149.

Bruhn, M. and F. Gallego (2008) Good, Bad, and Ugly Colonial Activities: Studying Development Across the Americas, Policy Research Working Paper no. 4641, Washington DC: The World Bank.

Brunnschweiler, C. and E. Bulte (2008) 'Linking Natural Resources to Slow Growth and More Conflict', Science, 320: 616-617.

Burke, J. (2007) Al-Qaeda: the True Story of Radical Islam, London: Penguin.

Burnside, C. and D. Dollar (1997) Aid, Policies and Growth, Policy Research Working Paper no. 1777, Washington DC: The World Bank.

Burnside, C. and D. Dollar (200o) 'Aid, Policies, and Growth', American Economic Review, 90 (4): $847-868$.

Burnside, C. and D. Dollar (2004) Aid, Policies, and Growth: Revisiting the Evidence, Policy Research Working Paper no. 3251, Washington DC: The World Bank.

Bussolo, M., R. de Hoyos and D. Medvedev (2008) Is the Developing World Catching up? Global Convergence and National Rising Dispersion, Policy Research Working Paper no. 4733, Washington DC: The World Bank.

Calderesi, R. (2006) The Trouble with Africa: Why Foreign Aid Isn't Working, New York: Palgrave Macmillan.

Carbone, M. (2008) 'Mission Impossible: The European Union and Policy Coherence for Development', European Integration, 30 (3): 323-342.

Care Deutschland-Luxemburg and Center for Development Research (2010) Waiting for the Water to Come? Poverty Reduction in Times of Global Climate Change, Bonn: Care.

Carothers, T. (1999) Aiding Democracy Abroad: The Learning Curve, Washington DC: Carnegie Endowment for International Peace.

Carothers, T. (1999) 'Civil Society', Foreign Policy, 117: 18-29. 
Carothers, T. (2002) 'The End of the Transition Paradigm', Journal of Democracy, 13 (1): 5-21. CGD (Commission on Growth and Development) (2008) The Growth Report: Strategies for Sustained Growth and Inclusive Development, Washington DC: The World Bank.

CGD (2009) Health and Growth (eds. M. Spence and M. Lewis), Washington DC: The World Bank. CGG (Commission on Global Governance) (1995) Our Global Neighbourhood, Oxford: Oxford University Press.

Chabal, P. (2009) Africa: the Politics of Suffering and Smiling, London: Zed Books.

Chabal, P. and J.-P. Daloz (1999) Africa Works: The Political Instrumentalization of Disorder, Bloomington: Indiana University Press.

Chabal, P. and J.-P. Daloz (2006) Culture Troubles: Politics and the Interpretation of Meaning, London: Hurst.

Chandler, D. (2006) Empire in Denial: The Politics of State-building, London: Pluto Press.

Chang, H.-J. (2002) Kicking Away the Ladder: Development Strategy in Historical Perspective, London: Anthem.

Chang, H.-J. (2005) Why Developing Countries need Tariffs? How WTO NAMA Negotiations Could Deny Developing Countries Right to a Future, Geneva: South Centre.

Chang, H.-J. (2007) Bad Samaritans: Rich Nations, Poor Policies and the Threat to the Developing World, London: Random House.

Chang, H.-J. (2009a) 'Under-explored Treasure Troves of Development. Lessons from the Histories of Small, Wealthy European Countries', in M. Kremer, P. van Lieshout and R. Went (eds.) Doing Good or Doing Better: Development Policies in a Globalising World, WRR Investigation, Amsterdam: Amsterdam University Press.

Chang, H.-J. (2009b) Industrial Policy: Can We Go Beyond an Unproductive Confrontation?, Paper for the Annual World Bank Conference on Development Economics (22-24 June), available on http://siteresources.worldbank.org/INTABCDESK2009/Resources/ Ha-Joon-Chang.pdf.

Chant, S. (2008) 'The "Feminisation of Poverty" and the "Feminisation of Anti-Poverty" Programmes: Room for Revision?', Journal of Development Studies, 44 (2): 165-197.

Chappell, L. and A. Glennie (2009) Maximising the Development Outcomes of Migration: A Policy Perspective, London: Institute for Public Policy Research.

Chatterjee, D. (2004) The Ethics of Assistance: Morality and the Distant Needy, Cambridge Studies in Philosophy and Public Policy, Cambridge: Cambridge University Press.

Chen, S. and M. Ravallion (2008) The Developing World is Poorer Than We Thought, But No Less Successful in the Fight Against Poverty, Policy Research Working Paper no. 4703, Washington DC: The World Bank.

Cheru, F. (2006) 'Building and Supporting PRsPs in Africa: What Has Worked Well so Far? What Needs Changing?’ Third World Quarterly, 27 (2): 355-376.

Christiaensen, L., L. Demery and J. Kuhl, (2010) The (Evolving) Role of Agriculture in Poverty Reduction. An Empirical Perspective, Working Paper 36, Helsinki: UNU-WIDER.

Christian Aid (2009) False Profits: Robbing the Poor to Keep the Rich Tax-free, London: Christian Aid. Cilliers, J. (2008) Africa in the New World: How Global and Domestic Developments Will Impact by 2025, Tshwane (Pretoria): Institute for Security Studies.

Cimoli, M., Dosi, G. and J. Stiglitz (2009) Industrial Policy and Development: The Political Economy of Capabilities Accumulation, Oxford: Oxford University Press.

Claessens, S., N. van Horen, T. Gurcanlar and J. Mercado (2008) Foreign Bank Presence in Developing Countries 1995-2006: Data and Trends, Paper (version March) available on 
http://www.dnb.nl/binaries/Foreign\%2obanks\%2oin\%2odeveloping\%2ocountries\% 20\%20march\%202008_tcm46-212581.pdf.

Clark, G. (2007) A Farewell to Alms: A BriefEconomic History of the World, Princeton: Princeton University Press.

Clark, M. (2009) 'Securing the Future in a Connected Planet', Speech by the Chief Executive of the Commonwealth Scientific and Industrial Research Organisation, Canberra: CSIRO.

Clemens, M., S. Radelet and R. Bhavnani (2004) Counting Chickens when they Hatch: The Short-term Effect of Aid on Growth, Working Paper no. 44, Washington DC: Center for Global Development.

Cobham, A. (2005) Tax Evasion, Tax Avoidance and Development Finance, Oxford Department of International Development QEH Working Paper no. 129, Oxford: University of Oxford.

Coelho, B. and K. Gallagher (2010) Capital Controls and 21st Century Financial Crises: Evidence from Colombia and Thailand, PERI Working Paper 213, available on http://www.peri.umass. $\mathrm{edu} /$ fileadmin/pdf/working_papers/working_papers_201-250/WP213.pdf.

Coghlan, M. and A. Poskitt (2009) Getting Back on the Rails: The Private Sector and Development - A Christian Aid report, London: Christian Aid.

Cohen, J. and W. Easterly (2009) 'Introduction: Thinking Big Versus Thinking Small', in J. Cohen and W. Easterly (eds.) What Works in Development? Thinking Big and Thinking Small, Washington D.C.: Brookings Institution Press.

Coleman, J. (1990) Foundations of Social Theory, Cambridge, Mass.: Belknap Press of Harvard University.

Collier, P. (2007) The Bottom Billion: Why the Poorest Countries Are Failing and What Can Be Done About It, Oxford: Oxford University Press.

Collier, P. (2009) Wars, Guns, and Votes: Democracy in Dangerous Places, New York: Harper Collins Publishers.

Commission on Capital Flight from Developing Countries (2009) Tax Havens and Development: Status, Analyses and Measures, Oslo: Norad.

CONCORD (2009) Spotlight on Policy Coherence, Brussels: O. Consolo, CONCORD.

Cornia, G., R. Jolly and F. Stewart (1987) Adjustment with a Human Face. Volume 1: Protecting the Vulnerable and Promoting Growth, Oxford: Oxford University Press.

Cornwall, A. and K. Brock (2005) 'What Do Buzzwords Do for Development Policy? A Critical Look at "Participation", "Empowerment" and "Poverty reduction”, Third World Quarterly, 26 (7): 1043-106o.

Cornwall, A., E. Harrison and A. Whitehead (eds.) (2007) Feminisms in Development. Contradictions, Contestations and Challenges, London: Zed Books.

СРВ (Netherlands Bureau for Economic Policy Analysis) (2006) China and the Dutch Economy: Stylised Facts and Prospects, Document 127, The Hague: СРB.

СРB (2007) India and the Dutch Economy: Stylised Facts and Prospects, Document 155, The Hague: CPB.

Crafts, N. (2001) 'Historical Perspectives on Development', in G. Meier and J. Stiglitz (eds.) Frontiers of Development Economics: the Future in Perspective, New York: Oxford University Press.

Creusen, H. and A. Lejour (2009) The Contribution of Trade Policy to the Openness of the Dutch Economy, СРВ Document 194, The Hague: СРВ.

Cuesta, J. (2010) ‘Knowledge or Knowledgeable Banks? International Financial Institutions' Generation of Knowledge in Times of Crisis', Development Policy Review 28 (1): 43-62. 
Cullather, N. (2004) 'Miracles of Modernization: The Green Revolution and the Apotheosis of Technology', Diplomatic History, 28 (2).

Daniel, S. and A. Mittal (2009) The Great Land Grab, Rush for World's Farmland Threatens Food Security for the Poor, Oakland: the Oakland Institute.

Davies, J., S. Sandström, A. Shorrocks and E. Wolff (2007) Estimating the Level and Distribution of Global Household Wealth, Research Paper no. 77, Helsinki: UNU-WIDER.

Davis, D. (2004) Discipline and Development: Middle Classes and Prosperity in East Asia and Latin America, Cambridge, uk: Cambridge University Press.

Dearden, S. (2008) 'Delivering the EU's Development Policy: Policy Evolution and Administrative Reform', Perspectives on European Politics and Society, 9 (2): 114-127.

Deaton, A. (2009) Instruments of Development: Randomization in the Tropics, and the Search for the Elusive Keys to Economic Development, NBER Working Paper no. 1469o, Cambridge Mass.: National Bureau of Economic Research.

DEFRA (UK Department for Environment, Food and Rural Affairs) (2005) The Economic, Social and Ecological Value of Ecosystem Services: A Literature Review, Final Report, London:

Economics for the Environment Consultancy.

Dekker, M. and A. Wilms (2010) 'Health Insurance and Other Risk-Coping Strategies in Uganda: The Case of Microcare Insurance Ltd.', World Development 38 (3): 369-378.

Dellevoet, A. (2005) 'Armoedebestrijding begint bij de mondiale middenklasse', Socialisme en Democratie, 62 (3): 10-20.

DeMartino, G. (200o) Global Economy, Global Justice: Theoretical Objections and Policy Alternatives to Neoliberalism, New York: Routledge.

Derksen, H. and P. Verhallen (2008) Reinventing International NGOs: A View from the Dutch Cofinancing System, in W. Easterly (ed.) Reinventing Foreign Aid, Cambridge, Mass.: MIT Press.

Dervis, K. (2005) A Better Globalization: Legitimacy, Governance, and Reform, Washington DC: Center for Global Development.

Dervis, K. (2008) The Climate Change Challenge, Wider Annual Lecture 11, Helsinki: UnU-WIDER. Develtere, P. (2009) De vrije markt van de ontwikkelingssamenwerking, Leuven: Davidsfonds.

Develtere, P. and T. de Bruyn (2009) 'The Emergence of a Fourth Pillar in Development Aid', Development in Practice, 19 (7): 912-922.

DFID (Department for International Development) (2009a) Eliminating World Poverty: Building our Common Future. Report on the DFID Conference on the Future of International Development, (March), London: DFID.

DFID (2009b) Eliminating World Poverty: Building our Common Future, White paper, London: DFID. Diamond, J. (1998) Guns, Germs, and Steel: The Fates of Human Societies, London: Vintage Books.

Diamond, L. (2008) The Spirit of Democracy: The Struggle to Build Free Societies Throughout the World, New York: Times Books.

Dierikx, M. (ed.) (2002-2008) Nederlandse ontwikkelingssamenwerking: Bronnenuitgave. Deel 1-5, The Hague: Instituut voor Nederlandse Geschiedenis (ING).

Dietz, T., F. Obeng, J. Obure and F. Zaal (2009) 'Subjective Truths. Participatory Development Assessment', The Broker, 15 (August).

Dietz, T., A. de Ruijter, E. van Dongen, B. Helmsing and P. Knorringa (2006) Evaluation of the Themebased Co-financing Programme (TMF) of the Dutch Ministry of Foreign Affairs, Synthesis Report, Berenschot: Utrecht.

Dietz, T. and S. Zanen (2009) 'Assessing Interventions and Change Among Presumed Beneficiaries of 
“Development": A Toppled Perspective on Impact Evaluation', in P. Hoebink (ed.) The Netherlands Yearbook on International Cooperation 2008, Assen: Van Gorcum.

Dijk, M.P. van (2006) Managing Cities in Developing Countries, Cheltenham, uk: Edward Elgar.

Dijkstra, A.G. (2008) The Impact of International Debt Relief, Routledge Series in Development Economics, London: Routledge.

Djankov, S., J. Montalvo and M. Reynal-Querol (2007) The Curse of Aid, Washington DC: The World Bank.

Dobbins, J. (2007) The Beginner's Guide to Nation-building, RAND Corporation Monograph Series, Santa Monica, CA: RAND National Security Research Division.

Dollar D. and R. Gatti (1999) Gender Inequality, Income and Growth: Are Good Times Good for Women? Policy Research Report on Gender and Development Working Paper no. 1, Washington, DC: The World Bank.

Dollar, D. and A. Kraay (2001a) Growth is Good for the Poor, Policy research Working Paper no. 2587, Washington DC: The World Bank.

Dollar, D. and A. Kraay (2001b) Trade, Growth and Poverty, Policy Research Working Paper no. 2615, Washington DC: The World Bank.

Donaldson, J. (2008) 'Growth is Good for Whom, When, How? Economic Growth and Poverty Reduction in Exceptional Cases', World Development, 36 (11): 2127-2143.

Doucouliagos, H. and M. Paldam (2008) 'Aid Effectiveness on Growth: A Meta Study', European Journal of Political Economy, 24: 1-24.

Dowden, R. (2009) Africa: Altered States, Ordinary Miracles, New York: Public Affairs.

Draper, P. (2008) 'Africa-EU Trade Relations: Round Number Two!', Article Available on www.voxeu.org/index.php?q=node/896

Duffield, M. (2007) Development, Security and Unending War: Governing the World of Peoples, Cambridge, UK: Polity Press.

Duflo, E. and M. Kremer (2008) 'Use of Randomization in the Evaluation of Development', in W. Easterly (ed.) Reinventing Foreign Aid, Cambridge, Mass.: MIT Press.

Dutch Ministry of Foreign Affairs (1950) Nota betreffende de Nederlandse bijdrage aan het programma der Verenigde Naties voor technische hulp aan economisch laag-ontwikkelde landen, Handelingen der Staten-Generaal 1949-1950, Bijlagen Tweede Kamer no. 1734 - 4.

Dutch Ministry of Foreign Affairs (1956) Nota inzake de hulpverlening aan minder ontwikkelde gebieden, Handelingen der Staten-Generaal 1955-1956, Bijlagen Tweede Kamer no. 4334 - 2.

Dutch Ministry of Foreign Affairs (1962) Nota over de hulp aan minder ontwikkelde landen, Handelingen der Staten-Generaal 1961-1962, Bijlagen Tweede Kamer no. 6817 - 1.

Dutch Ministry of Foreign Affairs (1990) Een wereld van verschil: Nieuwe kaders voor ontwikkelingssamenwerking in de jaren negentig, Tweede Kamer 21813.

Dutch Ministry of Foreign Affairs (2006) Voortgangsrapportage: Os-beleidscoherentie, The Hague: Ministerie van Buitenlandse Zaken.

Dutch Ministry of Foreign Affairs (2008) Voortgangsrapportage: Os-beleidscoherentie 2008, The Hague: Ministerie van Buitenlandse Zaken.

Dutch Ministry of Foreign Affairs (2009a) Beleidsnotitie maatschappelijke organisaties: 'Samenwerken, Maatwerk, Meerwaarde', The Hague: Ministerie van Buitenlandse Zaken.

Dutch Ministry of Foreign Affairs (2009b) Samen werken aan mondiale uitdagingen: Nederland en multilaterale Ontwikkelingssamenwerking, The Hague: Ministerie van Buitenlandse Zaken.

Dutch Ministry of Foreign Affairs (2009c) Resultaten in ontwikkeling: Rapportage 2007-2008, The Hague: Ministerie van Buitenlandse Zaken. 
Dutch Ministry of Foreign Affairs (2009d) Vaststelling van de begrotingsstaten van het Ministerie van Buitenlandse Zaken voor het jaar 2010, The Hague: Ministerie van Buitenlandse Zaken.

Dutch Ministry of Foreign Affairs (2010) Notitie groei, armoede en ongelijkheid, The Hague: Ministerie van Buitenlandse Zaken.

Dutch Ministry of Foreign Affairs and Dutch Ministry of Justice (2008) Beleidsnotitie internationale migratie en ontwikkeling 2008, The Hague: Ministerie van Buitenlandse Zaken.

Dutch Ministry of Foreign Affairs and Dutch Ministry of Agriculture, Nature and Food Quality (2008) Beleidsbrief ontwikkelingssamenwerking; Briefministers met een toelichting op de inzet ten aanzien van landbouw, rurale bedrijvigheid en voedselzekerheid in ontwikkelingslanden, Tweede Kamer 31250, nr. 14.

Duyvesteyn, I. (2009) 'De interventieparadox. Buitenlandse inmenging werkt contraproductief', Socialisme en Democratie, 66 (7/8): 20-27.

Easterly, W. (1999) 'Life During Growth', Journal of Economic Growth, 4 (3): 239-275.

Easterly, W. (2001a) The Elusive Quest for Growth, Cambridge, Mass.: MIT Press.

Easterly, W. (2001b) 'The Middle Class Consensus and Economic Development', Journal of Economic Growth, 6 (4): 317-335.

Easterly, W. (2006) The White Man's Burden: Why the West's Efforts to Aid the Rest Have Done So Much Ill and So Little Good, New York: Penguin Press.

Easterly, W. (2007) How the Millennium Development Goals Are Unfair to Africa, Global Economy and Development Working Paper no. 14, Washington DC: Brookings Institution Press.

Easterly, W. (2008a) Can the West Save Africa?, NBER Working Paper no. 14363, Cambridge, Mass.: National Bureau of Economic Research.

Easterly, W. (2008b) ‘Introduction: Can't Take It Anymore?’ in W. Easterly (ed.) Reinventing Foreign Aid, Cambridge, Mass.: MIT Press.

Easterly, W. (2009) 'Big Answers for Big Questions: The Presumption of Growth Policy’, in J. Cohen and W. Easterly (eds.) What Works in Development? Thinking Big and Thinking Small, Washington DC: Brookings Institution Press.

Easterly, W., R. Levine and D. Roodman (2003) 'New Data, New Doubts: Revisiting “Aid, Policies, and Growth"', American Economic Review, 94 (3): 774-780.

Easterly, W. and T. Pfutze (2008) 'Where Does the Money Go? Best and Worst Practices in Foreign Aid', The Journal of Economic Perspectives: A Journal of the American Economic Association, 22 (2): 29-52.

Easterly, W., J. Ritzen and M. Woolcock (2006) ‘Social Cohesion, Institutions and Growth', Economics and Politics, 18 (2): 103-120.

ECDPM (European Centre for Development Policy Management) (2009a) State of the EPA Negotiations in May 2009, Briefing note prepared by ECDPM, Maastricht: ECDPM.

ECDPM (2009b) Linking Policy and Practice, Annual Report 2008, Maastricht: ECDPM.

ECDPM \& ICEI (Instituto Complutense de Estudios Internacionales) (2006) EU Mechanisms that Promote Policy Coherence for Development: a Scoping Study, Studies in European Development Co-operation Evaluation no. 2, Amsterdam: Aksant.

ECLAC (Economic Commission for Latin America and the Caribbean) (2008) Structural Change and Productivity Growth 20 Years Later: Old Problems, New Opportunities, Santiago, Chile: ECLAC.

Economist, The (2009) What Goes up: Remittances to Developing Countries, August (1): 6o. Edwards, M. (2004) Civil Society, Cambridge, uk: Polity Press.

Edwards, M. (2008) ‘Have NGOs “Made a Difference?” From Manchester to Birmingham with an 
Elephant in the Room', in A. Bebbington, S. Hickey and D. Mitlin (eds.) Can NGOs Make a Difference? The Challenge of Development Alternatives, London: Zed Books.

Edwards, M. (2009a) 'Why "Philanthrocapitalism” Is Not the Answer: Private Initiatives and International Development', in M. Kremer, P. van Lieshout and R. Went (eds.) Doing Good or Doing Better: Development Policies in a Globalising World, WRR Investigation, Amsterdam: Amsterdam University Press.

Edwards, M. (20ogb) Civil Society: Second Edition, Cambridge, uk: Polity Press.

Egenhofer, C., L. van Schaik, M. Kaeding, A. Hudson and J. Núñez Ferrer (2006) Policy Coherence for Development in the EU Council: Strategies for the Way Forward, Brussels: Centre for European Policy Studies.

Eisenstadt, S. (ed.) (2002) Multiple Modernities, New Brunswick: Transaction Publishers.

Elliot, K. (2009) Opening Markets for Poor Countries: Are We There Yet?, Working Paper no. 184, Washington DC: Center for Global Development.

Ellis, S. (2007) 'Religion and Politics: Taking African Epistemologies Seriously', Journal of Modern African Studies, 45 (3): 385-402.

Ellis, S. and G. ter Haar (2004) Worlds of Power: Religious Thought and Political Practice in Africa, London: Hurst.

Embong, A. (2001) Southeast Asian Middle Classes: Prospects for Social Change and Democratization, Bangi, Selangor: Universiti Kebangsaan Malaysia.

Engel, P., N. Keijzer, J. van Seters and E. Spierings (2009) External Evaluation of the Policy Coherence Unit of the Netherlands Ministry of Foreign Affairs, Discussion Paper no. 91, Maastricht: ECDPM.

ERT (European Round Table of Industrialists) (2000) Improved Investment Conditions: Third Survey on Improvements in Conditions for Investment in the Developing World, Brussels: ERT.

Estevadeordal, A., B. Frantz and T. Nguyen (eds.) (2002) Regional Public Goods: From Theory to Practice, Washington DC: Inter-American Development Bank.

Etzioni, A. (2007) Security First: For a Muscular, Moral Foreign Policy, New Haven: Yale University Press.

EUHES (Group of heads of the EU Member states' development cooperation evaluation services and the European Commission) (2007) Evaluating Coordination, Complementarity and Coherence in EU Development Policy: A Synthesis. Studies in European Development Co-operation Evaluation no. 2, Amsterdam: Aksant.

European Commission (2005) Communication from the Commission to the Council, the European Parliament and the European Economic and Social Committee. Policy Coherence for Development. Accelerating Progress Towards Attaining the Millennium Development Goals, COM (2009) 134 final, Brussels: European Commission.

European Commission (2007) EU Report on Policy Coherence for Development, СОм (2007) 545 final, Brussels: European Commission.

European Commission (2009a) Communication from the Commission to the European Parliament, the Council, the European Economic and Social Committee and the Committee of the Regions Supporting Developing Countries in Coping with the Crisis, Сом (2009) 16o final, Brussels: European Commission.

European Commission (2009b) Communication from the Commission to the Council, the European Parliament, the European Economic and Social Committee and the Committee of the Regions. Policy Coherence for Development - Establishing the Policy Framework for a Whole-of-theUnion Approach, СОм (2009) 458 final, Brussels: European Commission. 
European Commission (2009c) Commission StaffWorking Document Accompanying the Report from the Commission to the Council on EU 2009 Report on Policy Coherence for Development, COM (2009) 461 final, Brussels: European Commission.

European Commission (2009d) Aid Effectiveness Agenda: Benefits of a European Approach, Project no. 2008/170204- version 1, Herts: HTSP Limited.

Evans, A. (2009) The Feeding of the Nine Billion: Global Food Security for the 21st Century, London: Royal Institute of International Affairs.

Evans, A., B. Jones and D. Steven (2010) Confronting the Long Crisis of Globalization: Risk, Resilience and International Order, Washington DC: Brookings, Report available on http://globaldashboard.org/wp-content/uploads/2010/Long_Crisis.pdf.

Evans, P. (1995) Embedded Autonomy: States and Industrial Transformation, Princeton: Princeton University Press.

Evans, P. (2004) 'Development as Institutional Change: The Pitfalls of Monocropping and the Potentials of Deliberation', Studies in Comparative International Development, 38 (4): 30-52.

Evans, P. (2009) 'Population Health and Development: An Institutional-Cultural Approach to Capability Expansion', in P. Hall and M. Lamont (eds.) Successful Societies: How Institutions and Culture Affect Health, Cambridge: Cambridge University Press.

Faist, T. (2008) 'Migrants as Transnational Development Agents: An Inquiry into the Newest Round of the Migration-Development Nexus', Population, Space and Place, 14.

FAO (2007) World-wide Agroclimatic Database, Rome: FAO.

FAO (2008) Assessment of the World Food Security and Nutrition Situation, Committee on World Food Security Thirty-fourth Session, (October), Rome: FAO.

FAO (2009a) The State of Food Insecurity in the World 2009: Economic Crises - Impacts and Lessons Learned, Rome: FAO.

FAO (2009b) Bridging the Gap. FAO’s Programme for Gender Equality in Agriculture and Rural Development, Rome: FAO.

Faye, M. and P. Niehaus (2010) Political Aid Cycles, Paper available on http://dss.ucsd.edu/ $\sim$ pniehaus/papers/pac.pdf.

Feeny, S. and M. McGillivray (2009) 'Aid Allocation to Fragile States: Absorptive Capacity Constraints', Journal of International Development, 21 (5): 618-632.

Felipe, J. and N. Usui (2008) Rethinking the Growth Diagnostics Approach: Questions from the Practitioners, Economics Working Paper no. 132 (November), Manila: Asian Development Bank.

Fernandes, L. (2006) India's New Middle Class: Democratic Politics in an Era of Economic Reform, Minneapolis: University of Minnesota Press.

Ferrier, K. (2006) Armoede: De angel in onze rijkdom, Kampen: Ten Have.

Filmer, D. and J. Hammer and L. Pritchett (200o) 'Weak Links in the Chain: A Diagnosis of Health Policy in Poor Countries', The World Bank Research Observer 15: 194-224.

Findlay, R. and K. O'Rourke (2007) Power and Plenty: Trade, War, and the World Economy in the Second Millennium, Princeton: Princeton University Press.

Fiszbein, A. and N. Schady et al. (2009) Conditional Cash Transfers: Reducing Present and Future Poverty, A World Bank Policy Research Report, Washington DC: The World Bank.

Fowler, A. (2000) 'NGO futures: Beyond Aid: NGDO Values and the Fourth Position', Third World Quarterly, 21 (4): 589-603.

Fowler, A. (2008) 'Development and the New Security Agenda: W(h)ither(ing) NGo Alternatives?', in A. Bebbington, S. Hickey and D. Mitlin (eds.) Can NGOs Make a Difference? The Challenge of Development Alternatives, London: Zed Books. 
Fraser, A and L. Whitfield (2009) 'Understanding Contemporary Aid Relationships', in L. Whitfield (ed.) The Politics of Aid: African Strategies for Dealing with Donors, Oxford: Oxford University Press.

Fresco, L. (2009) 'Challenges for Food System Adaptation Today and Tomorrow', Environmental Science and Policy, 12, 378-385.

Frenkel, R. and M. Rapetti (2009) 'A Developing Country View of the Current Global Crisis: What Should not be Forgotten and What Should Be Done', Cambridge Journal of Economics, 33: 685-702.

Friedman, T. (1999) The Lexus and the Olive Tree, New York: Farrar, Straus and Giroux.

Fritz, V. and A. Rocha Menocal (2007) 'Developmental States in the New Millennium: Concepts and Challenges for a New Aid Agenda', Development Policy Review, 25 (5): 531-552.

Fukuyama, F. (2004) State-building: Governance and World Order in the 21st Century, Ithaca, NY: Cornell University Press.

Fukuyama, F. (2007) ‘Development and the Limits of Institutional Design', in N. Dinello and Vladimir Popov (eds.) Political Institutions and Development: Failed Expectations and Renewed Hopes, Cheltenham: Edward Elgar.

Gallagher, K. (2008) 'Understanding Developing Country Resistance to the Doha Round', Review of International Political Economy, 15 (1).

Gaventa J. and R. McGee (eds.) (2010) Citizen Action and National Policy Reform: Making Change Happen, London: Zed Books.

Gennip, J. van (2008) Zie om en doe wel. Wereldwijde armoedebestrijding in de 2oste en 21ste eeuw (en de betekenis daarbij van de 'doe-het-zelfhulp'), Paper available on http://www. worldconnectors.nl/upload/cms/219_2008-11-27_Zie_om_en_Doe_wel_inclusief_ bijlage__2_Suzanne.pdf.

George, C. (2010) The Truth About Trade: The Real Impact of Liberalization, London: Zed Books. Ghani, A. and C. Lockhart (2008) Fixing Failed States: A Framework for Rebuilding a Fractured World, Oxford: Oxford University Press.

Ghosh, J. and C.P. Chandrasekhar (2009) 'The Costs of "Coupling": The Global Crisis and the Indian Economy', Cambridge Journal of Economics, 33: 725-739.

Gibson, C., K. Andersson, E. Ostrom and S. Shivakumar (2005) The Samaritan's Dilemma: The Political Economy of Development Aid, Oxford: Oxford University Press.

Gijsbers, L. en B. van der Lelij (2009) Barometer internationale samenwerking. NCDO Onderzoeksrapport, Amsterdam: Motivaction.

Gittings, J. (2006) The Changing Face of China. From Mao to Market, Oxford: Oxford University Press.

Glennie, J. (2008) The Trouble with Aid: Why Less Could Mean More for Africa, London: Zed Books.

Global Commission on International Migration (2005) Migration in an Interconnected World: New Directions for Action, Report for the GCIM, Geneva: SRO-Kundig.

Goderis, B. en H. Verbon (2007) De effectiviteit van (on) conditionele ontwikkelingshulp, Préadvies voor de Koninklijke Vereniging van Staathuishoudkunde (KVs), Amsterdam: KVs.

Government Offices of Sweden (2008) Global Challenges - Our Responsibility: Sweden's Policy for Global Development, Stockholm: Information Office, The Ministry of Foreign Affairs.

Grant, U. and R. Marcus (2009) Chronic Poverty and PRSPS: A Desk Study, Background Paper for the Chronic Poverty Report 2008-09, Manchester: Chronic Poverty Research Center.

Gready, P. (2008) 'Rights-based Approaches to Development: What Is the Value-added?' Development in Practice, 18 (6): 735-747. 
Green, D. (2008) From Poverty to Power: How Active Citizens and Effective States Can Change the World, Oxford: Oxfam International.

Griffith-Jones, S. and J. Ocampo (2009) The Financial Crisis and its Impact on Developing Countries, Working Paper no. 53, Brasilia: UNDP International Policy Centre for Inclusive Growth.

Grimm, S., J. Mackie, M.-L. de Bergh, J. Frederiksen, J. Zinke and C. Freres (2005) Assessment of the EC Development Policy, DPS Study Report, Final Report, Maastricht: ECDPM/ ICEI/ ODI.

Grindle, M. (2001) 'In Quest of the Political: the Political Economy of Development Policy Making', in G. Meier and J. Stiglitz (eds.) Frontiers of Development Economics: The Future in Perspective, New York: Oxford University Press.

Grindle, M. (2004) 'Good Enough Governance: Poverty Reduction and Reform in Developing Countries', Governance, 17 (4): 525-548.

Grindle, M. (2007) 'Good Enough Governance Revisited’, Development Policy Review, 25 (5): 533-574. Grotenhuis, R. (2008) Geloven dat het kan: Nieuwe perspectieven op ontwikkeling, macht en verandering, Kampen: Ten Have.

Grotenhuis, R. (2009) Over grenzen heen. Nieuwe perspectieven op civil society in de strijd tegen armoede, The Hague: Cordaid.

Gruffydd Jones, B. (2008) 'The Global Political Economy of Social Crisis: Towards a Critique of the "Failed State” Ideology', Review of International Political Economy, 15 (2): 180-205.

Grugel, J. and N. Piper (2009) ‘Do Rights Promote Development?’, Global Social Policy, 9 (1): 79-98.

Gu, J., J. Humphrey and D. Messner (2007) Global Governance and Developing Countries: The Implications of the Rise of China, DIE Discussion Paper no. 18, Bonn: Deutsches Institut für Entwicklungspolitik.

Guijt, I. (2008) 'Civil Society Participation as the Focus of Northern NGO Support: The Case of Dutch Co-financing Agencies', in A. Bebbington, S. Hickey and D. Mitlin (eds.) Can NGOs Make a Difference? The Challenge of Development Alternatives, London: Zed Books.

Guimbert, S. (2010) Cambodia 1998-2008: An Episode of Rapid Growth, Policy Research Working Paper 5271, Washington DC: World Bank.

Gunning, J.W. (2005) Budget Support, Conditionality, and Impact Evaluation, Paper presented at the Practitioners' forum on budget support, organized by the World Bank, (May 5-6), Cape Town, South Africa.

Gunning, J.W. (2006) Aid Evaluation: Pursuing Development as if Evidence Matters, Swedish Economic Policy Review 13, Stockholm: Regeringskansliet.

Haan, A. de (2009) How the Aid Industry Works: An Introduction to International Development, Sterling va: Kumarian Press.

Haas, H. de (2007) Remittances, Migration and Social Development: A Conceptual Review of the Literature, Social Policy and Development Programme Paper no. 34, Geneva: UNRISD.

Haggard, S. and R. Kaufman (2008) Development, Democracy, and Welfare States: Latin America, East Asia, and Eastern Europe, Princeton: Princeton University Press.

HAI (Health Action International) and Oxfam International (2009) Trading Away Access to Medicines: How the European Commission's Trade Agenda has Taken a Wrong Turn, Amsterdam: HAI Europe.

Hamers, S. en B. Mathijssen (2008) Meer fairtrade producten in de boodschappentas. Aankoopgedrag van fairtrade producten door Nederlandse huishoudens in 2008, Dongen: GFK panel services (for NCDO).

Handley, G. (2009) Beyond the Numbers: Using Aid to Combat the Crisis in Poor Countries Requires More Than Just Cash, Blog (version February 26) available on http://blogs.odi.org.uk/blogs/ 
Hanlon, J., A. Barrientos and D. Hulme (2010) Just Give Money to the Poor: The Development Revolution from the Global South, Sterling, va: Kumarian Press.

Hanushek, E. and L. Wößmann (2007) Education Quality and Economic Growth, Washington DC: The World Bank.

Harris, D., M. Moore and H. Schmitz (2009) Country Classifications for a Changing World, DIE Discussion Paper no. 9, Bonn: Deutsches Institut für Entwicklungspolitik.

Harrison L. and S. Huntington (eds.) (2000) Culture Matters How Values Shape Human Progress, New York: New York Basic Books.

Hausmann, R. (2008) The Other Hand: High Bandwidth Development Policy, Center for International Development Working Paper no. 179, Cambridge, Mass.: Harvard University.

Hausmann, R., B. Klinger and R. Wagner (2008) Doing Growth Diagnostics in Practice: A 'Mindbook', Center for International Development Working Paper no. 17, Cambridge, Mass.: Harvard University.

Hausmann, R. and D. Rodrik (2006) Doomed to Choose: Industrial Policy as Predicament (first draft), Cambridge, Mass.: Harvard Kennedy School of Government.

Hausmann, R., D. Rodrik and A. Velasco (2005) Growth Diagnostics, Cambridge, Mass.: Harvard Kennedy School of Government, Paper available on http://ksghome.harvard.edu/ $\sim$ drodrik/barcelonafinalmarch2005.pdf.

Headey, D. (2008) 'Geopolitics and the Effect of Foreign Aid on Economic Growth: 1970-2001', Journal of International Development, 20 (2): 161-180.

Hearn, J. (2007) African NGOs: the New Compradors?, Development and Change, 38 (6): 1095-1110, The Hague: Institute of Social Studies.

Hellema, D. (2007) 'Problematische ambities van vredesopbouw: naar een rehabilitatie van de staat', Internationale spectator, 61 (12): 607-611.

Helmich, H. (2008) Public Support for International Co-operation in the Netherlands, Including the latest Public Opinion Results on Support for International Development 2008, Paper available on http://www.contextmasterclass.nl/docs/200807281756301393.pdf.

Helpman, E. (2004) The Mystery of Economic Growth, Cambridge, Mass. and London: The Belknap Press of Harvard University Press.

Helmsing, B. and P. Knorringa (2009) 'Enterprise Development Interventions by Dutch Development NGOS: Is there Increased Involvement of Private Sector Actors and does that Make a Difference?' in P. Hoebink (ed.) The Netherlands Yearbook on International Cooperation 2008, Assen: Van Gorcum.

Hemerijck, A., B. Knapen and E. van Doorne (eds.) (2009) Aftershocks: Economic Crisis and Institutional Choice, Amsterdam: Amsterdam University Press.

Heres, M. and F. Bieckmann (2007) 'Een inktvlek in een veranderende wereld: Debat over het kennisbeleid op Buitenlandse Zaken' (Dutch version of 'Oiling the Wheels of Change'), The Broker, August 32010.

Hettne, B. and F. Söderbaum (2006) Regional Cooperation: A Tool for Addressing Regional and Global Challenges, Expert Paper Series Seven: Cross-cutting Issues, Stockholm: International Task Force on Global Public Goods.

Hettne, B., F. Söderbaum and P. Stålgren (2008) The EU as a Global Actor in the South, sIEPS Report no. 8, Stockholm: Svenska Institutet För Europapolitiska Studier.

Hickey, S. and G. Mohan (2008) 'The Politics of Establishing Pro-poor Accountability: What Can Poverty Reduction Strategies Achieve?' Review of International Political Economy, 15 (2): 234-258. 
Ho, P. (2009) 'Beyond Development Orthodoxy: Chinese Lessons in Pragmatism and Institutional Change', in M. Kremer, P. van Lieshout and R. Went (eds.) Doing Good or Doing Better: Development Policies in a Globalising World, WRR Investigation, Amsterdam: Amsterdam University Press.

Hoebink, P. (2010) Verschuivende vensters: Veranderingen in het institutionele landschap van de Nederlandse ontwikkelingssamenwerking, Webdocument available on www.wrr.nl.

Hoekstra, A. and P. Hung (2002) 'Virtual Water Trade: A Quantification of Virtual Water Flows Between Nations in Relation to International Crop Trade', Value of Water Research Report Series, 11, Delft: IHE.

't Hoen, E. (2009) The Global Politics of Pharmaceutical Monopoly Power: Drug Patents, Access, Innovation and the Application of the WTO Doha Declaration on Trips and Public Health, Diemen, Амв Publishers.

Hout, W. and R. Robison (eds.) (2008) Governance and the Depoliticisation of Development, Routledge/GARNET Series Europe in the World, vol. 4, London: Routledge.

Hsiao, H.-h. (ed.) (2006) The Changing Faces of the Middle Classes in Asia-Pacific, Taipei: Center for Asia-Pacific Area Studies.

Hubbard, R. and W. Duggan (2009) The Aid Trap: Hard Truths about Ending Poverty, New York: Columbia Business School Pub.

Huber, E. (2009) 'Including the Middle Classes? Latin American Social Policies after the Washington Consensus' in M. Kremer, P. van Lieshout and R. Went (eds.) Doing Good or Doing Better: Development Policies in a Globalising World, WRR Investigation, Amsterdam: Amsterdam University Press.

Hulme, D. and A. Shepherd (2003) 'Conceptualizing Chronic Poverty', World Development, 31 (3): 403-423.

Hunt, J. and N. Kasynathan (2001) 'Pathways to Empowerment? Reflections on Microfinance and Transformation in Gender Relations in South Asia', in C. Sweetman (ed.) Gender, Development and Money. Focus on Gender Series, Oxford: Oxfam.

Huntington, S. (1996) The Clash of Civilizations and the Remaking of World Order, New York: Simon \& Schuster.

Hussain, M., A. Berg and S. Aiyar (2009) 'The Macroeconomic Management of Increased Aid: Policy Lessons from Recent Experience', Review of Development Economics, 13 (o1): 491-509.

IAASTD (International Assessment of Agricultural Knowledge, Science, and Technology for Development Project) (2009) Agriculture at a Crossroads: Global report, Washington DC: Island Press.

IAC (InterAcademy Council) (2004) Realizing the Promise and Potential of African Agriculture, Amsterdam: IAC.

ICCO (2008) Dialogue of the Deaf: An Assessment of Europe's Developmental Approach to Trade Negotiations, Utrecht: ICCO.

ICHRP (International Council on Human Rights Policy) (2008) Climate Change and Human Rights: A Rough Guide, Geneva: ICHRP.

IDA (International Development Association of The World Bank) (2007) Aid Architecture: An Overview of the Main Trends in Official Development Assistance Flows, Washington DC: The World Bank.

IDB (Inter-American Development Bank) (2009) Policy Trade-offs for Unprecedented Times: Confronting the Global Crisis in Latin America and the Caribbean, Washington DC: IDB. IEG (Independent Evaluation Group of The World Bank) (2008) Doing Business: An Independent 
Evaluation. Taking the Measure of the World Bank-IFC Doing Business Indicators, Washington DC: The World Bank.

IEO (Independent Evaluation Office of the International Monetary Fund) (2007) Structural Conditionality in IMF-supported Programs, Evaluation report, Washington DC: IEO.

ILO (International Labour Organization) and wHO (World Health Organization) (2009) The Social Protection Floor. A Joint Crisis Initiative of the UN Chief Executives Board for Co-ordination on the Social Protection Floor, Geneva: ILO and wHO.

IMF (International Monetary Fund) (2007) World Economic Outlook: Globalization and Inequality, Washington DC: IMF.

IMF, OECD, World Bank and UN (2000) A Better World for All: Progress Towards the International Development Goals, Document available on www.paris21.org/betterworld.

IOB (Policy and Operations Evaluation Department) (2008a) Het Nederlandse Afrikabeleid 1998-2006: Evaluatie van de bilaterale samenwerking, ІОВ evaluaties no. 308, The Hague: Ministerie van Buitenlandse Zaken.

ІОВ (2008b) "Ahead of the Crowd?” The Process of Implementing the Paris Declaration. Case study: the Netherlands, Agency-level evaluation conducted during the first phase of the evaluation of the implementation of the Paris Declaration, The Hague: Ministerie van Buitenlandse Zaken.

Irz, X., L. Lin, C. Thirtle and S. Wiggins (2001) 'Agricultural Productivity Growth and Poverty Alleviation', Development Policy Review, 19 (4): 449-466.

Ishikawa, S. (2005) Supporting Growth and Poverty Reduction: Toward Mutual Learning from the British Model in Africa and the Japanese Model in East Asia, Tokyo: Japan Bank for International Cooperation.

ITFGPG (International Task Force on Global Public Goods) (2006) Meeting Global Challenges: International Cooperation in the National Interest, Final Report, Stockholm.

ITU (International Telecommunication Union) (2009) Measuring the Information Society: The ICT Development Index, Geneva: ITU.

Jack, W. and M. Lewis (2009) Health Investments and Economic Growth: Macroeconomic Evidence and Microeconomic Foundations, Washington DC: The World Bank.

Jackson, T. (2009) Prosperity without Growth? The Transition to a Sustainable Economy, London: Sustainable Development Commission.

Janssen, W. (2009) Management of the Dutch Development Cooperation, PhD Thesis (December), Enschede: Universiteit Twente.

Jarstad, A. and T. Sisk (eds.) (2008) From War to Democracy: Dilemmas of Peacebuilding, Cambridge, UK: Cambridge University Press.

Jenkins, P. (2007) God's Continent: Christianity, Islam and Europe's Religious Crisis, New York: Oxford University Press.

Johnson, C. (1982) Miti and the Japanese Miracle: The Growth of Industrial Policy, 1925-1975, Stanford: Stanford University Press.

Jolly, R., L. Emmerij, D. Ghai and F. Lapeyre (2004) UN Contributions to Development Thinking and Practice, United Nations Intellectual History Project Series, Bloomington: Indiana University Press.

Jolly, R., L. Emmerij and T. Weiss (2009) UN Ideas that Changed the World, United Nations Intellectual History Project Series, Bloomington: Indiana University Press.

Jones, N., A. Datta and H. Jones et al. (2009) Knowledge Policy and Power: Six Dimensions of the Knowledge-Development Policy Interface, ODI Synthesis Paper, London: Overseas Development Institute. 
Juma, C. (2006) The 2006 Hinton Lecture: Redesigning African Economies: the Role of Engineering in International Development, London: The Royal Academy of Engineering.

Kahler, M. (2009) 'Statebuilding after Afghanistan and Iraq', in R. Paris and T. Sisk (eds.) The Dilemmas of Statebuilding: Confronting the Contradictions of Postwar Peace Operations, Abingdon: Routledge.

Kaiser, J., I. Knoke and H. Kowsky (2009) Towards a Renewed Debt Crisis? Risk Profiles of the Poorest Countries in the Light of the Global Economic Slowdown, Dialogue on Globalization Occasional Paper no. 44, Berlin: Friedrich Ebert Stiftung.

Kamruzzaman, P. (2009) 'Poverty Reduction Strategy Papers and the Rhetoric of Participation', Development in Practice, 19 (1): 61-71.

Kanbur, R. (2001) Cross-border Externalities, International Public Goods and their Implications for Aid Agencies, First Draft, Ithaca: Cornell University.

Kanbur, R. (2002) IFI's an IPG's: Operational Implications for the World Bank, Ithaca: Cornell University.

Kaplan, S. (2008) Fixing Fragile States: A New Paradigm for Development, Westport, Connecticut: Praeger Security International.

Kaplan, S. (2009) 'Fixing Fragile States: Solutions that Make Local Sense', Policy Review, 152 (December \& January): 63-78.

Kaplinsky, R. (2009) 'Turning the China-India Threat to Africa into an Opportunity', in M. Kremer, P. van Lieshout and R. Went (eds.) Doing Good or Doing Better: Development Policies in a Globalising world, WRR Investigation, Amsterdam: Amsterdam University Press.

Kanbur, R. (2002) Education, Empowerment and Gender Inequalities, Paper Prepared for the Annual Bank Conference on Development Economics, Washington DC April 29-30.

Kapur, D. (2007) 'The Janus Face of Diasporas', in B. Merz, L. Cen and P. F. Geithner (eds.) Diasporas and Development, Cambridge, Mass.: Harvard University Press.

Kapur, D. and M. Crowley (2008) Beyond the ABCs: Higher Education and Developing Countries, Working Paper no. 139, Washington DC: Center for Global Development.

Kar, D. and D. Cartwright-Smith (2009) Illicit Financial Flows from Developing Countries 2002-2006, Washington DC: Global Financial Integrity.

Karlan, D. and J. Zinman (2009) Expanding Microenterprise Credit Access: Using Randomized Supply Decisions to Estimate the Impacts in Manila, paper available on http://www.dartmouth. edu/ jzinman/Papers/expandingaccess_manila_julog.pdf.

Kaul, I. and P. Conceição (2006) 'Why Revisit Public Finance Today? What this Book is about', in I. Kaul and P. Conceição (eds.) The New Public Finance: Responding to Global Challenges, Oxford: Oxford University Press.

Kaul, I., I. Grundberg and M. Stern (eds.) (1999) Global Public Goods: International Cooperation in the 21st Century, Publication for the United Nations Development Program, New York: Oxford University Press.

Kaul, I. and R. Mendoza (2003) 'Advancing the Concept of Public Goods', in I. Kaul, P. Conceição, K. le Goulven and R. Mendoza (eds.) Providing Global Public Goods: Managing Globalization, Oxford: Oxford University Press.

Kennedy, H. (2004) The Prophet and the Age of the Caliphates: The Islamic Near East from the Sixth to the Eleventh Century, Harlow: Pearson.

Kenny, C. (2009) The Success of Development: Innovation, Ideas and the Global Standard of Living, Book draft (March 5) was available on http://charleskenny.blogs.com/.

Khan, M. (2005) 'Markets, States and Democracy: Patron-client Networks and the Case for Democ- 
racy in Developing Countries', Democratization, 12 (5): 704-724.

Khan, M. (2007) Governance, Economic Growth and Development since the 1960s, DESA Working Paper no. 54, New York: United Nations.

Khan, M. (2010) Papua New Guinea Country Diagnostic Study, Manila: ADB, Study available on www.adb.org/Projects/Country-Diagnostic-Studies/PNG-Country-Diagnostic-Study.pdf.

Kharas, H. (2007) Trends and Issues in Development Aid, Working Paper no. 1, Washington DC: Brookings Institution Press.

Khor, M. (2008) 'The World Trading System and Development Concerns', in N. Serra and J. Stiglitz (eds.) The Washington Consensus Reconsidered: Towards a New Global Governance, Oxford: Oxford University Press.

Kinsbergen, S. and L. Schulpen (2010) De anatomie van het PI: De resultaten van 5 jaar onderzoek naar particuliere initiatieven, Nijmegen: CIDIN, Radboud Universiteit Nijmegen.

Klasen, S. (2002) 'Low Schooling for Girls, Slower Growth for All? Cross-Country Evidence on the Effect of Gender Inequality in Education and Economic Development' World Bank Economic Review, 16 (3): 345-73.

Klasen, S. and F. Lamanna (2009) 'The Impact of Gender Inequality in Education and Employment on Economic Growth: New Evidence for a Panel of Countries'. Feminist Economics, 15 (3): 91132.

Knack, S. and A. Rahman (2008) ‘Donor Fragmentation', in W. Easterly (ed.) Reinventing Foreign Aid, Cambridge, MA: MIT Press.

Kniivilä, M. (2008) 'Industrial Development and Economic Growth: Implications for Poverty Reduction and Income Inequality', in D. O’Connor and M. Kjöllerström (eds.) Industrial Development in the 21st Century, London: Zed Books.

KNMI (Royal Netherlands Meteorological Institute) (2009) Verdamping, De Bilt: KNMI.

Kobayashi, T. (2008) Evolution of Chinese Aid Policy, JBICI Working Paper no. 27, Tokyo: JBIC.

Koch D.-J., A. Dreher, P. Nunnenkamp and R. Thiele (2009) 'Keeping a Low Profile: What Determines the Allocation of Aid by Non-governmental Organizations?', World Development, 37 (5): $902-918$.

Koch D.-J., and B. Loman (2009) 'Geographical Choices of Dutch NGOs: Orthodoxies and Realities', in P. Hoebink (ed.) The Netherlands Yearbook on International Cooperation 20o8, Assen: Van Gorcum.

Koenders, B. (2009) 'Strengthening the Capacity of Innovation Systems', in H. Molenaar, L. Box and R. Engelhard (eds.) Knowledge on the Move: Emerging Agendas for Development-oriented Research, Leiden: International Development Publications.

Kohli, A. (2004) State-directed Development: Political Power and Industrialization in the Global Periphery, Cambridge, uk: Cambridge University Press.

Koppen, B. van, S. Smits, P. Moriarty, F. Penning de Vries, M. Mikhail and E. Boelee (2009) Climbing the Water Ladder: Multiple-use Water Services for Poverty Reduction, Technical Paper Series no. 52, The Hague: IRC International Water and Sanitation Centre.

Korten, D. (1990) Getting to the Twenty-first Century: Voluntary Action and the Global Agenda, West Hartford: Kumarian Press.

Kraay, A (2004) 'When Is Growth Pro-Poor? Cross-Country Evidence', IMF Working Paper 4-47, Washington DC: IMF.

Kremer, M., P. van Lieshout and R. Went (eds.) (2009) Doing Good or Doing Better: Development Policies in a Globalising World, WRR Investigation, Amsterdam: Amsterdam University Press. 
Krueger, A. (2009) 'From Despair to Hope: The Challenge of Promoting Poverty Reduction', Progress in Development Studies, 9: 269-284.

Krugman, P. (1993) Towards a Counter-counterrevolution in Development Theory, Proceedings of the World Bank Annual Conference on Development Economics 1992, Washington DC: The World Bank.

Krugman, P. (2007) The Conscience of a Liberal, New York: W.w. Norton.

Krugman, P. (2008) 'Inequality and Redistribution', in N. Senna and J. Stiglitz (eds.) The Washington Consensus Reconsidered: Towards a New Global Governance, Oxford: Oxford University Press.

Kruijt, D. and M. Maks (2004) Een belaste relatie: 25 jaar ontwikkelingsamenwerking Nederland - Suriname 1975-200o, Tweede Kamer 20361, nr. 113.

Kurlantzick, J. (2007) Charm Offensive: How China's Soft Power is Transforming the World, New Haven: Yale University Press.

Kuyvenhoven, A. (2007) Africa, Agriculture, Aid, Wageningen: Wageningen University.

Kuznetsov, Y. (ed.) (2006) Diaspora Networks and the International Migration of Skills: How Countries Can Draw on Their Talent Abroad, The World Bank Institute Development Studies, Washington DC: The World Bank.

Landes, D.S. (1998) The Wealth and Poverty of Nations: Why Some are So Rich and Some So Poor, London: Abacus.

Lange, J. de (2010) 'Winning Hearts, Changing Mindsets: Interventions as Change Management', The Broker, 18: 22-25.

Lavenex, S. and R. Kunz (2008) 'The Development-migration Nexus in EU External Relations', European Integration, 30 (3): 439-457.

Lee, B., L. Lliev and F. Preston (2009) Who Owns Our Low Carbon Future? Intellectual Property and Energy Technologies, London: Chatham House.

Leftwich, A. (2008) Developmental States, Effective States and Poverty Reduction: The Primacy of Politics, York: University of York, Department of Politics.

Lewis, D. and N. Kanji (2009) Non-governmental Organizations and Development, Routledge Perspectives on Development, London: Routledge.

Lewis, D. and D. Mosse (2006) 'Encountering Order and Disjuncture: Contemporary Anthropological Perspectives on the Organization of Development', Oxford Development Studies, 34 (1).

Li, T. (2007) The Will to Improve: Governmentality, Development, and the Practice of Politics, Durham: Duke University Press.

Light, D. (2009) Advanced Market Commitments: Current Realities and Alternate Approaches, Amsterdam: Health Action International (HAI) Europe.

Lin, J.Y. (2009a) 'Walk, Don't Run', The Economist, July 11: 68.

Lin, J.Y. (2009b) Economic Development and Transition: Thought, Strategy, and Viability, Cambridge, UK: Cambridge University Press.

Lin, J.Y. (2010) New Structural Economics: A Framework for Rethinking Development, Policy Research Working Paper 5197, Washington DC: World Bank.

Lin, J.Y. and H.-J. Chang (2009) 'DPR Debate: Should Industrial Policy in Developing Countries Conform to Comparative Advantage or Defy It?’, Development Policy Review, 27 (5): 483-502.

Lin, J. and C. Monga (2010) The Growth Report and New Structural Economics, Policy Research Working Paper 5336, Washington DC: World Bank.

Lindauer, D. and L. Pritchett (2002) 'What's the Big Idea? The Third Generation of Policies for Economic Growth', Economia, 3 (1): 1-39. 
Lister, S. (2004) The Future of International NGOs. New Challenges in a Changing World Order, London: British Overseas NGOs for Development.

Lopez-Calva, L. and N. Lustig (2009) The Recent Decline of Inequality in Latin America: Argentina, Brazil, Mexico and Peru, ECINEQ Society for the Study of Economic Inequality Working Paper Series no. 140, Palma de Mallorca: ECINEQ.

Loser, C. (2009) Global Financial Turmoil and Emerging Market Economies: Major Contagion and a Shocking Loss of Wealth, Manila: Asian Development Bank.

Lui, D. and S. Bilal (2009) Contentious Issues in the Interim EPAs: Potential Flexibility in the Negotiations, Discussion Paper no. 89, Maastricht: ECDPM.

Maat, H. (2008) 'Statistics and Field Experiments in Agriculture: The Emerging Discipline of Inferential Statistics', in I. Stamhuis, P. Klep and J. van Maarseveen (eds.) The Statistical Mind in Modern Society. The Netherlands 1850-1940 (2 vols.): 91-112.

Maddison, A. (2001) The World Economy: A Millennial Perspective, Paris: OECD.

Maddison, A. (2009) Statistics on World Population and GDP, Statistics available on www.ggdc.net/maddison/

Mann, M. (2005) The Dark Side of Democracy: Explaining Ethnic Cleansing, Cambridge, UK: Cambridge University Press.

Manning, R. (2009) Using Indicators to Encourage Development: Lessons from the Millennium Development Goals, Report 01, Copenhagen: Danish Institute for International Studies.

Manor, J. (ed.) (2007) Aid that Works: Successful Development in Fragile States. Washington DC: The World Bank.

Mansfield, E. and J. Snyder (2001) 'Democratic Transitions, Institutional Strength, and War', in C. Crocker, F. Osler Hampson and P. Aall (eds.) Turbulent Peace: The Challenges of Managing International Conflict, Washington DC: United States Institute of Peace Press.

Mara, D. (2008) 'Sanitation Now: What is Good Practice and What is Poor Practice?', in: Proceedings of the IWA International Conference 'Sanitation Challenge: New Sanitation and Models of Governance', Wageningen University: Wageningen.

Massoud, M., A. Tarhini, J. Nasr (2009) 'Decentralized Approaches to Wastewater Treatment and Management: Applicability in Developing Countries', Journal of Environmental Management, 90: 652-659.

Matthews, S. (2004) Post-development Theory and the Question of Alternatives: a View from Africa, Third World Quarterly, 25 (2): 373-384.

Maxwell, S. (2005) The Washington Consensus is Dead! Long Live the Meta-narrative, ODI Working Paper no. 243, London: Overseas Development Institute.

Mayhew, S. (2005) 'Hegemony, Politics and Ideology: The Role of Legislation in NGO-government Relations in Asia', Journal of Development Studies, 41 (5): 727-758.

Mayoux, L. (2001) 'Tackling the Down Side: Social Capital, Women's Empowerment and MicroFinance in Cameroon', Development and Change, 32: 435-464.

Mazzucato, V. (2008) 'The Double Engagement: Transnationalism and Integration - Ghanaian Migrants' Lives between Ghana and the Netherlands', Journal of Ethnic and Migration Studies, 34 (2): 199-216.

MEA (Millennium Ecosystem Assessment) (2005) Ecosystems and Human Well-being: Synthesis, Washington DC: Island Press.

Meier, G. (2001) 'The Old Generation of Development Economists and the New', in G. Meier and J. Stiglitz (eds.) Frontiers of Development Economics: The Future in Perspective, New York: Oxford University Press. 
Meredith, M. (2005) The State of Africa: A History of Fifty Years of Independence, London: Free Press. Migdal, J.S. (2001) State in Society: Studying How States and Societies Transform and Constitute One Another, Cambridge Studies in Comparative Politics, Cambridge, uk: Cambridge University Press.

Milanovic, B. (2002a) 'True World Income Distribution, 1988 and 1993: First Calculation Based on Household Surveys Alone', The Economic Journal, 112: 51-92.

Milanovic, B. (2002b) The Ricardian Vice: Why Sala-I-Martin's Calculations of World Income Inequality are Wrong, Washington DC: The World Bank.

Milanovic, B. (2005) Worlds Apart: Measuring International and Global Inequality, Princeton: Princeton University Press.

Milanovic, B. (2007) An Even Higher Global Inequality than Previously Thought: A Note on Global Inequality Calculations Using the 2005 ICP Results, World Bank Policy Research Working Paper series, First (preliminary) Draft (28 December), Washington DC: The World Bank.

Ministry of Foreign Affairs Norway (Utenriksdepartementet) (2006) Cancellation of Debts Incurred as a Result of the Norwegian Ship Export Campaign (1976-1980), Annex to Press Release no. 118/06 02.10.06.

Minoiu, C. and S. Reddy (2007) 'Aid Does Matter after All: Revisiting the Relationship between Aid and Growth', in J. Ocampo, K.S. Jomo and R. Vos (eds.) Growth Divergences: Explaining Differences in Economic Performance, India: Orient Longman Private Limited.

Minoiu, C. and S. Reddy (2009) Development and Economic Growth: A Positive Long-run Relation, IMF Working Paper no. 09/118, Washington DC: International Monetary Fund.

Miquel-Florensa, J. (2007) Aid Effectiveness: A Comparison of Tied and Untied Aid, Paper (version April 9), York: York University.

Misch, F, Gemmell, N. and R. Kneller (2010) Is Dealing with Growth Constraints a Second-Best Policy Strategy? Evidence from Endogenous Growth Models with Public Finance, Paper available on www.hks.harvard.edu/fs/drodrik/Growth\%2odiagnostics\%2opapers/Misch\%2obinding\%2oconstraints.pdf.

Mistry, P. (2005) 'Reasons for Sub-Saharan Africa's Development Deficit that the Commission for Africa Did not Consider', African Affairs, 417: 665-678.

Misturelli, F. and C. Heffernan (2008) 'What is Poverty? A Diachronic Exploration of the Discourse on Poverty from the 1970s to the 200os', The European Journal of Development Research, 20 (4): 666-684.

Mkandawire, T. (2001) 'Thinking about Developmental States in Africa', Cambridge Journal of Economics, 25 (3): 289.

Mkandawire, T. (2004) 'Social Policy in a Development Context: Introduction', in T. Mkandawire (ed.) Social Policy in a Development Context, Basingstoke: Palgrave Macmillan.

Mkandawire, T. (2008) 'Social Sciences and the Next Development Agenda', Forum for Development Studies, 35 (1): 101-118.

Mkandawire, T. (2010a) 'From Maladjusted States to Democratic Developmental States in Africa', in O. Edigheji (ed.), Constructing a Democratic Developmental State in South Africa, Cape town: HSRC Press.

Mkandawire, T. (2010b) 'How the New Poverty Agenda Neglected Social and Employment Policies in Africa', Journal of Human Development and Capabilities, 11 (1): 37-56.

Molden, D. (2007) Water for Food, Water for Life: A Comprehensive Assessment of Water Management in Agriculture, London: Earthscan.

Molenaar, H. (2009) 'Knowledge on the Move: The Dutch Debate on Research for Development', in 
P. Hoebink (ed.) The Netherlands Yearbook on International Cooperation 2008, Assen: Van Gorcum.

Molenaar, H., L. Box and R. Engelhard (2009) Knowledge on the Move: Emerging Agendas for Development-oriented Research, Leiden: International Development Publications.

Molenaers, N. en R. Renard (2007) Ontwikkelingshulp faalt: Is participatie het redmiddel? Leuven: Acco.

Molenaers, N. and R. Renard (2009) 'The Trouble with Participation: Assessing the New Paradigm', in M. Kremer, P. van Lieshout and R. Went (eds.) Doing Good or Doing Better: Development Policies in a Globalising World, WRR Investigation, Amsterdam: Amsterdam University Press.

Molyneux, M. (2002) 'Gender and the Silences of Social Capital: Lessons from Latin America', Development and Change 33 (2): 167-188.

Momsen, J. (2010) Gender and Development, London: Routledge.

Moore, B. (1966) Social Origins of Dictatorship and Democracy: Lord and Peasant in the Making of the Modern World, Middlesex: Penguin Books.

Moore, M. and H. Schmitz (2008) Idealism, Realism and the Investment Climate in Developing Countries, IDS Working Paper no. 307, Brighton: Institute of Development Studies.

Morrissey, O., D. W. te Velde and A. Hewitt (2002) ‘Defining International Public Goods', in M. Ferroni and A. Mody (eds.) International Public Goods: Incentives, Measurement, and Financing, Boston: Kluwer Academic Publishers.

Moss, T. (2007) African Development: Making Sense of the Issues and Actors, Boulder: Lynne Rienner. Moss, T., G. Pettersson and N. van de Walle (2006) 'An Aid-institutions Paradox? A Review Essay on Aid Dependency and State Building in Sub-Saharan Africa', Working Paper no. 74, Washington DC: Center for Global Development.

Moss, T., G. Pettersson and N. van de Walle (2008) 'An Aid-institutions Paradox? A Review Essay on Aid Dependency and State Building in Sub-Saharan Africa', in W. Easterly (ed.) Reinventing Foreign Aid, Cambridge, Mass.: MIT Press.

Mosse, D. (2005) Cultivating Development: An Ethnography of Aid Policy and Practice, London: Ann Arbor.

Moyo, D. (2009) Dead Aid. Why Aid Is Not Working and How There Is Another Way for Africa, London: Allen Lane.

Mwenda, A. and R. Tangri (2005) 'Patronage Politics, Donor Reforms, and Regime Consolidation in Uganda', African Affairs, 416: 449-467.

Myrdal, G. (1968) Asian Drama, an Inquiry into the Poverty of Nations, A Twentieth Century Fund Study, 3 vols, New York: Pantheon Books.

Narayan, D. (1999) Bonds and Bridges: Social Capital and Poverty, Poverty Reduction and Economic Management Network, Policy Research Working Paper no. 2167, Washington DC: The World Bank.

National Intelligence Council (2008) Global Trends 2025: A Transformed World, Washington DC: US Government Printing Office.

Nayyar, D. (2003) 'Globalization and Development Strategies', in J. Toye (ed.) Trade and Development: Directions for the 21st Century, Cheltenham: Edward Elgar.

Nayyar, D. (2006) 'Globalisation, History and Development: A Tale of Two Centuries', Cambridge Journal of Economics, 30: 137-159.

Negre, M. (2010) Concepts and Operationalization of Pro-Poor Growth, Working Paper 47, Helsinki: UNU-WIDER. 
Netherlands Environmental Assessment Agency (2009a) Beyond 2015: Long-term Development and the Millennium Development Goals, Bilthoven: PBL.

Netherlands Environmental Assessment Agency (2009b) Growing within Limits. A Report to the Global Assembly 2009 of the Club of Rome, Bilthoven: PBL.

Nijs, L. en R. Renard (2009) Reforming Government Funding of Development NGOs. A Comparative Analysis of Eight European Donors, ІОВ Working Paper 2009.01, Antwerp: University of Antwerp.

Nissanke, M. and E. Thorbecke (2006) 'Channels and Policy Debate in the Globalization-InequalityPoverty Nexus', World Development, 34 (8): 1338-136o.

North, D. (2005) Understanding the Process of Economic Change, Princeton: Princeton University Press.

North, D., J. Wallis and B. Weingast (2009) Violence and Social Orders: A Conceptual Frameworkfor Interpreting Recorded Human History, Cambridge, UK: Cambridge University Press.

Nussbaum, M. (2006) Frontiers of Justice: Disability, Nationality, Species Membership, Cambridge, Mass.: Belknap Press of Harvard University.

O'Connor, D. and M. Kjöllerström (eds.) (2008) Industrial Development in the 21st Century, London: Zed Books.

Ocampo, J.A. (2002) 'The Role of Regional Institutions', in J. Teunissen (ed.) A Regional Approach to Financial Crisis Prevention: Lessons from Europe and Initiatives in Asia, Latin America and Africa, The Hague: Fondad.

Ocampo, J.A. (2009) 'Latin America and the Global Financial Crisis', Cambridge Journal of Economics, 33: 703-724.

Ocampo, J.A. and J. Stiglitz (eds.) (2008) Capital Market Liberalization and Development, Oxford: Oxford University Press.

Ockwell, D. (2009) Scoping Note on the Difficulties Developing Countries Face in Accessing Markets for Eco-innovation, Draft Paper Commissioned by the OECD Environment Directorate (October), Brighton: University of Sussex.

Ockwell, D., R. Haum, A. Mallett and J. Watson (2008) Intellectual Property Rights and Low Carbon Technology Transfer: Conflicting Discourses of Diffusion and Development, Brighton: University of Sussex, Working Paper available on http://www.sussex.ac.uk/sussex energygroup/documents/ockwell_et_al_conflicting_discourses_of_dev_diffusion.pdf.

Odén, B. (2009) The Swedish Policy for Global Development: Implementation and Changes, Perspectives no. 12, Göteborg: Göteborgs Universitet.

Odén, B. and O. Lundquist (2007) Policy Coherence: Vital for Global Development, Perspectives no. 5, Göteborg: Göteborgs Universitet.

Odén, B. and L. Wohlgemuth (2007) Swedish Development Cooperation Policy in an International Perspective, Perspectives no. 9, Göteborg: Göteborgs Universitet.

oECD (2009) Integrating Climate Change Adaptation into Development Co-operation. Policy

Guidance, Paris: OECD.

OECD/DAC (1996) Shaping the 21st Century, Paris: OECD.

OECD/DAC (2008a) 2008 Survey on Monitoring the Paris Declaration: Making Aid More Effective by 2010, Paris: OECD.

OECD/DAC (2008b) Synthesis Report on Policy Coherence for Development (COM/SG/ DC $\mathrm{D}(2008) 1 / \mathrm{REV} 1)$, Paris: OECD.

OECD/DAC (2009a) Development Co-operation Report 2009, Paris: OECD.

OECD/DAC (2009b) Managing Aid: Practices of DAC Member Countries, Paris: OECD. 
OECD/DAC (2009c) Turning African Agriculture into a Business: A Reader, Source OECD, Agriculture \& Food, 10: 1-63, Paris: OECD.

Olsen, G. (2008) 'Coherence, Consistency and Political Will in Foreign Policy: The European Union's Policy Towards Africa', Perspectives on European Politics and Society, 9 (2): 157-171.

O’Neill, O. (2004) ‘Global Justice: Whose Obligations?’, in D. Chatterjee (ed.) The Ethics of Assistance: Morality and the Distant Needy, Cambridge: Cambridge University Press.

Opschoor, H. (2007) Environment and Poverty: Perspectives, Propositions, Policies, Institute of Social Studies Working Paper no. 437, The Hague: IsS.

Ostry, J., A. Ghosh, K. Habermeier, M. Chamon, M. Qureshi, and D. Reinhardt (2010) Capital Inflows: The Role of Controls, IMF Staff Position Note SPN 10 (04).

Oxfam (2009) What Happened at the G2O? Initial Analysis of the London Summit, Oxfam briefing note, (April 3), London: Oxfam GB.

Oyèrónké Oyěwùmí (1997), The Invention of Women: Making an African Sense of Western Gender Discourses, University of Chicago Press, Chicago.

Pakenham T. (1991) The Scramble for Africa, London: Weidenfeld and Nicolson.

Paris, R. (2004) At War's End: Building Peace after Civil Conflict, Cambridge, uk: Cambridge University Press.

Patomäki, H. (2001) Democratising Globalisation: The Leverage of the Tobin Tax, London: Zed Books.

Patrick, S. (2007) Haiti: New Terms of Engagement?, Comments to United States Institute of Peace Event on 'Haiti: no Longer Failed State?', Speech available on http://www.cgdev.org/doc/ commentary/opinion/Patrick_USIP_Haiti_2.7.07.pdf.

Paxton, P. and S. Knack (2008) Individual and Country-Level Factors Affecting Support for Foreign Aid, World Bank Policy Research Working Paper 4714, Washington DC: The World Bank.

Pearson, R. (2007) ‘Reassessing Paid Work and Women's Empowerment: Lessons from the Global Economy', in A. Cornwall, E. Harrison and A. Whitehead (eds.) Feminisms in Development. Contradictions, Contestations and Challenges, London: Zed Books.

Pekelharing, P. (2009) 'Global Justice and the State', in M. Kremer, P. van Lieshout and R. Went (eds.) Doing Good or Doing Better: Development Policies in a Globalising World, WRR Investigation, Amsterdam: Amsterdam University Press.

Picard, L. and T. Buss (2009) A Fragile Balance: Re-examining the History of Foreign Aid, Security, and Diplomacy, Sterling, va: Kumarian Press.

Ploeg, F. van der and S. Poelhekke (2009) 'Volatility and the Natural Resource Curse', Oxford Economic Papers, 61 (4): 727-76o.

Pogge, T. (2005) 'Real World Justice', The Journal of Ethics, 9: 29-53.

Pogge, T. (2008) 'Growth and Inequality', Dissent, Winter: 66-75.

Pogge, T. and S. Reddy (2005) How not to Count the Poor, New York: Columbia University, Paper (version October 29) Paper available on http://ssrn.com/abstract=893159.

Polanyi, K. (1944) The Great Transformation, Boston: Beacon Press.

Polman, L. (2010) War Games: The Story of Aid and War in Modern Times, London: Viking.

Portes, A. (1998) 'Social Capital: Its Origins and Applications in Modern Sociology', Annual Review of Sociology, 24.

Portes, A. and P. Landolt (200o) 'Social Capital: Promise and Pitfalls of its Role in Development', Journal of Latin American studies, 32.

Pouris, A. and A. Pouris (2009) 'The State of Science and Technology in Africa (2000-2004): 'a Scientometric Assessment', Scientometrics, 79 (2): 297-309.

Pritchett, L. (2008) 'It Pays to be Ignorant: A Simple Political Economy of Rigorous Program Evalua- 
tion', in W. Easterly (ed.) Reinventing Foreign Aid, Cambridge, Mass.: MIT Press.

Pritchett, L. (2009a) Does Schooling Help Explain Any of the Big Facts about Growth, Revised version of presentation given to the Growth Commission on October 19, 2007, Cambridge, Mass.: Harvard Kennedy School of Government.

Pritchett, L. (2009b) Long Term Challenges in Education: Are there Feasible Steps Today?, Background Paper for Perdee Center Workshop Shaping Tomorrow Today, Cambridge, Mass.: Harvard Kennedy School of Government.

Pritchett, L. and G. Fanjul (2009) Goldilocks Globalization: Finding 'Just Right' Regulation of Crossborder Labor Flows, Working Paper, Cambridge, Mass.: Harvard Kennedy School of Government.

Pritchett, L. and M. Woolcock (2008) 'Solutions when the Solution is the Problem: Arraying the Disarray in Development', in W. Easterly (ed.) Reinventing Foreign Aid, Cambridge, Mass.: MIT Press.

Pronk, J. (2008) Het pantser afleggen, Amsterdam: Bert Bakker.

Przeworski, A., M. Alvarez, J.A. Cheibub and F. Limongi (2000) Democracy and Development: Political Institutions and Well-being in the World, 1950-199o, Cambridge Studies in the Theory of Democracy, Cambridge, uk: Cambridge University Press.

Putnam, R. (1993) Making Democracy Work, Princeton: Princeton University Press.

Putnam, R. (2000) Bowling Alone, New York: Simon \& Schuster.

Quak, E. (2009) Het onzichtbare label: Perspectiefop duurzaam handelen, Amsterdam: KIT Publishers.

Rabbinge, R. (2009) ‘Bio-Fuels Versus Food Production’, in B. Berendsen (ed.) Emerging Global Scarcities and Power Shifts, Amsterdam: KIT Publishers.

Rabbinge, R. and P. Bindraban (2005) 'Poverty, Agriculture and Biodiversity', in J. Riggs, Conserving Biodiversity, Report of the Aspen Institute Environmental Policy Forum, (April 2004), Washington DC: Aspen Institute.

Rabbinge, R. and C. van Diepen (200o) 'Changes in Agriculture and Land Use in Europe', European Journal of Agronomy, 13: 85-100.

Radelet, S. (2005) From Pushing Reforms to Pulling Reforms: The Role of Challenge Programs in Foreign Aid Policy, Working Paper no. 53, Washington DC: Center for Global Development.

Radelet, S., M. Clemens and R. Bhavnani (2004) Aid and Growth: The Current Debate and Some New Evidence, Paper available on http://www.imf.org/external/np/seminars/eng/2005/ famm/pdf/radele.pdf.

Rahman, S. (2006) 'Development, Democracy and the NGO Sector: Theory and Evidence from Bangladesh', Journal of Developing Societies, 22 (4): 451-474.

Rajan, R. (2009) A New Bretton Woods?, Commission on Growth and Development Working Paper 59, Washington DC: The World Bank.

Rajan, R. and A. Subramanian (2005) Aid and Growth: What Does the Cross-country Evidence Really Show?, IMF Working Paper no. 05/127, Washington DC: International Monetary Fund.

Ramo, J. (2004) The Beijing Consensus, London: Foreign Policy Centre.

Rashid, A. (2006) Taliban, Amsterdam: Olympus.

Ravallion, M. (2009a) ‘Should the Randomistas Rule?’, Economists’ Voice, February: 1-5.

Ravallion, M. (2009b) Do Poorer Countries Have Less Capacity for Redistribution?, Policy Research Working Paper no. 5046, Washington DC: The World Bank.

Ravallion, M. (2009c) A Comparative Perspective on Poverty Reduction in Brazil, China and India, Policy research working paper no. 508o, Washington DC: The World Bank. 
Reid, R. (2009) A History of Modern Africa: 1800 to the Present, Malden, Mass.: Wiley-Blackwell.

Reinert, E. (2007a) How Rich Countries Got Rich ... and Why Poor Countries Stay Poor, London: Constable \& Robinson.

Reinert, E. (2007b) 'Institutionalism Ancient, Old, and New: A Historical Perspective on Institutions and Uneven Development', in H.-J. Chang (ed.) Institutional Change and Economic Development, London: Anthem.

Renard, R. (2006) The Cracks in the New Aid Paradigm, Іов Discussion Paper 2006.01, Antwerp: University of Antwerp.

Richard, J. (2002) High Noon: Twenty Global Problems, Twenty Years to Solve Them, New York: Basic Books.

Richards, P., M. de Bruin-Hoekzema, S. Hughes, C. Kudadjie-Freeman, S. Offei, P. Struik et al. (2009) 'Seed Systems for African Food Security: Linking Molecular Genetic Analysis and Cultivator Knowledge in West Africa', International Journal of Technology Management, 45 (1/2): 196-214.

Riddell, R. (2007) Does Foreign Aid Really Work? Oxford: Oxford University Press.

Riddell, R. (2009) 'Does Foreign Aid Work?’, in M. Kremer, P. van Lieshout and R. Went (eds.) Doing Good or Doing Better: Development Policies in a Globalising World, WRR Investigation, Amsterdam: Amsterdam University Press.

Rist, G. (2007) Le développement: Histoire d'une croyance occidentale, Paris: Presses de Sciences Po.

Robeyns, I. (2005) 'The Capability Approach: A Theoretical Survey', Journal of Human Development, 6, (1): 93-114

Rodríguez, F. (2007) 'Growth Empirics in a Complex World: A Guide for Applied Economists and Policymakers', in J. A. Ocampo, K.S. Jomo and R. Vos (eds.) Growth Divergences: Explaining Differences in Economic Performance, London and New York: Zed Books.

Rodrik, D. (2000) Comments on 'Trade, Growth, and Poverty' by D. Dollar and A. Kraay, Paper available on http://ksghome.harvard.edu/ drodrik/Rodrik\%20on\%2o Dollar-Kraay.pdf.

Rodrik, D. (2002) After Neoliberalism, What?, Paper available on http://www.hks.harvard.edu/fs/ drodrik/After\%2oNeoliberalism.pdf.

Rodrik, D. (2006) The Social Cost of Foreign Exchange Reserves, Paper available on http://www.hks. harvard.edu/fs/drodrik/papers.html.

Rodrik, D. (2007a) One Economics, Many Recipes. Globalization, Institutions and Economic Growth, Princeton: Princeton University Press.

Rodrik, D. (2007b) Normalizing Industrial Policy, Paper available on http://www.hks.harvard.edu/ fs/drodrik/papers.html.

Rodrik, D. (2008a) 'Second-best Institutions', American Economic Review, 98 (2): 100-104.

Rodrik, D. (2008b) The New Development Economics: We Shall Experiment, but How Shall We Learn, Paper for the Brookings Development Conference, Cambridge, Mass.: Harvard University, available on http://ksghome.harvard.edu/\%7Edrodrik/The\% $20 \mathrm{New} \% 20$ Development\% 2oEconomics.pdf.

Rodrik, D. and A. Subramanian (2008) Why Did Financial Globalization Disappoint?, Paper available on http://www.hks.harvard.edu/fs/drodrik/Why_Did_FG_Disappoint_March_24_20o8.pdf.

Rodrik, D. (2010a) 'Diagnostics Before Prescription', Journal of Economic Perspectives, forthcoming.

Rodrik, D. (2010b) The Case Against International Financial Coordination (11-02-2010), Article available on http://www.project-syndicate.org/commentary/rodrik4o/Eng.

Rombouts, H. (2006) Civil Society Participation in Fragile States: Critical Thoughts on the New Development Paradigm and its Implementation, Institute of Development Policy and Manage- 
ment Discussion Paper 2006.06, Antwerp: University of Antwerp.

Roodman, D. (2007a) 'The Anarchy of Numbers: Aid, Development, and Cross-country Empirics', World Bank Economic Review, 21 (2): 255-278, Washington DC: The World Bank.

Roodman, D. (2007b) Macro Effectiveness Research: A Guide for the Perplexed, Working Paper no. 134, Washington DC: Center for Global Development.

Roodman, D. (2008) Through the Looking Glass, and What OLs Found There: On Growth, Foreign Aid, and Reverse Causality, Working Paper no. 137, Washington DC: Center for Global Development.

Roodman, D. and J. Morduch (2009) The Impact of Microcredit on the Poor in Bangladesh: Revisiting the Evidence, Washington DC: Center for Global Development.

Rose, P. (2009) 'NGO Provision of Basic Education: Alternative or Complementary Service Delivery to Support Access to the Excluded?', Compare: a Journal of Comparative and International Education, 39 (2): 219-233.

Rostow, W. (1960) The Stages of Economic Growth: A Non-Communist Manifesto, Cambridge, UK: Cambridge University Press.

Roy, I. (2008) 'Civil Society and Good Governance: (Re-)conceptualizing the Interface', World Development, 36 (4): 677-705.

Ruben, R, J. Pender and A. Kuyenhoven (eds.) (2007) Sustainable Poverty Reduction in Less Favoured Areas: Problems, Options and Strategies, Cabi Publishing: Wallingford.

Ruben, R. and L. Schulpen (2009) 'How to Allocate Public Funding to Nongovernmental Development Organizations: a Critical Assessment of the Dutch Co-financing System.' Nonprofit and Voluntary Sector Quarterly, 38 (2): 287-306.

Rueda-Sabater, E., V. Ramachandran and R. Kraft (2009) A Fresh Look at Global Governance: Exploring Objective Criteria for Representation, Working Paper no. 16o, Washington DC: Center for Global Development.

Rueschemeyer, D., E. Huber and J. Stephens (1992) Capitalist Development and Democracy, Chicago: University of Chicago Press.

Ruggie, J. (1982) 'International Regimes, Transactions, and Change: Embedded Liberalism in the Postwar Economic Order', International Organisation, 36 (Spring).

Ruggie, J. (2007) Business and Human Rights: The Evolving International Agenda, KSG Faculty Research Working Paper no. 07-029 (June), Cambridge, Mass.: Harvard Kennedy School of Government.

Saad-Filho, A. (2007) 'Life Beyond the Washington Consensus: An Introduction to Pro-poor Marcroeconomic Policies', Review of Political Economy, 19 (4): 513-537.

Sabel, C. and S. Reddy (2007) 'Learning to Learn: Undoing the Gordian Knot of Development Today', Challenge, 50 (5): 73-92.

Sachs, J. (2005) The End of Poverty: Economic Possibilities for Our Time, New York: Penguin Press. Sala-i-Martin, X. (2002a) The Disturbing 'Rise' of Global Income Inequality, NBER Working Paper no. 8904, Cambridge, Mass: National Bureau of Economic Research.

Sala-i-Martin, X. (2002b) The World Distribution of Income, NBER Working Paper, no. 8905, Cambridge, Mass: National Bureau of Economic Research.

Sánchez, M. and R. Vos (2009) Impact of the Global Crisis on the Achievement of the MDGs in Latin America, DESA Working Paper no. 74, New York: UN.

Sander, T. and K. Lowney (2006) Social Capital Building Toolkit (version 1.2), Saguaro Seminar:

Civic Engagement in America, Cambridge, Mass.: Harvard Kennedy School of Government.

Sandler, T. (2002a) ‘Demand and Institutions for Regional Public Goods', in A. Estevadeordal, 
B. Frantz and T. R. Nguyen (eds.) Regional Public Goods: From Theory to Practice, Washington DC: Inter-American Development Bank.

Sandler, T. (2002b) 'Financing International Public Goods', in M. Ferroni and A. Mody (eds.) International Public Goods: Incentives, Measurement, and Financing, Boston: Kluwer Academic Publishers.

Sandler, T. (2005) Regional Public Goods and International Organizations, Dallas: University of Texas, Paper available on www.utdallas.edu/ tmso630oo/website/ downloads.html.

Sandler, T. (2006) 'Recognizing the Limits to Cooperation Behind National Borders: Financing the Control of Transnational Terrorism', in I. Kaul and P. Conceição (eds.) The New Public Finance: Responding to Global Challenges, Oxford: Oxford University Press.

Sandler, T. (2007) Regional Public Goods, Aid and Development, Dallas: University of Texas, Paper available on www.adbi.org/conf-seminar-papers/2007/11/o6/2407.regional.public.goods. aid.development/.

Savedoff, W. and R. Levine (2006) Learning from Development: The Case for an International Council to Catalyze Independent Impact Evaluations of Social Sector Interventions, Working Paper no. 98, Washington DC: Center for Global Development.

Saxenian, A. (2006) The New Argonauts: Regional Advantage in a Global Economy, Cambridge, Mass.: Harvard University Press.

Saxenian, A. and C. Sabel (2008) 'Venture Capital in the "Periphery": The New Argonauts, Global Search, and Local Institutions', Roepke Lecture in Economic Geography, Economic Geography, 84 (4): 379-394.

Schaik, L. van and N. Maes (2008) 'Bilateral and EU Development Cooperation: Delivering More and Better Aid', Eu Policy Perspectives’ Seminar Series Overview Paper, The Hague: Clingendael European Studies Programme.

Schmidt, R. (2009) The Currency Transaction Tax: Rate and Revenue, Tokyo: United Nations University Press.

Schulpen, L. (2007a) Development in the 'Africa for Beginners': Dutch Private Initiatives in Ghana and Malawi, Nijmegen: CIDIN, Radboud Universiteit Nijmegen.

Schulpen, L. (2007b) 'The NGDO Battle: Changes in the Subsidy Structure of Private Aid Organisations in the Netherlands', in P. Hoebink (ed.) The Netherlands Yearbook on International Cooperation 2008, Assen: Van Gorcum.

Shah, A. (2007) Participatory Budgeting: Public Sector Governance and Accountability Series, Washington DC: World Bank.

Scott, J. C. (1998) Seeing Like a State: How Certain Schemes to Improve the Human Condition Have Failed, Yale Agrarian Studies, New Haven: Yale University Press.

Seguino, S. (2000a) 'Gender Inequality and Economic Growth: A Cross-Country Analysis', World Development, 28 (7): 1211-1230.

Seguino, S. (200ob) 'Accounting for Gender in Asian Economic Growth', Feminist Economics, 3: 27-58. Sen, A. (1999) Development as Freedom, Oxford: Oxford University Press.

Sen, A. (2006) Identity and Violence: The Illusion of Destiny, London: Penguin.

SER (2009) Waarde winnen, ook in de keten: Eerste voortgangsrapportage initiatief internationaal maatschappelijk verantwoord ondernemen, The Hague: SER.

Severino, J.-M. and O. Ray (2009) The End of ODA: Death and Rebirth of a Global Public Policy, Working Paper no. 167, Washington DC: Center for Global Development.

Sindzingre, A. (2007) 'Financing the Developmental State: Tax and Revenue Issues', Development Policy Review, 25 (5): 615-632. 
Skeldon, R. ( 'Migration and Development: Contested Consequences', in M. Kremer, P. van Lieshout and R. Went (eds.) Doing Good or Doing Better: Development Policies in a Globalising World, wRR Investigation, Amsterdam: Amsterdam University Press.

Soares, B. and R. Otayek (2007) Islam and Muslim Politics in Africa, New York: Palgrave Macmillan. Soete, L. (2009) 'International Research Partnerships on the Move', in H. Molenaar, L. Box and R. Engelhard (eds.) Knowledge on the Move: Emerging Agendas for Development-oriented Research, Leiden: International Development Publications.

Solomon, S. (1995) The Confidence Game: How Unelected Central Bankers are Governing the Changed World Economy, New York: Simon \& Schuster.

Son, H. and N. Kakwani (2008) 'Economic Growth and Poverty Reduction: Measurement Issues Using Income and Non-income Indicators', World Development, 36 (6): 1048-1066.

South Centre (2010) EPAs: The Wrong Development Model for Africa and Options for the Future, Analytical note March 2010, Geneva: Switzerland.

Srinivas, K. (2009) Climate Change, Technology Transfer and Intellectual Property Rights, Research and Information System for Developing Countries (RIS) Discussion Papers no. 153, New Delhi: RIs.

Stanton, E. (2007) The Human Development Index: A History, PERI Working Paper no. 127, Amherst: Political Economy Research Institute.

State Secretary for Economic Affairs (2008) Kabinetsreactie op SER-advies 'Duurzame globalisering een wereld te winnen', Tweede Kamer $26485 \mathrm{nr} .62$.

Steer, L. and C. Wathne (2009) Mutual Accountability at Country Level: Emerging Good Practice, ODI Background Note, (April), London: Overseas Development Institute.

Stern, N. (2007) The Economics of Climate Change. The Stern Review, Cambridge, uk: Cambridge University Press.

Stewart, F. (2003) 'Income Distribution and Development', in J. Toye (ed.) Trade and Development: Directions for the 21st Century, Cheltenham: Edward Elgar.

Stiglitz, J. (2002) Globalization and its Discontents, New York: W.W. Norton.

Stiglitz, J. (2006) Making Globalization Work. The Next Steps to Global Justice, London: Allen Lane. Stiglitz, J. (2008) 'Is There a Post-Washington Consensus Consensus?', in N. Serra and J. Stiglitz (eds.) The Washington Consensus Reconsidered: Towards a New Global Governance, Oxford: Oxford University Press.

Stiglitz, J. and A. Charlton (2006) Fair Trade for All: How Trade Can Promote Development, Oxford: Oxford University Press.

Stiglitz, J., J.A. Ocampo, S. Spiegel, R. Ffrench-Davis and D. Nayyar (2006) Stability with Growth: Macroeconomics, Liberalization, and Development, Oxford: Oxford University Press.

Stiglitz, J., A. Sen and J.-P. Fitoussi (2009) Report by the Commission on the Measurement of Economic Performance and Social Progress, Report available on www.stiglitz-sen-fitoussi.fr.

Stokke, O. (2009) The UN and Development: From Aid to Cooperation, United Nations Intellectual History Project Series, Bloomington: Indiana University Press.

Storm, S. (2005) Development, Trade or Aid? un Views on Trade, Growth and Poverty, Development and Change, 36 (6): 1239-1261.

Swaan, A. de (1988) In Care of the State: Health Care, Education, and Welfare in Europe and the USA in the Modern Era, New York: Oxford University Press.

Swidler, A. (2009) 'Responding to AIDS in Sub-Saharan Africa: Culture, Institutions, and Health', in P. Hall and M. Lamont, Successful Societies: How Institutions and Culture Affect Health, Cambridge: Cambridge University Press. 
Szirmai, A. (2005) Dynamics of Socio-economic Development: An Introduction, Cambridge, UK: Cambridge University Press.

Szirmai, A. (2008) Explaining Success and Failure in Development, Maastricht: Maastricht University. Tandon, Y. (2008) Ending Aid Dependence, Oxford: Fahamu.

Tarrow, S. (2005) New Transnational Activism, Cambridge, UK: Cambridge University Press.

Task Force on Financial Integrity and Economic Development (2009) Country-by-country Reporting:

Holding Multinational Corporations to Account Wherever They Are, Washington DC: Task

Force on Financial Integrity and Economic Development.

Therien, J.-P. and V. Pouliot (2006) 'The Global Compact: Shifting the Politics of International Development?', Global Governance, 12: 55-75.

Thomas, A. (2008) 'Whatever Happened to Reciprocity? Implications of Donor Emphasis on "Voice" and "Impact" as Rationales for Working with NGOs in Development', in A. Bebbington, S. Hickey and D. Mitlin (eds.) Can NGOs Make a Difference? The Challenge of Development Alternatives, London: Zed Books.

Thorbecke, E. (2007) 'The Evolution of the Development Doctrine, 1950-2005', in G. Mavrotas and A. Shorrocks (eds.) Advancing Development: Core Themes in Global Economics, Basingstoke: Palgrave MacMillan.

Tilly, C., P. Evans, D. Rueschemeyer and T. Skocpol (1985) War Making and State Making as Organized Crime, Cambridge, uk: Cambridge University Press.

Todd, E. (1987) The Causes of Progress: Culture, Authority, and Change. Family, Sexuality, and Social Relations in Past Times, Oxford, UK: B. Blackwell.

Toye, J. and R. Toye (2004) The UN and Global Political Economy: Trade, Finance, and Development, United Nations Intellectual History Project Series, Bloomington: Indiana University Press.

Transparency International (2009) Global Corruption Barometer, Berlin: Transparency International. Treillet, S. (2002) L'économie du développement, Paris: Nathan/vuef.

Tulder, R. van and F. Fortanier (2009) 'Business and Sustainable Development: From Passive Involvement to Active Partnerships', in M. Kremer, P. van Lieshout and R. Went (eds.) Doing Good or Doing Better: Development Policies in a Globalising World, WRR Investigation, Amsterdam: Amsterdam University Press.

UN (2006) World Economic and Social Survey 2006: Diverging Growth and Development, Department of Economic and Social Affairs, New York: UN.

UN (2008) World Economic and Social Survey 2008: Overcoming Economic Insecurity, Department of Economic and Social Affairs, New York: UN.

UN (2009a) Recommendations by the Commission of Experts of the President of the General Assembly on Reforms of the International Monetary and Financial System, A/63/XXX, (March 19), New York: UN.

UN (2009b) World Economic Situation and Prospects 2009: Update as of mid-2009, New York: UN. UN (2009c) World Economic and Social Survey 2009: Promoting Development, Saving the Planet, Department of Economic and Social Affairs, New York: UN.

UN (2009d) Report of the Commission of Experts of the President of the General Assembly on Reforms of the International Monetary and Financial System (September 21), New York: UN.

UNAIDS (2008) Report on the Global AIDS Epidemic, Geneva: UNAIDS.

UNCTAD (1999) World Investment Report: Foreign Direct Investment and the Challenge of Development, Geneva: UNCTAD.

UNCTAD (2004) Trade and Gender: Opportunities and Challenges for Developing Countries, Geneva: UNCTAD. 
UNCTAD (2005) Economic Development in Africa: Rethinking the Role of Foreign Direct Investments, Geneva: UNCTAD.

UNCTAD (2007) World Investment Report 2007: Transnational Corporations, Extractive Industries, and Development, Geneva: UNCTAD.

UNCTAD (2008a) World Investment Report 2008, Geneva: UNCTAD.

UNCTAD (2008b) Trade and Development Report, 2008, Geneva: UNCTAD.

UNCTAD (2008c) Follow-up International Conference on Financing for Development to Review the Implementation of the Monterrey Consensus, Issues Note by the UNCTAD Secretariat, (October 27), Geneva: UNCTAD.

UnCTAD (2009a) The Global Economic Crisis: Systemic Failures and Multilateral Remedies, Geneva: UNCTAD.

UNCTAD (2009b) The Least Developed Countries Report 2009: The State and Development Governance, Geneva: UNCTAD.

UNCTAD (2009c) World Investment Report: Transnational Corporations, Agricultural Production and Development, Geneva: UNCTAD.

UNCTAD (2009d) Trade and Development Report, 2009, Geneva: UNCTAD.

UNCTAD (2009e) Economic Development in Africa Report 2009: Strengthening Regional Economic Integration for Africa's Development, Geneva: UNCTAD.

UNDP (2003) Making Global Trade Workfor People, London: Earthscan.

UNDP (2004) Human Development Report 2004: Cultural Liberty in Today's Diverse World, New York: Oxford University Press.

UNDP (2009) Human Development Report 2009: Overcoming Barriers: Human Mobility and Development, Basingstoke: Palgrave Macmillan.

Unesco (2009) EFA Global Monitoring Report 2009. Overcoming Inequality: Why Governance Matters, Oxford: Oxford University Press.

UnIDO (2008) Public Goods for Economic Development, Vienna: UNIDO.

United Nations Population Division (2009) World Population Prospects: The 2008 Revision, Highlights, New York: UN, Department of Economic and Social Affairs.

United Nations, DESA (2007) Auditing for Social Change: A Strategy for Citizen Engagement in Public Sector Accountability, New York: United Nations.

United Nations, DESA (2008) People Matter, Civic Engagement in Public Governance. World Public Sector Report 2008, New York: United Nations.

UNRISD (2005) Gender Equality: Striving for Justice in an Unequal World. UNRISD: Geneva.

Unsworth, S. (2008) Is Political Analysis Changing Donor Behaviour?, Paper (version September 29) available on http://www.devents.org.uk/Change-unsworth.doc.

Us Geological Survey (2009) Mineral Commodity Summaries, Washington DC: United States Government Printing Office.

Valencia Lomelí, E. (2009) ‘Conditional Cash Transfer Programs: Achievements and Illusions', Global Social Policy, 9 (2): 167-171.

Vandemoortele, J. (2009) Taking the MDGs Beyond 2015: Hasten Slowly, Paper available on www.eadi.org.

Varshney, A. (ed.) (2002) Ethnic Conflict and Civic Life: Hindus and Muslims in India, New Haven: Yale University Press.

Vaughan, O. (2003) Chiefs, Power, and Social Change: Chiefship and Modern Politics in Botswana, 1880s-199os, Trenton: Africa World Press.

Veen, R. van der (2004) Afrika: Van de Koude Oorlog naar de 21e eeuw, Amsterdam: KIT. 
Velde, D.W. te (2008) 'Financing International Public Goods: A Framework to Address Aid for Trade', in D. Njinkeu and H. Cameron (eds.) Aid for Trade and Development, Cambridge, UK: Cambridge University Press.

Velde, D.W. te, A. Hewitt and O. Morrissey (2006) Aid Financing for International Public Goods: Recent Development, Paper prepared for the United Nations Industrial Development Organization, Vienna: UNIDO.

Voorhoeve, J. (2007) From War to the Rule of Law: Peace Building after Violent Conflicts, WRR Investigation 16, Amsterdam: Amsterdam University Press.

Vu, T. (2007) State Formation and the Origins of Developmental States in South Korea and Indonesia, Studies in Comparative International Development, 41 (4): 27-56.

Wade, R. (2003) 'What Strategies are Viable for Developing Countries Today? The World Trade Organization and the Shrinking of "Development Space", Review of International Political Economy, $10(4): 621-644$.

Wade, R. (2004) Governing the Market: Economic Theory and the Role of Government in East Asian Industrialization, Princeton: Princeton University Press.

Wade, R. (2008) ‘Globalization, Growth, Poverty and Inequality', in J. Ravenhill (ed.) Global Political Economy, Oxford: Oxford University Press.

Wade, R. (2009a) 'From Global Imbalances to Global Reorganisations', Cambridge Journal of Economics, 33: 539-562.

Wade, R. (2009b) 'Rethinking Industrial Policy for Low Income Countries', African Development Review, 21 (2): 352-366.

Wagner, S. (2008) The New Invisible College: Science for Development, Washington DC: Brookings Institution Press.

Wal, M. de (2009) Een sector onder vuur: Ontwikkelingssamenwerkingsorganisaties en hun strategieën in een veranderende wereld, Amsterdam: KIT.

Warner, J. and C. Burger (forthcoming) Global Governance of Food Calamities, Paper commissioned by the Dutch Ministry of Agriculture, Nature and Food Quality.

Weiss, J. (2008) 'The Aid Paradigm for Poverty Reduction: Does it Make Sense?’, Development Policy Review, 26 (4): 407-426.

Weiss, T. and R. Thakur (2010) Global Governance and the UN: An Unfinished Journey, United Nations Intellectual History Project, Bloomington: Indiana University Press.

Went, R. (2009) 'Wereldeconomie kan niet zonder eigen veiligheidsraad', Christen Democratische Verkenningen, zomer: 248-256.

Went, R. (2010) Internationale publieke goederen: Karakteristieken en typologie, Webdocument beschikbaar op www.wrr.nl.

Wesseling, H.L. (2003) Europa's koloniale eeuw: De koloniale rijken in de negentiende eeuw 1815-1919, Amsterdam: Bert Bakker.

Weyzig, F. and M. van Dijk (2008) Tax Haven and Development Partner: Incoherence in Dutch Government Policies, MPRA Paper no. 12526, available on http://mpa.ub.uni-muenchen. $\mathrm{de} / 12526$.

White, H. (1992) Should we Expect Aid to Increase Economic Growth?, Working Paper Series Iss no. 127, The Hague: Institute of Social Studies.

White, H. (2007) Evaluating Aid Impact, MPRA paper no. 6716, Munich: University of Munich.

Whitfield, L. (2009) The Politics of Aid: African Strategies for Dealing with Donors, Oxford: Oxford University Press.

Wijffels, H. (2008) Global Public Goods and Global Governance: An Agenda, Speech at WRR lecture, 
Lecture available on http://www.wrr.nl/dsc?c=getobject\&s=obj\&! sessionid=1ofxauyo3h54uVxzYXpiK38LdWziQ!2wD5FEogvlsUlCp3MoaGBFhXO qKEXXlWdp\&objectid=5006\&!dsname=default\&isapidir=/gvisapi/.

Williamson, J. (ed.) (1990) Latin American Adjustment: How Much has Happened? Washington DC: Institute for International Economics.

Williamson, J. (2008) 'A Short History of the Washington Consensus', in N. Serra and J. Stiglitz (eds.) The Washington Consensus Reconsidered: Towards a New Global Governance, Oxford: Oxford University Press.

Winters, A. (2001) Coherence with no 'Here': WTO Co-operation with the World Bank and the IMF, London: Centre for Economic Policy Research (draft November 2001).

Wolf, M. (2004) Why Globalization Works, New Haven: Yale University Press.

Woolcock, M. (1998) 'Social Capital and Economic Development: Toward a Theoretical Synthesis and Policy Framework', Theory and Society, 27.

Woolcock, M. and D. Narayan (200o) 'Social Capital: Implications for Development Theory, Research and Policy', The World Bank Research Observer, 15 (2), Washington DC: The World Bank.

Woolcock, M., S. Szreter and V. Rao (2009) How and Why Does History Matter for Development Policy, BWPI Working Paper 68 available on www.manchester.ac.uk/bwpi.

World Bank (2001a) World Development Report 2000/2001: Attacking Poverty, Oxford: Oxford University Press.

World Bank (2001b) Engendering Development: Through Gender Equality in Rights, Resources, and Voice, Washington DC: World Bank.

World Bank (2003) World Development Report 2004: Making Services Workfor Poor People, Washington DC: The World Bank.

World Bank (2005) Economic Growth in the 1990s: Learning from a Decade of Economic Reform, Washington DC: The World Bank.

World Bank (2006) Global Economic Prospects: Economic Implications of Remittances and Migration, Washington DC: The World Bank.

World Bank (2007) Meeting the Challenges of Global Development: A Long-term Strategic Exercise for the World Bank Group, Washington DC: The World Bank.

World Bank (2008a) World Development Report 20o8: Agriculture for Development, Washington DC: The World Bank.

World Bank (2008b) Migration and Remittances Factbook 2008, Washington DC: The World Bank.

World Bank (2008c) Vietnam Country Overview, Washington DC: The World Bank

World Bank (2008d) World Bank Development Indicators, Washington DC: The World Bank.

World Bank (2009a) Global Monitoring Report 2009: A Development Emergency, Washington DC: The World Bank.

World Bank (2009b) World Development Report 2010: Development and Climate Change, Washington DC: The World Bank.

World Commission on the Social Dimension of Globalization (2004) A Fair Globalization: Creating Opportunities for All, Geneva: ILO.

World Economic Forum (2009) Global Gender Gap Report, Geneva: World Economic Forum. wHO (World Health Organization) (2001) Macroeconomics and Health: Investing in Health for Economic Development, Report of the Commission on Macroeconomics and Health. Chaired by J. Sachs, Geneva: WHO.

WHO (2008) Primary Health Care: Now More than Ever. Geneva: WHO. 
World Water Council (2004) E-conference Synthesis: Virtual Water Trade - Conscious Choices, Report available on http://www.worldwatercouncil.org/fileadmin/wwc/Library/Publications_ and_reports/virtual_water_final_synthesis.pdf.

WRR (Dutch Scientific Council for Government Policy) (2001) Ontwikkelingsbeleid en goed bestuur, WRR-rapport 58, The Hague: SDU.

WRR (2006a) Lerende overheid: Een pleidooi voor probleemgerichte politiek, WRR-rapport 75, Amsterdam: Amsterdam University Press.

WRR (2006b) De verzorgingsstaat herwogen, WRR-rapport 76, Amsterdam: Amsterdam University Press.

WRR (2006c) Dynamiek in islamitisch activisme: Aanknopingspunten voor democratisering en mensenrechten, WRR-rapport 73, Amsterdam: Amsterdam University Press.

WRR (2006d) Klimaatstrategie - tussen ambitie en realisme, WRR-rapport 74, Amsterdam: Amsterdam University Press.

WTO (2008a) International Trade Statistics, Geneva: wTO.

WTO (2008b) World Trade Report 2008: Trade in a Globalizing World, Geneva: WTO.

Yayawardena, L. (1993) 'Comment on "Toward a Counter-counterrevolution in Development Theory” by Krugman', Proceedings of the World Bank Annual Conference on Development Economics 1992, Washington DC: The World Bank.

Yusuf, S. (2009) Development Economics Through the Decades: A Critical Look at 30 Years of the World Development Report, Washington DC: The World Bank.

Zadek, S. (2008) 'Collaborative Governance: The New Multilateralism for the Twenty-first Century', in L. Brainard and D. Chollet (eds.) Global Development 2.o: Can Philanthropists, the Public, and the Poor Make Poverty History?, Washington DC: Brookings Institution Press.

Zakaria, F. (2003) The Future of Freedom: Illiberal Democracy at Home and Abroad, New York: w.w. Norton.

Zarsky, L. (2010) Climate-resilient Industrial Development Paths: Design Principles and Alternative Models, Working Paper 10-o1, London: International Institute for Environment and Development (IIED).

Zenawi, M. (no year) Dead End: The Neoliberal Paradigm and the African Renaissance, Master's Thesis, Erasmus University Rotterdam.

Zimmerman R. (2008) The Fallout from the Financial Crisis: The End of Public Support for Development Aid?, Paris: OECD. 